\title{
Dynamic regulation of subcellular calcium handling in the atria
}

Citation for published version (APA):

Schönleitner, P. (2020). Dynamic regulation of subcellular calcium handling in the atria: modifying effects of stretch and adrenergic stimulation. [Doctoral Thesis, Maastricht University]. ProefschriftMaken Maastricht. https://doi.org/10.26481/dis.20201215ps

Document status and date:

Published: 01/01/2020

DOI:

$10.26481 /$ dis.20201215ps

Document Version:

Publisher's PDF, also known as Version of record

\section{Please check the document version of this publication:}

- A submitted manuscript is the version of the article upon submission and before peer-review. There can be important differences between the submitted version and the official published version of record.

People interested in the research are advised to contact the author for the final version of the publication, or visit the DOI to the publisher's website.

- The final author version and the galley proof are versions of the publication after peer review.

- The final published version features the final layout of the paper including the volume, issue and page numbers.

Link to publication

\footnotetext{
General rights rights.

- You may freely distribute the URL identifying the publication in the public portal. please follow below link for the End User Agreement:

www.umlib.nl/taverne-license

Take down policy

If you believe that this document breaches copyright please contact us at:

repository@maastrichtuniversity.nl

providing details and we will investigate your claim.
}

Copyright and moral rights for the publications made accessible in the public portal are retained by the authors and/or other copyright owners and it is a condition of accessing publications that users recognise and abide by the legal requirements associated with these

- Users may download and print one copy of any publication from the public portal for the purpose of private study or research.

- You may not further distribute the material or use it for any profit-making activity or commercial gain

If the publication is distributed under the terms of Article $25 \mathrm{fa}$ of the Dutch Copyright Act, indicated by the "Taverne" license above, 


\section{Dynamic Regulation of \\ Subcellular Calcium Handling}

in the Atria

Modifying Effects of Stretch

and Adrenergic Stimulation

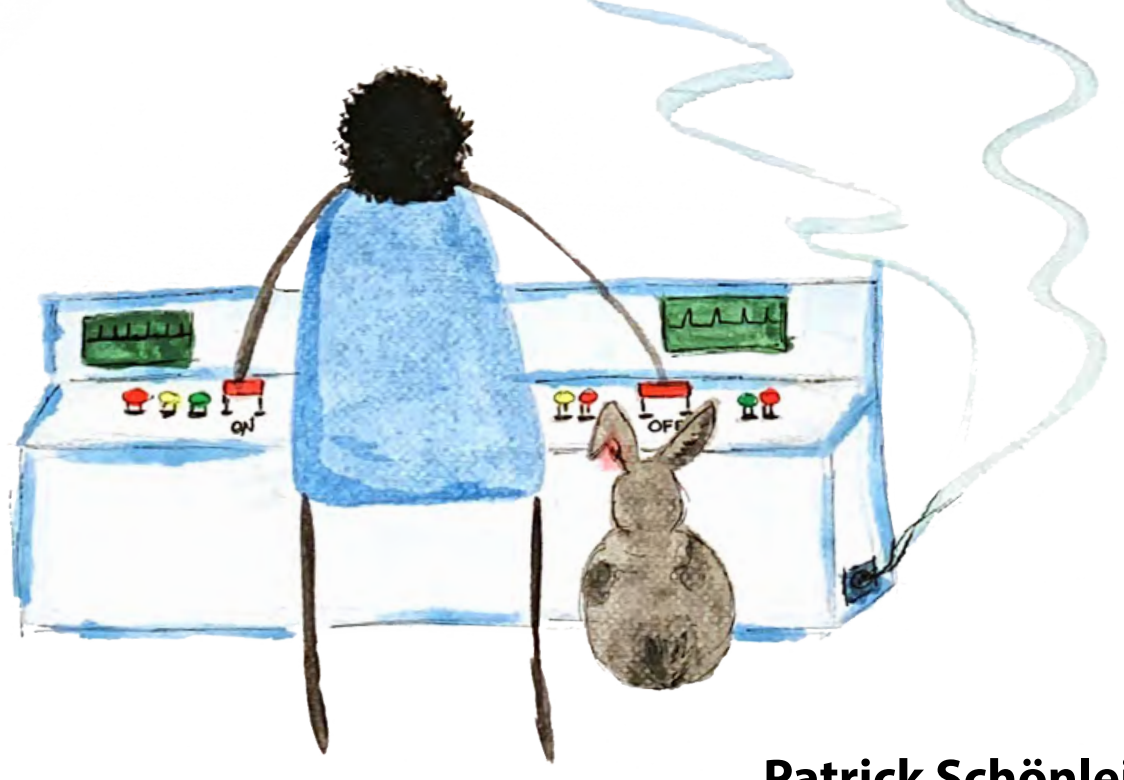

Patrick Schönleitner 


\section{Dynamic Regulation of Subcellular Calcium Handling in the Atria}

Modifying Effects of Stretch and Adrenergic Stimulation

Patrick Schönleitner 


\section{Colofon}

Cover and design:

Printing:
Giulia Gatta

Proefschriftmaken || Proefschriftmaken.nl

All rights reserved. No part of this publication may be reproduced, stored in a retrieval system or transmitted, in any form or by any means, electronic, mechanical, photocopying, recording or otherwise, without prior permission of the author or the copyright-owning journals for published chapters. 


\title{
Dynamic Regulation of \\ Subcellular Calcium Handling in the Atria
}

\section{Modifying Effects of Stretch and Adrenergic Stimulation}

\section{PROEFSCHRIFT}

\author{
Ter verkrijging de graad van doctor aan de Universiteit Maastricht, \\ op gezag van de Rector Magnificus, Prof. Dr. Rianne M. Letschert, \\ volgens het besluit van het College der Decanen \\ in het openbaar te verdedigen op: \\ Dinsdag 15 december 2020 om 10.00 uur
}

door

\section{Patrick Schönleitner}




\section{Supervisors:}

Prof.dr. U. Schotten

Prof.dr. H.J.G.M Crijns

\section{Co-supervisor:}

Dr. Gudrun Antoons

\section{Assessment Committee:}

Prof. dr. P.G.A. Volders (chair)

Dr. T.P. de Boer (UMC Utrecht)

Prof. W.E. Louch (University of Oslo, Norway)

Prof. dr. F.W. Prinzen

This research is supported by European Initial Training Network grant "RADical reduction of Oxidative stress in cardiovascular diseases (RADOX)" 


\section{TABLE OF CONTENT}

Chapter $1 \quad$ General Introduction

Chapter 2 Mechanosensitivity of microdomain calcium signalling in the heart

Chapter $3 \quad$ Stretch-induced increase in $\mathrm{Ca}^{2+}$ spark in atrial myocytes requires an intact microtubular network but not redox modulation

Chapter 4 Adrenergic control of RyR $\mathrm{Ca}^{2+}$-release microdomains in atrial fibrillation

Chapter 5 Quantification of local strain heterogeneities in isolated cardiomyocytes

Chapter 6 General Discussion

Appendix

Summary

Zusammenfassung

Valorization 131

Acknowledgments 135

Curriculum vitae 


\section{Chapter I}

General Introduction

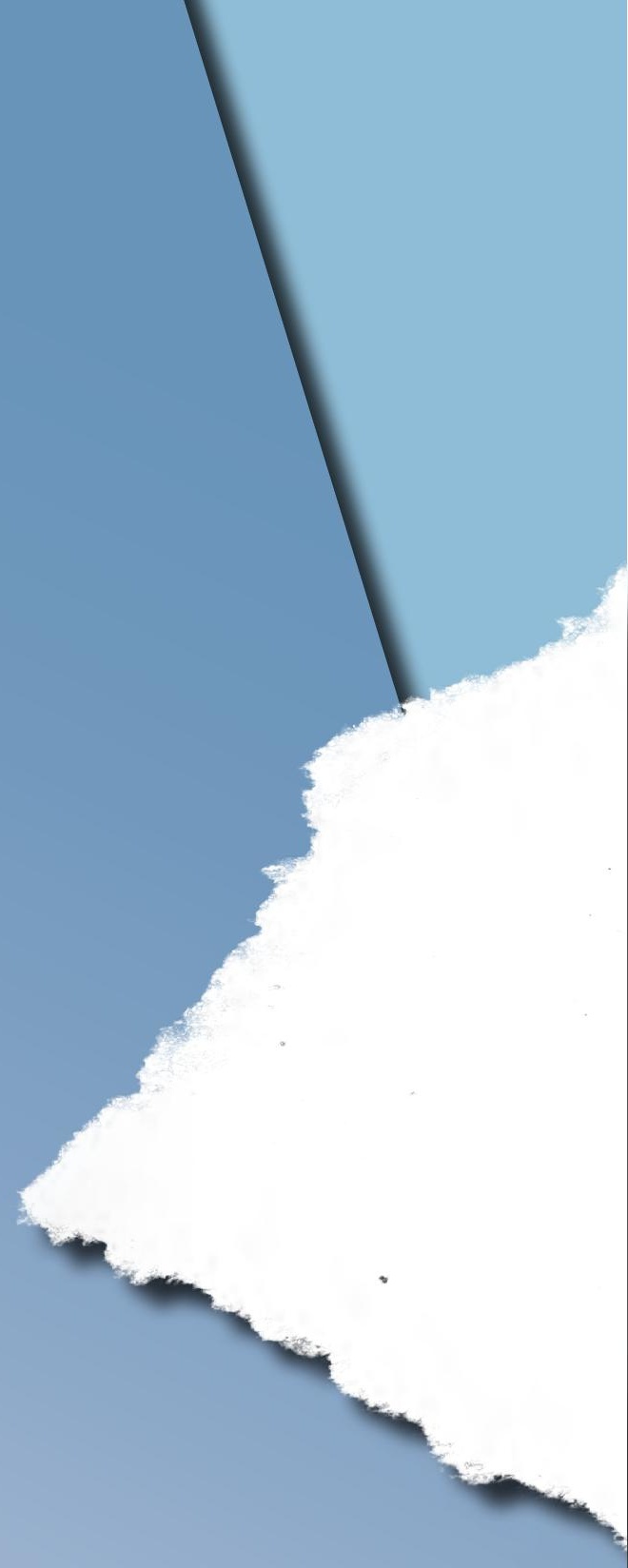



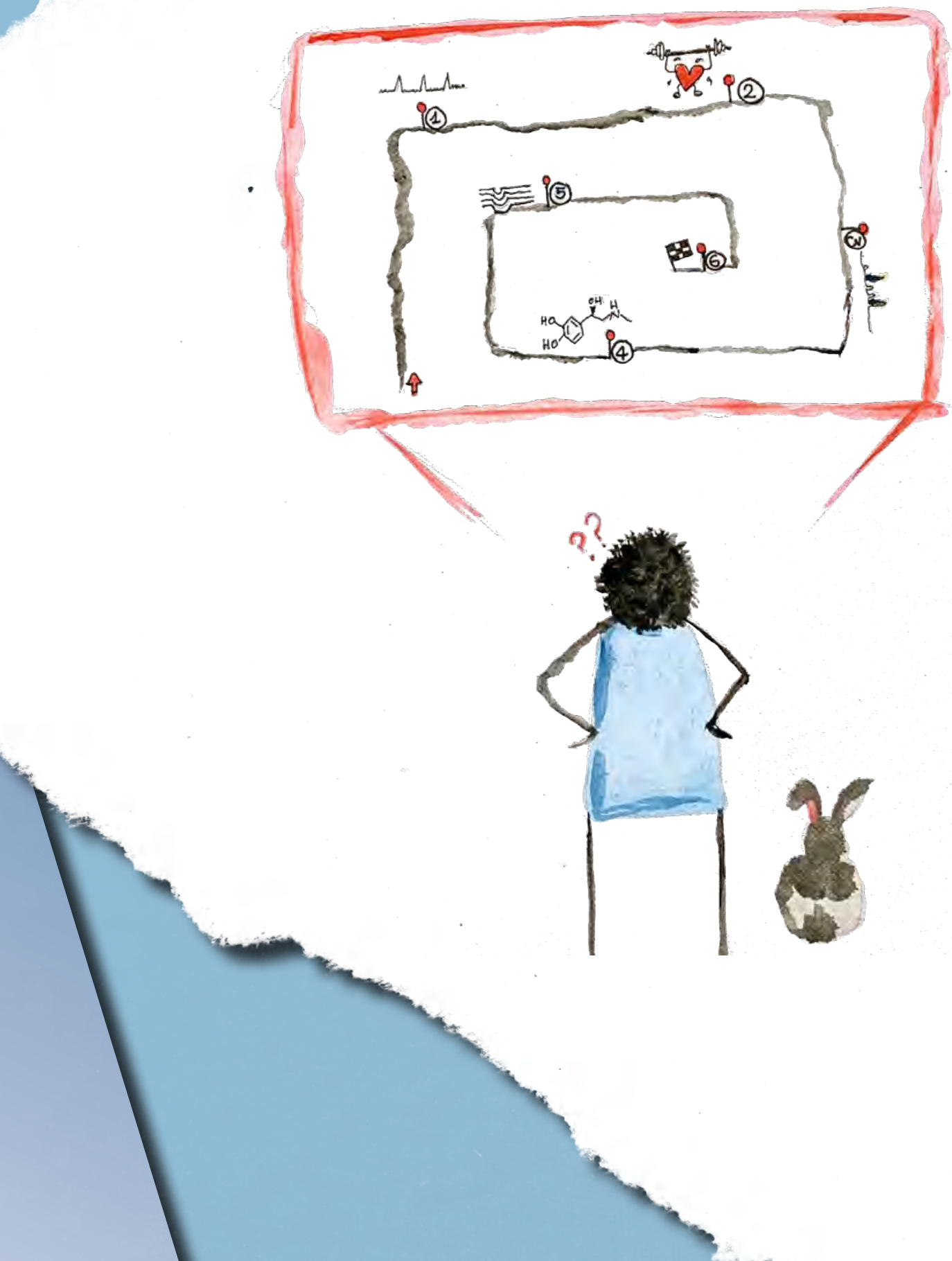


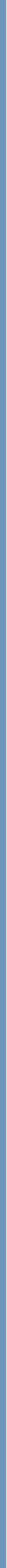




\section{GENERAL INTRODUCTION}

Atrial fibrillation (AF) is characterised by fast and irregular activation of the atria and is the most common sustained arrhythmia in adults. It is associated with increased mortality and morbidity, reduces the quality of life and life expectancy, and puts a considerable strain on health care systems across the globe. ${ }^{1,2}$ In 2010 approximately 250.000 people in the Netherlands and 7.2 million across Europe suffered from AF. With an ageing population, we expect these numbers to double by the middle of the century. ${ }^{3}$ Despite the considerable burden on the health care system and the massive research efforts, treatment of AF remains unsatisfactory. Lack in our pathophysiological understanding of distinct mechanisms of AF initiation and maintenance led us to focus on symptom control, without adequate treatment of AF itself. Understanding the arrhythmogenic potential of mechanical stimuli, autonomic regulation, and local structural and functional heterogeneity may provide new insights and improve rhythm control strategies for AF.

\section{Effects of acute stretch and adrenergic stimulation on the development of AF}

Twenty-five years ago, Wijffels et al. observed in conscious chronically instrumented goats that initially short-lived episodes of AF, when artificially maintained, become sustained over time. ${ }^{4}$ This phenomenon is known as 'AF begets AF'. Besides a shortening of the refractory period also other factors are involved in increasing AF stability over time, such as myocyte hypertrophy and atrial fibrosis. Also, the role of stretch and mechano-electric coupling in the initiation and maintenance of AF has gained attention. However, studies investigating the effect of acute atrial stretch in humans have yielded inconsistent results. In patients, without structural heart disease, atrial stretch is associated with a shortening of the atrial refractory period and increased the likelihood of developing AF. ${ }^{5}$ Another study found a non-uniform increase in ERP upon mechanical load in patients without structural heart disease. ${ }^{6}$ In patients with a history of paroxysmal AF, volume load tripled the number of patients experiencing prolonged episodes of AF. ${ }^{7}$ Acute stretch also increased the heterogeneity in atrial ERP, and this effect was pronounced in patients with a history of AF. ${ }^{8}$ In-vitro and in-vivo experiments in animal models support the notion of increased vulnerability for atrial arrhythmias in response to stretch. On a cellular level, the underlying mechanism of stretch-induced arrhythmias in the atria are incompletely understood. Differences in effects reported in human studies exploring stretch-induced alteration in atrial electrophysiology could be explained by uncontrolled autonomic effects as well as the heterogeneous effects of stretch on ERP throughout the atria.

Several reports link catecholamines to the development of atrial arrhythmias. ${ }^{9}$ Isoprenaline (ISO), a beta-adrenoreceptor agonist, induces AF episodes in $80 \%$ of patients undergoing catheter ablation for paroxysmal AF compared to $5 \%$ in the control group. ${ }^{10}$ Furthermore, prospective studies in patients with a history of AF showed that emotional stress doubles the occurrence of AF episodes (Lampert 2014) and that treating patients with beta-blockers attenuated the occurrence of new AF episodes associated with emotions leading to high sympathetic activity (Lampert 2019). ${ }^{11}$ 
Moderate amounts of stretch can potentially trigger lethal ventricular arrhythmias in ventricle with local structural heterogeneity. ${ }^{12}$ On a subcellular level, heterogeneities in $\mathrm{Ca}^{2+}$ reuptake and release have been reported. ${ }^{13}$ Subcellular heterogeneities, however, remain to be investigated.

This thesis investigates the effects of stretch and beta-adrenergic stimulation on $\mathrm{Ca}^{2+}$ handling with a potential role in pro-arrhythmic mechanisms in AF.

\section{Outline of this thesis}

In Chapter 2, we provide a detailed literature overview of the effects of mechanical stimuli on $\mathrm{Ca}^{2+}$ handling. In cardiac myocytes, $\mathrm{Ca}^{2+}$ signalling is tightly controlled in spatially confined spaces or microdomains. $\mathrm{Ca}^{2+}$ signalling at these microdomains is mechano-sensitive. To investigate mechano-sensitive microdomain $\mathrm{Ca}^{2+}$ handling in isolated cardiac myocytes, well defined reproducible mechanical stimuli need to be applied. We elaborate on technical considerations and discuss the type of mechanical stimuli cells can be subjected to. Myocytes react to changes in afterload, pre-load and shear stress differently. Furthermore, we discuss emerging differences between atrial and ventricular mechano-sensitivity and how the cellular structure could influence differences in mechano-sensing. Lastly, we explore the implication of mechano-sensitive $\mathrm{Ca}^{2+}$ handling on cardiac arrhythmias, focusing on subcellular structural alterations in disease and discuss the effect of contractile heterogeneity on arrhythmias.

The subcellular mechano-sensitive $\mathrm{Ca}^{2+}$ handling in the atria is not well understood. In Chapter 3, we investigate the effect of uniaxial stretch on atrial $\mathrm{Ca}^{2+}$ handling and possible implications for atrial arrhythmias. We show that stretch causes an increase in $\mathrm{Ca}^{2+}$ spark rate and provide evidence that this mechanism is distinct from the stretch evoked $\mathrm{Ca}^{2+}$ sparks in the ventricle. Furthermore, we demonstrate that stretch leads to coordinated $\mathrm{Ca}^{2+}$ waves, reminiscence of electrically stimulated transients, in close temporal proximity to the application of stretch. Unlike the increase in $\mathrm{Ca}^{2+}$ spark rate, coordinated $\mathrm{Ca}^{2+}$ release events were not inhibited by GsMTx4, a blocker of mechanosensitive channels.

In Chapter 4, we investigate the effect of adrenergic stimulation on subcellular $\mathrm{Ca}^{2+}$ handling in atrial myocytes. We show that after short term rapid pacing $\mathrm{CaT}$ amplitude is reduced in atrial myocytes, mainly due to a loss in $\mathrm{CaT}$ amplitude in uncoupled regions. After ISO treatment, the $\mathrm{CaT}$ amplitude normalised to control conditions. We investigate possible pathways that could lead to the rescue of CaTs in atrial myocytes and identified a pronounced rephosphorylation of $\mathrm{Ca}^{2+}$ release channels in atrial myocytes after tachypacing as a potential mechanism.

Heterogeneity in contraction can be another source for atrial arrhythmias and subcellular alteration in $\mathrm{Ca}^{2+}$ handling. To better quantify the effects of subcellular heterogeneity, we developed and tested a new method to semi-automatically analyse spatiotemporal heterogeneities of subcellular contraction in transmitted line scan images of isolated myocytes. In Chapter 5, we present this method in detail and show the effects of ISO treatment and stretch on myocyte contraction. We show that ISO as well as stretch increase local strain heterogeneity. While cells that are not subjected to mechanical load show contractions throughout the 
whole length of the cell, albeit with different levels of strain, parts of pre-loaded myocytes lengthened during active contraction. This phenomenon has been described in multicellular preparations and associated with arrhythmia development.

Our data provide new insights into potential pro-arrhythmic mechanisms of stretch and adrenergic activation. The therapeutic relevance of these findings has to be addressed in future research projects.

\section{REFERNCES}

1. Thrall G, Lane D, Carroll D, Lip GY. Quality of life in patients with atrial fibrillation: a systematic review. Am J Med 2006;119:448 e441-419.

2. Benjamin EJ, Wolf PA, D’Agostino RB, Silbershatz H, Kannel WB, Levy D. Impact of atrial fibrillation on the risk of death: the Framingham Heart Study. Circulation 1998;98:946-952.

3. Krijthe BP, Kunst A, Benjamin EJ, Lip GY, Franco OH, Hofman A, Witteman JC, Stricker BH, Heeringa J. Projections on the number of individuals with atrial fibrillation in the European Union, from 2000 to 2060. Eur Heart J 2013;34:2746-2751.

4. Wijffels MC, Kirchhof CJ, Dorland R, Allessie MA. Atrial fibrillation begets atrial fibrillation. A study in awake chronically instrumented goats. Circulation 1995;92:1954-1968.

5. Tse HF, Pelosi F, Oral H, Knight BP, Strickberger SA, Morady F. Effects of simultaneous atrioventricular pacing on atrial refractoriness and atrial fibrillation inducibility: role of atrial mechanoelectrical feedback. J Cardiovasc Electrophysiol 2001;12:43-50.

6. Chen YJ, Tai CT, Chiou CW, Wen ZC, Chan P, Lee SH, Chen SA. Inducibility of atrial fibrillation during atrioventricular pacing with varying intervals: role of atrial electrophysiology and the autonomic nervous system. J Cardiovasc Electrophysiol 1999;10:1578-1585.

7. Antoniou A, Milonas D, Kanakakis J, Rokas S, Sideris DA. Contraction-excitation feedback in human atrial fibrillation. Clin Cardiol 1997;20:473-476.

8. Chen YJ, Chen SA, Tai CT, Wen ZC, Feng AN, Ding YA, Chang MS. Role of atrial electrophysiology and autonomic nervous system in patients with supraventricular tachycardia and paroxysmal atrial fibrillation. J Am Coll Cardiol 1998;32:732-738.

9. Sharifov OF, Fedorov VV, Beloshapko GG, Glukhov AV, Yushmanova AV, Rosenshtraukh LV. Roles of adrenergic and cholinergic stimulation in spontaneous atrial fibrillation in dogs. J Am Coll Cardiol 2004;43:483-490.

10. Oral H, Crawford T, Frederick M, Gadeela N, Wimmer A, Dey S, Sarrazin JF, Kuhne M, Chalfoun N, Wells D, Good E, Jongnarangsin K, Chugh A, Bogun F, Pelosi F, Jr., Morady F. Inducibility of paroxysmal atrial fibrillation by isoproterenol and its relation to the mode of onset of atrial fibrillation. $J$ Cardiovasc Electrophysiol 2008;19:466-470.

11. Lampert R, Burg MM, Jamner LD, Dziura J, Brandt C, Li F, Donovan T, Soufer R. Effect of beta-blockers on triggering of symptomatic atrial fibrillation by anger or stress. Heart Rhythm 2019;16:1167-1173.

12. Seo K, Inagaki M, Nishimura S, Hidaka I, Sugimachi M, Hisada T, Sugiura S. Structural heterogeneity in the ventricular wall plays a significant role in the initiation of stretch-induced arrhythmias in perfused rabbit right ventricular tissues and whole heart preparations. Circ Res 2010;106:176-184.

13. Hohendanner F, Ljubojevic S, MacQuaide N, Sacherer M, Sedej S, Biesmans L, Wakula P, Platzer D, Sokolow S, Herchuelz A, Antoons G, Sipido K, Pieske B, Heinzel FR. Intracellular dyssynchrony of diastolic cytosolic $[\mathrm{Ca}(2)(+)]$ decay in ventricular cardiomyocytes in cardiac remodeling and human heart failure. Circ Res 2013;113:527-538. 


\section{Chapter II}

\section{Mechanosensitivity of microdomain calcium signalling in the heart

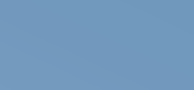

Patrick Schönleitner ${ }^{1}$, Ulrich Schotten ${ }^{1}$, Gudrun Antoons ${ }^{1}$ 


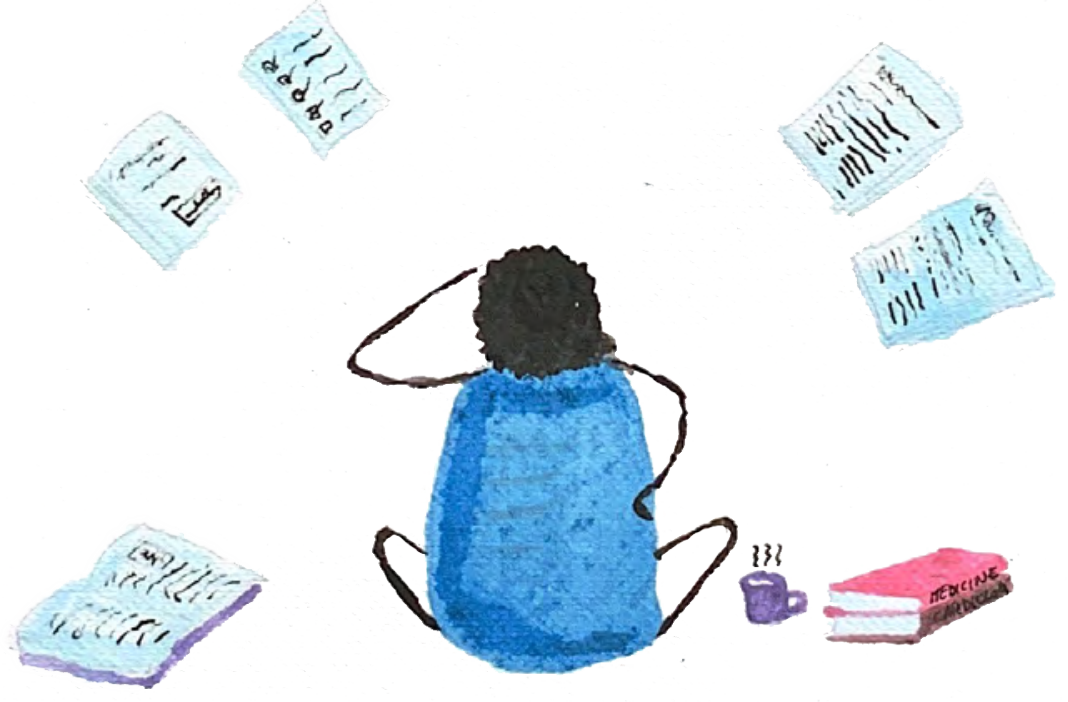




\section{ABSTRACT}

In cardiac myocytes, calcium $\left(\mathrm{Ca}^{2+}\right)$ signalling is tightly controlled in dedicated microdomains. At the dyad, i.e. the narrow cleft between t-tubules and junctional sarcoplasmic reticulum (SR), many signalling pathways combine to control $\mathrm{Ca}^{2+}$-induced $\mathrm{Ca}^{2+}$ release during contraction. Local $\mathrm{Ca}^{2+}$ gradients also exist in regions where SR and mitochondria are in close contact to regulate energetic demands. Loss of microdomain structures, or dysregulation of local $\mathrm{Ca}^{2+}$ fluxes in cardiac disease, is often associated with oxidative stress, contractile dysfunction and arrhythmias. $\mathrm{Ca}^{2+}$ signalling at these microdomains is highly mechanosensitive. Recent work has demonstrated that increasing mechanical load triggers rapid local $\mathrm{Ca}^{2+}$ releases that are not reflected by changes in global $\mathrm{Ca}^{2+}$. Key mechanisms involve rapid mechanotransduction with reactive oxygen species or nitric oxide as primary signalling molecules targeting SR or mitochondria microdomains depending on the nature of the mechanical stimulus. This review summarizes the most recent insights in rapid $\mathrm{Ca}^{2+}$ microdomain mechanosensitivity and re-evaluates its (patho)physiological significance in the context of historical data on the macroscopic role of $\mathrm{Ca}^{2+}$ in acute force adaptation and mechanically-induced arrhythmias. We distinguish between preload and afterload mediated effects on local $\mathrm{Ca}^{2+}$ release, and highlight differences between atrial and ventricular myocytes. Finally, we provide an outlook for further investigation in chronic models of abnormal mechanics (eg post-myocardial infarction, atrial fibrillation), to identify the clinical significance of disturbed $\mathrm{Ca}^{2+}$ mechanosensitivity for arrhythmogenesis.

\section{Non-standard Abbreviations and Acronyms}

AP, action potential; AT, axial tubule; $\mathrm{Ca} 2+$, calcium; CaMKII, $\mathrm{Ca} 2+/$ calmodulin-dependent protein kinase II; CICR, Ca2+ induced $\mathrm{Ca} 2+$ release; GSMTx4, Grammostola spatulata mechanotoxin-4; IP3, inositol 1,4,5-trisphosphate; LTCC, L-type Ca2+ channel; MCU, mitochondrial $\mathrm{Ca} 2+$ uniporter; $\alpha$-MHC, alpha-myosin heavy chain; $\mathrm{Na}+$, sodium; $\mathrm{NCX}$, $\mathrm{Na}+/ \mathrm{Ca} 2+$-exchanger; NHE1, Na+/H+ -Exchanger 1; NO, nitric oxide; NOS, nitric oxide synthase; eNOS, endothelial nitric oxide synthase; nNOS, neuronal nitric oxide synthase; NOX2, NADPH Oxidase Type 2; ROS, reactive oxygen species; RyR, ryanodine receptor; SAC, stretch activated channel; SERCA, sarco/endoplasmic reticulum Ca2+-ATPase; SR, sarcoplasmic reticulum; TnC, troponin C; TT, transverse tubule; AT, axial tubule 


\section{INTRODUCTION}

The heart is continuously exposed to a changing mechanical environment, both on a beat-tobeat basis (e.g. fluctuating blood pressure, exercise, emotional stress), and chronically (e.g. elevated venous return, high blood pressure). One of the most frequent challenges to the heart is acute stretch due to an increase in end-diastolic volume (preload), caused by either an increase in venous return, or aortic resistance. The stretch is immediately followed by a more powerful contraction. The larger the stretch, the more force is being generated by the muscle. This intrinsic mechanism of autoregulation allows fast adaptation of the heart to variations in haemodynamic load and is known as the Frank Starling mechanism. ${ }^{1,2}$ The initial increase in contractility is followed by a more gradual increase in force development that is responsible for the return of end-diastolic volume back to its original value. The secondary increase in force over a 10-15 min period was first observed by Von Anrep after clamping the ascending aorta in a dog, ${ }^{3}$ and later on demonstrated in an in vitro setting by Parmley and Chuck. ${ }^{4}$ Since then this phenomenon has been referred to as slow force response (SFR).

Accumulation of $\mathrm{Ca}^{2+}$ has been considered the mechanism that underlies the inotropy of the Anrep effect, ${ }^{5}$ while the Frank-Starling has been viewed as primarily a myofilament mechanism. ${ }^{6}$ Historically, $\mathrm{Ca}^{2+}$ effects have not considered important in the initial force response to stretch, but this view has been challenged by recent findings. Newly developed imaging tools and preload/afterload models have allowed the capture of subcellular $\mathrm{Ca}^{2+}$ dynamics at high spatiotemporal resolution during mechanical modulation and demonstrated fast local $\mathrm{Ca}^{2+}$ releases from the sarcoplasmic reticulum (SR) in response to stretch, while global systolic $\mathrm{Ca}^{2+}$ is maintained. ${ }^{7,8}$ These local $\mathrm{Ca}^{2+}$ release events are manifestations of sensitized SR Ca ${ }^{2+}$ release channels that may prime the muscle for more efficient $\mathrm{Ca}^{2+}$ release and mechanical synchrony. Other forms of mechanical stimulation, e.g. afterload and shear, also affect local $\mathrm{Ca}^{2+}$ release, but operate across different time scales, and appear to involve other mechanosensors, chemical signals of transduction and sources of $\mathrm{Ca}^{2+}$. In any case, the subcellular $\mathrm{Ca}^{2+}$ response to mechanical stimulation is spatially confined, and intact structural organization of $\mathrm{Ca}^{2+}$ release microdomains is key to spatiotemporal control of local $\mathrm{Ca}^{2+}$ release. A different structural organization as in atrial myocytes, or loss of structures in failing hearts, may cause uncontrolled $\mathrm{Ca}^{2+}$ releases that initiate arrhythmogenic events, shedding new light on the role of $\mathrm{Ca}^{2+}$ in stretch-induced arrhythmias. Disturbances in the $\mathrm{Ca}^{2+}$ handling substructure may be particularly relevant for arrhythmias associated with cardiac diseases where tissue mechanics are abnormal, or in the setting of atrial dilatation during atrial fibrillation.

In this review, we discuss current knowledge of mechanisms of mechano-transduction. In this context, the term $\mathrm{Ca}^{2+}$ mechanotransduction refers to processes through which myocytes sense and respond to mechanical stimuli by converting them into biochemical signals that affect $\mathrm{Ca}^{2+}$ signalling. Highlighting the most recent discoveries in this field, the review particularly focuses on fast processes of mechanically-induced $\mathrm{Ca}^{2+}$ release that involve mechanosensitive intracellular $\mathrm{Ca}^{2+}$ stores. We distinguish between different types of stimuli - preload, afterload and shear. In light of these new findings we revisit the role of $\mathrm{Ca}^{2+}$ in acute force adaptation, and stretch-induced arrhythmias. We highlight differences between atrial and ventricular myocytes, and speculate how dysregulation of $\mathrm{Ca}^{2+}$ mechanotransduction may become arrhythmogenic in cardiac disease. The long-term effects of mechanical load on $\mathrm{Ca}^{2+}$ signalling causing hypertrophy and remodeling have been discussed elsewhere ${ }^{9,10}$ and are beyond the scope of this review. 


\section{TECHNICAL CONSIDERATIONS}

The mechanical environment of cardiac myocytes within the beating heart is highly complex. With every cycle, cardiac myocytes are subjected to rapid changes in load and length. During diastolic filling, by Laplace's law, myocytes develop tension while being stretched. The larger the stretch, the more force is generated for contraction against afterload pressure through the Frank-Starling mechanism. During contraction, myocytes deform in the longitudinal direction by shortening, and transversally by thickening. Because of the laminar organization of myocyte layers in situ, cells also experience considerable shear during deformation.

In past decades, experimental techniques have been developed that aimed at controlling one or more mechanical components sensed by a single myocyte in an in-vitro setting. The most common approach to subject a single myocyte to preload is stretching the cell in longitudinal direction with a pair of carbon fibers or glass rods attached at both cell ends. The carbon fiber technique was introduced by Le Guennec et al. in the late 1980s. ${ }^{11}$ The attachment is presumably due to electrostatic forces between the carbon fiber and myocyte surfaces. ${ }^{12}$ Active and passive forces are recorded by optical monitoring of bending of the fibers. The preload can be adjusted by moving the carbon fibers relative to each other by means of piezoelectric translators or manual micromanipulators. A variation on this method is the use of a biological adhesive, MyoTak, to glue the myocyte to glass fibers. ${ }^{8}$ The method differs from the carbon fiber technique in some respects. Because glass rods are stiffer, cell length is isometrically 'clamped' during contraction, although local sarcomere movement is observed to some degree. Real-time acquisition of sarcomere strain is achieved by combining the stretch system with $2 \mathrm{D}$ video-capture ${ }^{13}$ or confocal microscopy. ${ }^{14}$ Another advantage of combining stretch with high-resolution life-cell imaging is the possibility of spatiotemporal $\mathrm{Ca}^{2+}$ imaging and/or patch-clamp studies during stretch. ${ }^{7,15}$ Recently, systems for dynamic control of mechanical load, subjecting myocytes to pressure-volume loops, have been implemented with the fiber technique. ${ }^{16-18}$

A different approach for stretching cells is the use of a gel matrix. Petroff et al. embedded myocytes in agarose in a deformable tube ${ }^{19}$ Because agarose is deformable but not elastic, pulling the tube results in stretch of the embedded cells. Also, during stretch the gel exerts compressive stress on the myocyte, which is not the case with carbon fiber stretch.

The group of Chen-Izu developed a viscoelastic hydrogel made of polyvinyl alcohol and boronic acid cross-linker that binds to cell surface glycans. ${ }^{20}$ Because of the gel's viscoelasticity, the myocyte works against the gel during contraction and experiences afterload. The viscoelasticity of the gel, and thus afterload, is tunable by the mixing ratio of the cross-linker and the polyvinyl alcohol. In addition to afterload, the myocyte also experience transverse compression and surface (shear) forces because of the tethering of the gel to the cell surface. The use of gels does not allow modulation of the afterload within the same cell.

To dissect the shear force component from other mechanical stresses, common techniques are the application of a pressurized jet of fluid directed tangential relative to the surface of the cell, ${ }^{21}$ or dragging fibers over the myocyte at a predefined velocity. ${ }^{22}$ Hydrojets through micropipettes have also been used to apply force at specific locations on the sarcolemma with nanoscale precision. Because hydrojets exerts pressure perpendicular to the cell surface, indentation causes stretch of the sarcolemma. ${ }^{23}$ 
Despite technical breakthroughs in recent years, the isolation of one mechanical stress component is still difficult to achieve in experimental settings. Usually one type of mechanical stimulus predominates, but other components contribute as well. These contributions make the comparison of results obtained by different methodologies challenging. In a recent review, Chen-Izu et al. provide a simplified framework to interpreting results from different stretch systems. ${ }^{24}$ In their conceptual view, mechanosensors are molecular 'springs' that sense strain, either inside the myocyte or on the surface. The dimensionality of the stretch system then defines what mechanosensor is activated. Myocyte stretch with carbon fibers or glass rods is considered a one-dimensional system, in which internal mechanosensors are activated, while surface mechanosensors will hardly experience any strain. In the $3 \mathrm{D}$ environment of a matrix gel, where a contracting myocyte pulls against the gel in the longitudinal direction and pushes against the gel in the transverse direction, also surface mechanosensors are activated. This concept has been proven very useful to explain apparent discrepancies between the available literature data obtained by different systems.

\section{EFFECT OF PRELOAD ON CA ${ }^{2+}$ SIGNALLING}

In the next section, we discuss the effects of acute stretch - a measure of preload - on systolic and diastolic $\mathrm{Ca}^{2+}$. We briefly mention generally accepted mechanisms causing the wellknown stretch-induced gradual increase of systolic $\mathrm{Ca}^{2+}$ transients underlying the SFR. The main focus is on recently discovered mechanisms of stretch-induced diastolic $\mathrm{Ca}^{2+}$ release, detectable at subcellular resolution, that mostly rely on intracellular $\mathrm{Ca}^{2+}$ stores. The sarcoplasmic reticulum and mitochondria as possible sources will be discussed in more detail.

\section{Effects of stretch on systolic $\mathrm{Ca}^{2+}$ transients}

In the late 70s, new techniques for measuring intracellular $\mathrm{Ca}^{2+}$ with $\mathrm{Ca}^{2+}$-sensitive bioluminescent proteins became available and made it possible to study the dynamic behaviour of $\mathrm{Ca}^{2+}$ in intact cardiac muscle preparations. ${ }^{25}$ Thus far, the relation between $\mathrm{Ca}^{2+}$ and force generation was assessed in skinned muscles revealing that increasing muscle length leads to increased myofilament $\mathrm{Ca}^{2+}$ sensitivity and thus more generated force by contraction. ${ }^{26}$ In skinned muscle, the dynamic component of $\mathrm{Ca}^{2+}$-induced $\mathrm{Ca}^{2+}$ release, and other $\mathrm{Ca}^{2+}-$ dependent signalling processes that require an intact intracellular environment and tight control of trans-sarcolemmal $\mathrm{Ca}^{2+}$ fluxes, is lost. Allen and Kurihara injected isolated papillary muscle and trabeculae with a $\mathrm{Ca}^{2+}$-binding photoprotein and monitored changes in intracellular $\mathrm{Ca}^{2+}$ and force of contraction upon stretch. ${ }^{27}$ The study demonstrated for the first time that the SFR was associated with an increase in the magnitude of the intracellular $\mathrm{Ca}^{2+}$ transient, an observation confirmed by many others, ${ }^{28-32}$ but not by all. ${ }^{33}$

The proposed mechanism underlying the slow $\mathrm{Ca}^{2+}$ response is an increase in intracellular sodium $\left(\mathrm{Na}^{+}\right)$resulting from complex interactions between multiple mechanosensitive pathways. The initial step probably involves auto-/paracrine activation of angiotensin receptors and downstream release of endothelin $\left({ }^{34-36}\right.$, but see also conflicting results by $\left.{ }^{37}\right)$. Myocardial $\mathrm{Na}^{+} / \mathrm{H}^{+}$exchanger activity (NHE1) is increased via complex pathways that either involve reactive oxygen species (ROS) production, ${ }^{38}$ or protein kinase $\mathrm{C}$ activation via the 
phospholipase $\mathrm{C}$ and inositol 1,4,5-trisphosphate (IP3) cascade. ${ }^{39}$ The subsequent increase in cytosolic $\mathrm{Na}^{+}$reduces the extrusion of $\mathrm{Ca}^{2+}$ via the $\mathrm{Na}^{+} / \mathrm{Ca}^{2+}$ exchanger (NCX) resulting in net gain of $\mathrm{Ca}^{2+}$ and therefore larger $\mathrm{Ca}^{2+}$ transients and twitch force. ${ }^{40}$ Several authors have also suggested the involvement of stretch activated channels (SAC) that conduct $\mathrm{Na}^{+}$and/ or $\mathrm{Ca}^{2+}{ }^{41,42} \mathrm{~A}$ proposed candidate for integrating both pathways is the TRPC6 channel, a stretch-activated non-selective cation channel that is also regulated by angiotensin via phospholipase $\mathrm{C}$ signalling, and that possibly activates kinases upstream of NHE $1 .{ }^{43} \mathrm{~A}$ very recent study implicated a similar role for TRPC $3 .{ }^{44}$ For a detailed discussion of signalling pathways underlying the SFR we refer to ${ }^{5}$.
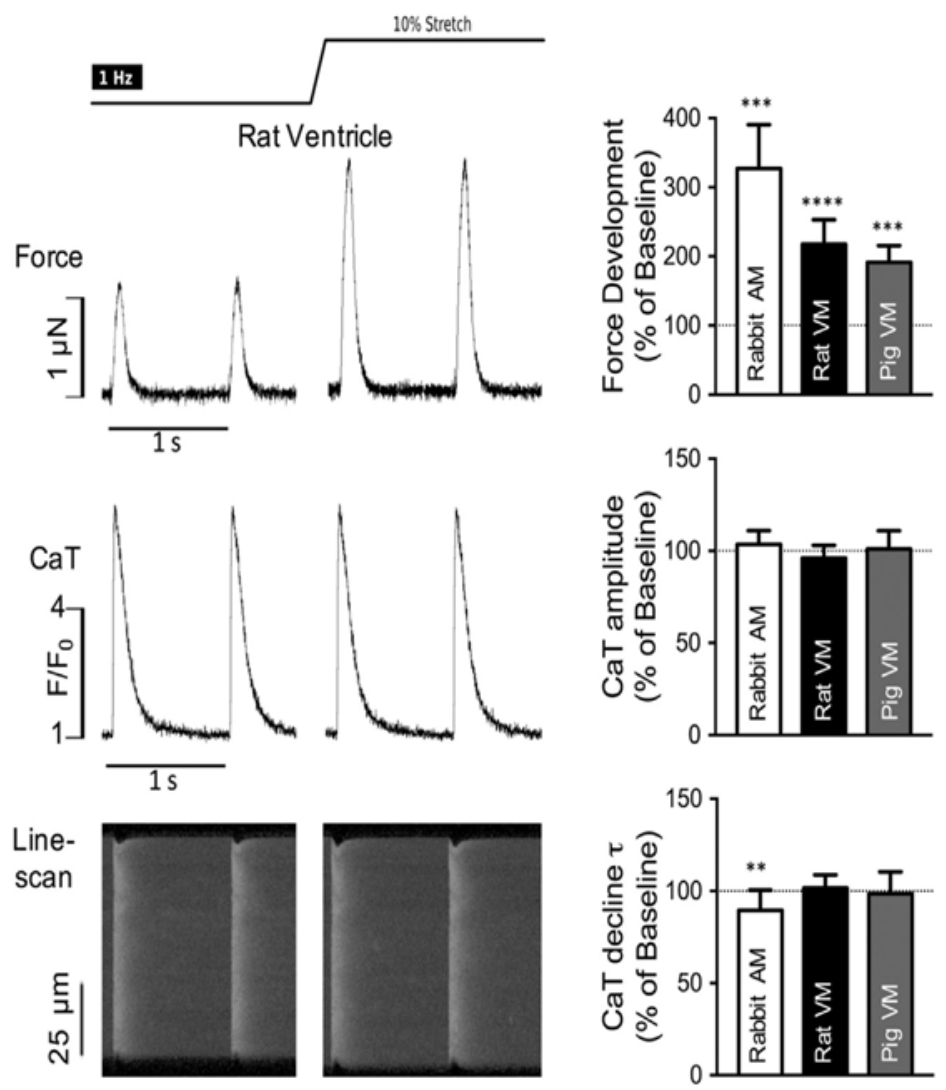

Figure 1. Effect of stretch on force and systolic $\mathrm{Ca}^{2+}$ Single ventricular (VM) or atrial myocytes (AM) were glued to glass fibers, coated with a biological adhesive (MyoTak, Ion Optix), electrically stimulated at $1 \mathrm{~Hz}$ and stretched to $10 \%$ of initial cell length, at $37^{\circ} \mathrm{C}$. A, Representative examples of force (top) and $\mathrm{Ca}^{2+}$ transients (CaT, middle) averaged from confocal line scans (Fluo4-AM, bottom) simultaneously recorded before and $15 \mathrm{~s}$ after cells were stretched. B, Averaged data of force and C, CaT amplitude comparing VM and AM of different species. Changes in response to stretch are expressed as percentage of baseline. $\mathbf{D}, \mathrm{Ca}^{2+}$ decay was faster in rabbit $\mathrm{AM}$, and unchanged in rat and pig VM. Whether the faster $\mathrm{Ca}^{2+}$ decay can be attributed to the structural and/or functional differences between AM and VM, or reflects species-dependent effects cannot be inferred from the presented data. (Rabbit AM, $\mathrm{n}=12$; Rat VM, n=11; Pig VM, n=6; mean \pm SEM). 
In contrast $\mathrm{SFR}, \mathrm{Ca}^{2+}$ is not centrally involved in the force potentiation during the fast phase. The early studies in multicellular preparations reporting on the role of $\mathrm{Ca}^{2+}$ in SFR noted no significant increase in intracellular $\mathrm{Ca}^{2+}$ during the fast phase after stretch. We, and others, ${ }^{29}$, ${ }^{31,45}$ confirmed this in single myocytes from different species and tissue (Figure 1). These results imply that an increase in myofilament $\mathrm{Ca}^{2+}$ sensitivity, rather than an increase in the amount of free $\mathrm{Ca}^{2+}$ available for binding to troponin $\mathrm{C}(\mathrm{TnC})$, is the primary cause of the fast stretch response. This idea had previously been proposed by Allen et al. to explain why $\mathrm{Ca}^{2+}$ transients declined faster while force relaxation became slower as the muscle was stretched and more force developed. ${ }^{27}$ Given that $\mathrm{Ca}^{2+}$ affinity of troponin is influenced by developed tension, ${ }^{46}$ relaxation in stretched muscle is slower because $\mathrm{Ca}^{2+}$ dissociates from the myofilaments more slowly due to the higher affinity of $\mathrm{TnC}$ for $\mathrm{Ca}^{2+} .{ }^{47}$ At the same time, removal of free $\mathrm{Ca}^{2+}$ is faster because more $\mathrm{Ca}^{2+}$ is buffered by TnC during the relaxation phase. ${ }^{27}$ Consistent with this theory, a sudden change in cell length during early relaxation causes a transient rise in free $\mathrm{Ca}^{2+}$ that is released from $\mathrm{TnC}$ due to the sudden drop in tension. ${ }^{48,}$ ${ }^{49}$ Under certain conditions, this could lead to initiation of arrhythmias ${ }^{50}$, as we will discuss later. Of note, the faster $\mathrm{Ca}^{2+}$ decline is not observed in single myocytes (Figure 1). ${ }^{29}$ The reason for this is unclear. Possibly the increase in $\mathrm{Ca}^{2+}$ affinity of $\mathrm{TnC}$ is too small to be detected as changes in the $\mathrm{Ca}^{2+}$ transient in single myocytes. Alternatively, it might be related to the interplay between stretch, action potential (AP) duration and $\mathrm{Ca}^{2+}$ removal. Changes in AP duration have secondary effects on $\mathrm{Ca}^{2+}$ removal via modulation of $\mathrm{NCX}$. If stretch prolongs $\mathrm{AP},{ }^{51,52,53}$ the effect on the $\mathrm{Ca}^{2+}$ transient would be opposite as to the $\mathrm{TnC}$ effect, i.e. slowing of $\mathrm{Ca}^{2+}$ decline. Such effects might be more pronounced in uncoupled myocytes that typically have longer AP than intact cardiac muscle. ${ }^{54,55}$

\section{Effects of stretch on diastolic $\mathrm{Ca}^{2+}$}

The first indication of stretch-dependent effects on diastolic $\mathrm{Ca}^{2+}$ came from early work in isolated papillary muscles. Nichols et al. demonstrated that an apparently similar SFR could be produced when muscle length was changed only during the diastolic period between contractions, ${ }^{56}$ speculating that stretch gives rise to diastolic $\mathrm{Ca}^{2+}$ influx that would then lead to greater $\mathrm{Ca}^{2+}$ sequestration by the SR. Allen et al. confirmed that diastolic length of papillary muscles controlled the size of the systolic $\mathrm{Ca}^{2+}$ transient, ${ }^{28}$ but failed to demonstrate directly an increase in diastolic $\mathrm{Ca}^{2+}$ concentration, possibly due to the insensitivity of aequorin to resting $\mathrm{Ca}^{2+}$ levels. Results in single myocytes are conflicting. Some studies monitoring whole-cell $\mathrm{Ca}^{2+}$ fluorescence with Indo-1 or Fura-2 reported increases in diastolic $\mathrm{Ca}^{2+}$ levels during stretch ${ }^{57,58}$ while others did not. ${ }^{29,}{ }^{45}$ Petroff et al. were the first to use confocal microscopy to monitor subcellular $\mathrm{Ca}^{2+}$ events during stretch and to providing direct evidence that stretch modulates the elementary $\mathrm{Ca}^{2+}$ release process, the $\mathrm{Ca}^{2+}$ spark. ${ }^{59}$ Stretch-induced increases in $\mathrm{Ca}^{2+}$ spark frequency are a phenomenon consistently observed in myocytes, ${ }^{7,8}$ also in response to other mechanical stimuli, such as shear stress and afterload. ${ }^{60,20}$ More controversy exists as to how the mechanical stimulus is sensed at the membrane and transmitted to intracellular $\mathrm{Ca}^{2+}$ stores, and what $\mathrm{Ca}^{2+}$ stores are possibly involved. 


\section{Sources of stretch-induced $\mathrm{Ca}^{2+}$ release}

\section{The concept of $\mathrm{Ca}^{2+}$ microdomains in cardiac cells}

During a cardiac cycle, contraction is initiated by a transient rise in intracellular $\mathrm{Ca}^{2+}$. The $\mathrm{Ca}^{2+}$ transient results from sarcolemmal $\mathrm{Ca}^{2+}$ influx through L-type $\mathrm{Ca}^{2+}$ channels (LTCC) during depolarization that activates ryanodine receptors (RyR) followed by $\mathrm{Ca}^{2+}$ being released from the SR. The relative contribution of $\mathrm{SR} \mathrm{Ca}^{2+}$ to the steady-state cytosolic $\mathrm{Ca}^{2+}$ transient depends on the species, ranging from $70-75 \%$ in larger animals to $90 \%$ in rodents. ${ }^{61}$ The efficiency of $\mathrm{Ca}^{2+}$-induced $\mathrm{Ca}^{2+}$ release (CICR) is supported by dedicated structures, so-called dyads, where LTCC face clusters of RyR in the SR (Figure 2). In this narrow cleft, $\mathrm{Ca}^{2+}$ is temporally and spatially constrained, and is 10 times higher than global $\mathrm{Ca}^{2+}$ before dissipating into the cytosol for binding to the myofilaments. ${ }^{6}$ In ventricular myocytes, dyadic microdomains are localized at t-tubules (TT), regularly spaced invaginations of the sarcolemma at Z-lines. TT interconnect and transverse the entire cytosol ensuring electrical and contractile synchrony throughout the myocyte. Dyads are also sites of compartmentalized regulation of $\mathrm{Ca}^{2+}$ signalling by kinases and ROS. For example, stimulation of $\mathrm{Ca}^{2+} /$ calmodulin-dependent protein kinase II (CaMKII) and ROS by faster heart rates sensitizes RyR in the dyads, but not RyR in regions that are not coupled to the sarcolemma. ${ }^{63}$ The source of ROS matters, because ROS produced by NADPH oxidase type 2 (NOX2), a membrane-bound NADPH oxidase located at TT and sarcolemma, but not mitochondrial ROS, preferentially modulate dyadic RYR under physiological conditions. ${ }^{64} \mathrm{NOX} 2$ has been reported to be involved in mechanosensitivity of $\mathrm{SR} \mathrm{Ca}^{2+}$ release. ${ }^{8}$ The dyad as nexus of $\mathrm{Ca}^{2+}$, ROS and mechanical signals will be discussed in the next section.

A similar $\mathrm{Ca}^{2+}$ microdomain may exist between the mitochondria and the SR. Mitochondria are located within subsarcolemmal, perinuclear, and intermyofibrillar regions of the myocyte, and are physically tethered to the SR by linker proteins, presumably Mitofusin- $2 .{ }^{65,66}$ Tethers can be observed throughout the muscle between mitochondria and junctional SR, or network SR. ${ }^{67}$ The distance between the RyR in the SR and mitochondria is within the nanometer range (37 - $270 \mathrm{~nm}$ according to ${ }^{68}$ ). Thus during SR $\mathrm{Ca}^{2+}$ release, the mitochondria are exposed to hot spots of $\mathrm{Ca}^{2+}$ reaching levels 10 -folds higher than in the bulk cytosol. ${ }^{69,70,71}$ The close proximity of SR and mitochondria is thought to facilitate efficient mitochondrial $\mathrm{Ca}^{2+}$ uptake via the mitochondrial $\mathrm{Ca}^{2+}$ uniporter during SR $\mathrm{Ca}^{2+}$ release. ${ }^{72,73}$ In the mitochondrial matrix, $\mathrm{Ca}^{2+}$ is important for activating Krebs cycle dehydrogenases to accelerate the regeneration of NADH that fuels the electron transport chain for the production of ATP. While passing the electron transport chain, electrons leak and produce superoxide that is rapidly transformed into $\mathrm{H}_{2} \mathrm{O}_{2}$ that can cross membranes and may influence the local redox environment of RyR in the SR-mitochondrial space. At the same time, $\mathrm{Ca}^{2+}$ contributes to the antioxidative capacity of the mitochondria, by indirectly helping to keeping $\mathrm{H}_{2} \mathrm{O}_{2}$ levels low, by regeneration of NADHP required for the activation of mitochondrial $\mathrm{H}_{2} \mathrm{O}_{2}$-eliminating enzymes (see ${ }^{74}$ for review).

Mitochondrial $\mathrm{Ca}^{2+}$ efflux is largely mediated via mitochondrial $\mathrm{NCX}$ and the permeability transition pore. Recent evidence suggests that $\mathrm{Ca}^{2+}$ release from mitochondria is triggered by stretch and shear. 
A

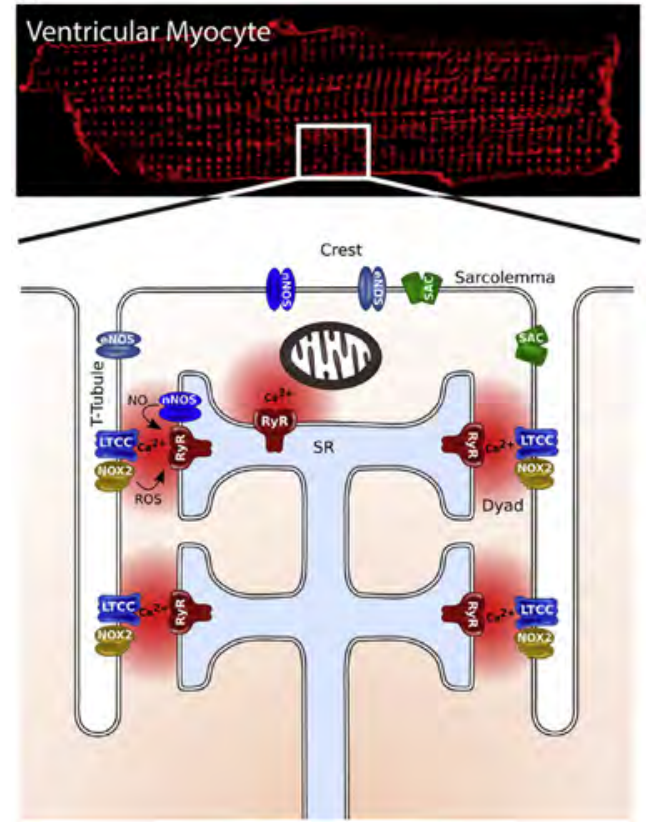

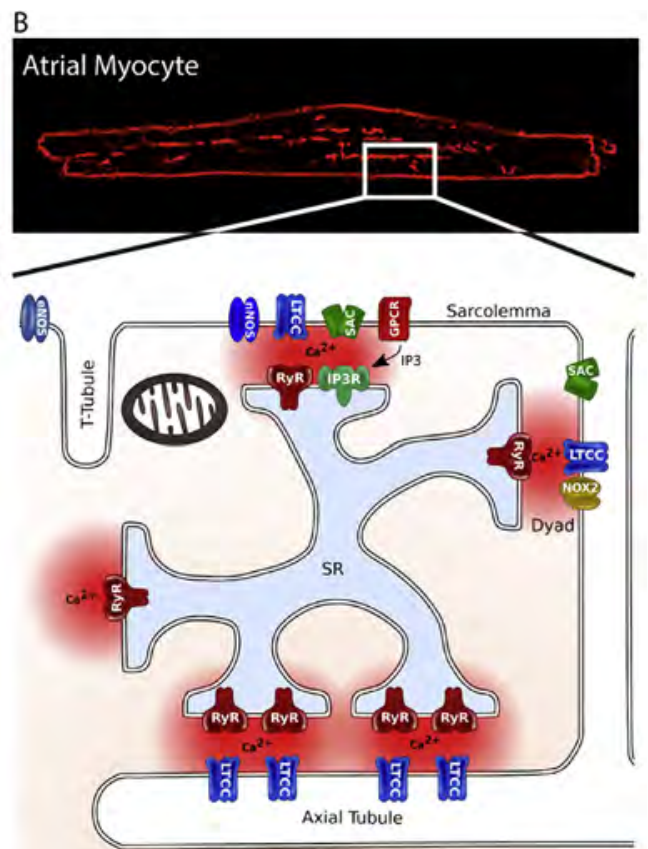

Figure 2. Structural organization of $\mathrm{Ca}^{2+}$ microdomains in atrial and ventricular myocytes. The schematic representation shows an enlarged detail of subcellular structures between adjacent sarcomeres in a ventricular (VM) and atrial myocyte (AM). The organization of transverse tubules (TT) and axial tubules (AT) is based on membrane stainings of rabbit myocytes (Di-8ANEPPS).A, VM have a regular pattern of junctional SR $\mathrm{Ca}^{2+}$ release sites along TT. Electrical signals (carried by L-Type $\mathrm{Ca}^{2+}$ channel, LTCC), $\mathrm{Ca}^{2+}$ (released by ryanodine receptors, RyR) and mechano-chemical signals (reactive oxygen species, ROS; nitric oxide, NO) convey at the dyad in coupled regions. Dyadic ROS is produced by NADPH Oxidase Type 2 (NOX2). Neuronal (nNOS) or endothelial nitric oxide synthase (eNOS) generates NO. The space between the sarcoplasmic reticulum (SR) and mitochondria forms a separate mechanosensitive $\mathrm{Ca}^{2+}$ microdomain. Connections between SR and intermyofibrillar mitochondria that constitute the bulk of the mitochondria in a cardiac myocyte are not depicted here, but are not excluded as a possible mechanosensitive $\mathrm{Ca}^{2+}$ site. B, AM have less dense and more irregular TT, but more AT in the central region of the cell that are coupled to SR and form highly efficient CICR sites. At the periphery, SR $\mathrm{Ca}^{2+}$ release is mediated by co-localized RyR and inositol 1,4,5-trisphosphate receptor (IP3R). Stretch-activated channels (SAC) may have direct access to subsarcolemmal release sites. Because of sparse TT, AM have more uncoupled release sites that propagate $\mathrm{Ca}^{2+}$ relatively slowly from the subsarcolemma to the center. See text for more details.

\section{Sarcoplasmic reticulum}

The SR is the main source of $\mathrm{Ca}^{2+}$ release during CICR. The elementary event of the release process is a $\mathrm{Ca}^{2+}$ spark produced by the opening of a RyR cluster. Opening of RyR is usually triggered by a rise in $\mathrm{Ca}^{2+}$ through LTCC activation, but may also occur spontaneously when RyR are sensitized to $\mathrm{Ca}^{2+}$ by phosphorylation, or oxidation and nitrosylation. A spontaneous $\mathrm{Ca}^{2+}$ spark is usually a local diastolic event that is restricted in time and space. The spatiotemporal constraints are imposed by the compartmentalized structure of the dyad limiting diffusion and ensuring precise control of RyR release. $\mathrm{A} \mathrm{Ca}^{2+}$ spark may start propagating when it increases in amplitude and duration due to high SR $\mathrm{Ca}^{2+}$ content and/or RyR sensitization. In such setting, $\mathrm{Ca}^{2+}$ sparks do activate neighbouring release units and evolve into a propagating $\mathrm{Ca}^{2+}$ wave. 
A single myocyte stretch immediately - within milliseconds - triggers a burst of $\mathrm{Ca}^{2+}$ sparks, that is reversible and declines within seconds. ${ }^{8,75}$ During moderate levels of stretch these sparks are restricted in time and space, but during large stretch they may degenerate into $\mathrm{Ca}^{2+}$ waves. The time course of $\mathrm{Ca}^{2+}$ sparks follows a stretch-induced increase in ROS. Like the $\mathrm{Ca}^{2+}$ response, the ROS signal is transient, and its amplitude is graded, ie, increases with increasing amounts of stretch. ${ }^{76,77}$ In ventricular rat myocytes, stretch-induced ROS is produced solely by NOX2. ${ }^{8,78}$ ROS sensitizes RyR to $\mathrm{Ca}^{2+}$. Possible mechanisms include direct oxidation of the receptor ${ }^{79}$, or indirectly, oxidation of calmodulin displacing the inhibitory binding calmodulin from RyR ${ }^{80}$, or RyR phosphorylation by oxidized CaMKII. ${ }^{81}$ CICR may therefore become more efficient during stretch. This particular pathway of mechanotransduction is termed X-ROS signalling, and an intact microtubule network comprises an essential structural component. ${ }^{8}$ Disruption of the microtubule abolishes the $\mathrm{Ca}^{2+}$ response to stretch. Importantly, X-ROS is independent of stretch-activated channels (SAC) and transsarcolemmal Ca ${ }^{2+}$ influx. ${ }^{82}$

Because X-ROS signalling is fast, tunable by graded stretch and confined to the dyad, it has been proposed to be an important for beat-to-beat adaptation to haemodynamic load. ${ }^{76}$ Although X-ROS operates on a much faster time-scale than the SFR (milliseconds vs minutes), it is intriguing to speculate that X-ROS and SFR are not separate pathways, but converge and regulate each other. The essential difference between SFR and X-ROS signalling in terms of $\mathrm{Ca}^{2+}$ is the gain: net gain during SFR vs. loss of $\mathrm{Ca}^{2+}$ due to enhanced SR $\mathrm{Ca}^{2+}$ leak by X-ROS. ${ }^{75}$ In order to interfere with SFR, X-ROS must be sustained, and activate secondary mechanisms that promote $\mathrm{Ca}^{2+}$ gain. While X-ROS induced ROS are typically transient during a single stretch of quiescent cells, ROS are maintained at higher steady-state levels when applying repetitive cycles of stretch, mimicking loading and unloading during a cardiac cycle. ${ }^{76}$ This observation would comply with the first requirement for X-ROS involvement in SFR in a beating heart. Besides other pathways, some studies suggested the involvement of SAC in $\mathrm{Ca}^{2+}$ accumulation during SFR. Interestingly, patch-clamp studies in stretched myocytes revealed NOX-dependent modulation of SAC, ${ }^{83}$ and this modulation may be facilitated by co-localization of NOX2 and SAC in caveolae. ${ }^{84}$ Thus although SAC are not involved in X-ROS signalling per se, they may function as modulators and downstream targets. In addition, NOX2 stimulates SR $\mathrm{Ca}^{2+}$ uptake via phospholamban phosphorylation, further shifting the balance towards $\mathrm{Ca}^{2+}$ gain. ${ }^{78}$ A possible link between X-ROS and SFR warrants further investigation.

X-ROS signalling is insensitive to inhibition of nitric oxide synthase (NOS) by L-NAME? By contrast, stretching myocytes in an agarose gel system increases nitric oxide (NO) production, $\mathrm{Ca}^{2+}$ spark frequency and the amplitude of electrically stimulated $\mathrm{Ca}^{2+}$ transients. ${ }^{19}$ There are several possible explanations. In a gel, myocytes experience additional surface forces due to compression. Surface mechanosensors may work via NO, while internal sensors may work via microtubule and ROS. ${ }^{24}$ Also, NO mechanosensitivity operates on a slower time scale of minutes. ${ }^{19}$ Thus, stretch-induced NO constitutes an enduring signal, unlikely to be involved in beat-to-beat adaptation, but possibly important for SFR.

It should be noted that not all studies identified the $\mathrm{SR}$ as the source of $\mathrm{Ca}^{2+}$ waves. In stretched trabeculae from rat ventricle, Wakayame et al. observed $\mathrm{Ca}^{2+}$ waves upon quick release of stretch. ${ }^{85}$ The initiation and propagation of these waves was not affected by increasing the 
open probability of RyR with caffeine, but caused by $\mathrm{Ca}^{2+}$ dissociation from the myofilaments. Others identified the mitochondria as source of stretch-induced $\mathrm{Ca}^{2+}$ release, as discussed next.

\section{Mitochondria}

Figure 2 depicts $\mathrm{Ca}^{2+}$ microdomains that are possibly mechanosensitive, including microdomains at the interface of SR and mitochondria located in the subsarcolemmal space underneath the crest between Z-lines. Hydrojet nanoindentation at this specific location triggered $\mathrm{Ca}^{2+}$ release events that were spatially restricted to the pressure site, did not rely on sarcolemmal $\mathrm{Ca}^{2+}$ influx or (exclusively) on SR release, but were inhibited by uncoupling of the mitochondrial proton gradient or by inhibition of the permeability transition pore. ${ }^{86}$ Disruption of microtubuli by colchicine stiffened the membrane and caused displacement of subsarcolemmal mitochondria, which was correlated with increased likelihood of producing mitochondrial $\mathrm{Ca}^{2+}$ waves. Thus intact sarcolemmal structure, high membrane compliance and subsarcolemmal mitochondria regularity are a prerequisite for the spatiotemporal control of mechanically-induced mitochondrial $\mathrm{Ca}^{2+}$ release. The authors could not exclude a role of the SR. Additional SR $\mathrm{Ca}^{2+}$ release triggered by the initial mitochondrial $\mathrm{Ca}^{2+}$ release could be necessary to produce a $\mathrm{Ca}^{2+}$ wave. Alternatively, the $\mathrm{SR}$ could be required for loading the mitochondria with $\mathrm{Ca}^{2+}$ to reach the threshold for release. The latter would be in line with previous experiments where shear stress was applied to the entire surface of the cell by pressurized flow and induced mitochondrial $\mathrm{Ca}^{2+}$ release. ${ }^{87} \mathrm{~A}$ second mechanical stimulus could

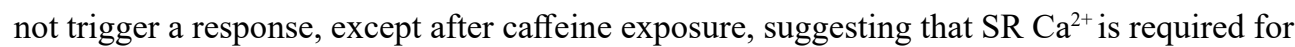
reloading the mitochondria.

The physiological significance of the mechanosensitive crosstalk between the SR and mitochondria is unclear. Speculative, crosstalk might provide a mechanism for fine-tuning SR $\mathrm{Ca}^{2+}$ release in response to rapid changes in pressure that are sensed by the mitochondria at the surface. When microdomains are disrupted, as in disease, mitochondrial $\mathrm{Ca}^{2+}$ release is no longer confined and becomes arrhythmogenic.

\section{EFFECT OF AFTERLOAD ON CA ${ }^{2+}$ SIGNALLING}

Afterload is the load against which the heart contracts to eject blood, and is closely related to arterial input impedance or aortic pressure. Stating differently, afterload is the pressure in the ventricular walls during ejection. In cardiac muscle and single myocytes, the concept of afterload can be translated to mechanical variables of peak twitch force and tension. Afterload is highest during isometric contractions, and lowest during isotonic contractions or unloaded shortening. Using the carbon fiber technique in isolated myocytes, Yasuda et al compared $\mathrm{Ca}^{2+}$ transients under isometric (high afterload) and isotonic (low afterload) conditions; the two modes of contraction were being alternated on a beat-to-beat basis. ${ }^{88}$ The isotonic $\mathrm{Ca}^{2+}$ transients exhibited higher amplitudes and faster decays. The faster $\mathrm{Ca}^{2+}$ decline is conform to the idea that tension influences $\mathrm{Ca}^{2+}$ affinity of $\mathrm{TnC}$. The higher $\mathrm{Ca}^{2+}$ affinity of $\mathrm{TnC}$, and thus increased $\mathrm{Ca}^{2+}$ buffering by myofilaments, may also account for the reduced amplitude of cytosolic $\mathrm{Ca}^{2+}$ transients during isometric contraction. 
In the cell-in-gel model developed by Chen-Izu group, afterload is conceptualized as viscoelastic resistance, thus an opposing force against which myocytes contract. The model also includes a component of shear stress. ${ }^{89}$ This is different from the above conventional expression of afterload as myocyte tension. The viscoelastic resistance could be varied by adjusting the stiffness of the gel. Myocytes contracting against an afterload produced higher $\mathrm{Ca}^{2+}$ transient amplitudes in systole, and smaller contractions. Afterload also increased $\mathrm{Ca}^{2+}$ spark occurrence in-between contractions. There was a positive correlation between spark rate and stiffness of the gel, and thus the amount of afterload. Interestingly, $\mathrm{Ca}^{2+}$ sparks did not appear immediately, but with a latency of about 10 s. Afterload had a much greater effect on diastolic spark rate than stretch, suggesting a different mechanism from preload.

Afterload mechanotransduction appears to involve NO signalling. The authors found, by pharmacological inhibition or genetic deletion, that both neuronal NOS (nNOS) and endothelial NOS (eNOS) contributed to the increase of systolic $\mathrm{Ca}^{2+}$, but only nNOS participated in the afterload-induced $\mathrm{Ca}^{2+}$ sparks. Due to the short life-time of NO, its effective signaling range is limited and dependent on the diffusion distance, amount produced and the buffer capacity of the cell. ${ }^{19,}, 90$ Therefore, one possible explanation for the distinct effects of nNOS vs. eNOS-derived NO on $\mathrm{Ca}^{2+}$ sparks is their different subcellular localization. While eNOS is localized at the caveolae in TTs and the surface sarcolemma, ${ }^{20,91,92} \mathrm{nNOS}$ is preferentially localized at the SR membrane in the vicinity of RyR. ${ }^{93}$ nNOS increases RyR Ca ${ }^{2+}$ leak, directly by S-nitrosylation or indirectly via CaMKII. ${ }^{90,94}$ In addition, nNOS facilitates SERCA $\mathrm{Ca}^{2+}$ reuptake which may compensate for the increased $\mathrm{SR} \mathrm{Ca}^{2+}$ leak and reduced basal LTCC current. ${ }^{95,96,97}$

The effects of eNOS on systolic $\mathrm{Ca}^{2+}$ transients are complex, with both positive and negative inotropic effects being reported..$^{92,98}$ This discrepancy may depend on variations in the levels of NO. In a study by Vila-Petroff using exogenous NO donors, high levels of NO induced a large increase in cGMP and a negative inotropic effect, while low levels of NO increased cAMP and caused positive inotropy via cGMP-independent activation of adenyl cyclase. ${ }^{98}$ The low exogenous NO concentration causing an increase in the $\mathrm{Ca}^{2+}$ transient amplitude in the study by Vila-Petroff is comparable to the levels of NO within the heart during haemodynamic load, ${ }^{99}$ and could explain the eNOS dependent increase in systolic $\mathrm{Ca}^{2+}$ under elevated afterload reported by Jian et al.. ${ }^{4}$ The net result of these additional effects on $\mathrm{Ca}^{2+}$ handling is an enduring effect on systolic $\mathrm{Ca}^{2+}$ during afterload. The harm of increased NO signalling is a significant increase in diastolic $\mathrm{Ca}^{2+}$ sparks that in some conditions form $\mathrm{Ca}^{2+}$ waves. ${ }^{100}$

\section{EFFECT OF SHEAR STRESS ON CA ${ }^{2+}$ SIGNALLING}

During each cardiac cycle, the myocardium undergoes complex 3D deformations. A significant component comprises longitudinal and transverse shearing due to the laminar architecture of the myocardial tissue. Sliding and rearrangement of laminar sheets may contribute to wall thickening during systole, ${ }^{101}$ and has also been associated with ventricular torsion during relaxation. ${ }^{102}$ Shear forces may therefore contribute significantly to ejection and filling of the chambers. The haemodynamic forces of blood flow causes additional shear stress at the luminal surface of the chamber wall. While shear stress in the myocardium is probably relatively low, the amount of shear may become significant in conditions of chronic haemodynamic turbulence, such as valvular diseases, or in the context of atrial fibrillation. 
Mechanistic studies addressing how shear forces that are transmitted to the individual myocyte might affect myocyte function are rather scarce. Most of the work on shear-sensitive ion channels has been done in atrial myocytes showing that their response appears to be mostly indirectly, via mechanisms of trafficking (e.g. Kv1.5 ${ }^{103}$ ) or shear-induced $\mathrm{Ca}^{2+}$ release (e.g. LTCC, TRPM4 ${ }^{104,105}$ ).

To date, several studies have reported effects of shear on myocyte $\mathrm{Ca}^{2+}$ homeostasis. ${ }^{60,87,104 \text {, }}$ ${ }^{106}$ From these studies, a rather complex picture has emerged of multiple shear-sensitive $\mathrm{Ca}^{2+}$ signalling pathways having distinct spatiotemporal patterns and mechanisms. Shear stress induces $\mathrm{Ca}^{2+}$ release from SR or mitochondria. ${ }^{48,57,106,87}$ Furthermore, the $\mathrm{Ca}^{2+}$ response to increased shear covers the entire spectrum from faster $\mathrm{Ca}^{2+}$ sparks to longer lasting transients. Woo et al observed in rat atrial myocytes an increase in $\mathrm{Ca}^{2+}$ sparks frequency under shear stress, with an onset of $200-300 \mathrm{~ms}$. The $\mathrm{Ca}^{2+}$ sparks were locally confined, preferentially located at the cell periphery. Higher pressure flow often triggered $\mathrm{Ca}^{2+}$ waves. ${ }^{48}$ In subsequent studies, the same group identified mechanisms of shear-induced $\mathrm{Ca}^{2+}$ waves. ${ }^{104,106}$ The waves were triggered by IP3 receptor-mediated $\mathrm{Ca}^{2+}$ release and involved recruitment of RyR for wave propagation. IP3 signalling was mediated through activation of purinoreceptors by shear-induced ATP release via connexin hemichannels. Shear-induced IP3 mediated $\mathrm{Ca}^{2+}$ waves had a variable latency $(0.2-3 \mathrm{~s})$ and shape. In contrast, $\mathrm{Ca}^{2+}$ transients originating from shear-induced mitochondrial $\mathrm{Ca}^{2+}$ release had different kinetics. The $\mathrm{Ca}^{2+}$ transients developed with a latency of $\sim 300 \mathrm{~ms}$, had a rising phase of $\sim 150 \mathrm{~ms}$ (two times slower than caffeine-induced transients) and an average duration of 2 seconds. ${ }^{21,87}$ They were observed in both atrial and ventricular myocytes and appeared to originate from mitochondrial sources with no involvement of IP3 signalling, sarcolemmal pathways and/or SR $\mathrm{Ca}^{2+}$ stores. Because shear-induced mitochondrial $\mathrm{Ca}^{2+}$ releases were most consistently observed after short caffeine exposures, the suggested role of the SR was to replenish the mitochondria with $\mathrm{Ca}^{2+}$ after shear-induced depletion. Although caution is warranted when comparing different experimental techniques, these findings are in line with the observations by Miragoli et al., ${ }^{86}$ who observed mitochondrial-mediated $\mathrm{Ca}^{2+}$ transients with comparable kinetics when applying hydrojet nanoindentation to subsarcolemmal mitochondria.

Taken together, shear stress can activate multiple pathways of mechano-transduction that have access to different $\mathrm{Ca}^{2+}$ pools. Why forces are transmitted to RyR and/or IP3 stores in some considers, but to the mitochondria in others, even when using similar techniques and experimental settings, remains to be established. The differences presumably lie in the details of amplitude, location and duration of the mechanical stimulus, or the nano-structural organization of the cell. Currently, it is also unclear whether shear responses share common pathways with other types of mechanical stimuli. A very recent study in ventricular myocytes suggested that shear-induced $\mathrm{Ca}^{2+}$ sparks involved activation of NOX2 and microtubules, but unlike stretch-induced X-ROS signalling, depended on mitochondrial ROS. ${ }^{107}$ Finally, the relevance to cardiac function as well as pathophysiology is far from understood.

\section{EMERGING DIFFERENCES BETWEEN ATRIAL AND VENTRICULAR MYOCYTES}

In atrial myocytes, the spatiotemporal organization of CICR and contraction is remarkably different from ventricular cells (fig 2). One striking difference is the structural organization of the tubule network. Ventricular myocytes typically have a dense and regularly spaced 
TT network, and this arrangement determines uniform $\mathrm{Ca}^{2+}$ release and contraction. In atrial myocytes, TT density is sparse, the pattern is more irregular, and large variations exist across species. Studies in several large animal species (eg. sheep, dog), and human tissue, identified the presence of an atrial TT network ( ${ }^{108-110}$ and reviewed by $\left.{ }^{111}\right)$. Early studies in smaller animals such as rats and cats reported that there are few, if any, TT structures, ${ }^{112,113}$ while very recent studies using super-resolution imaging methods highlighted the existence of an extensive TT network in rats. ${ }^{114,115}$ A possible explanation for this discrepancy is the large spatial heterogeneity of the TT system within the atria: some cells have complete lack of TT, while others have disorganized TT, and a minority has a TT organization similar to ventricular myocytes. ${ }^{65,116}$

Atrial myocytes have less junctional RyR in the central regions of the cell, but more at the cell periphery. ${ }^{117}$ As a result, during CICR $\mathrm{Ca}^{2+}$ is provided by release from junctional SR and non-junctional SR. This causes inhomogeneity of local $\mathrm{Ca}^{2+}$ transients: fast release in subcellular regions coupled to TT, and slow propagated release in non-coupled regions. Large heterogeneity slows the rise of global $\mathrm{Ca}^{2+}$ and hence contraction, however, this is at odds with the fast dynamics of contractile force we and others have observed in atrial myocytes. ${ }^{114,118}$ Figure 3 compares force and $\mathrm{Ca}^{2+}$ in an atrial and ventricular rabbit myocyte. Activation of force is faster in atrial myocytes. ${ }^{119}$ This could be attributed to higher levels of fast $\alpha$-myosin heavy chain (MHC) isoform in the atria, ${ }^{120,}{ }^{121}$ however, rodents like mice and rats have comparable levels of $\alpha$-MHC in atria and ventricle, ${ }^{122,}{ }^{123}$ and yet atrial contraction dynamics are faster. ${ }^{124}$ In Figure 3, the upstroke of the $\mathrm{Ca}^{2+}$ transient (spatially averaged $\mathrm{Ca}^{2+}$ signal from longitudinal line scans) is faster in the atrial cell despite significantly lower TT density. A recent study by Brandenburg et al., has provided an elegant explanation for
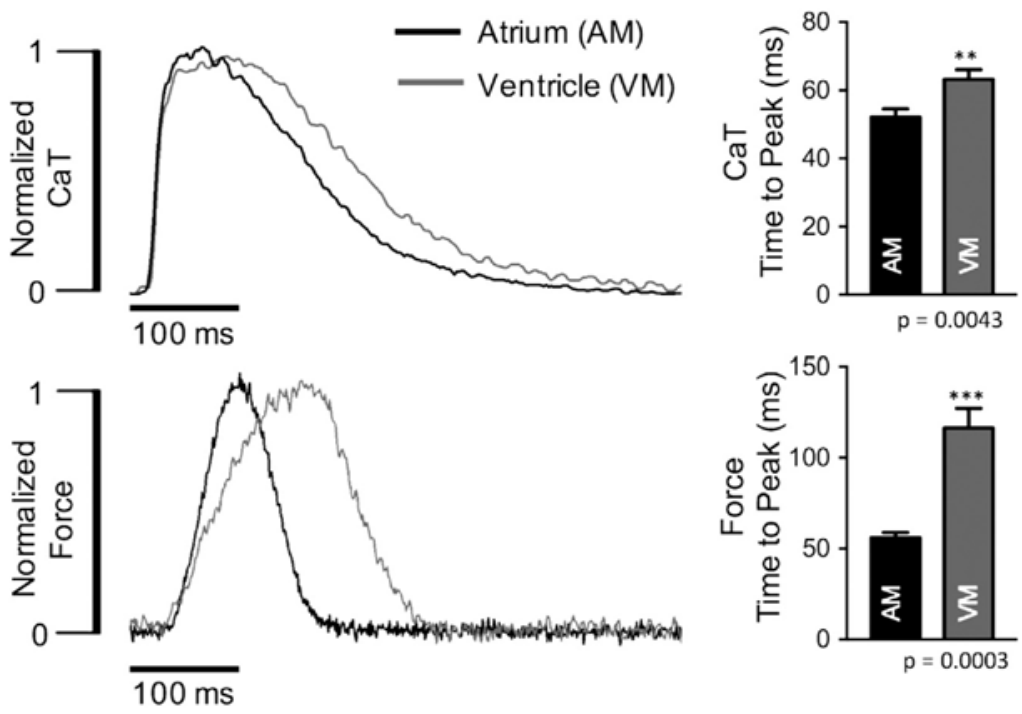

Figure 3. Comparison of $\mathrm{Ca} 2+$ and force kinetics in atrial and ventricular myocytes Examples of $\mathrm{Ca} 2+$ transients (A) and forces (B) recorded in an atrial (AM) and ventricular (VM) rabbit myocyte $\left(1 \mathrm{~Hz}, 37^{\circ} \mathrm{C}\right)$. Signals of AM (black trace) and VM (grey trace) are superimposed for comparison. AM has shorter time-to-peak of CaT (52 \pm 1 $\mathrm{ms}$ in $\mathrm{AM}$ vs. $63 \pm 3 \mathrm{~ms}$ in VM) and faster force development (56 $\pm 3 \mathrm{~ms}$ in AM vs. $116 \pm 11 \mathrm{~ms}$ in VM). Pooled data of $n=38$ for $A M$, and $n=38$ for VM. Data are presented as mean \pm SEM. Comparisons within groups were made by unpaired Student $t$ test, and values of $\mathrm{P}<0.05$ were taken to indicate statistical significance. 
the apparent discrepancy. ${ }^{125}$ Using state-of-the-art imaging, large axial tubule (AT) structures were detected that contained $\mathrm{Ca}^{2+}$ channels functionally coupled to RyR clusters at SR junctions in the central region of the atrial myocyte. AT were connected to the sarcolemma through a sparse network of TT. Interestingly, $\mathrm{Ca}^{2+}$ release at AT in the cell center was faster than $\mathrm{Ca}^{2+}$ release at peripheral sites due to AT-specific hyperphosphorylation of RyR clusters. This unique structure and functional regulation of $\mathrm{Ca}^{2+}$ release units at AT provide a means for more rapid shortening of central sarcomeres when TT are sparse.

In addition, atrial myocytes may be more dependent on IP3 signalling for CICR. IP3 receptors are much more abundant in atrial myocytes, and are - in contrast to ventricular cells - co-localized with junctional RyR at the cell periphery. ${ }^{126}$ IP3 receptors require both IP3 and $\mathrm{Ca}^{2+}$ for activation. When IP3 is high, e.g. by neurohumoral stimulation with endothelin-1 or angiotensin II, IP3-mediated $\mathrm{Ca}^{2+}$ release may contribute to the systolic $\mathrm{Ca}^{2+}$ transient, ${ }^{126}$ but can also trigger arrhythmogenic $\mathrm{Ca}^{2+}$ waves. ${ }^{126}$ Early data in cardiac cells reported an increase in IP3 levels during stretch. ${ }^{127}$ IP3-triggered $\mathrm{Ca}^{2+}$ release has been proposed to contribute to the stretch-induced $\mathrm{Ca}^{2+}$ accumulation and endothelin-sensitive SFR in human atrial muscle. ${ }^{37}$ IP3 signalling is also involved in shear stress-mediated $\mathrm{Ca}^{2+}$ waves. ${ }^{104,128}$

How can mechanotransduction be interpreted in view of these structural differences in atrial cells? The discussion is mainly speculative because no single cell studies with direct comparison between atrial and ventricular cells are available. $\mathrm{Ca}^{2+}$ mechanosensitivity of atrial cells has been mostly interrogated by shear stress that would predominantly activate surface mechanosensors; in ventricular cells, $\mathrm{Ca}^{2+}$ mechanosensitivity has been investigated during axial stretch that merely activates internal mechanosensors, except for the gel-based systems that also carry a component of shear. ${ }^{19}$ Both shear and stretch induce $\mathrm{Ca}^{2+}$ sparks and waves. ${ }^{8}$ In ventricular myocytes, the stretch response involves NOX2 that is located at the TT in the vicinity of junctional RyR. ${ }^{8}{ }^{78}$ In atrial cells, because of TT paucity, one would expect the subsarcolemma to be the primary site of stretch-induced $\mathrm{Ca}^{2+}$ release. Peripheral sparks have indeed been demonstrated in shear stress experiments, but $\mathrm{Ca}^{2+}$ sparks also occurred in more central regions, albeit at lower frequency. ${ }^{105}$ Whether these centrally located sparks simply originate from propagation from uncoupled RyR, or specifically originate at AT-SR junctions through a yet unknown mechanism remains to be established.

Importantly, in ventricular myocytes, stretch-triggered $\mathrm{Ca}^{2+}$ sparks/waves that arise from the SR or the mitochondria, do not involve sarcolemmal $\mathrm{Ca}^{2+}$ influx via SAC. ${ }^{7,}{ }^{105}$ In ventricular myocytes, SAC may not be ideally positioned to access RyR release sites, although some SAC, like TRPC1 and TRPC6, have also been found at TT. ${ }^{83,129}$ In atrial cells, because of the unique positioning of RyR at the sarcolemma, SAC may have direct access to release sites. Thus $\mathrm{Ca}^{2+}$ influx through SAC may activate RyR in its vicinity to release $\mathrm{Ca}^{2+}$ sparks. The suggestion of a more prominent role for SAC in atrial stretch-induced $\mathrm{Ca}^{2+}$ release would be consistent with the demonstrated inhibitory effect of GSMTx4 on stretch-induced atrial arrhythmias. ${ }^{130}$ The co-localization of IP3 receptors with RyR at peripheral release sites provides a clue why IP3 signaling seems to be more prominently involved in atrial $\mathrm{Ca}^{2+}$ mechanosensing, particularly during shear stress. Firstly, if IP3 is activated via autocrine mechanisms in response to pressurized flow, as proposed by ${ }^{106}$, then the IP3 receptors may produce $\mathrm{Ca}^{2+}$ sparks directly. Secondly, in doing so, they control local $\mathrm{Ca}^{2+}$ gradients and sensitize neighboring RyR to $\mathrm{Ca}^{2+}$. This would facilitate $\mathrm{Ca}^{2+}$ wave propagation in response to IP3-triggered $\mathrm{Ca}^{2+}$ release under shear stress. 
It should be emphasized that most atrial studies are on mechanisms of shear-specific mechanotransduction. At the myocyte level, stretch effects on (sub)cellular $\mathrm{Ca}^{2+}$ have hardly been studied. Emerging questions in this context include: does X-ROS signalling exist in atrial myocytes?; are RyR at AT recruited upon stretch, or is stretch-induced SR $\mathrm{Ca}^{2+}$ release restricted to the periphery?; and are SAC involved in stretch-induced $\mathrm{SR} \mathrm{Ca}^{2+}$ release, and if so, what is the identity and location of atrial SAC? These questions, and others, need to be answered before we understand the nature of stretch-induced atrial arrhythmias, and specifically the role of $\mathrm{Ca}^{2+}$.

\section{ROLE OF STRETCH-DEPENDENT CA ${ }^{2+}$ RELEASE IN ACUTE ARRHYTHMIAS}

Recently, $\mathrm{Ca}^{2+}$ mechanotransduction has been emerging as an auto-regulatory mechanism by which cardiac muscle adapts to acute changes in haemodynamic load. Within the physiological range of beat-to-beat haemodynamic changes, it compensates for loading by sensitization of $\mathrm{Ca}^{2+}$ release via ROS or NO. In cardiac diseases causing heart failure, such as hypertension, post-myocardial infarction and dilated cardiomyopathy, haemodynamic load can exceed the normal range. Failing hearts experience elevated filling pressures and additionally, an increase in blood pressure that causes abnormal contraction and mechanical dyssynchrony. ${ }^{131-134}$ Due to dilatation and thinning of the wall resulting from structural remodelling, ventricles experience higher wall stress. Dilatation is also an early event during progression of atrial fibrillation. ${ }^{135}$ Abnormal mechanics is often associated with cardiac rhythm disturbances, a concept referred to as mechano-electrical feedback. SAC provide a means to translate stress and strain into electrical activity. ${ }^{136}$ In light of recent discussions, it is conceivable that $\mathrm{Ca}^{2+}$ mechanotransduction deteriorates from an adaptive system into an arrhythmogenic mechanism in settings of excessive mechanical loading. Structural and functional remodelling of $\mathrm{Ca}^{2+}$ microdomains in disease adds a layer of complexity to our understanding.

As discussed above, mechanical load on myocytes induces a higher rate of diastolic $\mathrm{Ca}^{2+}$ sparks. ${ }^{7,8,19,94}$ Available data demonstrate that these sparks are mostly restricted in time and space, and thus in principle not pro-arrhythmogenic. If spatiotemporal control of local $\mathrm{Ca}^{2+}$ release is lost, as in diseased hearts due to structural and/or functional remodelling, stretch-induced $\mathrm{Ca}^{2+}$ sparks may more readily deteriorate into propagating $\mathrm{Ca}^{2+}$ waves causing depolarization of the membrane via activation of NCX underlying afterdepolarizations and ectopic initiation.

We have previously discussed that highly organized sarcolemma and TT structures control stretch-induced $\mathrm{Ca}^{2+}$ release impeding $\mathrm{Ca}^{2+}$ wave propagation. Dilated hearts are mostly deprived of TT structures. ${ }^{13}$ In a recent study in failing rats, TT disruption could be directly related to chronically elevated wall stress. ${ }^{138}$ As a result of TT loss, a larger fraction of RyR release sites is uncoupled, and local regulation by ROS via NOX2 is lost. Uncoupled regions appear to be preferentially regulated by mitochondrial ROS. Assuming ROS production in mitochondria is increased in heart failure, ${ }^{139}, 140$ uncoupled regions may become sites of frequent $\mathrm{Ca}^{2+}$ waves. $^{64}$ It is unknown if ROS-dependent regulation of these uncoupled regions is sensitive to stretch.

In heart failure rats, a recent study reported that loss of TT was associated with disorganization of the microtubule network, stiffer membranes and derangement of mitochondria ${ }^{86}$ As a result, mitochondrial $\mathrm{Ca}^{2+}$ releases in response to mechanical pressure were no longer 
spatially confined to the site of the mechanical stimulus, but propagated throughout the cell. Disruption of microtubules by colchicine in normal rat hearts caused a similar arrhythmogenic effect, suggesting a major role of microtubules in mechanical regulation.

$\mathrm{X}$-ROS signalling is also modulated by microtubules. The stretch-induced $\mathrm{Ca}^{2+}$ release is abolished by colchicine. ${ }^{7}$ Hypertrophied and failing human heart exhibits a denser microtubule network. ${ }^{141,{ }^{142}}$ An increased microtubule density is associated with pressure-overload, rather than volume-overload. ${ }^{143,144}$ Functionally, models with a high microtubule density, induced pharmacologically ${ }^{145}$ or by disease ${ }^{8}$, demonstrated hypersensitivity to mechanical stretch by producing more readily $\mathrm{Ca}^{2+}$ waves and arrhythmias. Remodelling of NADPH oxidases, such as an increase in NOX2 in early onset atrial fibrillation, ${ }^{146}$ may further contribute to exacerbated X-ROS signalling.

In the whole heart, tissue heterogeneity is an important factor for the initiation and propagation of mechanical arrhythmias. Structural heterogeneity causes mechanical dyssynchrony. The most typical example is myocardial infarction. In the infarcted heart, arrhythmias often initiate at the borderzone between the infarct and the normally contracting myocardium. ${ }^{147-149}$ Using an elegant model of controlled non-uniform contraction in rat trabeculae, the Ter Keurs group provided a possible explanation. ${ }^{150}$ In the model, induction of non-uniform contraction causes arrhythmogenic $\mathrm{Ca}^{2+}$ waves that initiate at the border zone of weak and strong contracting segments. Weak segments re-lengthen during contraction because they are pulled by the strong segments. Due to the release of force, $\mathrm{Ca}^{2+}$ dissociates from $\mathrm{TnC}$ more quickly, and the initial $\mathrm{Ca}^{2+}$ surge evolves into a propagating $\mathrm{Ca}^{2+}$ wave late during relaxation. The same phenomenon has also been observed during loaded contractions in trabeculae, where release of force during contraction or early relaxation causes a $\mathrm{Ca}^{2+}$ surge that manifests as afterdepolarizations on the electrical signal..$^{85,151,152}$

In normal hearts there is also some degree of structural heterogeneity, e.g. local differences in wall thickness, sufficient to cause mechanical dispersion upon stretch. It was demonstrated in rabbit ventricle that thin regions experienced greater relative stretch than thicker regions, which caused dispersion of local strain in the stretched muscle. ${ }^{153}$ Local strain correlated to a heterogeneous pattern of local depolarizations and focal excitation. In the intact rabbit heart these focal excitations developed into reentrant arrhythmias. Interestingly, local depolarizations were insensitive to $\mathrm{SR} \mathrm{Ca}^{2+}$ release inhibition, but were blocked by gadolinium, a non-selective SAC inhibitor. The molecular identity of SAC causing acute stretch-induced depolarization and triggered activity has yet to be identified; possible candidates include members of the TRP channel family, and the $\mathrm{K}^{+}$-selective TREK- 1 channel. ${ }^{136,154}$

Lastly, the graded response of cardiac muscle to mechanical load should be considered. In myocytes, the spark frequency increased with the amplitude of stretch; the relation describes a Hill function. ${ }^{19}$ A similar function described the increase in ROS production and velocity of wave propagation in relation to increasing stretch. ${ }^{77}$ Many studies in trabeculae and whole hearts reported that the probability of triggering an arrhythmogenic event is a function of the amplitude of stretch/diastolic volume. ${ }^{31,155-158}$ Interestingly, in tissue and the whole heart induction of arrhythmias by rapid stretch involve activation of SAC. ${ }^{130,156,159}$ By contrast, in single cells induction of arrhythmogenic $\mathrm{Ca}^{2+}$ waves do not require activation of SAC per se, regardless the source of the $\mathrm{Ca}^{2+}$ wave ( $\mathrm{SR}$ or mitochondrial $\mathrm{Ca}^{2+}$ release) and the type of stimulus (stretch, afterload and/or shear). One possible explanation is that SAC and non-sarcolemmal pathways of stretch-induced $\mathrm{Ca}^{2+}$ release are activated with different levels of stretch. With the available technology for single myocyte stretch, large stretches cannot be achieved experimentally. Unfortunately, for most experiments, data are not available to 
correlate in vitro parameters to in vivo read-outs, which makes it impossible to compare stretches in myocytes, tissue and whole heart. At present, the involvement of mechanically-induced $\mathrm{Ca}^{2+}$ waves in stretch- and afterload-induced arrhythmias in the diseased as well in the normal heart therefore remains an open question

\section{CONCLUSION AND OUTLOOK}

In myocytes, $\mathrm{Ca}^{2+}$ signaling is highly compartmentalized at dyads and SR-mitochondria stores. As we have discussed, these microdomains are highly mechanosensitive to preload and afterload. Preload is sensed by internal mechanosensors and rapidly transmitted to the dyad by ROS; afterload is sensed at the surface and involves NO, which is slower than ROS signaling. Many details are missing in this simplified scheme of $\mathrm{Ca}^{2+}$ mechanosensation due to gaps in our current knowledge. The molecular identity of mechanosensors, and how they distinguish between preload and afterload, is still largely unknown. What regulates microdomain-specificity, and whether crosstalk exists between the many signaling cascades of $\mathrm{Ca}^{2+}$ mechanosensation remains an open question.

Also, the (patho)physiological relevance is not clear. It has been suggested that stretch increases CICR efficiency, but if this also leads to faster force development is not evident given the much longer activation time of the myofilaments compared to $\mathrm{Ca}^{2+}$ release kinetics. Measurements of local force dynamics with newly developed fluorescent force probes could provide an answer. In addition, very few studies addressed $\mathrm{Ca}^{2+}$-targeted mechanotransduction in remodelled and diseased cells. Particularly in heart failure and atrial fibrillation, dysregulation of $\mathrm{Ca}^{2+}$ mechanosensitivity is expected, and may be relevant in the context of arrhythmias associated with these conditions.

Finally, a major challenge is translation to the in vivo situation. There is little information about the 3D mechanical environment sensed by the myocyte in a beating heart that could be directly transferred to an experimental setting, and vice versa, which makes a direct comparison of in vivo and in vitro findings difficult. For example, differences in experimental stretch and strain may account for the inconclusive results of SAC activation in stretched cells vs whole heart, which has implications when outlining antiarrhythmic strategies. In addition, structural complexity inherent to the heart is a complicating factor, particularly in the context of arrhythmias. Computational modelling could provide a bridge the gap between stretch in cellular experiments, myocardial tissue, and the whole heart. Filling this gap is crucial to gain more insight in the significance of $\mathrm{Ca}^{2+}$ microdomain mechanosensitivity, physiologically for the mechanical autoregulation of cardiac function, and pathophysiologically, for the initiation of arrhythmias.

\section{FUNDING}

This work was supported by a EU Innovative Training Network (RADical reduction of OXidative stress in cardiovascular disease, No. 316738), and by a grant from the Austrian Science Fund to G.A. (I2013-B27). 


\section{CONFLICT OF INTEREST}

P.S., U.S., and G.A. declared no conflicts of interest

\section{ACKNOWLEDGEMENTS}

The authors wish to thank Dr. John Walmsley from the Biomedical Engineering Department at Maastricht University for his critical reading and commenting on the manuscript. 


\section{REFERENCES}

1. Sagawa K. Translation of Otto frankltextquotesingles paper "Die Grundform des arteriellen Pulses" zeitschrift für biologie 37: 483-526 (1899). Journal of Molecular and Cellular Cardiology 1990;22:253254.

2. Patterson SW, Starling EH. On the mechanical factors which determine the output of the ventricles. The Journal of Physiology 1914;48:357-379.

3. von Anrep G. On the part played by the suprarenals in the normal vascular reactions of the body. The Journal of Physiology 1912;45:307-317.

4. Parmley WW, Chuck L. Length-dependent changes in myocardial contractile state. American Journal of Physiology-Legacy Content 1973;224:1195-1199.

5. Cingolani HE, Pérez NG, Cingolani OH, Ennis IL. The Anrep effect: 100 years later. American Journal of Physiology - Heart and Circulatory Physiology 2013;304:H175-H182.

6. de Tombe PP, Mateja RD, Tachampa K, Ait Mou Y, Farman GP, Irving TC. Myofilament length dependent activation. J Mol Cell Cardiol 2010;48:851-858.

7. Iribe G, Ward CW, Camelliti P, Bollensdorff C, Mason F, Burton RA, Garny A, Morphew MK, Hoenger A, Lederer WJ, Kohl P. Axial stretch of rat single ventricular cardiomyocytes causes an acute and transient increase in Ca2+ spark rate. Circ Res 2009;104:787-795.

8. Prosser BL, Ward CW, Lederer WJ. X-ROS signaling: rapid mechano-chemo transduction in heart. Science 2011;333:1440-1445.

9. Kehat I, Molkentin JD. Molecular pathways underlying cardiac remodeling during pathophysiological stimulation. Circulation 2010;122:2727-2735.

10. Ruwhof C. Mechanical stress-induced cardiac hypertrophy: mechanisms and signal transduction pathways. Cardiovascular Research 2000;47:23-37.

11. Guennec JL. A new method of attachment of isolated mammalian ventricular myocytes for tension recording: Length dependence of passive and active tension. Journal of Molecular and Cellular Cardiology 1990;22:1083-1093.

12. Yasuda S-I, Sugiura S, Kobayakawa N, Fujita H, Yamashita H, Katoh K, Saeki Y, Kaneko H, Suda Y, Nagai R, Sugi H. A novel method to study contraction characteristics of a single cardiac myocyte using carbon fibers. American Journal of Physiology-Heart and Circulatory Physiology 2001;281:H1442-H1446.

13. Gannier F, Bernengo JC, Jacquemond V, Gamier D. Measurements of Sarcomere Dynamics Simultaneously with Auxotonic Force in Isolated Cardiac Cells. IEEE Transactions on Biomedical Engineering 1993;40:1226-1232.

14. Pasqualin C, Gannier F, Yu A, Malécot CO, Bredeloux P, Maupoil V. SarConfoCal: simultaneous sarcomere length and cytoplasmic calcium measurements for laser scanning confocal microscopy images. Bioinformatics 2016:btw754.

15. Cooper PJ, Lei M, Cheng L-X, Kohl P. Selected contribution: Axial stretch increases spontaneous pacemaker activity in rabbit isolated sinoatrial node cells. Journal of Applied Physiology 2000;89:2099-2104.

16. Helmes M, Najafi A, Palmer BM, Breel E, Rijnveld N, Iannuzzi D, Van Der Velden J. Mimicking the cardiac cycle in intact cardiomyocytes using diastolic and systolic force clamps; measuring power output. Cardiovascular Research 2016;111:66-73.

17. Iribe G, Helmes M, Kohl P. Force-length relations in isolated intact cardiomyocytes subjected to dynamic changes in mechanical load. American Journal of Physiology - Heart and Circulatory Physiology 2007;292:H1487-H1497.

18. Nishimura S, Yasuda S-i, Katoh M, Yamada KP, Yamashita H, Saeki Y, Sunagawa K, Nagai R, Hisada T, Sugiura S. Single cell mechanics of rat cardiomyocytes under isometric, unloaded, and physiologically loaded conditions. American Journal of Physiology-Heart and Circulatory Physiology 2004;287:H196$\mathrm{H} 202$.

19. Petroff MG, Kim SH, Pepe S, Dessy C, Marban E, Balligand JL, Sollott SJ. Endogenous nitric oxide mechanisms mediate the stretch dependence of $\mathrm{Ca} 2+$ release in cardiomyocytes. Nat Cell Biol 2001;3:867-873.

20. Jian Z, Han H, Zhang T, Puglisi J, Izu LT, Shaw JA, Onofiok E, Erickson JR, Chen Y-J, Horvath B, Shimkunas R, Xiao W, Li Y, Pan T, Chan J, Banyasz T, Tardiff JC, Chiamvimonvat N, Bers DM, Lam $\mathrm{KS}$, Chen-Izu Y. Mechanochemotransduction during cardiomyocyte contraction is mediated by localized nitric oxide signaling. Science Signaling 2014;7.

21. MORAD M, JAVAHERI A, RISIUS T, BELMONTE S. Multimodality of Ca2\$ $\backslash$ mathplus $\$$ Signaling in Rat Atrial Myocytes. Annals of the New York Academy of Sciences 2005;1047:112-121.

22. Nishimura S, Nagai S, Katoh M, Yamashita H, Saeki Y, Okada J-i, Hisada T, Nagai R, Sugiura S. Microtubules Modulate the Stiffness of Cardiomyocytes Against Shear Stress. Circulation Research 2006;98:81-87.

23. Sánchez D, Johnson N, Li C, Novak P, Rheinlaender J, Zhang Y, Anand U, Anand P, Gorelik J, Frolenkov 
GI, Benham C, Lab M, Ostanin VP, Schäffer TE, Klenerman D, Korchev YE. Noncontact Measurement of the Local Mechanical Properties of Living Cells Using Pressure Applied via a Pipette. Biophysical Journal 2008;95:3017-3027.

24. Chen-Izu Y, Izu LT. Mechano-chemo-transduction in cardiac myocytes. Journal of Physiology 2017;595:3949-3958.

25. Allen DG, Blinks JR. Calcium transients in aequorin-injected frog cardiac muscle. Nature 1978;273:509513 .

26. Hibberd MG, Jewell BR. Calcium- and length-dependent force production in rat ventricular muscle. The Journal of Physiology 1982;329:527-540.

27. Allen DG, Kurihara S. The effects of muscle length on intracellular calcium transients in mammalian cardiac muscle. The Journal of Physiology 1982;327:79-94.

28. Allen DG, Nichols CG, Smith GL. The effects of changes in muscle length during diastole on the calcium transient in ferret ventricular muscle. The Journal of Physiology 1988;406:359-370.

29. Hongo K, White E, Le Guennec J-Y, Orchard CH. Changes in [Ca2+]i, [Na+]i and Ca2+ current in isolated rat ventricular myocytes following an increase in cell length. Journal of Physiology 1996;491:609619.

30. Kentish JC, Wrzosek A. Changes in force and cytosolic Ca2+ concentration after length changes in isolated rat ventricular trabeculae. Journal of Physiology 1998;506:431-444.

31. Tavi P, Han C, Weckstrom M. Mechanisms of stretch-induced changes in $[\mathrm{Ca} 2+] \mathrm{i}$ in rat atrial myocytes: role of increased troponin C affinity and stretch-activated ion channels. Circ Res 1998;83:1165-1177.

32. Shen X, Cannell MB, Ward M-L. Effect of SR load and pH regulatory mechanisms on stretch-dependent $\mathrm{Ca} 2 \$$ mathplus\$ entry during the slow force response. Journal of Molecular and Cellular Cardiology 2013;63:37-46.

33. Blinks JR, Endoh M. Modification of myofibrillar responsiveness to $\mathrm{Ca}++$ as an inotropic mechanism. Circulation 1986;73:III-85-III-98.

34. Alvarez BV, Pérez NG, Ennis IL, Camilión De Hurtado MC, Cingolani HE. Mechanisms underlying the increase in force and $\mathrm{Ca} 2+$ transient that follow stretch of cardiac muscle: A possible explanation of the Anrep effect. Circulation Research 1999;85:716-722.

35. Calaghan SC, White E. Contribution of angiotensin II, endothelin 1 and the endothelium to the slow inotropic response to stretch in ferret papillary muscle. Pflugers Archiv European Journal of Physiology 2001;441:514-520.

36. Perez NG, Hurtado MCCd, Cingolani HE. Reverse Mode of the Na\$ \mathplus\$-Ca2\$ $\backslash$ mathplus\$ Exchange After Myocardial Stretch : Underlying Mechanism of the Slow Force Response. Circulation Research 2001;88:376-382.

37. Kockskämper J, Lewinski Dv, Khafaga M, Elgner A, Grimm M, Eschenhagen T, Gottlieb PA, Sachs F, Pieske B. The slow force response to stretch in atrial and ventricular myocardium from human heart: Functional relevance and subcellular mechanisms. Progress in Biophysics and Molecular Biology 2008;97:250-267.

38. Caldiz CI, Garciarena CD, Dulce RA, Novaretto LP, Yeves AM, Ennis IL, Cingolani HE, Chiappe De Cingolani G, Pérez NG. Mitochondrial reactive oxygen species activate the slow force response to stretch in feline myocardium. Journal of Physiology 2007;584:895-905.

39. Woo SH, Lee CO. Effects of Endothelin-1 on Ca2\$ $\$ mathplus\$Signaling in Guinea-Pig Ventricular Myocytes: Role of Protein Kinase C. Journal of Molecular and Cellular Cardiology 1999;31:631-643.

40. VONLEWINSKI D, STUMME B, MAIER L, LUERS C, BERS D, PIESKE B. Stretch-dependent slow force response in isolated rabbit myocardium is Na dependent. Cardiovascular Research 2003;57:10521061.

41. Calaghan S, White E. Activation of $\mathrm{Na}+\mathrm{H}+$ exchange and stretch-activated channels underlies the slow inotropic response to stretch in myocytes and muscle from the rat heart. Journal of Physiology 2004;559:205-214.

42. Ward M-L, Williams IA, Chu Y, Cooper PJ, Ju Y-K, Allen DG. Stretch-activated channels in the heart: Contributions to length-dependence and to cardiomyopathy. Progress in Biophysics and Molecular Biology 2008;97:232-249.

43. Seo K, Inagaki M, Nishimura S, Hidaka I, Sugimachi M, Hisada T, Sugiura S. Structural Heterogeneity in the Ventricular Wall Plays a Significant Role in the Initiation of Stretch-Induced Arrhythmias in Perfused Rabbit Right Ventricular Tissues and Whole Heart Preparations. Circulation Research 2010;106:176-184.

44. Yamaguchi Y, Iribe G, Kaneko T, Takahashi K, Numaga-Tomita T, Nishida M, Birnbaumer L, Naruse K. TRPC3 participates in angiotensin II type 1 receptor-dependent stress-induced slow increase in intracellular Ca2\$mathplus\$ concentration in mouse cardiomyocytes. J Physiol Sci 2017;68:153-164.

45. White E, Guennec JL, Nigretto JM, Gannier F, Argibay JA, Garnier D. The effects of increasing cell length on auxotonic contractions\$ $\backslash$ mathsemicolon $\$$ membrane potential and intracellular calcium transients in single guinea-pig ventricular myocytes. Exp Physiol 1993;78:65-78. 
46. Landesberg A, Sideman S. Coupling calcium binding to troponin C and cross-bridge cycling in skinned cardiac cells. American Journal of Physiology-Heart and Circulatory Physiology 1994;266:H1260 H1271.

47. Janssen PML, Hunter WC. Force, not sarcomere length, correlates with prolongation of isosarcometric contraction. American Journal of Physiology - Heart and Circulatory Physiology 1995;269:H676-H685.

48. Housmans PR, Lee NKM, Blinks JR. Active shortening retards the decline of the intracellular calcium transient in mammalian heart muscle. Science 1983;221:159-161.

49. Ter Keurs HEDJ, Wakayama Y, Miura M, Shinozaki T, Stuyvers BD, Boyden PA, Landesberg A. Arrhythmogenic $\mathrm{Ca} 2+$ release from cardiac myofilaments. Progress in Biophysics and Molecular Biology 2006;90:151-171.

50. Lab MJ, Allen DG, Orchard CH. The effects of shortening on myoplasmic calcium concentration and on the action potential in mammalian ventricular muscle. Circ Res 1984;55:825-829.

51. Belus A, White E. Streptomycin and intracellular calcium modulate the response of single guinea-pig ventricular myocytes to axial stretch. Journal of Physiology 2003;546:501-509.

52. Zhang YH, Youm JB, Sung HK, Lee SH, Ryu SY, Ho WK, Earm YE. Stretch-activated and background non-selective cation channels in rat atrial myocytes. J Physiol 2000;523 Pt 3:607-619.

53. Zeng T, Bett GCL, Sachs F. Stretch-activated whole cell currents in adult rat cardiac myocytes. American Journal of Physiology-Heart and Circulatory Physiology 2000;278:H548-H557.

54. Veldkamp M. Norepinephrine induces action potential prolongation and early afterdepolarizations in ventricular myocytes isolated from human end-stage failing hearts. European Heart Journal 2001;22:955963.

55. Vermeulen JT, Mcguire MA, Opthof T, Coronel R, Bakker JMTD, Klopping C, Janse MJ. Triggered activity and automaticity in ventricular trabeculae of failing human and rabbit hearts. Cardiovascular Research 1994;28:1547-1554.

56. Nichols CG. The influence of $\backslash$ textquotesinglediastolic $\backslash$ textquotesingle length on the contractility of isolated cat papillary muscle. The Journal of Physiology 1985;361:269-279.

57. Gannier F, White E, Garnier D, Guennec J-YL. A possible mechanism for large stretch-induced increase in $[\mathrm{Ca} 2+](\mathrm{i})$ in isolated guinea-pig ventricular myocytes. Cardiovascular Research 1996;32:158-167.

58. Guennec JL, White E, Gannier F, Argibay JA, Garnier D. Stretch-induced increase of resting intracellular calcium concentration in single guinea-pig ventricular myocytes. Exp Physiol 1991;76:975-978.

59. Petroff MGV, Kim SH, Pepe S, Dessy C, Marbán E, Balligand J-L, Sollott SJ. Endogenous nitric oxide mechanisms mediate the stretch dependence of Ca2\$ $\$ mathplus\$ release in cardiomyocytes. Nat Cell Biol 2001;3:867-873.

60. Woo SH, Risius T, Morad M. Modulation of local Ca2+ release sites by rapid fluid puffing in rat atrial myocytes. Cell Calcium 2007;41:397-403.

61. Bassani JW, Bassani RA, Bers DM. Relaxation in rabbit and rat cardiac cells: species-dependent differences in cellular mechanisms. The Journal of Physiology 1994;476:279-293.

62. Acsai K, Antoons G, Livshitz L, Rudy Y, Sipido KR. Microdomain [Ca2+] near ryanodine receptors as reported by L-type Ca2+ and Na+/Ca2+ exchange currents. Journal of Physiology 2011;589:2569-2583.

63. Dries E, Bito V, Lenaerts I, Antoons G, Sipido KR, Macquaide N. Selective modulation of coupled ryanodine receptors during microdomain activation of calcium/calmodulin-dependent kinase II in the dyadic cleft. Circ Res 2013;113:1242-1252.

64. Dries E, Lenaerts I, Macquaide N, Santiago D, Claus P, Sipido KR. Altered CamkII and ros microdomains favor sparks in orphaned RyR after myocardial infarction. Biophysical J 2014;106:322a.

65. De Brito OM, Scorrano L. Mitofusin 2 tethers endoplasmic reticulum to mitochondria. Nature 2008;456:605-610.

66. García-Pérez C, Hajnóczky G, Csordás G. Physical coupling supports the local Ca2+ transfer between sarcoplasmic reticulum subdomains and the mitochondria in heart muscle. Journal of Biological Chemistry 2008;283:32771-32780.

67. Hayashi T, Martone ME, Yu Z, Thor A, Doi M, Hoist MJ, Ellisman MH, Hoshijima M. Three-dimensional electron microscopy reveals new details of membrane systems for Ca2+ signaling in the heart. Journal of Cell Science 2009;122:1005-1013.

68. Sharma VK, Ramesh V, Franzini-Armstrong C, Sheu S-S. Transport of Ca2+ from sarcoplasmic reticulum to mitochondria in rat ventricular myocytes. Journal of Bioenergetics and Biomembranes 2000;32:97-104.

69. Csordás G, Várnai P, Golenár T, Roy S, Purkins G, Schneider TG, Balla T, Hajnóczky G. Imaging Interorganelle Contacts and Local Calcium Dynamics at the ER-Mitochondrial Interface. Molecular Cell 2010;39:121-132.

70. Giacomello M, Drago I, Bortolozzi M, Scorzeto M, Gianelle A, Pizzo P, Pozzan T. Ca2+ Hot Spots on the Mitochondrial Surface Are Generated by $\mathrm{Ca} 2+$ Mobilization from Stores, but Not by Activation of Store-Operated Ca2+ Channels. Molecular Cell 2010;38:280-290.

71. Peskoff A, Langer GA. Calcium Concentration and Movement in the Ventricular Cardiac Cell during an 
Excitation-Contraction Cycle. Biophysical Journal 1998;74:153-174.

72. Maack C, Cortassa S, Aon MA, Ganesan AN, Liu T, O’Rourke B. Elevated Cytosolic Na \$ $\backslash$ mathplus\$ Decreases Mitochondrial Ca $2 \$$ mathplus\$ Uptake During Excitation-Contraction Coupling and Impairs Energetic Adaptation in Cardiac Myocytes. Circulation Research 2006;99:172-182.

73. Lu X, Ginsburg KS, Kettlewell S, Bossuyt J, Smith GL, Bers DM. Measuring Local Gradients of Intramitochondrial [Ca $2 \$ \backslash$ mathplus\$ ] in Cardiac Myocytes During Sarcoplasmic Reticulum Ca $2 \$ \backslash$ mathplus\$ Release. Circ Res 2013;112:424-431.

74. Nickel A, Kohlhaas M, Maack C. Mitochondrial reactive oxygen species production and elimination. Journal of Molecular and Cellular Cardiology 2014;73:26-33.

75. Iribe G, Kohl P. Axial stretch enhances sarcoplasmic reticulum Ca2+ leak and cellular Ca2+ reuptake in guinea pig ventricular myocytes: Experiments and models. Progress in Biophysics and Molecular Biology 2008;97:298-311.

76. Prosser BL, Khairallah RJ, Ziman AP, Ward CW, Lederer WJ. X-ROS signaling in the heart and skeletal muscle: stretch-dependent local ROS regulates $[\mathrm{Ca}(2)(+)]$ i. J Mol Cell Cardiol 2013;58:172-181.

77. Miura M, Taguchi Y, Nagano T, Sasaki M, Handoh T, Shindoh C. Effect of myofilament Ca2\$mathplus\$ sensitivity on Ca2\$ $\backslash$ mathplus\$ wave propagation in rat ventricular muscle. Journal of Molecular and Cellular Cardiology 2015;84:162-169.

78. Zhang M, Prosser BL, Bamboye MA, Gondim ANS, Santos CX, Martin D, Ghigo A, Perino A, Brewer AC, Ward CW, Hirsch E, Lederer WJ, Shah AM. Contractile Function During Angiotensin-II Activation. Journal of the American College of Cardiology 2015;66:261-272.

79. Sánchez G, Escobar M, Pedrozo Z, Macho P, Domenech R, Härtel S, Hidalgo C, Donoso P. Exercise and tachycardia increase NADPH oxidase and ryanodine receptor-2 activity: possible role in cardioprotection. Cardiovascular Research 2007;77:380-386.

80. Balog EM, Norton LE, Thomas DD, Fruen BR. Role of calmodulin methionine residues in mediating productive association with cardiac ryanodine receptors. American Journal of Physiology - Heart and Circulatory Physiology 2006;290:H794-H799.

81. Erickson JR, Joiner M-1A, Guan X, Kutschke W, Yang J, Oddis CV, Bartlett RK, Lowe JS, O’Donnell SE, Aykin-Burns N, Zimmerman MC, Zimmerman K, Ham A-JL, Weiss RM, Spitz DR, Shea MA, Colbran RJ, Mohler PJ, Anderson ME. A Dynamic Pathway for Calcium-Independent Activation of CaMKII by Methionine Oxidation. Cell 2008;133:462-474.

82. Iribe G, Ward CW, Camelliti P, Bollensdorff C, Mason F, Burton RAB, Garny A, Morphew MK, Hoenger A, Lederer WJ, Kohl P. Axial stretch of rat single ventricular cardiomyocytes causes an acute and transient increase in Ca2+ spark rate. Circulation Research 2009;104:787-795.

83. Dyachenko V, Rueckschloss U, Isenberg G. Modulation of cardiac mechanosensitive ion channels involves superoxide, nitric oxide and peroxynitrite. Cell Calcium 2009;45:55-64.

84. Gervásio OL, Whitehead NR, Yeung EW, Phillips WD, Allen DG. TRPC1 binds to caveolin-3 and is regulated by Src kinase - Role in Duchenne muscular dystrophy. Journal of Cell Science 2008;121:22462255 .

85. Wakayama Y, Miura M, Sugai Y, Kagaya Y, Watanabe J, Keurs HEDJt, Shirato K. Stretch and quick release of rat cardiac trabeculae accelerates $\mathrm{Ca} 2 \$ \backslash$ mathplus $\$$ waves and triggered propagated contractions. American Journal of Physiology-Heart and Circulatory Physiology 2001;281:H2133-H2142.

86. Miragoli M, Sanchez-Alonso JL, Bhargava A, Wright PT, Sikkel M, Schobesberger S, Diakonov I, Novak P, Castaldi A, Cattaneo P, Lyon AR, Lab MJ, Gorelik J. Microtubule-Dependent Mitochondria Alignment Regulates Calcium Release in Response to Nanomechanical Stimulus in Heart Myocytes. Cell Reports 2016;14:140-151.

87. Belmonte S, Morad M. 'Pressure-flow'-triggered intracellular Ca2+ transients in rat cardiac myocytes: Possible mechanisms and role of mitochondria. Journal of Physiology 2008;586:1379-1397.

88. Yasuda S-i, Sugiura S, Yamashita H, Nishimura S, Saeki Y, Momomura S-i, Katoh K, Nagai R, Sugi H. Unloaded shortening increases peak of $\mathrm{Ca} 2 \$$ mathplus $\$$ transients but accelerates their decay in rat single cardiac myocytes. American Journal of Physiology-Heart and Circulatory Physiology 2003;285:H470$\mathrm{H} 475$.

89. Shaw J, Izu L, Chen-Izu Y. Mechanical Analysis of Single Myocyte Contraction in a 3-D Elastic Matrix. PLOS ONE 2013;8:e75492.

90. Erickson JR, Nichols CB, Uchinoumi H, Stein ML, Bossuyt J, Bers DM. S-nitrosylation induces both autonomous activation and inhibition of calcium/calmodulin-dependent protein Kinase II $\delta$. Journal of Biological Chemistry 2015;290:25646-25656.

91. Feron O, Belhassen L, Kobzik L, Smith TW, Kelly RA, Michel T. Endothelial nitric oxide synthase targeting to caveolae. Specific interactions with caveolin isoforms in cardiac myocytes and endothelial cells. Journal of Biological Chemistry 1996;271:22810-22814.

92. Massion PB, Dessy C, Desjardins F, Pelat M, Havaux X, Belge C, Moulin P, Guiot Y, Feron O, Janssens S, Balligand J-L. Cardiomyocyte-Restricted Overexpression of Endothelial Nitric Oxide Synthase ( NOS3 ) Attenuates \$ \upbeta\$-Adrenergic Stimulation and Reinforces Vagal Inhibition of Cardiac Con- 
traction. Circulation 2004;110:2666-2672.

93. Xu KY, Huso DL, Dawson TM, Bredt DS, Becker LC. Nitric oxide synthase in cardiac sarcoplasmic reticulum. Proceedings of the National Academy of Sciences 1999;96:657-662.

94. Jian Z, Han H, Zhang T, Puglisi J, Izu LT, Shaw JA, Onofiok E, Erickson JR, Chen YJ, Horvath B, Shimkunas R, Xiao W, Li Y, Pan T, Chan J, Banyasz T, Tardiff JC, Chiamvimonvat N, Bers DM, Lam $\mathrm{KS}$, Chen-Izu Y. Mechanochemotransduction during cardiomyocyte contraction is mediated by localized nitric oxide signaling. Sci Signal 2014;7:ra27.

95. Vielma AZ, León L, Fernández IC, González DR, Boric MP. Nitric Oxide Synthase 1 Modulates Basal and \$upbeta\$-Adrenergic-Stimulated Contractility by Rapid and Reversible Redox-Dependent S-Nitrosylation of the Heart. PLOS ONE 2016;11:e0160813.

96. Burkard N, Rokita AG, Kaufmann SG, Hallhuber M, Wu R, Hu K, Hofmann U, Bonz A, Frantz S, Cartwright EJ, Neyses L, Maier LS, Maier SKG, Renné T, Schuh K, Ritter O. Conditional neuronal nitric oxide synthase overexpression impairs myocardial contractility. Circulation Research 2007;100:e32-e44.

97. Carnicer R, Suffredini S, Liu X, Reilly S, Simon JN, Surdo NC, Zhang YH, Lygate CA, Channon KM, Casadei B. The Subcellular Localisation of Neuronal Nitric Oxide Synthase Determines the Downstream Effects of NO on Myocardial Function. Cardiovascular research 2017;113:321-331.

98. Vila-Petroff MG, Younes A, Egan J, Lakatta EG, Sollott SJ. Activation of Distinct cAMP-Dependent and cGMP-Dependent Pathways by Nitric Oxide in Cardiac Myocytes. Circulation Research 1999;84:1020 1031.

99. Pinsky DJ, Patton S, Mesaros S, Brovkovych V, Kubaszewski E, Grunfeld S, Malinski T. Mechanical Transduction of Nitric Oxide Synthesis in the Beating Heart. Circulation Research 1997;81:372-379.

100. Awasthi S, Izu LT, Mao Z, Jian Z, Landas T, Lerner A, Shimkunas R, Woldeyesus R, Bossuyt J, Wood B, Chen Y-J, Matthews DL, Lieu DK, Chiamvimonvat N, Lam KS, Chen-Izu Y, Chan JW. Multimodal SHG-2PF Imaging of Microdomain Ca2+-Contraction Coupling in Live Cardiac Myocytes. Circulation Research 2016;118:e19-e28.

101. LeGrice IJ, Takayama Y, Covell JW. Transverse Shear Along Myocardial Cleavage Planes Provides a Mechanism for Normal Systolic Wall Thickening. Circulation Research 1995;77:182-193.

102. Ashikaga H, Criscione JC, Omens JH, Covell JW, Ingels Jr. NB. Transmural left ventricular mechanics underlying torsional recoil during relaxation. American Journal of Physiology - Heart and Circulatory Physiology 2004;286:H640-H647.

103. Boycott HE, Barbier CSM, Eichel CA, Costa KD, Martins RP, Louault F, Dilanian G, Coulombe A, Hatem SN, Balse E. Shear stress triggers insertion of voltage-gated potassium channels from intracellular compartments in atrial myocytes. Proceedings of the National Academy of Sciences of the United States of America 2013;110:E3955-E3964.

104. Son MJ, Kim JC, Kim SW, Chidipi B, Muniyandi J, Singh TD, So I, Subedi KP, Woo SH. Shear stress activates monovalent cation channel transient receptor potential melastatin subfamily 4 in rat atrial myocytes via type 2 inositol 1,4,5-trisphosphate receptors and $\mathrm{Ca}(2+)$ release. $J$ Physiol 2016;594:29853004.

105. Lee S, Kim J-C, Li Y, Son M-J, Woo S-H. Fluid pressure modulates L-type Ca2\$ $\$ mathplus\$ channel via enhancement of $\mathrm{Ca} 2 \$ \backslash$ mathplus $\$$-induced $\mathrm{Ca} 2 \$ \backslash$ mathplus $\$$ release in rat ventricular myocytes. American Journal of Physiology-Cell Physiology 2008;294:C966-C976.

106. Kim J-C, Woo S-H. Shear stress induces a longitudinal Ca2\$ $\backslash$ mathplus\$wave via autocrine activation of P2Y1purinergic signalling in rat atrial myocytes. J Physiol 2015;593:5091-5109.

107. Kim J-C, Wang J, Son M-J, Woo S-H. Shear stress enhances Ca2 + sparks through Nox2-dependent mitochondrial reactive oxygen species generation in rat ventricular myocytes. Biochimica et Biophysica Acta - Molecular Cell Research 2017;1864:1121-1131.

108. Boyden PA, Hoffman BF. The effects of atrial electrophysiology and structure of surgically induced right atrial enlargement in dogs. Circulation Research 1981;49:1319-1331.

109. Lenaerts I, Bito V, Heinzel FR, Driesen RB, Holemans P, D’Hooge J, Heidbuchel H, Sipido KR, Willems R. Ultrastructural and functional remodeling of the coupling between $\mathrm{Ca} 2+$ influx and sarcoplasmic reticulum $\mathrm{Ca} 2+$ release in right atrial myocytes from experimental persistent atrial fibrillation. Circ Res 2009;105:876-885.

110. Richards MA, Clarke JD, Saravanan P, Voigt N, Dobrev D, Eisner DA, Trafford AW, Dibb KM. Transverse tubules are a common feature in large mammalian atrial myocytes including human. American Journal of Physiology-Heart and Circulatory Physiology 2011;301:H1996-H2005.

111. Dibb KM, Clarke JD, Eisner DA, Richards MA, Trafford AW. A functional role for transverse (t-) tubules in the atria. Journal of Molecular and Cellular Cardiology 2013;58:84-91.

112. Blatter LA, Kockskämper J, Sheehan KA, Zima AV, Hüser J, Lipsius SL. Local calcium gradients during excitation-contraction coupling and alternans in atrial myocytes. Journal of Physiology 2003;546:19-31.

113. Brette F, Komukai K, Orchard CH. Validation of formamide as a detubulation agent in isolated rat cardiac cells. American Journal of Physiology - Heart and Circulatory Physiology 2002;283:H1720-H1728.

114. Brandenburg S, Kohl T, Williams GS, Gusev K, Wagner E, Rog-Zielinska EA, Hebisch E, Dura M, Didie 
M, Gotthardt M, Nikolaev VO, Hasenfuss G, Kohl P, Ward CW, Lederer WJ, Lehnart SE. Axial tubule junctions control rapid calcium signaling in atria. J Clin Invest 2016;126:3999-4015.

115. Glukhov AV, Balycheva M, Sanchez-Alonso JL, Ilkan Z, Alvarez-Laviada A, Bhogal N, Diakonov I, Schobesberger S, Sikkel MB, Bhargava A, Faggian G, Punjabi PP, Houser SR, Gorelik J. Direct evidence for microdomain-specific localization and remodeling of functional L-type calcium channels in rat and human atrial myocytes. Circulation 2015;132:2372-2384.

116. Frisk M, Koivumaki JT, Norseng PA, Maleckar MM, Sejersted OM, Louch WE. Variable t-tubule organization and Ca2+ homeostasis across the atria. Am J Physiol Heart Circ Physiol 2014;307:H609-620.

117. Carl SL, Felix K, Caswell AH, Brandt NR, Ball Jr. WJ, Vaghy PL, Meissner G, Ferguson DG. Immunolocalization of sarcolemmal dihydropyridine receptor and sarcoplasmic reticular triadin and ryanodine receptor in rabbit ventricle and atrium. Journal of Cell Biology 1995;129:673-682.

118. Hohendanner F, Maxwell JT, Blatter LA. Cytosolic and nuclear calcium signaling in atrial myocytes: IP3-mediated calcium release and the role of mitochondria. Channels 2015;9:129-138.

119. Lüss I, Boknik P, Jones LR, Kirchhefer U, Knapp J, Linck B, Lüss H, Meissner A, Müller FU, Schmitz W, Vahlensieck U, Neumann J. Expression of Cardiac Calcium Regulatory Proteins in Atrium v Ventricle in Different Species. Journal of Molecular and Cellular Cardiology 1999;31:1299-1314.

120. Miyata S, Minobe W, Bristow MR, Leinwand LA. Myosin Heavy Chain Isoform Expression in the Failing and Nonfailing Human Heart. Circulation Research 2000;86:386-390.

121. Reiser PJ, Portman MA, Ning X-H, Moravec CS. Human cardiac myosin heavy chain isoforms in fetal and failing adult atria and ventricles. American Journal of Physiology-Heart and Circulatory Physiology 2001;280:H1814-H1820.

122. Kracklauer MP, Feng H-Z, Jiang W, Lin JL-C, Lin JJ-C, Jin J-P. Discontinuous thoracic venous cardiomyocytes and heart exhibit synchronized developmental switch of troponin isoforms. FEBS J 2012:n/an/a.

123. Lyons GE, Schiaffino S, Sassoon D, Barton P, Buckingham M, Develop- Alp NJ, Schotten U, Casadei B. Atrial sources of reactive oxygen species mental regulation of myosin gene expression in mouse cardiac muscle. $J$ Cell vary with the duration and substrate of atrial fibrillation: implications for the Biol 1990;111:2427 2436.

124. Liu R, Feng HZ, Jin JP. Physiological contractility of cardiomyocytes in the wall of mouse and rat azygos vein. Am J Physiol Cell Physiol 2014;306:C697-704.

125. Brandenburg S, Kohl T, Williams GSB, Gusev K, Wagner E, Rog-Zielinska EA, Hebisch E, Dura M, Didié M, Gotthardt M, Nikolaev VO, Hasenfuss G, Kohl P, Ward CW, Lederer WJ, Lehnart SE. Axial tubule junctions control rapid calcium signaling in atria. Journal of Clinical Investigation 2016;126:39994015 .

126. Mackenzie L, Bootman MD, Laine M, Berridge MJ, Holmes A, Li W-H, Lipp P. The role of inositol 1,4,5-trisphosphate receptors in Ca2\$ $\backslash$ mathplus $\$$ signalling and the generation of arrhythmias in rat atrial myocytes. The Journal of Physiology 2002;541:395-409.

127. Dassouli A, Sulpice J-C, Roux S, Crozatier B. Stretch-induced inositol trisphosphate and tetrakisphosphate production in rat cardiomyocytes. Journal of Molecular and Cellular Cardiology 1993;25:973982.

128. Kim J-C, Woo S-H. specific localization and remodeling of functional L-type calcium channels in. Circulation 2015;132:2372 2384 .

129. Huang H, Wang W, Liu P, Jiang Y, Zhao Y, Wei H, Niu W. TRPC1 expression and distribution in rat hearts. European Journal of Histochemistry 2009;53:217-224.

130. Bode F, Sachs F, Franz MR. Tarantula peptide inhibits atrial fibrillation. Nature 2001;409:35-36.

131. Breithardt O-A, Stellbrink C, Herbots L, Claus P, Sinha AM, Bijnens B, Hanrath P, Sutherland GR. Cardiac resynchronization therapy can reverse abnormal myocardial strain distribution in patients with heart failure and left bundle branch block. Journal of the American College of Cardiology 2003;42:486-494.

132. Claus P, Omar AMS, Pedrizzetti G, Sengupta PP, Nagel E. Tissue Tracking Technology for Assessing Cardiac Mechanics: Principles, Normal Values, and Clinical Applications. JACC: Cardiovascular Imaging 2015;8:1444-1460.

133. Siogas K, Pappas S, Graekas G, Goudevenos J, Liapi G, Sideris DA. Segmental wall motion abnormalities alter vulnerability to ventricular ectopic beats associated with acute increases in aortic pressure in patients with underlying coronary artery disease. Heart 1998;79:268-273.

134. Young A. Regional heterogeneity of function in nonischemic dilated cardiomyopathy. Cardiovascular Research 2001;49:308-318.

135. Eckstein J, Verheule S, de Groot N, Allessie M, Schotten U. Mechanisms of perpetuation of atrial fibrillation in chronically dilated atria. Progress in Biophysics and Molecular Biology 2008;97:435-451.

136. Peyronnet R, Nerbonne JM, Kohl P. Cardiac Mechano-Gated Ion Channels and Arrhythmias. Circ Res 2016;118:311-329.

137. Louch WE, Sejersted OM, Swift F. There Goes the Neighborhood: Pathological Alterations in T-Tubule Morphology and Consequences for Cardiomyocyte Handling. Journal of Biomedicine and Biotechnolo- 
gy 2010;2010:1-17.

138. Frisk M, Ruud M, Espe EKS, Aronsen JM, Røe ÅT, Zhang L, Norseng PA, Sejersted OM, Christensen GA, Sjaastad I, Louch WE. Elevated ventricular wall stress disrupts cardiomyocyte t-Tubule structure and calcium homeostasis. Cardiovascular Research 2016;112:443-451.

139. Bayeva M, Gheorghiade M, Ardehali H. Mitochondria as a therapeutic target in heart failure. Journal of the American College of Cardiology 2013;61:599-610.

140. Ide T, Tsutsui H, Kinugawa S, Utsumi H, Kang D, Hattori N, Uchida K, Arimura K-I, Egashira K, Takeshita A. Mitochondrial electron transport complex I is a potential source of oxygen free radicals in the failing myocardium. Circulation Research 1999;85:357-363.

141. Aquila-Pastir LA, DiPaola NR, Matteo RG, Smedira NG, McCarthy PM, Moravec CS. Quantitation and distribution of $\beta$-tubulin in human cardiac myocytes. Journal of Molecular and Cellular Cardiology 2002;34:1513-1523.

142. Heling A, Zimmermann R, Kostin S, Maeno Y, Hein S, Devaux B, Bauer E, Klövekorn W-P, Schlepper M, Schaper W, Schaper J. Increased expression of cytoskeletal, linkage, and extracellular proteins in failing human myocardium. Circulation Research 2000;86:846-853.

143. Tsutsui H, Tagawa H, Kent RL, McCollam PL, Ishihara K, Nagatsu M, Cooper G. Role of microtubules in contractile dysfunction of hypertrophied cardiocytes. Circulation 1994;90:533-555.

144. Tsutsui H, Ishihara K, Cooper G. Cytoskeletal role in the contractile dysfunction of hypertrophied myocardium. Science 1993;260:682-687.

145. Parker KK, Taylor LK, Atkinson B, Hansen DE, Wikswo JP. The effects of tubulin-binding agents on stretch-induced ventricular arrhythmias. European Journal of Pharmacology 2001;417:131-140.

146. Reilly SN, Jayaram R, Nahar K, Antoniades C, Verheule S, Channon KM, Alp NJ, Schotten U, Casadei B. Atrial Sources of Reactive Oxygen Species Vary With the Duration and Substrate of Atrial Fibrillation. Circulation 2011;124:1107-1117.

147. Calkins H, Maughan WL, Weisman HF, Sugiura S, Sagawa K, Levine JH. Effect of acute volume load on refractoriness and arrhythmia development in isolated, chronically infarcted canine hearts. Circulation 1989;79:687-697.

148. Coronel R, Wilms-Schopman FJG, Degroot JR. Origin of ischemia-induced phase 1b ventricular arrhythmias in pig hearts. Journal of the American College of Cardiology 2002;39:166-176.

149. Josephson ME, Harken AH, Horowitz LN. Endocardial excision: A new surgical technique for the treatment of recurrent ventricular tachycardia. Circulation 1979;60:1430-1439.

150. Wakayama Y, Miura M, Stuyvers BD, Boyden PA, ter Keurs HE. Spatial nonuniformity of excitation-contraction coupling causes arrhythmogenic Ca2+ waves in rat cardiac muscle. Circ Res 2005;96:12661273 .

151. Daniels MCG, Fedida D, Lamont C, Ter Keurs HEDJ. Role of the sarcolemma in triggered propagated contractions in rat cardiac trabeculae. Circulation Research 1991;68:1408-1421.

152. Ter Keurs HEDJ, Wakayama Y, Miura M, Stuyvers BD, Boyden PA, Landesberg A. Spatial nonuniformity of contraction causes arrhythmogenic $\mathrm{Ca} 2+$ waves in rat cardiac muscle. Annals of the New York Academy of Sciences 2005;1047:345-365.

153. Seo K, Inagaki M, Nishimura S, Hidaka I, Sugimachi M, Hisada T, Sugiura S. Structural heterogeneity in the ventricular wall plays a significant role in the initiation of stretch-induced arrhythmias in perfused rabbit right ventricular tissues and whole heart preparations. Circ Res 2010;106:176-184.

154. Decher N, Ortiz-Bonnin B, Friedrich C, Schewe M, Kiper AK, Rinné S, Seemann G, Peyronnet R, Zumhagen S, Bustos D, Kockskämper J, Kohl P, Just S, González W, Baukrowitz T, Stallmeyer B, Schulze-Bahr E. Sodium permeable and "hypersensitive" TREK-1 channels cause ventricular tachycardia. EMBO Molecular Medicine 2017;9:403-414.

155. Franz MR, Burkhoff D, Yue DT, Sagawa K. Mechanically induced action potential changes and arrhythmia in isolated and in situ canine hearts. Cardiovascular Research 1989;23:213-223.

156. Hansen DE, Borganelli M, Stacy Jr. GP, Taylor LK. Dose-dependent inhibition of stretch-induced arrhythmias by gadolinium in isolated canine ventricles. Circulation Research 1991;69:820-831.

157. Hansen DE, Craig CS, Hondeghem LM. Stretch-induced arrhythmias in the isolated canine ventricle. Evidence for the importance of mechanoelectrical feedback. Circulation 1990;81:1094-1105.

158. Nazir SA, Lab MJ. Mechanoelectric feedback in the atrium of the isolated guinea-pig heart. CardiovasC Res 1996;32:112-119.

159. Wang J, Ma Y, Sachs F, Li J, Suchyna TM. GsMTx4-D is a cardioprotectant against myocardial infarction during ischemia and reperfusion. J Mol Cell Cardiol 2016;98:83-94. 
Mechanosensitivity of microdomain calcium signalling in the heart | 


\section{Chapter III}

Stretch-induced increase in $\mathrm{Ca}^{2+}$ spark in atrial myocytes requires an intact microtubular network but not redox modulation

Patrick Schönleitner ${ }^{1}$, Marion Kuiper ${ }^{1}$, Ulrich Schotten ${ }^{1}$, Peter Kohl2,3, Rémi Peyronnet ${ }^{2,3}$, Gudrun Antoons ${ }^{1}$

1 Dept of Physiology, Cardiovascular Research Institute Maastricht, Maastricht University, The Netherlands

2 Institute for Experimental Cardiovascular Medicine, University Heart Centre Freiburg - Bad Krozingen, Medical Center - University of Freiburg, Freiburg, Germany

3 Faculty of Medicine, University of Freiburg 


\section{ABSTRACT}

Aim: Mechanical stretch modulates atrial electrophysiology and promotes the initiation and maintenance of atrial fibrillation (AF). Acute stretch of intact atria may induce depolarization and premature contractions. One possible mechanism is a stretch-induced increase in sarcoplasmic reticulum (SR) $\mathrm{Ca}^{2+}$-leak, as observed in ventricular myocytes. By analyzing $\mathrm{Ca}^{2+}$-spark and -wave dynamics, we aimed to determine whether diastolic stretch activates $\mathrm{SR} \mathrm{Ca}^{2+}$-release, whether this may cause aftercontractions in single atrial myocytes, and what the underlying mechanisms are.

Methods and Results: Rabbit atrial myocytes were glued to glass micro-rods and stretched uniaxially. Force, sarcomere length (SL) and confocal $\mathrm{Ca}^{2+}$-images were recorded simultaneously. Application of diastolic stretch (13\% of resting SL) produces an instantaneous increase in $\mathrm{Ca}^{2+}$-spark rate to $163 \pm 19 \%$ of control without altering individual spark properties. The stretch-induced increase in $\mathrm{Ca}^{2+}$-spark rate was absent in $\mathrm{Na}^{+} / \mathrm{Ca}^{2+}$-free medium and could be prevented by application of the microtubule-depolymerizing agent colchicine, but not by either NADPH oxidase 2 inhibition (by gp91ds-tat) or global reactive oxygen species scavenging (by N-acetylcysteine). Counterintuitively, GsMTx-4 (a blocker of cation-nonselective stretch-activated ion channels) increased diastolic spark rate in non-stretch cells to levels that were indistinguishable from those otherwise reached upon stretch.

In addition, highly synchronized spontaneous $\mathrm{Ca}^{2+}$-waves were observed in stretched cells. These $\mathrm{Ca}^{2+}$-waves required external $\mathrm{Na}^{+}$and $\mathrm{Ca}^{2+}$, indicating a depolarization-dependent mechanism ('escape beats'). Treatment with GsMTx-4 did not prevent occurrence of escape beats, and there was no acute effect of stretch on electrically-triggered $\mathrm{Ca}^{2+}$-transients.

Conclusion: These data confirm the presence of stretch-induced diastolic SR $\mathrm{Ca}^{2+}$-release in atrial myocytes, involving a mechanism that requires an intact microtubular network, but that is independent of redox signaling. The occurrence of synchronized $\mathrm{Ca}^{2+}$ waves during stretch indicates that, in parallel, membrane-depolarization may induce aftercontractions in stretched atrial myocytes. 
NON-STANDARD ABBREVIATIONS AND ACRONYMS

AT

CaT

CICR

FDHM

FWHM

GsMTx-4

NAC

NCX

NOX2

RT

SAC

$\mathrm{SAC}_{\text {NS }}$

SiS

SL

TT

TTP
Axial tubule

$\mathrm{Ca}^{2+}$-transient amplitude

$\mathrm{Ca}^{2+}$-induced $\mathrm{Ca}^{2+}$-release

Full duration at half maximum fluorescence

Full width at half maximum fluorescence

Grammostola spatulata mechanotoxin 4

$\mathrm{N}$-acetylcysteine

$\mathrm{Na}^{+} / \mathrm{Ca}^{2+}$ exchanger

NADPH oxidase 2

Relaxation time

Stretch-activated ion channels

Non-selective cation stretch-activated ion channels

stretch-induced increase in $\mathrm{Ca}^{2+}$-spark rate

Sarcomere length

Transverse tubules

Time to peak 


\section{INTRODUCTION}

With each heartbeat, the heart experiences variations in its mechanical environment. The healthy myocardium responds to stretch by an immediate increase in force of contraction (Frank-Starling mechanism). This occurs both in ventricles and atria. In addition to effects on contractility, mechanical stretch influences electrophysiology. In the atria, stretch changes action potential shape, refractory period and conduction..$^{1-4}$ Atrial stretch has been linked to the triggering of premature beats and it is thought to increase susceptibility to atrial fibrillation. ${ }^{5}$

The principal mechanism underlying the Frank-Starling response is generally referred to as an increase in myofilament $\mathrm{Ca}^{2+}$ sensitivity. ${ }^{6}$ More recently, another mechanism as suggested to fine-tune excitation-contraction coupling in response to stretch: ${ }^{7,8}$ mechanical modulation of the open probability of ryanodine receptors (RyR) might optimize $\mathrm{Ca}^{2+}$-induced $\mathrm{Ca}^{2+}-$ release (CICR) in response to diastolic stretch, and help to terminate CICR upon contraction. ${ }^{9}$

Two pathways from stretch to modulation of RyR have been proposed. Firstly, the microtubule network may be a central component of this mechanism, as disruption of it eliminates mechanical stress-dependent calcium signaling. The spatial relationship between microtubules, T-tubular system (TT) and sarcoplasmic reticulum (SR) membranes, as revealed by electron tomography, also supports the possibility of microtubules transmitting mechanical signals directly from the cell surface to the SR membrane, possibly modulating RyR activity akin to sarcolemmal stretch-activated ion channels (SAC). ${ }^{7}$

Secondly, a membrane-bound NADPH-oxidase (NOX2), which is predominantly located in TT close to RyR of the junctional SR, may react to axial stretch with a burst in reactive oxygen species (ROS) production. The produced ROS increases the open probability of RyRs, which can give rise to a sudden rise in $\mathrm{Ca}^{2+}$ spark rate (stretch-induced sparks; SiS). ${ }^{8}$

In addition, non-selective cation $\mathrm{SAC}\left(\mathrm{SAC}_{\mathrm{NS}}\right)$ may affect membrane potential and $\mathrm{Ca}^{2+}$ signaling. $\mathrm{SAC}_{\mathrm{NS}}$ are permeable to $\mathrm{Na}^{+}, \mathrm{K}^{+}$and $\mathrm{Ca}^{2+}$, and they could modulate RyR activity either directly via $\mathrm{Ca}^{2+}$ influx, or indirectly via $\mathrm{Na}^{+}$influx, increasing local $\mathrm{Ca}^{2+}$ levels via effects on $\mathrm{Na}^{+} / \mathrm{Ca}^{2+}$ exchange (NCX). $\mathrm{SAC}_{\mathrm{NS}}$ currents have been functionally demonstrated in atrial cells at the whole-cell and single-channel level. ${ }^{10}$ Inhibiting $\mathrm{SAC}_{\mathrm{NS}}$ with GsMTx-4 (Grammostola spatulata mechanotoxin 4) inhibited the stretch-induced slowing of conduction and delayed the onset of burst-pacing induced AF in rabbit atrial myocardium, ${ }^{11}$ highlighting their potential relevance for our study.

In this study, we applied axial stretch to rabbit single atrial myocytes and observed an immediate increase in diastolic $\mathrm{Ca}^{2+}$-spark rate, similar to what had been reported in rat ventricular myocytes. ${ }^{7}$ We investigated the roles of ROS, microtubules and $\mathrm{SAC}_{\mathrm{NS}}$ in the stretch-induced increase in $\mathrm{Ca}^{2+}$, and studied the impact of stretch on cellular $\mathrm{Ca}^{2+}$-transients and active force production, as well as on the initiation of spontaneous $\mathrm{Ca}^{2+}$-waves, with the aim of identifying further the mechanisms underlying atrial stretch-induced automaticity. 


\section{MATERIAL AND METHODS}

All animal experiments were approved by the Dutch animal welfare body (DEC2014-112) and performed in accordance with the Directive 2010/63/EU of the European Parliament on the protection of animals used for scientific purposes. Rabbit atrial myocytes were isolated as previously described (see online supplement for detail). ${ }^{12}$ Only rod shaped myocytes with clear homogenous cross striation were selected. Cells were Fluo-4 AM loaded, glued to two thin glass fibres using a bio-adhesive, and stretched from diastolic resting length by axial movement of one rod, connected to a piezo-electric translator controlled by a variable voltage source. The voltage signal to generate stretch of different amplitudes was calculated based on the distance between the two glass rods. The relative increase in rod distance was greater than the actual change in sarcomere length (SL), due to partial membrane sliding of the rods (Fig 1A). A $10 \%$ and $20 \%$ increase in distance between rods, referred to in this study as application of moderate and severe stretch, caused an increase in SL of $6 \%$ and $13 \%$, respectively (Tab. 1). Larger strains could not be achieved consistently, due to further increased sliding, partial detachment of rods.

Isometric peak force and $\mathrm{Ca}^{2+}$-transients were recorded during $2 \mathrm{~Hz}$ stimulation at different levels of preload. SR Ca ${ }^{2+}$ content was estimated from the peak amplitude of $\mathrm{SR} \mathrm{Ca}^{2+}$ release events, induced by rapid application of $10 \mathrm{mmol} / \mathrm{L}$ caffeine in the external solution. For isometric force and $\mathrm{SR} \mathrm{Ca}^{2+}$ content measurements, an external solution containing $1.8 \mathrm{mM}$ $\mathrm{Ca}^{2+}$ was used. $\mathrm{Ca}^{2+}$-sparks were observed using confocal line scan recordings and after preconditioning of cells by electrical pacing for 2 minutes at $2 \mathrm{~Hz}$. Control activity was recorded for $20 \mathrm{~s}$, followed by $20 \mathrm{~s}$ of stretch. At $1.8 \mathrm{mM}$ external $\mathrm{Ca}^{2+}$, line scans revealed a relatively small number of $\mathrm{Ca}^{2+}$ spark events (data not shown) and for 4/16 cell isolations, sparks were not detected (data not shown). Therefore, experiments were carried out in NT containing $3.6 \mathrm{mM}$ of $\mathrm{Ca}^{2+}$ (100\% of the cell isolations led to spark observations) $21 / 21$ rabbits. At this concentration, atrial myocytes displayed robust $\mathrm{Ca}^{2+}$ spark rates during measurements while remaining quiescent at rest. All experiments were performed at $37^{\circ} \mathrm{C}$.

$\mathrm{Ca}^{2+}$-sparks were analyzed automatically, using the ImageJ Plugin Spark Master and are expressed as events per second normalized to the length of the line scan (sparks s${ }^{-1} 100 \mu \mathrm{m}^{-1}$ ). Data are shown as Tukey boxplots or mean \pm SEM. Statistical comparisons were made using paired Wilcoxon matched-pairs signed rank test, Mann-Whitney-U test, Kruskal-Wallis or Friedman test for multiple comparison, as appropriate; a p-value $<0.05$ was considered indicative of statistically significant differences between means. Throughout the manuscript, $n$ numbers are written in square brackets with the first number corresponding to the number of cells observed, and the second number corresponding to number of animals the interrogated cells originated from. An expanded methods section is available in the online supplement. 


\section{RESULTS}

A
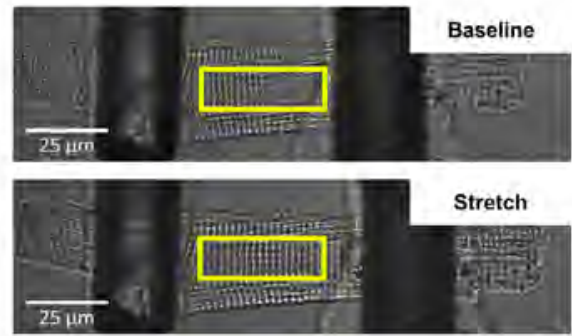

B

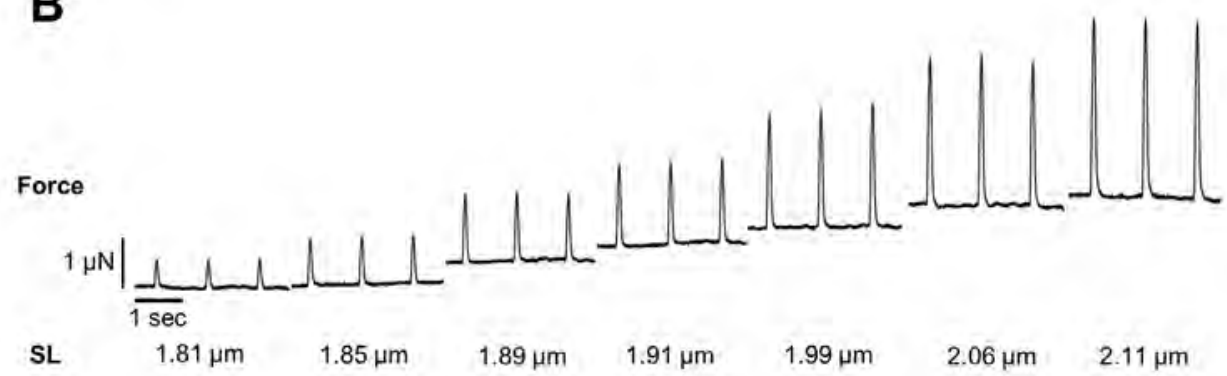

C

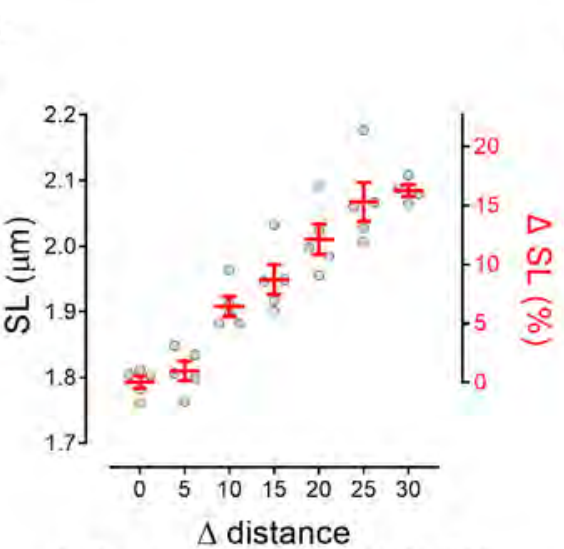

between mounting points (\%)

D

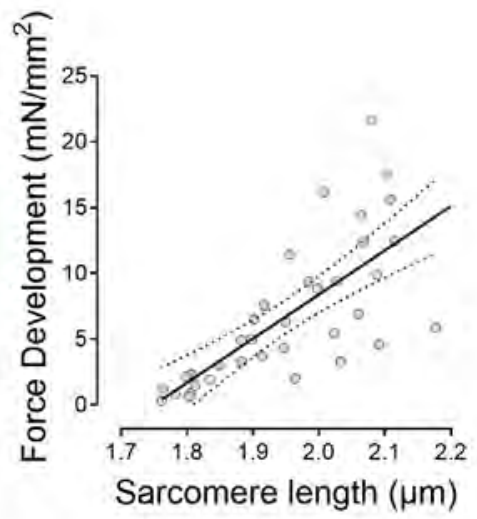

Figure 1. Technical approach and verification of single atrial myocyte stretch. A, rabbit atrial myocyte, attached to glass microrods coated with a biological adhesive. Left, non-stretched; right, after severe stretch. Yellow box, region of interest for calculating sarcomere length (SL). B, Example of force recordings at different levels of isometric stretch, increasing SL. Forces were recorded at the end of each $20 \mathrm{~s}$ stretch step. C, Relation between amount of stretch (calculated as the relative increase in distance between glass rods) and change in SL. The right Y-axis shows relative changes in mean SL $(\Delta \mathrm{SL}$, expressed as percentage difference relative to mean SL at $0 \%$ stretch). From $0 \%$-stretch to $20 \%$-stretch, a Friedman test was performed to test for significance. Due to missing values $25 \%$ and $30 \%$ stretch (cell detachment), they were omitted from analysis. D, Isometric peak force as a function of SL, linearly fitted, showing 95\% confidence interval [5/3]. All experiments were performed with $\mathrm{NT}$ containing $1.8 \mathrm{mM} \mathrm{CaCl}_{2}$. 


\section{Acute effects of axial stretch on force and $\mathrm{Ca}^{2+}$-transients in atrial myocytes}

The stretch-induced increase in force development (Frank-Starling response) is said to occur in the absence of noticeable changes in systolic $\mathrm{Ca}^{2+}$-transients, ${ }^{1}$ and this has been confirmed in our cells. SL of electrically paced atrial myocytes was recorded at baseline (with the two glass rods in their initial position after cell attachment), moderate (10\% increase in inter-rod distance) and severe stretch (20\%), Fig 1 A-D. SL was $1.75 \pm 0.07 \mu \mathrm{m}$ in non-stretched cells, $1.85 \pm 0.09 \mu \mathrm{m}$ at moderate stretch, and $1.98 \pm 0.09 \mu \mathrm{m}$ at sever stretch (Fig 1C and Table1).

\begin{tabular}{cccc}
\hline $\begin{array}{c}\text { Increase in distance } \\
\text { between rods }(\%)\end{array}$ & $\mathrm{SL}(\mu \mathrm{m})$ & $\Delta \mathrm{SL}(\%)$ & $\begin{array}{c}\text { Fractional } \\
\text { efficiency } \\
(\% \Delta \mathrm{SL} / \% \text { rods })\end{array}$ \\
\hline 0 & $1.79 \pm 0.02$ & & \\
5 & $1.81 \pm 0.03$ & 1.12 & 0.22 \\
10 & $1.91 \pm 0.03$ & 6.70 & 0.67 \\
15 & $1.95 \pm 0.05$ & 8.94 & 0.60 \\
20 & $2.01 \pm 0.05$ & 12.29 & 0.61 \\
25 & $2.07 \pm 0.06$ & 15.64 & 0.63 \\
30 & $2.08 \pm 0.02$ & 16.20 & 0.54 \\
\hline
\end{tabular}

Table 1. Changes in sarcomere length by increasing amounts of stretch. The amplitude of stretch (\%) is defined as the relative increase in distance between the glass rods to which a cell is attached. The efficiency of stretch was assessed by the ratio of the relative change in sarcomere length $(\Delta \mathrm{SL})$ and change in distance between rods.

\begin{tabular}{|c|c|c|c|}
\hline Force & Baseline & $\begin{array}{l}\text { Moderate } \\
\text { Stretch }\end{array}$ & Severe Stretch \\
\hline$T T P_{F}(m s)$ & $71.8 \pm 11.5$ & $65.6 \pm 6.7$ & $75.7 \pm 7.2$ \\
\hline$+\mathrm{dF} / \mathrm{dt}\left(\mathrm{mN} / \mathrm{mm}^{2} / \mathrm{s}\right)$ & $57.6 \pm 6.4$ & $161.7 \pm 15.4$ * & $252.0 \pm 22.6 \#^{* *}$ \\
\hline Peak Force $\left(\mathrm{mN} / \mathrm{mm}^{2}\right)$ & $2.39 \pm 0.38$ & $6.76 \pm 1.03^{*}$ & $11.26 \pm 1.38 \# \#^{*}$ \\
\hline$-\mathrm{dF} / \mathrm{dt}\left(\mathrm{mN} / \mathrm{mm}^{2} / \mathrm{s}\right)$ & $-32.6 \pm 4.3$ & $-89.24 \pm 9.5^{*}$ & $-141.9 \pm 15.1 \#, *$ \\
\hline $\mathrm{RT}_{50}(\mathrm{~ms})$ & $46.9 \pm 4.6$ & $49.9 \pm 5.4$ & $54.7 \pm 6.9$ \\
\hline $\mathrm{RT}_{90}(\mathrm{~ms})$ & $149.7 \pm 14.8$ & $142.9 \pm 10.9$ & $140.4 \pm 8.9$ \\
\hline Сат & Baseline & $\begin{array}{l}\text { Moderate } \\
\text { Stretch }\end{array}$ & Severe Stretch \\
\hline $\mathrm{TF}_{50}(\mathrm{~ms})$ & $17.0 \pm 1.2$ & $15.6 \pm 0.9$ & $17.0 \pm 1$ \\
\hline$\pi P_{\mathrm{Ca}}(\mathrm{ms})$ & $53.4 \pm 3.5$ & $52.7 \pm 3.4$ & $52.7 \pm 4.6$ \\
\hline CaT amplitude $\left(\mathrm{F} / \mathrm{F}_{0}\right)$ & $2.36 \pm 0.18$ & $2.40 \pm 0.20$ & $2.35 \pm 0.26$ \\
\hline $\mathrm{RT}_{50}(\mathrm{~ms})$ & $58.2 \pm 4.3$ & $56.9 \pm 3.8$ & $56.0 \pm 4.0$ \\
\hline $\mathrm{RT}_{90}(\mathrm{~ms})$ & $152.9 \pm 11.4$ & $141.0 \pm 8.7$ & $140.5 \pm 8.2$ \\
\hline Tau (ms) & $55.2 \pm 6.2$ & $52.1 \pm 5.6$ & $50.1 \pm 5.3$ \\
\hline
\end{tabular}

Table 2. Summarized data for single myocyte contraction and $\mathrm{Ca}^{2+}$-transient kinetics Abbr. Force: $\mathrm{TTP}_{\text {force }}$, time-to-peak force development; $+\mathrm{dF} / \mathrm{dt}$, peak force generation; $-\mathrm{dF} / \mathrm{dt}$, maximal relaxation velocity; $\mathrm{RT}_{50 \text {, force }}$, time to $50 \%$ relaxation; $\mathrm{RT}_{90 \text {, force }}$, time to $90 \%$ relaxation. $\mathrm{Ca}^{2+}$-transients: $\mathrm{FT}_{50}$, time to $50 \%$ fluorescence; $\mathrm{TTP}_{\mathrm{Ca}}$, timeto-peak fluorescence; CaT, $\mathrm{Ca}^{2+}$-transient amplitude; $\mathrm{RT}_{50, \mathrm{Ca}}$ and $\mathrm{RT}_{90, \mathrm{Ca}}$, time from peak to $50 \%$ and $90 \%$ of $\mathrm{Ca}^{2+}$ decay; Tau, $\mathrm{Ca}^{2+}$ decay assessed by mono-exponential fitting. ${ }^{*} \mathrm{p}<0.05$ vs. baseline, $\# \mathrm{p}<0.05$ vs. $10 \%$ stretch, [9/4]. 
SL did not exceed $2.2 \mu \mathrm{m}$ during stretch (Fig 1D), which is within the physiological range of diastolic filling. ${ }^{13}$ Force increased with SL (Fig 1D), by a factor of 2.8 and 4.7 for the two levels of stretch assessed in this study (Table 2).
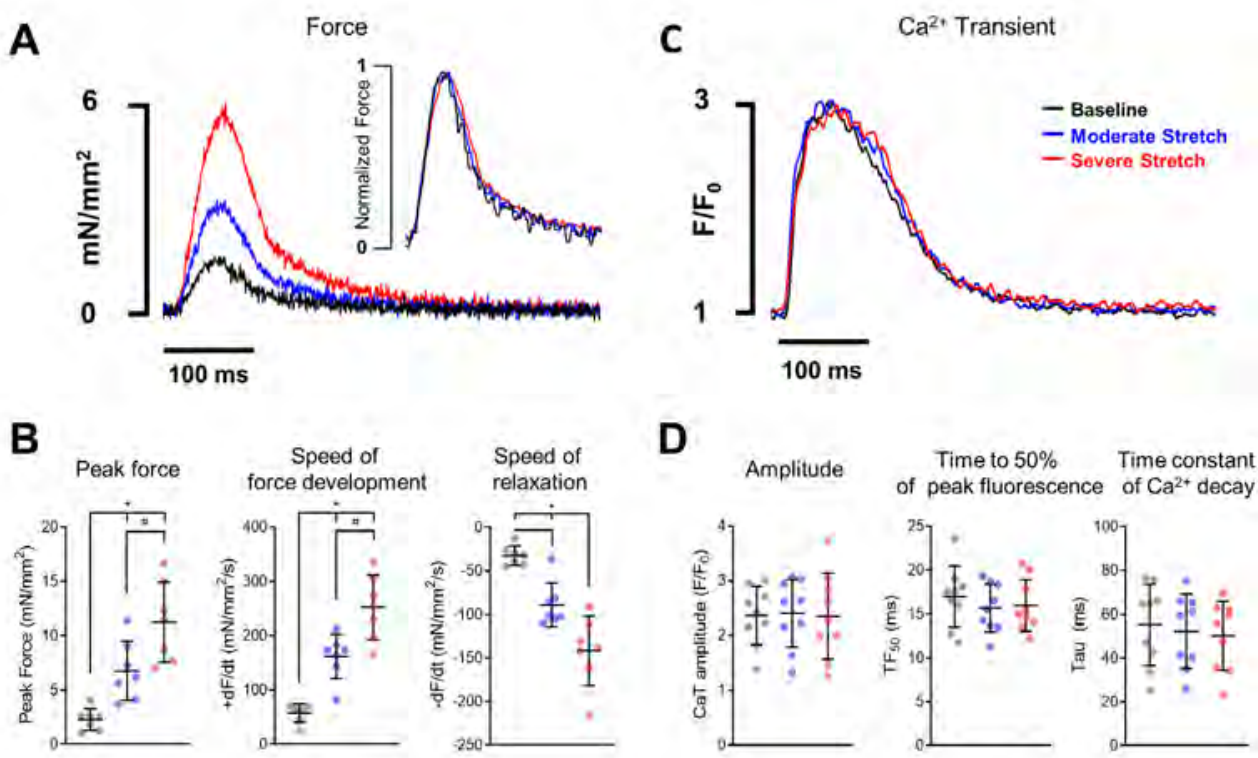

Figure 2. Changes in systolic $\mathrm{Ca}^{2+}$ and force parameters in atrial rabbit myocytes during moderate and severe stretch. Representative example of $\mathbf{A}$, force of contraction and $\mathbf{B}, \mathrm{Ca}^{2+}$-transients simultaneously recorded $20 \mathrm{~s}$ after the onset of stretch in an atrial myocyte paced at $2 \mathrm{~Hz}$ and superfused with NT at $37^{\circ} \mathrm{C}$. Superimposed black, blue and red traces are representing baseline, moderate and severe stretch, respectively. $\mathbf{C}$, Average change in force $(\mathrm{mN} /$ $\mathrm{mm}^{2}$, left) and speed of contraction $(+\mathrm{dP} / \mathrm{dt}$, middle) or relaxation $(-\mathrm{dP} / \mathrm{dt}$, right) as a function of diastolic stretch (8 cells). D, Left, $\mathrm{Ca}^{2+}$-transient amplitude $\left(\mathrm{F} / \mathrm{F}_{0}\right)$; Middle, time to $50 \%$ peak fluorescence $\left(\mathrm{TF}_{50}\right.$, in $\left.\mathrm{ms}\right)$; Left, time constant of $\mathrm{Ca}^{2+}$ removal (tau, in ms). Mean data of [9/4], Friedman test with Dunn's post hoc test for panel B and $\mathrm{D},{ }^{*} \mathrm{p}<0.05$. All experiments were performed with NT containing $1.8 \mathrm{mM} \mathrm{CaCl}_{2}$.

To characterize the relationship between $\mathrm{Ca}^{2+}$, force and stretch in rabbit atrial cells, we simultaneously measured force of contraction (Fig. 2 A, B) and $\mathrm{Ca}^{2+}$-transients (Fig. 2 C, D) in three consecutive beats at $20 \mathrm{~s}$ after application of different levels of diastolic stretch.

Superimposed traces of active force development (Fig 2A) further illustrate a stretch-dependent acceleration of force development $(+\mathrm{dF} / \mathrm{dt})$ and relaxation $(-\mathrm{dF} / \mathrm{dt}, \mathrm{Fig} 2 \mathrm{~B})$. Time to peak $\left(\mathrm{TTP}_{\mathrm{F}}\right)$ contraction, and to half maximal relaxation $\left(\mathrm{RT}_{50}\right)$, were unaltered (Table 2). $\mathrm{Ca}^{2+}$-transients were measured $20 \mathrm{~s}$ after the onset of stretch when changes in force had reached steady state (Fig 2C). Stretch had no effect on the amplitude of $\mathrm{Ca}^{2+}$-transients, their rate of rise (SR release) and decay times (Fig 2D). In a subset of cells, we applied caffeine as an indirect means of measuring total SR $\mathrm{Ca}^{2+}$-load after steady-state stimulation at resting SL length and during severe stretch. The amplitudes of caffeine-evoked $\mathrm{Ca}^{2+}$-release measured after $20 \mathrm{~s}$ of severe stretch were not altered $\left(6.8 \pm 0.4 \mathrm{~F} / \mathrm{F}_{0}[16 / 5]\right.$, vs $7.7 \pm 0.6[10 / 5]$ at resting length, not shown [NS]), suggesting no significant effects on $\mathrm{SR} \mathrm{Ca}^{2+}$-load. Averaged data of $\mathrm{Ca}^{2+}$-transient parameters are summarized in Table 2. 

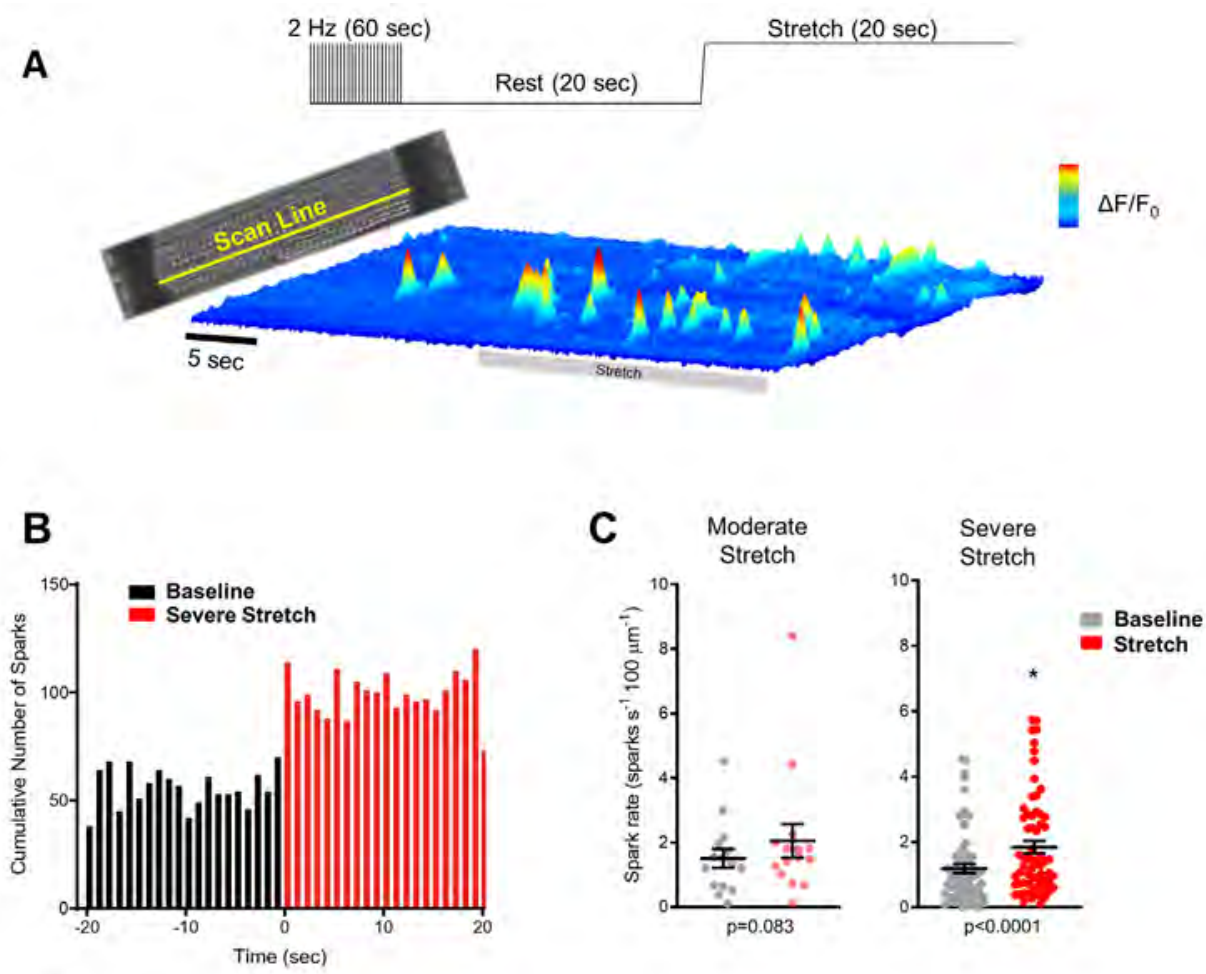

D

E
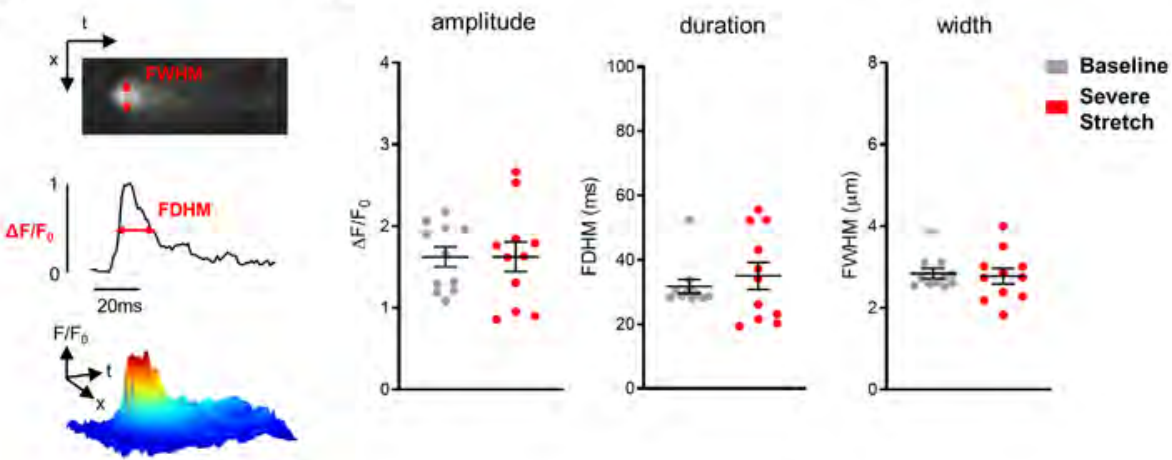

Figure 3. Stretch-activated diastolic $\mathrm{Ca}^{2+}$-release events in rabbit atrial myocytes. A, Typical example of a Fluo-4 intensity surface plot of a longitudinal confocal line scan through a rabbit atrial myocyte, showing diastolic $\mathrm{Ca}^{2+}$-release events (sparks) before and during severe stretch. Prior to the recording, the cell was conditioned at $2 \mathrm{~Hz}$ in NT containing $3.6 \mathrm{mmol} / \mathrm{L} \mathrm{Ca}^{2+}$. The indicated Scan line provides an estimate of the region scanned. B, The histogram ( $1 \mathrm{~s}$ bin size) shows the cumulative number of sparks illustrating the swift and sustained (for $20 \mathrm{~s}$ ) stretch-induced increase in $\mathrm{Ca}^{2+}$-spark activity upon severe stretch [65/15]. C, Average $\mathrm{Ca}^{2+}$-spark frequency in response to moderate stretch (left, [15/5]) and severe stretch (right, [65/15]). D, Line-scan image and fluorescence intensity profile of a single $\mathrm{Ca}^{2+}$-spark illustrating the analysis of basic $\mathrm{Ca}^{2+}$-spark characteristics; amplitude $\left(\Delta \mathrm{F} / \mathrm{F}_{0}\right)$, width (full width at half maximum fluorescence, FWHM), and duration (full duration at half maximum fluorescence, FDHM). Bottom: Surface plot of the $\mathrm{Ca}^{2+}$-spark shown at the top. E, $\mathrm{Ca}^{2}$-spark parameters before and after severe stretch ([11/3], NS). The statistical test used was the Wilcoxon matched pairs signed rank test and expressed as mean $\pm \mathrm{SEM},{ }^{*} \mathrm{p}<0.05$. All experiments were performed with $\mathrm{NT}$ containing $3.6 \mathrm{mM} \mathrm{CaCl}$. 


\section{Atrial myocyte stretch increases diastolic $\mathrm{Ca}^{2+}$-spark rate}

We next examined stretch effects on $\mathrm{Ca}^{2+}$-spark activity in atrial myocytes exposed to high $\mathrm{Ca}^{2+}(3.6 \mathrm{mmol} / \mathrm{L})$ using the protocol illustrated in Fig 3A. The onset of stretch, indicated by the arrow on the fluorescence surface plot (Fig 3A), coincided with a robust increase in $\mathrm{Ca}^{2+}$-spark rate. SiS was rapid in onset (i.e. detected within the first $1 \mathrm{~s}$ analysis bin after application of stretch) and sustained over the $20 \mathrm{~s}$ period of stretch, as illustrated by the

A

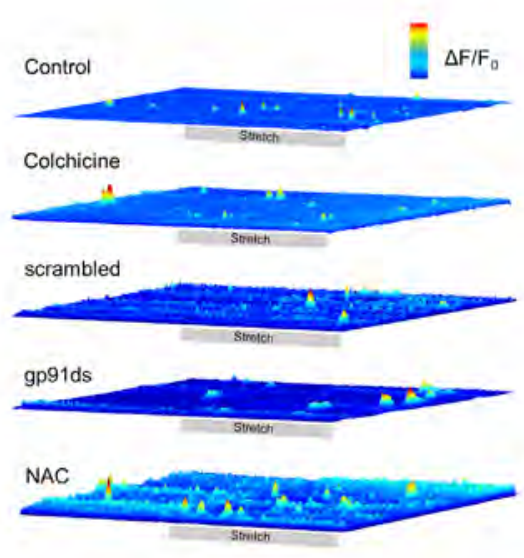

D

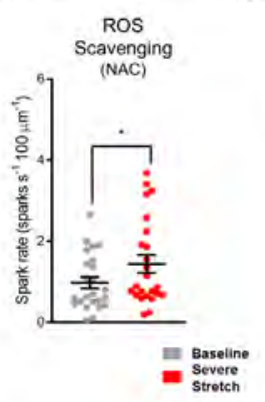

E
B

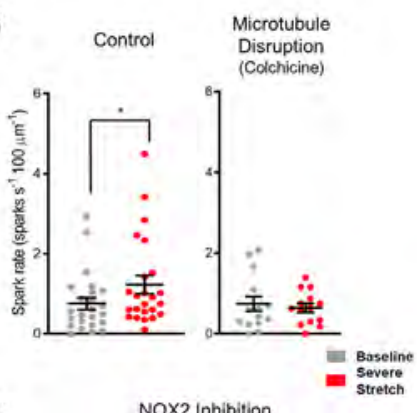

C

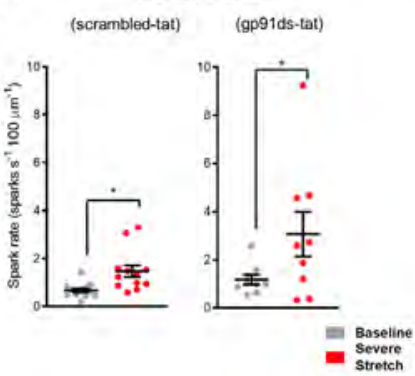

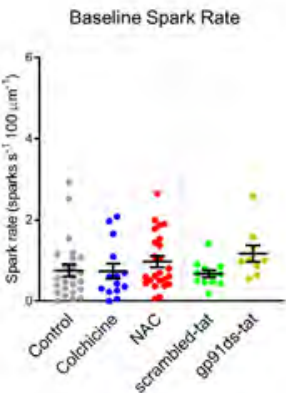

Figure 4. Role of ROS and microtubules in stretch-induced increase in $\mathrm{Ca}^{2+}$-spark rate in atrial myocytes. A, Fluorescence surface plots of stretched atrial myocytes treated with colchicine (to inhibit microtubule polymerization), gp91ds and scrambled peptides (NOX2 inhibition), and N-acetylcysteine (ROS scavenger). B-D, Averaged spark rate before (black) and during stretch (red) in untreated control cells ([24/5]), cells treated with colchicine (10 $\mu \mathrm{mol} / \mathrm{L}, 2 \mathrm{~h}$ pre-incubation, [16/4]), NOX2 inhibitor gp91ds-tat (3 $\mu \mathrm{mol} / \mathrm{L},[9 / 4])$, inactive scrambled peptide (incubation for $2 \mathrm{~h}$ in NT containing $1.8 \mathrm{Ca}^{2+} \mathrm{mmol} / \mathrm{L},[12 / 5]$ ), and $\mathrm{N}$-acetylcysteine (NAC, $10 \mathrm{mmol} / \mathrm{L}$, added to the perfusion $5 \mathrm{~min}$ before spark measurements, [24/5]). E, Comparison of baseline $\mathrm{Ca}^{2+}$-spark rate in non-stretched cells after treatment with colchicine and ROS inhibitors. Mean \pm SEM, ${ }^{*} p<0.05$, Wilcoxon matched-pairs signed rank test, except E, where a Kruskal-Wallis test with Dunn's post hoc test was used. All experiments shown it this figure were carried out in NT containing $3.6 \mathrm{mM} \mathrm{CaCl}_{2}$. 
histogram in Fig 3B. SiS was graded by the amplitude of stretch, reaching $136 \pm 34 \%$ of baseline at moderate (average over $20 \mathrm{~s} ; \mathrm{p}=0.08)$, and $163 \pm 19 \%$ at severe stretch $(\mathrm{p}<0.05$, Fig 3C). No stretch-induced alteration of individual $\mathrm{Ca}^{2+}$-spark characteristics, such as spark amplitude, width and duration was detected (Fig 3D and E).

\section{SiS requires microtubular integrity, but not ROS production}

Previous work in rat ventricular myocytes suggested that SiS requires ROS activity, ${ }^{8}$ and microtubular integrity. ${ }^{7}$ We confirm that disruption of microtubule polymerization, using colchicine, abrogates SiS elicited by axial stretch of atrial myocytes (Fig 4A and B). In contrast, NOX2 inhibition by gp91ds-tat failed to prevent SiS (Fig 4C). To test whether ROS production by sources other than NOX2 influences SR $\mathrm{Ca}^{2+}$-release during stretch, we repeated the experiment with a general ROS scavenger, N-acetylcysteine, and found that global ROS inhibition did not prevent SiS either (Fig 4D). Neither gp91ds-tat nor N-acetylcysteine altered $\mathrm{Ca}^{2+}$-spark frequency in non-stretched cells (Fig 4E). Taken together, these results suggest that ROS is responsible neither for $\mathrm{Ca}^{2+}$-sparks observed in non-stretched atrial myocytes at high $\mathrm{Ca}^{2+}$, nor their stretch-induced increase (e.g. examples in Fig 3A and 4A).

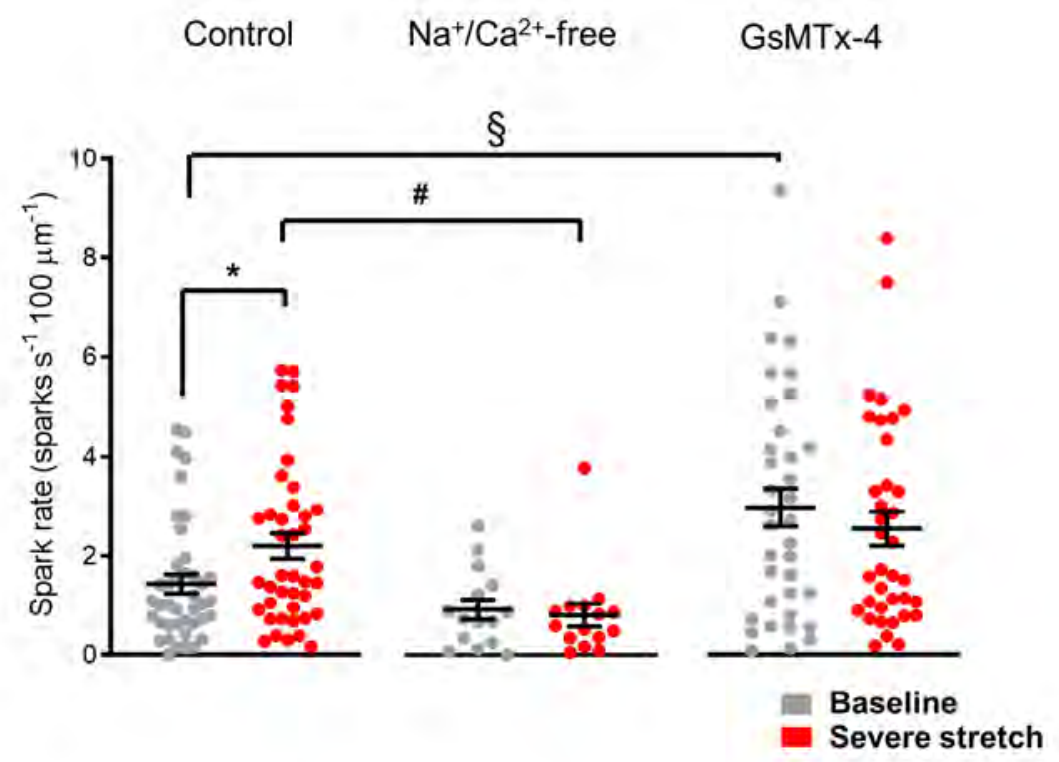

Figure 5. Stretch-dependent increase in $\mathrm{Ca}^{2+}$-spark rate depends on trans-sarcolemmal cation influx. Left, $\mathrm{Ca}^{2+}$-spark rate before (black bar) and during stretch (red bar) in control conditions (Normal Tyrode solution, [45/9]); Middle, after cessation of $2 \mathrm{~Hz}$ pacing and rapid switching to $\mathrm{Na}^{+} / \mathrm{Ca}^{2+}$-free external solution [15/4]; Right, during treatment with GsMTx-4 (2 $\mu \mathrm{mol} / \mathrm{L}$, superfused for $10 \mathrm{~min}$ pre-stretch [36/6]). All experiments were carried out in NT containing $3.6 \mathrm{mM} \mathrm{CaCl}_{2}$. A mixed ANOVA with a Simple Main Effects test was carried out to test for statistical significance. 


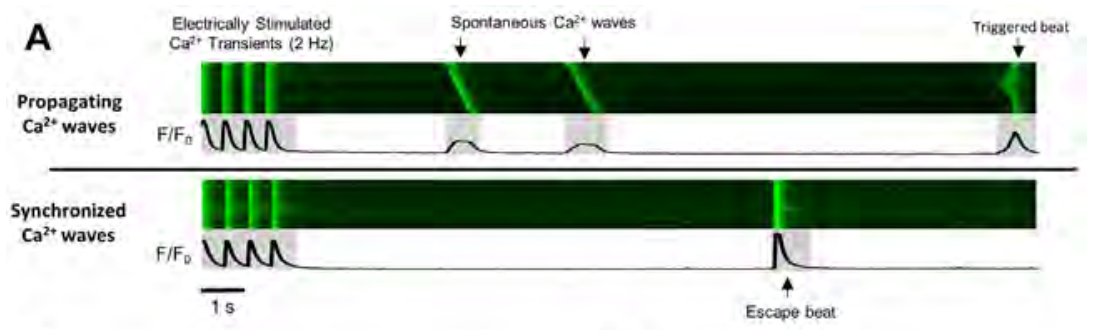

B

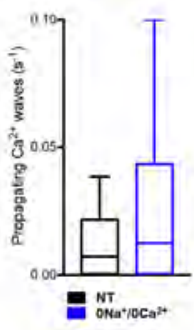

D

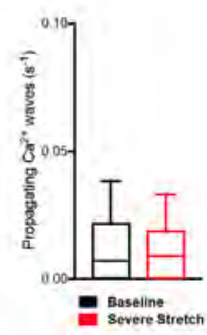

$\mathbf{F}$

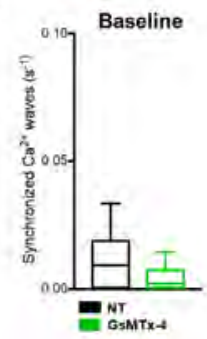

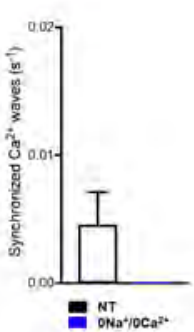

C
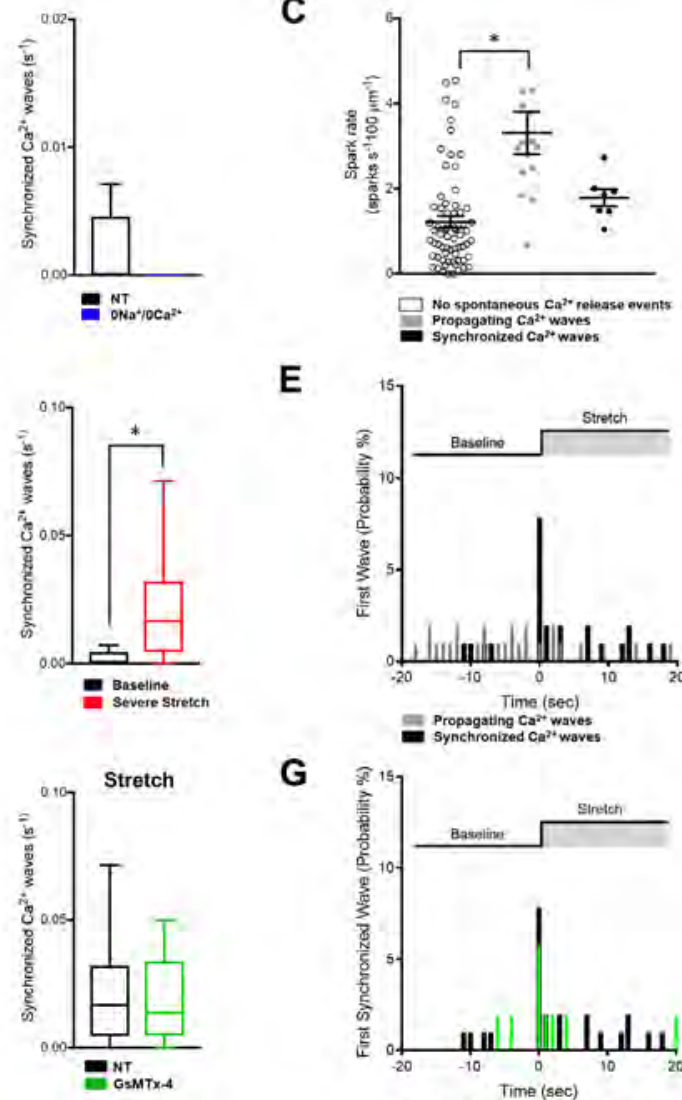

E

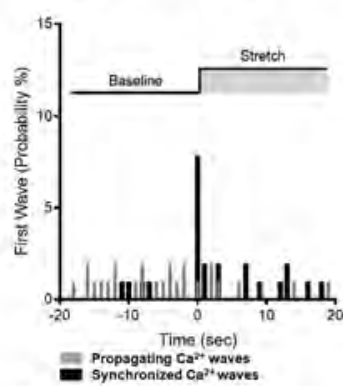

G

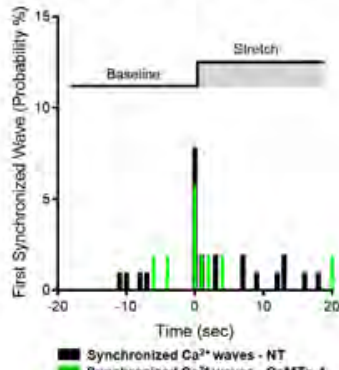

Figure 6. Characteristics of spontaneous $\mathrm{Ca}^{2+}$-waves and stretch-induced excitation in atrial myocytes. $\mathrm{A}$, $\mathrm{XY}$ image of confocal line scans in non-stretched cells showing propagating $\mathrm{Ca}^{2+}$-waves (upper panel) and spontaneous synchronized $\mathrm{Ca}^{2+}$-release (escape beat, lower panel) during a resting period following $2 \mathrm{~Hz}$ stimulation. B, Frequency of propagating (left) and synchronized $\mathrm{Ca}^{2+}$-waves (right) during superfusion with NT (black graphs, $\mathrm{N}=15$, mean of 3 to 8 cells) and $\mathrm{Na}^{+} / \mathrm{Ca}^{2+}$-free solution (blue graphs, 6 hearts, mean of 2 to 5 cells). Synchronized $\mathrm{Ca}^{2+}$-waves had a low incidence in unstretched cells and were not observed in $\mathrm{Na}^{+} / \mathrm{Ca}^{2+}$-free solution. C, Comparison of $\mathrm{Ca}^{2+}$-spark rate preceding propagating [15/10] and synchronized waves [7/6] vs. cells without waves [66/15]. Effect of stretch on frequency (15 hearts, mean of 3 to 8 cells) (D), and timing of first (E) propagating or synchronized $\mathrm{Ca}^{2+}$-waves under baseline (20 s recording before stretch) and during $20 \mathrm{~s}$ of severe stretch. The highest incidence of synchronized $\mathrm{Ca}^{2+}$-waves coincided with the stretch stimulus ( $\mathrm{t}=0$, shaded area). Percentage occurrence of waves ( $\%$ of cells producing the first wave during a given time interval) was calculated from 102 cells. F-G, GsMTx- 4 had no effect on frequency (NT, 15 hearts, mean of 3 to 8 cells; GsMTx-4, 6 hearts, mean of 2 to 6 cells) and timing of synchronized $\mathrm{Ca}^{2+}$-waves (NT, [102/15]; GsMTx-4 [52/6]). For B, D and F a Mann-Whitney-U test was utilized to test for statistical significance, in C a Kruskal-Wallis test with Dunn's post hoc test was used. All experiments were carried out in $\mathrm{NT}$ containing $3.6 \mathrm{mM} \mathrm{CaCl}_{2}$. 
$\mathrm{Ca}^{2+}$-sparks may be triggered by $\mathrm{Ca}^{2+}$ influx through sarcolemmal ion channels causing $\mathrm{Ca}^{2+}-$ induced $\mathrm{Ca}^{2+}$-release via RyR. Potential candidates for mechanically modulated diastolic $\mathrm{Ca}^{2+}$ influx are $\mathrm{SAC}_{\mathrm{NS}}$. To assess this possibility, we performed $\mathrm{Ca}^{2+}$-spark measurements in $\mathrm{Na}^{+} / \mathrm{Ca}^{2+}$-free solution to prevent $\mathrm{Ca}^{2+}$ and $\mathrm{Na}^{+}$entry during diastolic stretch.

After cessation of $2 \mathrm{~Hz}$ pacing, the solution was switched from $\mathrm{NT}$ to $\mathrm{Na}^{+} / \mathrm{Ca}^{2+}$-free solution once intracellular $\mathrm{Ca}^{2+}$ levels had reached diastolic values. No significant difference in baseline $\mathrm{Ca}^{2+}$-spark rate was detected $(\mathrm{p}=0.270)$. SiS was abolished in $\mathrm{Na}^{+} / \mathrm{Ca}^{2+}$-free solution, suggesting that in atrial myocytes trans-sarcolemmal influx of $\mathrm{Ca}^{2+}$ and/or $\mathrm{Na}^{+}$is required for the stretch-induced increase in spark rate (Fig. 5, left and middle).

To address the role of $\mathrm{SAC}_{\mathrm{NS}}$ more directly, we repeated the stretch protocol in cells treated with the $\mathrm{SAC}_{\mathrm{NS}}$ inhibitor GsMTx-4. Interestingly, non-stretched cells exposed to GsMTx-4 showed a higher $\mathrm{Ca}^{2+}$-spark rate compared to control cells $\left(3 \mathrm{~s}^{-1} 100 \mu \mathrm{m}^{-1}, \mathrm{n}=36\right.$, vs. $1.5 \mathrm{~s}^{-1}$ $100 \mu \mathrm{m}^{-1}$ in control, $\left.\mathrm{n}=42, \mathrm{p}<0.05\right)$ which was not significantly different from the rate detected in the stretched control cells. When GsMTx-4 treated cells were subsequently stretched, there was no further increase in $\mathrm{Ca}^{2+}$-spark rate (Fig. 5, right). Of note, GsMTx-4 did had no effect on the amplitude of $\mathrm{Ca}^{2+}$-transients $\left(\mathrm{F} / \mathrm{F}_{0}\right.$ of $5.89 \pm 0.30$ in control and $6.03 \pm 0.26$ in GsMTx-4, NS).

\section{SiS can promote spontaneous excitation in single atrial cells}

In $17 \%$ of atrial cells exposed to high extracellular $\mathrm{Ca}^{2+}$ we observed large spontaneous $\mathrm{Ca}^{2+}$-releases upon cessation of $2 \mathrm{~Hz}$ stimulation $(\mathrm{n}=19$ of 112 non-stretched cells from 15 animals). As illustrated in Fig 6A, two types of spontaneous $\mathrm{Ca}^{2+}$-release events could be distinguished on confocal line scans: self-propagating $\mathrm{Ca}^{2+}$-waves that were initiated in one site and travelled across the cell (upper panel) and synchronized $\mathrm{Ca}^{2+}$ releases along the entire cell (lower panel) whose kinetics did not differ from electrically stimulated $\mathrm{Ca}^{2+}$-transients (assessed by time-to-peak of averaged line scan $\mathrm{Ca}^{2+}$ signals; $68 \pm 9 \mathrm{~ms} v \mathrm{~s}$. $59 \pm 3 \mathrm{~ms}$ for electrically stimulated $\mathrm{Ca}^{2+}$-transients, paced at $\left.2 \mathrm{~Hz}[18 / 10], \mathrm{p}=0.304\right)$. Synchronized $\mathrm{Ca}^{2+}-$ waves were not observed in the absence of external $\mathrm{Na}^{+}$and $\mathrm{Ca}^{2+}$ (Fig 6B). Synchronized waves were not preceded by an increase in diastolic spark rate $\left(1.8 \pm 0.2 \mathrm{~s}^{-1} 100 \mu \mathrm{m}^{-1}[7 / 6]\right.$, $\mathrm{p}=0.5$, Fig $6 \mathrm{C}$ ). In contrast, propagating $\mathrm{Ca}^{2+}$-waves were initiated by an increase in $\mathrm{Ca}^{2+}-$ spark rate $\left(1.2 \pm 0.2 \mathrm{~s}^{-1} 100 \mu \mathrm{m}^{-1}\right.$ at baseline in myocytes not exhibiting $\mathrm{Ca}^{2+}$-waves and $3.3 \pm$ $0.5 \mathrm{~s}^{-1} 100 \mu \mathrm{m}^{-1}$ in myocytes with propagating $\mathrm{Ca}^{2+}$-waves before a wave initiation, [15/10], $\mathrm{p}$ $<0.0001$, Fig 6C), and they continued to occur during perfusion with $\mathrm{Na}^{+} / \mathrm{Ca}^{2+}$-free solution (Fig 6B). Thus, propagating $\mathrm{Ca}^{2+}$-waves relied on local RyR-mediated SR $\mathrm{Ca}^{2+}$-release and are independent from coordinated activation of $\mathrm{SR} \mathrm{Ca}^{2+}$-release by membrane depolarization.

In spite of the increase in $\mathrm{Ca}^{2+}$-spark rate by stretch the incidence of propagating $\mathrm{Ca}^{2+}$-waves did not change (for baseline $0.012 \pm 0.004 \mathrm{~s}^{-1}$ vs. $0.017 \pm 0.006 \mathrm{~s}^{-1}$ at stretch, NS). The occurrence of spontaneous cell-wide $\mathrm{Ca}^{2+}$-release events (escape beats), however, increased 8 -fold during stretch (Fig 6D). To illustrate the temporal relationship between propagating $\mathrm{Ca}^{2+}$-waves (grey), or escape beats (black), and stretch, we plotted the occurrence of the first event in relation to stretch in 1 -second bins (Fig 6E). While the probability of $\mathrm{Ca}^{2+}$-wave occurrence is equally distributed before and during stretch, synchronized $\mathrm{Ca}^{2+}$-release peaked 
shortly after the onset of stretch (with $7.8 \%$ of cells showing escape beats within $1 \mathrm{~s}$ after onset of stretch). Together these data indicate that stretch-induced 'escape beats' depend on electrical triggering of an action potential (AP), rather than on mechanically-induced release of $\mathrm{Ca}^{2+}$ from the SR.

A possible mechanism would involve activation of $\mathrm{SAC}_{\mathrm{NS}}$ upon stretch, producing a transient inward current large enough to reach the AP threshold. We therefore analyzed the effect of GsMTx-4 on the incidence of stretch-induced escape beats. GsMTx-4 failed to prevent spontaneously occurring synchronized $\mathrm{Ca}^{2+}$-release during stretch (Fig 6F and $\mathrm{G}$, [102/15] and [52/6] for NT and GsMTx-4 respectively).

\section{DISCUSSION}

In the present study, we investigate the effect of axial stretch on $\mathrm{Ca}^{2+}$ handling in rabbit atrial myocytes exposed to elevated extracellular $\mathrm{Ca}^{2+}$, and assess potential proarrhythmic implications. The main findings of this study are that in the $20 \mathrm{~s}$ after the onset of stretch: (I) axial stretch induces $\mathrm{SiS}$ without affecting systolic $\mathrm{Ca}^{2+}$-transients, (II) an intact microtubular network and extracellular $\mathrm{Na}^{+}$and $\mathrm{Ca}^{2+}$, but not ROS, are required for the generation of $\mathrm{SiS}$ in atrial myocytes, (III) stretch increases the likelihood of spontaneous synchronized $\mathrm{Ca}^{2+}$-wave activity ('escape beats'), and (IV) inhibition of $\mathrm{SAC}_{\mathrm{NS}}$ by GsMTx-4 raises background spark rate without changing the propensity of proarrhythmic events.

\section{Atrial myocyte stretch produces a diastolic SR $\mathrm{Ca}^{2+}$ leak}

Direct evidence that stretch causes diastolic SR $\mathrm{Ca}^{2+}$ leak was provided in studies of mouse and rat ventricular myocytes that used confocal microscopy to visualize SiS. ${ }^{7}{ }^{14}$ Microtubulemediated mechanical activation of RyR, ${ }^{7}$ redox modifications of RyR by ROS, ${ }^{8}$ or on a slower time scale by nitric oxide, ${ }^{14,15}$ were identified as possible mechanisms of this response.

In rabbit atrial cells we did not find evidence for the involvement of NOX2, or ROS from other sources, in SiS. We confirmed the necessity of an intact microtubular network and found that the induction of $\mathrm{Ca}^{2+}$-sparks by stretch requires trans-sarcolemmal influx of $\mathrm{Na}^{+}$ and/or $\mathrm{Ca}^{2+}$, in contrast to what has been observed in rat ventricular myocytes. In rat ventricular myocytes, SiS was abolished neither by removal of extracellular $\mathrm{Na}^{+}$and $\mathrm{Ca}^{2+}$, nor by treatment with GsMTx $-4 .^{7}$ In rabbit atrial myocytes we observed an increase in baseline spark rate in the presence of GsMTx-4 to no less than those caused by stretch in control cells, and no further increase in spark rate upon subsequent axial stretch. This suggests that in atrial myocytes, the mechanism of SiS differs from ventricular cells in that it involves $\mathrm{Na}^{+}$and/or $\mathrm{Ca}^{2+}$ influx. Interestingly, inhibition of $\mathrm{SAC}_{\mathrm{NS}}$ had no effect on the propensity of stretch-induced synchronized $\mathrm{Ca}^{2+}$ waves. Thus, the nature of the trans-sarcolemmal $\mathrm{Na}^{+}$and/ or $\mathrm{Ca}^{2+}$ flux pathway that, presumably by raising sub-membrane $\mathrm{Ca}^{2+}$ levels activates RyR, triggering $\mathrm{Ca}^{2+}$-sparks and or membrane depolarization, remains obscure.

Whether RyR activation is direct (via $\mathrm{Ca}^{2+}$ influx) or indirect (via $\mathrm{Na}^{+}$influx affecting $\mathrm{NCX}$ balance) is not known either. ${ }^{16}$ 
Our data further demonstrate that interfering with microtubule integrity prevents $\mathrm{SiS}$ in rabbit atrial myocytes. Because SiS requires $\mathrm{Na}^{+}$and/or $\mathrm{Ca}^{2+}$ influx via the sarcolemma, a plausible explanation for the diminished SiS by the inhibitor of microtubule polymerization colchicine in our experiments may be the disruption of a mechanical link between cytoskeleton and sarcolemma, reducing the stretch-induced increase in activity of the hitherto unknown trans-sarcolemmal ion flux pathway. ${ }^{21}$ In rat ventricular myocytes, it has been proposed that microtubules mechanically interfere with the SR in a way that may increase RyR gating during stretch. ${ }^{7}$ Whether such microtubule-dependent mechanism of RyR mechanosensitivity, or alterations in the local topology of SAC, NCX, and RyR induced by microtubular disruption, is effective in atrial myocytes requires further investigation.

\section{Effects of SiS on diastolic and systolic $\mathrm{Ca}^{2+}$ function}

Diastolic $\mathrm{Ca}^{2+}$ is regulated by stretch via effects on $\mathrm{SR} \mathrm{Ca}^{2+}$-leak and re-uptake, and trans-sarcolemmal $\mathrm{Ca}^{2+}$ fluxes, as demonstrated in guinea-pig ventricular myocytes. ${ }^{31}$ The balance between these fluxes varies among species. Rabbit atrial myocytes gain $\mathrm{Ca}^{2+}$ during diastole, reflected by positive rest potentiation of SR $\mathrm{Ca}^{2+}$ load, ${ }^{32}$ which is consistent with the drop in baseline $\mathrm{Ca}^{2+}$-sparks we observed after switching to $\mathrm{Na}^{+} / \mathrm{Ca}^{2+}$-free medium (Fig 5). Stretch-dependent activation of an additional SAC-mediated $\mathrm{Ca}^{2+}$ influx, combined with SR $\mathrm{Ca}^{2+}$-leak due to $\mathrm{SiS}$, did not result in a detectable increase of SR load and systolic global $\mathrm{Ca}^{2+}$-transients during the first $20 \mathrm{~s}$ of acute stretch.

The absence of a fast stretch effect on bulk systolic $\mathrm{Ca}^{2+}$ does not exclude participation of $\mathrm{SAC}$ in the fine-tuning of CICR in local release domains. In ventricular myocytes, spatiotemporal analysis of local $\mathrm{Ca}^{2+}$-transients from line scans showed that during stretch L-type $\mathrm{Ca}^{2+}$ channels recruited more RyR release sites in TT-coupled regions (due to increased RyR sensitivity and higher local $\mathrm{Ca}^{2+}$ concentrations), ${ }^{8}$ from which the authors concluded that stretch increases CICR efficiency on a beat-to-beat basis without changing systolic $\mathrm{Ca}^{2+}$. In atrial myocytes, the spatiotemporal regulation of CICR is different from ventricular cells, mainly because of differences in structural organization of the tubule network. The atrial network, including that of rabbit cells, consists of sparse transverse, and more abundant axial TT membrane structures in the center of the cell. ${ }^{33}$ As a consequence, CICR is more heterogeneous with the fastest sites of $\mathrm{SR} \mathrm{Ca}^{2+}$-release at axial tubules. ${ }^{34}$ Protein localizations studies have demonstrated a longitudinal distribution of canonical transient receptor potential (TRPC) mechanosensitive channels consistent with an axial TT profile. ${ }^{27}$ It is plausible, therefore, that SAC activation recruits RyR not only at the surface sarcolemma, but also at axial TT junctions. Indeed, using line scans positioned in the cell center we observed acute $\mathrm{SiS}$, as well as propagating and synchronized $\mathrm{Ca}^{2+}$-waves deep inside rabbit atrial myocytes.

\section{Possible mechanisms of stretch-dependent triggered activity}

We observed a higher incidence of spontaneous $\mathrm{Ca}^{2+}$-waves during diastolic stretch, in agreement with stretch-induced afterdepolarizations and triggered activity seen in whole hearts. ${ }^{2,35}$ These included propagating and synchronized waves, distinguished by their spatio-temporal dynamics in confocal line scans (Fig 6A). Propagating waves depended on $\mathrm{Ca}^{2+}$-release from the $\mathrm{SR}$, as witnessed by an increase in spontaneous spark rate prior to wave onset (to $3.3 \pm$ 
$0.5 \mathrm{~s}^{-1} 100 \mu \mathrm{m}^{-1}$, Fig 6C). They were also not dependent on the availability of extracellular $\mathrm{Na}^{+}$and/or $\mathrm{Ca}^{2+}$. Acute stretch, causing SiS, might be expected to increase the frequency of spontaneously occurring propagating waves, as reported for very large stretches $(>20 \%)$ in rat ventricular myocytes. ${ }^{36}$ In our experiments, their incidence was similarly low in stretched and relaxed states, possibly because SiS in our experiments (to $1.8 \pm 0.2 \mathrm{~s}^{-1} 100 \mu \mathrm{m}^{-1}$, Fig $3 \mathrm{C}$ ) was not sufficient for wave initiation.

In contrast, synchronized $\mathrm{Ca}^{2+}$-wave occurrence was increased during stretch (of $13 \%$ ), in particular immediately after the onset of the stretch stimulus. They were not preceded by a higher $\mathrm{Ca}^{2+}$-spark frequency (Fig 6C), and trans-sarcolemmal influx of $\mathrm{Na}^{+}$and/or $\mathrm{Ca}^{2+}$ was required. The latter indicates that they likely arise from spontaneous membrane depolarization / action potential (AP) generation, with some similarity of the concept of 'escape beats' in cardiac tissue. Stretch-induced synchronized $\mathrm{Ca}^{2+}$-waves are therefore likely to be the consequence of membrane depolarization, presumably caused by diastolic inward currents upon $\mathrm{SAC}_{\mathrm{NS}}$ activation. ${ }^{37}$ Unexpectedly, SAC inhibition by GsMTx-4 was not sufficient to suppress this stretch-induced triggered activity (even though the peptide did act on the cells, as witnessed by the reduced $\mathrm{SiS}$ ). This points to the presence of stretch-induced inward currents that are not inhibited by GsMTx-4, perhaps including the fast cardiac $\mathrm{Na}^{+}$-channel $\mathrm{Na}_{\mathrm{v}} 1.5 .{ }^{38} \mathrm{Na}_{\mathrm{V}} 1.5$ mechanosensitivity is inhibited by ranolazine, ${ }^{39}$ an antianginal drug with $\mathrm{Na}^{+}$channel blocking properties that shows promise for the treatment of $\mathrm{AF}^{40}$

Taken together, a stretch-induced increase in depolarizing currents and lowering AP threshold, rather than spontaneous $\mathrm{Ca}^{2+}$-releases from the $\mathrm{SR}$, may underlie triggered activity upon severe stretch in atrial myocardium.

\section{Outlook}

Sustained atrial dilatation is one of the strongest clinical predictors of $\mathrm{AF}^{41}$ but even acute stretch can increase vulnerability to AF in patients. ${ }^{42}$ Atrial mapping studies in intact sheep hearts revealed that during stretch focal discharges emerged from regions between the pulmonary veins and posterior left atrium, ${ }^{43}$ which is suggestive of an afterdepolarization related mechanism. In atrial tissue, stretch induced early and delayed afterdepolarizations, which triggered premature AP that evolved into non-sustained runs of AF in rat, ${ }^{35}$ and rabbit. ${ }^{44}$ This is in keeping with our observation in single cells that stretch-induced triggered activity is primarily an electrically driven phenomenon.

The fact that we did not observe anti-arrhythmic effects of GsMTx-4 in single myocytes, while several studies in whole hearts reported that SAC blockers reduced AF vulnerability, ${ }^{11,44}$ could be due to tissue-related stretch phenomena. Heterogenous tissue structures, such as atria, create a substrate for electrical dispersion, which could be exacerbated by stretch, presumably due to heterogenous activation of SAC. ${ }^{45,46}$ It is possible, therefore, that GsMTx-4 exerts its anti-arrhythmic action by reducing local dispersion of excitation, as was demonstrated with the use of gadolinium, a non-specific SAC blocker, in rabbit ventricle. ${ }^{46}$ 


\section{Limitations}

$\mathrm{Ca}^{2+}$-sparks were recorded in line scan mode because the speed of the confocal microscope did not enable two-dimensional imaging at sufficient rates to resolve sparks. Because atrial cells have a highly heterogeneous distribution of coupled RyR release sites, it is possible that we have underestimated the extent of SiS, and any spatial heterogeneity in this response. Furthermore, we did not perform membrane potential measurements. Combining patchclamp with single cell stretch is technically challenging and associated with alterations in cell homeostasis. We therefore analyzed $\mathrm{Ca}^{2+}$ fluorescence as a readout of afterdepolarizations and triggered activity.

To inhibit $\mathrm{SAC}_{\mathrm{NS}}$, we used GsMTx-4, a peptide that exerts its specific inhibitory action on $\mathrm{SAC}_{\mathrm{NS}}$ by penetrating in the outer lipid monolayer as membrane tension increases. ${ }^{47}$ High concentrations of GsMTx-4 ( $>12 \mu \mathrm{mol} / \mathrm{L})$ potentiate mechanosensitive ion channel activity. ${ }^{48}$ At a concentration $(2 \mu \mathrm{mol} / \mathrm{L})$ that inhibits $\mathrm{SAC}_{\mathrm{NS}}{ }^{49}$ and $\mathrm{SiS}$ (Fig 5), we observed that GSMTX-4 caused a counter-intuitive stretch-independent increase in $\mathrm{Ca}^{2+}$-sparks by an unknown mechanism. The GsMTx-4 data should therefore be interpreted with caution.

\section{Conclusion}

In atrial myocytes, stretch produces an increase in diastolic $\mathrm{Ca}^{2+}$-spark rate via a mechanism that requires trans-sarcolemmal $\mathrm{Na}^{+}$and/or $\mathrm{Ca}^{2+}$ flux via stretch-activated ion channels, and an intact microtubule network. The kinetics of stretch-induced synchronized $\mathrm{Ca}^{2+}$ waves and their absence in $\mathrm{Na}^{+}$and $\mathrm{Ca}^{2+}$ conditions suggest membrane depolarization, rather than an increased SR Ca ${ }^{2+}$-leak as underlying cause. Synchronized $\mathrm{Ca}^{2+}$ waves appear to be independent from GsMTx-4-sensitive stretch-activated ion channels. Thus, molecular identification of the ion channels involved in triggered activity may introduce new atria-specific strategies for more effective treatment of stretch-induced AF vulnerability.

\section{ACKNOWLEDGEMENTS}

We thank Daniel Johnson from the Centre for Cardiovascular Sciences in Birmingham for helpful scientific discussions and Prof Ursula Ravens from the University Heart Centre Freiburg for critical reading of the manuscript.

\section{FUNDING}

This work was supported by an EU Innovative Training Network (RADical reduction of oxidative stress in cardiovascular disease, No. 316738), and by a grant from the Austrian Science Fund to G.A. (I2013-B27). 


\section{REFERENCES}

1. Tavi P, Han C, Weckstrom M. Mechanisms of stretch-induced changes in $[\mathrm{Ca} 2+]$ i in rat atrial myocytes: role of increased troponin C affinity and stretch-activated ion channels. Circ Res 1998;83:1165-1177.

2. Nazir SA, Lab MJ. Mechanoelectric feedback in the atrium of the isolated guinea-pig heart. Cardiovasc Res 1996;32:112-119.

3. Ravelli F, Allessie M. Effects of atrial dilatation on refractory period and vulnerability to atrial fibrillation in the isolated Langendorff-perfused rabbit heart. Circulation 1997;96:1686-1695.

4. Ravelli F, Mase M, del Greco M, Marini M, Disertori M. Acute atrial dilatation slows conduction and increases AF vulnerability in the human atrium. Journal of cardiovascular electrophysiology 2011;22:394401.

5. Ravelli F. Mechano-electric feedback and atrial fibrillation. Prog Biophys Mol Biol 2003;82:137-149.

6. de Tombe PP, Mateja RD, Tachampa K, Ait Mou Y, Farman GP, Irving TC. Myofilament length dependent activation. J Mol Cell Cardiol 2010;48:851-858.

7. Iribe G, Ward CW, Camelliti P, Bollensdorff C, Mason F, Burton RA, Garny A, Morphew MK, Hoenger A, Lederer WJ, Kohl P. Axial stretch of rat single ventricular cardiomyocytes causes an acute and transient increase in Ca2+ spark rate. Circ Res 2009;104:787-795.

8. Prosser BL, Ward CW, Lederer WJ. X-ROS signaling: rapid mechano-chemo transduction in heart. Science 2011;333:1440-1445.

9. Cannell MB. Pulling on the heart strings: a new mechanism within Starling's law of the heart? : Am Heart Assoc, 2009.

10. Kim D. Novel cation-selective mechanosensitive ion channel in the atrial cell membrane. Circ Res $1993 ; 72: 225-231$.

11. Bode F, Sachs F, Franz MR. Tarantula peptide inhibits atrial fibrillation. Nature 2001;409:35-36.

12. Verkerk AO, Geuzebroek GS, Veldkamp MW, Wilders R. Effects of acetylcholine and noradrenalin on action potentials of isolated rabbit sinoatrial and atrial myocytes. Front Physiol 2012;3:174.

13. Yagi N, Okuyama H, Toyota H, Araki J, Shimizu J, Iribe G, Nakamura K, Mohri S, Tsujioka K, Suga H, Kajiya F. Sarcomere-length dependence of lattice volume and radial mass transfer of myosin cross-bridges in rat papillary muscle. Pflugers Arch 2004;448:153-160.

14. Petroff MG, Kim SH, Pepe S, Dessy C, Marban E, Balligand JL, Sollott SJ. Endogenous nitric oxide mechanisms mediate the stretch dependence of $\mathrm{Ca} 2+$ release in cardiomyocytes. Nat Cell Biol 2001;3:867-873.

15. Jian Z, Han H, Zhang T, Puglisi J, Izu LT, Shaw JA, Onofiok E, Erickson JR, Chen YJ, Horvath B, Shimkunas R, Xiao W, Li Y, Pan T, Chan J, Banyasz T, Tardiff JC, Chiamvimonvat N, Bers DM, Lam $\mathrm{KS}$, Chen-Izu Y. Mechanochemotransduction during cardiomyocyte contraction is mediated by localized nitric oxide signaling. Science signaling 2014;7:ra27.

16. Kirber MT, Guerrero-Hernandez A, Bowman DS, Fogarty KE, Tuft RA, Singer JJ, Fay FS. Multiple pathways responsible for the stretch-induced increase in $\mathrm{Ca} 2+$ concentration in toad stomach smooth muscle cells. J Physiol 2000;524 Pt 1:3-17.

17. Zou H, Lifshitz LM, Tuft RA, Fogarty KE, Singer JJ. Visualization of Ca2+ entry through single stretch-activated cation channels. Proc Natl Acad Sci U S A 2002;99:6404-6409.

18. Cannell MB, Kong CH. Local control in cardiac E-C coupling. J Mol Cell Cardiol 2012;52:298-303.

19. Sigurdson W, Ruknudin A, Sachs F. Calcium imaging of mechanically induced fluxes in tissue-cultured chick heart: role of stretch-activated ion channels. Am J Physiol 1992;262:H1110-H1115.

20. Lederer WJ, Niggli E, Hadley RW. Sodium-calcium exchange in excitable cells: fuzzy space. Science 1990;248:283-283.

21. Isenberg G, Kazanski V, Kondratev D, Gallitelli MF, Kiseleva I, Kamkin A. Differential effects of stretch and compression on membrane currents and $[\mathrm{Na}+] \mathrm{c}$ in ventricular myocytes. ProgBiophysMolBiol 2003;82:43-56.

22. Peyronnet R, Nerbonne JM, Kohl P. Cardiac Mechano-Gated Ion Channels and Arrhythmias. Circ Res 2016;118:311-329.

23. Bae C, Sachs F, Gottlieb PA. The mechanosensitive ion channel Piezol is inhibited by the peptide GsMTx4. Biochemistry 2011;50:6295-6300.

24. Louis M, Zanou N, Van Schoor M, Gailly P. TRPC1 regulates skeletal myoblast migration and differentiation. J Cell Sci 2008;121:3951-3959.

25. Spassova MA, Hewavitharana T, Xu W, Soboloff J, Gill DL. A common mechanism underlies stretch activation and receptor activation of TRPC6 channels. Proc Natl Acad Sci U S A 2006;103:16586-16591.

26. Gomis A, Soriano S, Belmonte C, Viana F. Hypoosmotic- and pressure-induced membrane stretch activate TRPC5 channels. J Physiol 2008;586:5633-5649.

27. Jiang Y, Huang H, Liu P, Wei H, Zhao H, Feng Y, Wang W, Niu W. Expression and localization of TRPC proteins in rat ventricular myocytes at various developmental stages. Cell Tissue Res 2014;355:201-212. 
28. Makarewich CA, Zhang H, Davis J, Correll RN, Trappanese DM, Hoffman NE, Troupes CD, Berretta RM, Kubo H, Madesh M, Chen X, Gao E, Molkentin JD, Houser SR. Transient receptor potential channels contribute to pathological structural and functional remodeling after myocardial infarction. Circ Res 2014; 115:567-580.

29. Camacho Londono JE, Tian Q, Hammer K, Schroder L, Camacho Londono J, Reil JC, He T, Oberhofer M, Mannebach S, Mathar I, Philipp SE, Tabellion W, Schweda F, Dietrich A, Kaestner L, Laufs U, Birnbaumer L, Flockerzi V, Freichel M, Lipp P. A background Ca2+ entry pathway mediated by TRPC1/ TRPC4 is critical for development of pathological cardiac remodelling. Eur Heart J 2015;36:2257-2266.

30. Doleschal B, Primessnig U, Wolkart G, Wolf S, Schernthaner M, Lichtenegger M, Glasnov TN, Kappe CO, Mayer B, Antoons G, Heinzel F, Poteser M, Groschner K. TRPC3 contributes to regulation of cardiac contractility and arrhythmogenesis by dynamic interaction with NCX1. Cardiovasc Res 2015;106:163173.

31. Iribe G, Kohl P. Axial stretch enhances sarcoplasmic reticulum Ca2+ leak and cellular Ca2+ reuptake in guinea pig ventricular myocytes: experiments and models. Prog Biophys Mol Biol 2008;97:298-311.

32. Bers DM. SR Ca loading in cardiac muscle preparations based on rapid cooling contractures. Am J Physiol 1989;256:C109-C120.

33. Brandenburg S, Pawlowitz J, Fakuade FE, Kownatzki-Danger D, Kohl T, Mitronova GY, Scardigli M, Neef J, Schmidt C, Wiedmann F, Pavone FS, Sacconi L, Kutschka I, Sossalla S, Moser T, Voigt N, Lehnart SE. Axial Tubule Junctions Activate Atrial $\mathrm{Ca}(2+)$ Release Across Species. Front Physiol 2018;9:1227.

34. Brandenburg S, Kohl T, Williams GS, Gusev K, Wagner E, Rog-Zielinska EA, Hebisch E, Dura M, Didie M, Gotthardt M, Nikolaev VO, Hasenfuss G, Kohl P, Ward CW, Lederer WJ, Lehnart SE. Axial tubule junctions control rapid calcium signaling in atria. J Clin Invest 2016;126:3999-4015.

35. Kamkin A, Kiseleva I, Wagner KD, Leiterer KP, Theres H, Scholz H, Gunther J, Lab MJ. Mechano-electric feedback in right atrium after left ventricular infarction in rats. J Mol Cell Cardiol 2000;32:465-477.

36. Iribe G, Kohl P. Non-sarcolemmal stretch-activated channels. In: Kohl P, Sachs F, Franz MR, eds. Cardiac mechano-electric coupling and arrhythmias, second edition ed: Oxford University Press, 2011:35-41.

37. Zhang YH, Youm JB, Sung HK, Lee SH, Ryu SY, Ho WK, Earm YE. Stretch-activated and background non-selective cation channels in rat atrial myocytes. J Physiol 2000;523 Pt 3:607-619.

38. Beyder A, Rae JL, Bernard C, Strege PR, Sachs F, Farrugia G. Mechanosensitivity of Nav1.5, a voltage-sensitive sodium channel. J Physiol 2010;588:4969-4985.

39. Beyder A, Strege PR, Reyes S, Bernard CE, Terzic A, Makielski J, Ackerman MJ, Farrugia G. Ranolazine decreases mechanosensitivity of the voltage-gated sodium ion channel $\mathrm{Na}(\mathrm{v}) 1.5$ : a novel mechanism of drug action. Circulation 2012;125:2698-2706.

40. Guerra F, Romandini A, Barbarossa A, Belardinelli L, Capucci A. Ranolazine for rhythm control in atrial fibrillation: A systematic review and meta-analysis. Int J Cardiol 2017;227:284-291.

41. Psaty BM, Manolio TA, Kuller LH, Kronmal RA, Cushman M, Fried LP, White R, Furberg CD, Rautaharju PM. Incidence of and risk factors for atrial fibrillation in older adults. Circulation 1997;96:2455-2461.

42. Thanigaimani S, McLennan E, Linz D, Mahajan R, Agbaedeng TA, Lee G, Kalman JM, Sanders P, Lau DH. Progression and reversibility of stretch induced atrial remodeling: Characterization and clinical implications. Prog Biophys Mol Biol 2017;130:376-386.

43. Yamazaki M, Vaquero LM, Hou L, Campbell K, Zlochiver S, Klos M, Mironov S, Berenfeld O, Honjo H, Kodama I, Jalife J, Kalifa J. Mechanisms of stretch-induced atrial fibrillation in the presence and the absence of adrenocholinergic stimulation: interplay between rotors and focal discharges. Heart Rhythm 2009;6:1009-1017.

44. Bode F, Katchman A, Woosley RL, Franz MR. Gadolinium decreases stretch-induced vulnerability to atrial fibrillation. Circulation 2000;101:2200-2205.

45. Kuijpers NH, Potse M, van Dam PM, ten Eikelder HM, Verheule S, Prinzen FW, Schotten U. Mechanoelectrical coupling enhances initiation and affects perpetuation of atrial fibrillation during acute atrial dilation. Heart Rhythm 2011;8:429-436.

46. Seo K, Inagaki M, Nishimura S, Hidaka I, Sugimachi M, Hisada T, Sugiura S. Structural heterogeneity in the ventricular wall plays a significant role in the initiation of stretch-induced arrhythmias in perfused rabbit right ventricular tissues and whole heart preparations. Circ Res 2010;106:176-184.

47. Gnanasambandam R, Ghatak C, Yasmann A, Nishizawa K, Sachs F, Ladokhin AS, Sukharev SI, Suchyna TM. GsMTx4: Mechanism of Inhibiting Mechanosensitive Ion Channels. Biophys J 2017;112:31-45.

48. Isenberg G. Isolated ventricular myocytes: contractions dependent on currents through sodium channels modified by lanthanum. Pflügers Arch 1985;403:suppl.

49. Suchyna TM, Johnson JH, Hamer K, Leykam JF, Gage DA, Clemo HF, Baumgarten CM, Sachs F. Identification of a peptide toxin from Grammostola spatulata spider venom that blocks cation-selective stretch-activated channels. J Gen Physiol 2000;115:583-598. 


\section{SUPPLEMENTS - MATERIAL AND METHODS}

\section{Cell Preparation}

All experimental protocols were approved by the Dutch animal welfare body (DEC2014-112) and they conformed with the directive of the European Parliament and of the Council on the protection of animals used for scientific purposes 2010/63/EU. New Zealand White Rabbits (2-3 kg) of either sex were purchased from Envigo, UK. Rabbits were anesthetised with (50 $\left.\mathrm{mg} \mathrm{kg}{ }^{-1}\right) / x y l a z i n e ~\left(5 \mathrm{mg} \mathrm{kg}^{-1}\right)$ and euthanised by a concussive blow to the head. The heart was quickly excised and submerged in cold isolation buffer containing (in mmol/L): 133 $\mathrm{NaCl}, 5 \mathrm{KCl}, 2 \mathrm{MgCl}_{2}, 1.2 \mathrm{KH}_{2} \mathrm{PO}_{4}, 6$ Taurine, 6 Creatine, 10 Glucose, 10 HEPES at pH 7.4 with $\mathrm{NaOH}$. Subsequently, the heart was mounted on a Langendorff setup (gravity-fed: 90 $\mathrm{cm} \mathrm{H}_{2} 0$ ) and perfused via the coronary vasculature for $8 \mathrm{~min}$ at $37^{\circ} \mathrm{C}$ to flush out remaining blood. Collagenase B $\left(0.4 \mathrm{mg} \mathrm{mL}^{-1}\right)$, Collagenase $\mathrm{P}\left(0.15 \mathrm{mg} \mathrm{mL}^{-1}\right)$, Trypsin Inhibitor $(0.15$ $\mathrm{mg} \mathrm{mL}-1)$, Hyaluronidase $\left(0.25 \mathrm{mg} \mathrm{mL}^{-1}\right)$ and $15 \mu \mathrm{mol} / \mathrm{L} \mathrm{CaCl}_{2}$ were added to the isolation buffer and recirculated for $15 \mathrm{~min}$ until the atria softened. Thereafter, the left atrium was removed, transferred to a beaker with warm isolation buffer (supplemented with $0.5 \mathrm{mg} \mathrm{mL}^{-1}$ fatty-acid free albumin and $15 \mu \mathrm{mol} / \mathrm{L} \mathrm{CaCl}_{2}$ ). The tissue was cut into small pieces and single cells were dissociated by gentle shaking. After filtering the cell suspension through a 200 $\mu \mathrm{m}$ nylon mesh, $\mathrm{Ca}^{2+}$ was stepwise reintroduced up to a final concentration of $1.8 \mathrm{mmol} / \mathrm{L}$. Isolated atrial myocytes were stored at room temperature for up to $8 \mathrm{~h}$.

\section{System set-up}

To apply uniaxial stretch to intact atrial myocytes, two 3D micromanipulators were mounted on a TE-2000-U inverted microscope (Nikon, Amsterdam, Netherlands). On one micromanipulator, a piezo motor (Mad City Labs, Madison, USA) was attached, on the other a static holder. On both, the piezo motor and the holder, 35 um diameter glass needles with a length $<1.5 \mathrm{~mm}$ were fixed. The glass needles were coated with an aluminium silicate suspension (IonOptix pre-coat, IonOptix, Amsterdam, Netherlands). After the pre-coat was air dried, the needles were immersed in a small drop of MyoTak (IonOptix), a biological adhesive, until a uniform layer formed and swiftly submerged in experimental buffer to avoid polymerization of the glue.

\section{Uni-axial stretch}

Myocytes were transferred to a cell chamber with a rotation inlay, which allows one to align cells perpendicular to the glass needles (Figure 1A). To prevent cells from adhering to the glass bottom of the chamber, the coverslip was coated with a thin layer of Poly-HEMA. Only quiescent myocytes with clear and homogenous cross-striation and sharp well-defined boarders were used for the experiments. Coated glass rods were lowered onto myocytes near opposite cell ends and gently pressed down to optimize the contact area between the glue and the cell . After the myocyte was firmly attached to the system, it was lifted completely from the chamber bottom without stretching the myocyte prior to the start of the experiment. Cells were perfused with Normal Tyrode (NT) solution (containing in mmol/L: $135 \mathrm{NaCl}$, 
$5 \mathrm{KCl}, 1 \mathrm{MgCl}_{2}, 10$ Glucose, 10 HEPES at pH 7.4 with $\mathrm{NaOH}$ ). For experiments shown in Figures 1-2, myocytes were perfused with $\mathrm{NT}$ containing $1.8 \mathrm{mM} \mathrm{CaCl}_{2}$, experiments depicted in Figure 3-7 were carried in NT containing $3.6 \mathrm{mM} \mathrm{CaCl}_{2}$. To achieve the desired amount of axial-stretch, the piezo-motor was controlled with an analog output of a Digidata 1440 AD converter (Molecular Devices, Berkshire, UK) and the resulting displacement of piezo-motor was digitized and monitored in pClamp 10.2 (Molecular Devices). Uniaxial stretch was applied at a speed of $0.5 \mu \mathrm{m} / \mathrm{ms}$. The necessary voltage to achieve the desired piezo displacement was calculated based on the distance between the mounting points of the glass micro-rods measured on a 2D transmitted light image of the attached cell. Due to the thin layer of MyoTak, elongation of attached cells does not follow exactly 1:1 the piezo actuator displacement. In a subset of cells, sarcomere length (SL) at different levels of stretch was assessed within a ROI (in Figure 1A marked by a yellow box), based on IonOptix's SarcLen software (http://www.ionoptix.com/wp-content/uploads/2014/07/SarcLen-Algorithm.pdf) in response to glass rod displacements.

For force measurements, the static holder was replaced with an optical force transducer (Optiforce V1, IonOptix). The data were collected via an analog input of the Digidata 1440 at $1 \mathrm{kHz}$. Force traces were analysed using Clampfit 10 (Molecular Devices). Time to peak (TTP) was analysed in two ways. Firstly, TTP was defined as the time from start of contraction to peak force. To normalize forces to the Myocyte's cross sectional area, a confocal Z-stack $(0.5 \mu \mathrm{m}$ between planes $)$ was recorded after attaching the cell to the glass rods. The $\mathrm{Ca}^{2+}$ signal positive pixels in the $\mathrm{XZ}$ - plane equidistant from both mounting points were used to calculate the cross sectional area. Secondly, due to the difficulty to reliably identify the peak of a signal in noisy biological data, we measured the time from the beginning of the contraction to the $90^{\text {th }}$ percentile of the measured peak value. Results were comparable between the two ways of assessment.

\section{Confocal imaging and $\mathrm{Ca}^{2+}$ measurement}

Atrial myocytes were loaded with Fluo4-AM ( $5 \mu \mathrm{mol} / \mathrm{L}$, Thermo Fisher) dissolved in DMSO containing (w/v) 20\% - Pluronic F127 for $20 \mathrm{~min}$, followed by $20 \mathrm{~min}$ for the de-esterification of the dye. Cells were scanned at $1.68 \mathrm{~ms} /$ line with a $488 \mathrm{~nm}$ argon ion laser, attached to a confocal line-scan unit (Nikon c1) with a pixel size between $100-200 \mathrm{~nm}$, using a 40x NA 1.3 Oil immersion objective. Cells were electrically stimulated at $2 \mathrm{~Hz}$ (Myopacer, IonOptix) for $60 \mathrm{~s}$ prior to application of the stretch. Steady-state $\mathrm{Ca}^{2+}$ transient analysis was carried out manually on spatially averaged transients obtained by integrating the line-scan from the final three to five $\mathrm{Ca}^{2+}$ transients prior to baseline $\mathrm{Ca}^{2+}$ spark measurements. $\mathrm{Ca}^{2+}$ transient amplitude was calculated by normalizing the peak of the $\mathrm{Ca}^{2+}$ dependent signal to the average signal intensity during diastole. $\mathrm{TF}_{50}$ and TTP were defined as the time to reach the half-maximum and maximum fluorescence of the $\mathrm{Ca}^{2+}$ transient, respectively. The decay phase of the transient was fitted with a mono-exponential decay function to assess $\mathrm{Ca}^{2+}$ reuptake kinetics. $\mathrm{Ca}^{2+}$ spark measurements were performed in NT containing 3.6 $\mathrm{mmol} / \mathrm{L} \mathrm{Ca}^{2+}$, unless stated otherwise. Absolute values of baseline $\mathrm{Ca}^{2+}$ spark rate could vary between isolations, which did not affect the relative response to stretch. To compare different interventions, we used control measurements from the same isolation. A pressurised perfusion system fitted with solenoid valves controlled by an 8-channel valve controller (Warner Instrument) was used to deliver solutions locally via a multi-channel inline heater 
with a single outlet (Cell MicroControls, Norfolk, USA) at $37^{\circ} \mathrm{C}$. The perfusion system allowed for a reliable switch between experimental solutions in $<300 \mathrm{~ms}$. For measurements carried out in $\mathrm{Na}^{+} / \mathrm{Ca}^{2+}$ free conditions, the solution was switched from NT when $\mathrm{Ca}^{2+}$ levels reached diastolic values after the last stimulated $\mathrm{Ca}^{2+}$ transient, and perfusion with the $\mathrm{Na}^{+} / \mathrm{Ca}^{2+}$ free solution continued for the remainder of line-scan measurements. $\mathrm{Na}^{+} / \mathrm{Ca}^{2+}$ free solution contained in mmol/L: $135 \mathrm{LiCl}, 5 \mathrm{KCl}, 1 \mathrm{MgCl}_{2}, 10$ Glucose, 10 HEPES at $\mathrm{pH} 7.4$ with $\mathrm{LiOH}$. SR $\mathrm{Ca}^{2+}$ load was determined by rapid switching to NT supplemented with $10 \mathrm{mmol} / \mathrm{L}$ caffeine. $\mathrm{Ca}^{2+}$ sparks were automatically analyzed using the Image J Plugin Spark Master (https://sites.google.com/site/sparkmasterhome/). To minimize the detection of false positive sparks the cut-off value within Spark Master, Criterion, was set to 4.2.

\section{Material suppliers and concentrations used}

Collagenase B, Collagenase P, Trypsin inhibitor was purchased from Roche (Basel, Switzerland). Hyaluronidase was purchased from Worthington (Lakewood, USA). Gp91dstat and the scrambled control peptide (Anaspec, Liege, Belgium) were used at $3 \mu \mathrm{mol} / \mathrm{L}$ with pre-incubation for 2 h. N-acetylcysteine (NAC, Sigma Aldrich, Darmstadt, Germany), $10 \mathrm{mmol} / \mathrm{L}$, was added to the superfusate and wash-on started $5 \mathrm{~min}$ prior to the experiment ${ }^{1}$. Cells were pre-treated with $10 \mu \mathrm{mol} / \mathrm{L}$ colchicine (Sigma Aldrich/Merck, Darmstadt Germany) for 2 hours ${ }^{2}$. GsMTx-4 was purchased from Alomone (Jerusalem, Israel) and used at $2 \mu \mathrm{mol} / \mathrm{L}$ with $10 \mathrm{~min}$ pre-incubation and applied via direct perfusion during the experiment ${ }^{2}$ All other chemicals were purchased from Sigma Aldrich/Merck (Darmstadt, Germany).

\section{Data presentation and statistical analysis}

Data are shown as Tukey boxplots (the upper whisker of the box plot is the largest dataset number smaller than 1.5 interquartile range above the third quartile, the lower whisker of the box plot is the largest dataset number larger than 1.5 interquartile range below the second quartile) or mean \pm standard error to the mean. Statistical comparisons were made using paired Wilcoxon matched-pairs signed rank test, Mann-Whitney-U test, Kruskal-Wallis or Friedman test for multiple comparison, where appropriate (indicated in the figure legend). Statistical analysis was performed using Prism 8 software (GraphPad Software Inc.) and a p-value $<0.05$ was considered indicative of a statistically significant difference.

\section{References}

1. Prosser BL, Ward CW, Lederer WJ. X-ROS signaling: rapid mechano-chemo transduction in heart. Science 2011;333:1440-1445.

2. Iribe G, Ward CW, Camelliti P, Bollensdorff C, Mason F, Burton RA, Garny A, Morphew MK, Hoenger A, Lederer WJ, Kohl P. Axial stretch of rat single ventricular cardiomyocytes causes an acute and transient increase in Ca2+ spark rate. Circ Res 2009;104:787-795. 
Control

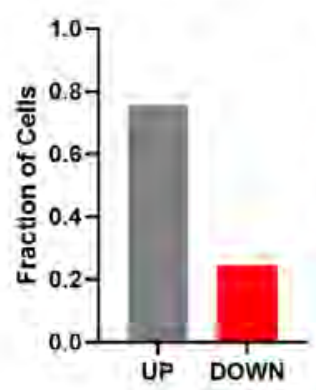

$\mathrm{Na}^{\prime} / \mathrm{Ca}^{2+}-$ free

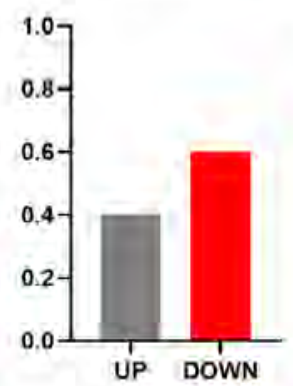

GsMTx-4

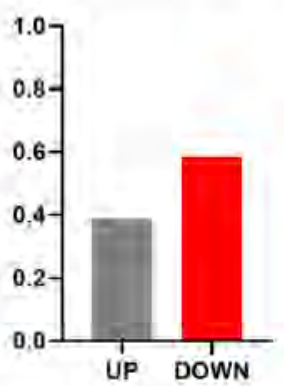

Supplemental Figure 1 Fraction of atrial myocytes that exhibited higher (UP) or lower (DOWN) $\mathrm{Ca}^{2+}$ spark rates after severe stretch. Left: In control conditions $76 \%$ of interrogated cells reacted to stretch with an increase in $\mathrm{Ca}^{2+}$ spark rate. Middle: In contrast, the fraction of myocytes showing lower spark rates after stretch is in $\mathrm{Na}^{+} / \mathrm{Ca}^{2+}$ free solution $(60 \%)$, and among cells treated with GsMTx-4 (58\%, right). 


\section{Chapter IV}

\section{Adrenergic control of RyR $\mathrm{Ca}^{2+}-$ release microdomains in atrial fibrillation}

Patrick Schönleitner ${ }^{1}$, Anne Cuypers ${ }^{1}$, Roy Snijckers ${ }^{1}$, Owen Gibson ${ }^{1}$, Marion Kuiper ${ }^{1}$, Gudrun Antoons ${ }^{1}$, Harry Crijns ${ }^{2}$, Ulrich Schotten ${ }^{1}$

1 Dept of Physiology, Cardiovascular Research Institute Maastricht, Maastricht University, The Netherlands 



\section{ABSTRACT}

Aim: Short-term high atrial activation rates alone induce $\mathrm{Ca}^{2+}$ signalling silencing in rabbit atria, characterised by the loss of centripetal $\mathrm{Ca}^{2+}$ propagation and reduced propensity of the atria for spontaneous $\mathrm{Ca}^{2+}$ release and ectopic activity. Activation of the sympathetic nervous system correlates with the occurrence of atrial arrhythmias. In this study, we investigate the effect of Isoprenaline (ISO), an adrenoreceptor agonist, on subcellular $\mathrm{Ca}^{2+}$ release to assess possible proarrhythmic alterations in $\mathrm{Ca}^{2+}$ handling against the background of antiarrhythmic adaptations after in-vivo rapid atrial pacing.

Methods and Results: After rapid pacing rabbit atrial myocytes were treated with $300 \mu \mathrm{M}$ ISO. Line scans along the short axis of the myocytes revealed normalised CaT amplitude in rapidly paced myocytes after ISO treatment. Spatiotemporal analysis of the CaTs uncovered faster $\mathrm{Ca}^{2+}$ release in central RYRs of RAP myocytes. Immunohistochemical staining showed low levels of RYRs phosphorylation at Ser-2808 after pacing and a pronounced rephosphorylation after ISO treatment. Although RYR phosphorylation and $\mathrm{SR} \mathrm{Ca}^{2+}$ content were higher after adrenergic stimulation, spark frequency was not significantly altered.

Conclusion: After five days of rapid atrial pacing beta-adrenergic stimulation normalises $\mathrm{CaT}$ amplitude mainly by increasing central $\mathrm{CaT}$ amplitude. While phosphorylation of RYRs at Ser-2808 might support the $\mathrm{Ca}^{2+}$ induced $\mathrm{Ca}^{2+}$ release in central regions of the myocyte, it did not lead to more frequent $\mathrm{Ca}^{2+}$ release events in central RYR clusters supporting the notion that RYR phosphorylation on Ser-2808 is not sufficient to produce $\mathrm{Ca}^{2+}$ instabilities in the atria. 


\section{INTRODUCTION}

Right after the onset of atrial fibrillation (AF), the high atrial activation rate increases intracellular $\mathrm{Ca}^{2+}$ load. ${ }^{1,2} \mathrm{In}$ an animal model of tachypacing, we previously described a mechanism, that prevents the uncontrolled overload with $\mathrm{Ca}^{2+}$ during sustained high activation rates. This mechanism, termed $\mathrm{Ca}^{2+}$ signalling silencing, develops within five days after the onset of rapid pacing. It is characterised by reduced $\mathrm{Ca}^{2+}$ influx via $\mathrm{I}_{\mathrm{CaL}}$, an increased $\mathrm{Ca}^{2+}$ efflux via $\mathrm{I}_{\mathrm{NCX}}$ and a higher $\mathrm{Ca}^{2+}$ buffer capacity. ${ }^{3}$ Without significant alterations in $\mathrm{SR} \mathrm{Ca}^{2+}$ content or $\mathrm{Ca}^{2+}$ wave frequency, $\mathrm{Ca}^{2+}$ signalling silencing can counteract $\mathrm{Ca}^{2+}$ signalling instabilities reported in $\mathrm{AF}^{4}$

Until recently atrial myocytes were believed to be nearly devoid of a functional transverse-axial tubule (TAT) network, a crucial component in effective $\mathrm{Ca}^{2+}$ induced $\mathrm{Ca}^{2+}$ release. Without a TAT network, $\mathrm{Ca}^{2+}$ entry via L-type $\mathrm{Ca}^{2+}$ channels (LTCC) was thought to trigger ryanodine receptor (RYR) clusters close to the sarcolemma followed by a slow propagation of $\mathrm{Ca}^{2+}$ release towards the centre of the cell. ${ }^{3,5}$ However, recent reports of a specialised TAT network in atrial myocytes challenge this view. ${ }^{6-8}$ Compared to the ventricle the TAT network in atrial myocytes is sparse and contains a significant fraction of axial tubules (AT), i.e. tubules orientated along the long axis of the myocytes. Dense clusters of RYRs colocalise along ATs to form "super-hubs" of fast $\mathrm{Ca}^{2+}$ release. RYRs that comprise super hubs are highly phosphorylated by PKA, a downstream target of beta-adrenoreceptor signalling, and therefore could be the primary location where pro-arrhythmogenic $\mathrm{Ca}^{2+}$ sparks - typically occurring during sympathetic activation - arise from. ${ }^{6}$

Although several reports link beta-adrenoreceptor signalling to the development of arrhythmias in vulnerable atria ${ }^{9-11}$, atrial trabeculae from AF patients show less frequent arrhythmogenic events in response to adrenergic stimulation compared to trabeculae from sinus rhythm patients. ${ }^{12}$

In the present study, we attempt to reconcile the proarrhythmic potential of beta-adrenergic stimulation against the background of antiarrhythmic adaptations of $\mathrm{Ca}^{2+}$ signalling silencing after a period of high electrical activation rates. We study subcellular $\mathrm{Ca}^{2+}$ release in response to isoprenaline, a beta-adrenoreceptor agonist, in a well-characterised rabbit model of atrial tachypacing and link the functional information to ultrastructural alterations.

\section{MATERIALS AND METHODS}

\section{Rapid Atrial pacing Model}

All experimental protocols were approved by the Dutch animal welfare body (DEC2014112) and were conform with the directive 2010/63/EU. Male and female New Zealand White rabbits $(2.5-3.0 \mathrm{~kg})$ were anaesthetised with ketamine $(50 \mathrm{mg} / \mathrm{kg}) / \mathrm{xylazine}(5 \mathrm{mg} / \mathrm{kg})$ via intramuscular injection. Animals were endotracheally intubated and ventilated with a rate of $\sim 30 /$ minute. Anaesthesia was maintained with $1.5 \%$ Isoflurane. Under x-ray guidance, a pacemaker lead was implanted via the left jugular vein into the right atrium. The lead location was considered suitable when the pacing threshold was lower than $0.5 \mathrm{~V}$. Only animals with 
an $\mathrm{AV}$-conduction pattern of 3:1, resulting in a ventricular rate of $\sim 200 / \mathrm{min}$ - a physiological rate for rabbits - were implanted with a Medtronic Itrel pacemaker in a subcutaneous pocket behind the left shoulder blade. After one week of recovery, the right atrium was rapidly stimulated using the implanted device at a frequency of $10 \mathrm{~Hz}$ for five days at $4 \mathrm{x}$ threshold. In Sham operated animals only the pacemaker lead was implanted.

\section{Cell preparation}

Animals were anesthetized with ketamine $(50 \mathrm{mg} / \mathrm{kg}) / \mathrm{xylazine}(5 \mathrm{mg} / \mathrm{kg})$ i.m. The implanted pacemaker lead was extracted through a small incision over the left jugular vein. Thereafter, the animal was euthanised by a concussive blow to the head. The heart was swiftly excised and transferred to a Petri dish filled with ice-cold isolation buffer containing (in $\mathrm{mM}$ ): $\mathrm{NaCl}$ 133, $\mathrm{KCl} 5, \mathrm{MgCl} 2, \mathrm{KH}_{2} \mathrm{PO}_{4}$ 1.2, Taurine 6, Creatine 6, Glucose 10, Hepes 10, adjusted to ph 7.2 with $\mathrm{NaOH}$. Major cardiac arteries supplying the ventricle were ligated to ensure proper enzyme flow through the atria during enzymatic digestion. Hearts were mounted on a gravity-driven Langendorff system with a water column height of $90 \mathrm{~cm}$. The heart was perfused retrogradely via the aorta with nominal $\mathrm{Ca}^{2+}$ free isolation buffer for $8 \mathrm{~min}$ at $37^{\circ} \mathrm{C}$ to wash out remaining blood. Collagenase $\mathrm{B}\left(0.4 \mathrm{mg} \mathrm{ml}^{-1}\right)$, Collagenase $\mathrm{P}\left(0.15 \mathrm{mg} \mathrm{ml}^{-1}\right)$, Trypsin Inhibitor $\left(0.15 \mathrm{mg} \mathrm{ml}^{-1}\right)$, Hyaluronidase $\left(0.25 \mathrm{mg} \mathrm{ml}^{-1}\right)$ and $15 \mu \mathrm{mol} / \mathrm{L} \mathrm{CaCl}_{2}$ were then added to the isolation buffer and recirculated for $15 \mathrm{~min}$. For RAP animals the enzyme solution was recirculated for $18 \mathrm{~min}$, and the concentration of Trypsin inhibitor was reduced to $0.12 \mathrm{mg}^{*} \mathrm{ml}^{-1}$. The left atria were removed, transferred to a beaker containing warm isolation buffer supplemented with $0.5 \mathrm{mg} \mathrm{ml}^{-1}$ fatty-acid free albumin and $15 \mu \mathrm{mol} / \mathrm{L} \mathrm{CaCl}$, and cut into small pieces. Single cells were dissociated by gentle shaking and filtering the suspension through a $200 \mu \mathrm{m}$ nylon mesh. External $\mathrm{Ca}^{2+}$ was stepwise reintroduced to a final concentration of $1.8 \mathrm{mM}$. Isolated myocytes were stored at room temperature for up to $8 \mathrm{~h}$.

\section{Immunocytochemistry}

Nr. 1.5 Coverslips (Ø $13 \mathrm{~mm}$, Thermo Scientific, Belgium) were coated with Laminin (40 $\mu \mathrm{l} / \mathrm{ml}$ in PBS) overnight at $4{ }^{\circ} \mathrm{C}$. The coated coverslips were placed in $35 \mathrm{~mm}$ Petri dishes to which left atrial cell suspension was added. After the myocytes attached to the Laminin coated coverslips, $5 \mu \mathrm{M}$ Alexa Fluor 633-conjugated Wheat Germ Agglutinin (WGA) to stain the cell membrane and TAT, was added for 10 minutes. Thereafter, the coverslips were placed in a perfusion bath and electrically stimulated for 5 minutes at $1 \mathrm{~Hz}$. Cells were superfused with either Normal Tyrode (NT) or NT supplemented with $300 \mathrm{~nm}$ Isoproterenol (ISO) at $37^{\circ} \mathrm{C}$. After stimulation the coverslips were transferred to a Petri dish filled with $2 \%$ paraformaldehyde (PFA) for $10 \mathrm{~min}$. After fixation, atrial myocytes were permeabilised with $0.5 \%$ Trition X-100 in phosphate buffered saline (PBS) and subsequently washed once with PBS. To reduce unspecific antibody binding 10\% normal goat serum in PBS was added for 1 hour. Afterwards, cells were washed with PBS and incubated with the primary antibody against RyR (1:50) overnight at $4{ }^{\circ} \mathrm{C}$. Cells were washed $3 \mathrm{x}$ with PBS and incubated with a secondary antibody conjugated to Alexa Fluor 488 (1:100) for 2 hours at room temperature. Antibody against RYR-p2808 was labelled with a 532 Alexa Fluo Zenon labelling kit according to the provided manual. Cells were incubated for 2 hours at room temperature with 
the labelled antibody. To wash out all unbound ABs cells were washed with PBS $3 \mathrm{x}$ for $10 \mathrm{~min}$ before fixating once more with 4\% PFA for $10 \mathrm{~min}$ to avoid the dissociation of the Zenon labelling kit complex. Coverslips were mounted on microscopy slides with a Mowiol/ DABCO based mounting medium and left to cure overnight at $4{ }^{\circ} \mathrm{C}$ in the dark.

Confocal images of the stained myocytes were taken with an inverted LEICA TCS SPE equipped with a $63 \mathrm{x}$ oil immersion microscope. Fluorophores were excited in sequence at $488 \mathrm{~nm}, 532 \mathrm{~nm}$, and $633 \mathrm{~nm}$ and emission detected at 500-532 nm, 544-633 nm, and 645$745 \mathrm{~nm}$, respectively. Pixel size was set at $70 \mathrm{~nm}$ in the XY plane and the pinhole set at 1 Airy unite. All images were recorded from a central plain of the cell through the nucleus.

\section{Confocal Calcium and T-Tubule imaging}

Isolated atrial myocytes were loaded with 5uM of Fluo4-AM in 20\% Pluronic acid in NT supplemented with $1 \mathrm{mM}$ of Probenecid for 15-20 min. Cells were washed with NT for 10 min to allow the de-esterification of the calcium dye. The cell suspension was transferred to a cell chamber coated in Laminin for $15 \mathrm{~min}$ to facilitate the attachment of the myocytes to the glass bottom. The dish containing the cardiac myocytes was transferred to the microscopy stage, and the solution was exchanged with NT containing the membrane dye di-4-ANEPPS at a concentration of $5 \mu \mathrm{M}$ for additional 10 minutes to stain the cell membrane and TATnetwork. During the experiment cells were continuously superfused with NT alone or with NT supplemented with $300 \mathrm{nM}$ of ISO at $37^{\circ} \mathrm{C}$ using an inline perfusion heater (cell microsystem). Myocytes were treated $5 \mathrm{~min}$ with Isoprenaline (ISO) and electrically stimulated at $1 \mathrm{~Hz}$ before images were taken. Line scans of double-stained myocytes were taken with a Nikon C1 confocal microscope mounted on an inverted Nikon Eclipse 2000E along the short axis of the myocyte through the central plain avoiding the nucleus. Pixel size was set to achieve the highest possible temporal resolution (1,53 ms per line). Both dyes were excited with a $488 \mathrm{~nm}$ Argon laser, Fluo-4 emission was collected at 525 $\pm 12 \mathrm{~nm}$ and di-4-ANEPPS emission was collected above $650 \mathrm{~nm}$. All solutions contained $20 \mu \mathrm{M}$ of Blebbistatin to avoid movement artefacts during line scans.

\section{Image analysis}

\section{Confocal line scans}

Steady-state $\mathrm{Ca}^{2+}$ transient analysis was carried out automatically on whole-line averaged signals, or on a per-line basis, obtained from one to three $\mathrm{Ca}^{2+}$ transients by costume written Matlab algorithms. Local $\mathrm{Ca}^{2+}$ transients were analysed after PURE-LET denoising in Image J and subsequent line-wise fitting of the local CaT transient based on a method by Tian et al. ${ }^{13}$ Local and global CaT amplitudes were calculated by normalising the peak of the $\mathrm{Ca}^{2+}$ dependent signal to the average signal intensity during diastole, TF50 and TTP (Time to Peak) were defined as the time to reach the half-maximum and maximum fluorescence of the $\mathrm{Ca}^{2+}$ transient, respectively. The decay phase of the CaT was fitted with a mono-exponential function to assess the $\mathrm{Ca}^{2+}$ reuptake kinetics. Rate of $\mathrm{CaT}$ rise was defined as the time from $25 \%$ max fluorescence to $90 \%$ max fluorescence divided by the difference in fluorescence intensity at both time points. The simultaneously recorded membrane images were median-filtered ( $2 \times 2 \mathrm{px}$ kernel) and binarised with the Otsu-method to separate signal 
positive regions (Sarcolemma or TAT system) from the signal negative region. A distance map was generated from the processed binary images. The outmost signal positive structures were assigned to the subsarcolemmal (SS) compartment. Signal positive structures between the SS were assigned as axial tubule AT and based on the distance map uncoupled regions (UC) were assigned to the pixels furthest away from any membrane structure. Based on this assignment, the underlying local $\mathrm{Ca}^{2+}$ transient could be allocated accordingly. $\mathrm{Ca}^{2+}$ sparks that appeared in-between electrically evoked beats were manually counted and expressed as sparks per second.

\section{RyR-P2808 signal analysis of RyR-clusters}

The fraction of highly phosphorylated RyR-p2808 clusters among all clusters was determined using ImageJ based on a method published by Brandenburg et. al ${ }^{6}$. Normalised RYR-p2808 signals were calculated from confocal images with a pixel size of $100 \mathrm{~nm}$. Regions of interest (ROIs) were selected from which nuclear signals were omitted as they reflect unspecific cross-reactions of the RYR-p2808 antibody. Cytosolic RYR-P2808, RyR and WGA signals were background-corrected by subtracting the modal grayscale value for each ROI. After local contrast enhancement (CLAHE) and image smoothing ( 3 x 3 mean filter), RyR clusters were detected within a maximum tolerance of 15 grayscale levels (8-bit grayscale image). A binarised image was generated, dilated, and subjected to water shedding. The binarised image represented combined cluster detection from both channels (RYR and RYR-p2808). Next, the average normalised phosphorylation at RYR-p2808 was calculated for each resulting cluster-segment as RYR-p2808 / RyR ratio data. RYR-p2808 signals throughout a given cluster population were graphed as a frequency distribution histogram (bin size 0.2). Experimental data were normalised by using the first peak position of the cluster phosphorylation distribution in the ISO population as a threshold. This approach determined the fraction of highly phosphorylated RYR clusters among all clusters.

ImageJ was used to determine spatial relations of RyR-clusters relative to the membrane and TAT network. For this purpose, myocytes were stained with WGA prior to fixation. The resulting images of myocyte membrane structures were binarised by Otsu-thresholding (radius $1 \mu \mathrm{m})$ following local contrast enhancement and image smoothing ( $3 \times 3$ mean filter). Next, RYR-p2808/RYR signal maxima were determined with 15 grayscale levels ( 8 bit) noise tolerance. Subsequently, the RYR-p2808/RYR signals were correlated with the WGA membrane signal, and assigned to either of three groups: subsarcolemmal (SS - RYR clusters located on the outermost signal positive regions of a myocyte), TAT network (TAT - clusters correlated with membrane positive structures within a myocyte) and uncoupled RYRs clusters (UC - Clusters that were not associated with any membrane structures).

\section{Electrophysiology and Epifluorescence $\mathrm{Ca}^{2+}$ measurements}

Cells were stimulated in the whole-cell voltage-clamp configuration (Axon 200B-amplifier) and the signal was digitised using an Axon Digidata 1440a AD converter. Myocytes were constantly perfused with Normal Tyrode at $37^{\circ} \mathrm{C}$. The patch pipettes were pulled with a Sutter Instruments P-87 Micropipette Puller and fire-polished with MF-900 Microforge (Narishige, Japan) to a final resistance of 2-3 MOhm. For the extracellular solution, $\mathrm{KCl}$ was replaced with $10 \mathrm{mM} \mathrm{CsCl}$. The pipettes were back-filled with intracellular solution containing (in 
$\mathrm{mM}$ ): caesium aspartate 120, TEACl 10, $\mathrm{NaCl} 5$, Hepes $10, \mathrm{MgCl}_{2} 0.5, \mathrm{MgATP} 5, \mathrm{pH} 7.2$ adjusted with $\mathrm{CsOH}$. $\mathrm{I}_{\mathrm{CaL}}$ current was measured by a voltage step from -40 to $10 \mathrm{mV}$ for $200 \mathrm{~ms}$. SR calcium was determined by integrating outwork current elicited by a caffeine application (10mM for $8 \mathrm{~s})$ while clamping the cell at $-70 \mathrm{mV}$.

\section{Materials}

Collagenase B, Collagenase P, Trypsin inhibitor was purchased from Roche (Basel, Switzerland). Hyaluronidase was purchased from Worthington (Lakewood, USA). Fluo4AM, 532 Alexa Fluo Zenon labelling kit, WGA and Di-4-ANEPPS were purchased from Thermo Fisher (Dreieich, Germany) all other chemicals were purchased from Sigma Aldrich/ Merck (Darmstadt, Germany).

\section{Statistics}

Statistical analyses were performed with Microsoft Excel, GraphPad Prism (version 8.2.1) Data are shown as mean \pm SEM. Statistical comparisons were made using statistically applicable tests. For Figure 1,7C,8B a 2-way ANOVA with a Bonferroni post hoc test, for Figure 2, a repeated-measures 2-way ANOVA was used. Data presented in figure 3B were tested with an unpaired t-test. Histogram data were tested with Friedman test. A p-value $<0.05$ was considered statistically significant.

\section{RESULTS}

\section{Acute effects of Isoprenaline on $\mathrm{Ca}^{2+}$ transients after short term tachypacing}

After five days of tachypacing, we assessed the $\mathrm{Ca}^{2+}$ transients (CaT) in untreated AMs (CTRL) and AMs exposed to Isoprenaline (ISO) by averaging the pixel intensities of each scan line over time. AMs from SHAM operated animals served as control. During $1 \mathrm{~Hz}$ electrical stimulation AMs from RAP animals showed a marked reduction in CaT amplitude (Fig 1C, Left) compared to SHAM AMs (CaT amplitude [F/F0]: $3.51 \pm 0.12$ in SHAM vs. $2.55 \pm 0.13$ in RAP, $\mathrm{n} / \mathrm{N}=72 / 6$ in SHAM vs $\mathrm{n} / \mathrm{N}=33 / 5$ in RAP, $* * * \mathrm{p}<0.001)$. Both groups reacted with a significant increase in CaT amplitude to ISO treatment (SHAM: CTRL vs. ISO \# $\mathrm{p}<0.0001$, RAP: CTRL vs ISO $\S \mathrm{p}<0.0001)$. The CaT amplitude after ISO was similar between groups as the ISO effect was more pronounced in RAP AMs (CaT amplitude [F/F0]: $4.78 \pm 0.19$ in SHAM vs. $4.28 \pm 0.18$ in RAP, $n / N=56 / 6$ in SHAM vs $n / N=43 / 5$ in RAP, $p=$ $0.19)$.

$\mathrm{Ca}^{2+}$ reuptake (Fig1C, Right) behaved similarly to the CaT amplitude. In CTRL AMs reuptake was slower in RAP than in SHAM (TAU [ms]: $381 \pm 14$ in SHAM vs. $457 \pm 27$ in RAP, * $\mathrm{p}<0.05, \mathrm{n} / \mathrm{N}=72 / 6$ in SHAM vs $\mathrm{n} / \mathrm{N}=33 / 5$ in RAP). ISO hastened $\mathrm{Ca}^{2+}$ reuptake in both groups significantly (SHAM: CTRL vs. ISO \# $\mathrm{p}<0.0001$, RAP: CTRL vs ISO $\S \mathrm{p}<0.0001$ ), 
A
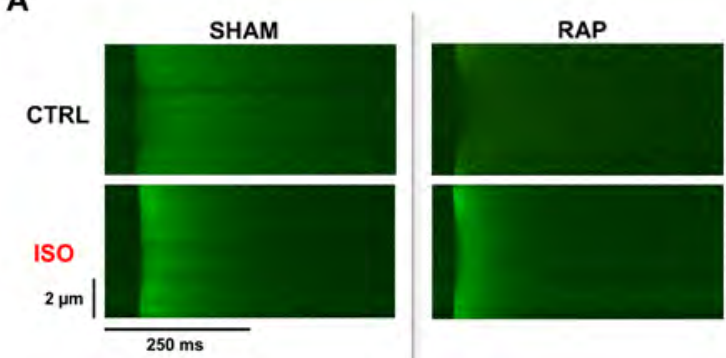

B
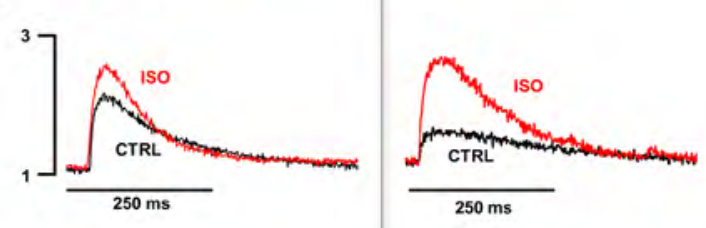

C
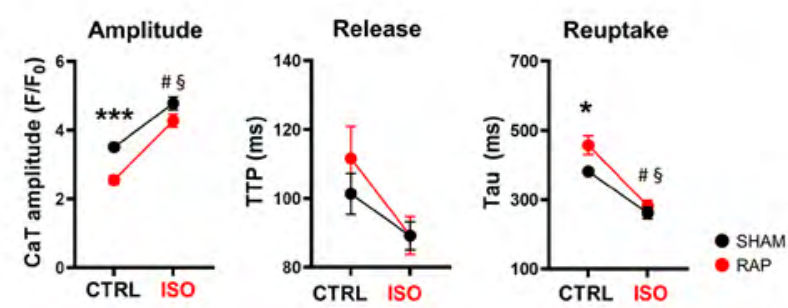

Figure 1 ISO treatment normalises CaT amplitude and kinetics in atrial myocytes (AMs). A, Representative examples of transversal confocal line scans of SHAM (right) and RAP (left) in CTRL conditions (top) and after 5 min of $300 \mu \mathrm{M}$ Isoprenaline (bottom) exposure. B, Line averaged CaTs normalised to diastolic fluorescence $\left(\mathrm{F}_{0}\right)$, CTRL conditions in black and ISO treatment in red. C, Mean data of CaT kinetics form SHAM and RAP myocytes in CTRL conditions and after treatment with ISO. Left, CaT amplitude $\left(\mathrm{F} / \mathrm{F}_{0}\right),{ }^{* * *} \mathrm{p}<0.001$. Centre, Time to maximal fluorescence (time to peak - TTP). Right, $\mathrm{Ca}^{2+}$ reuptake assessed by the time constant of $\mathrm{Ca}^{2+}$ decay (TAU). For all graphs CTRL: $\mathrm{n} / \mathrm{N}=72 / 6$ in SHAM and $\mathrm{n} / \mathrm{N}=33 / 5$ in RAP, ISO: $\mathrm{n} / \mathrm{N}=56 / 6$ in SHAM and $\mathrm{n} / \mathrm{N}=43 / 5$ in RAP.

but more so in RAP AMs so that the $\mathrm{Ca}^{2+}$ reuptake between groups was not different after ISO (TAU [ms]: $261 \pm 17$ in SHAM vs. $281 \pm 16$ in RAP, $n / N=56 / 6$ in SHAM vs n/ $\mathrm{N}=43 / 5$ in RAP, $\mathrm{p}=0.770)$.

$\mathrm{Ca}^{2+}$ release was not different between CTRL and ISO in SHAM AMs (Fig1C, Centre, TTP [ms]: $101 \pm 6$ in CTRL and $89 \pm 4$ in ISO, $\mathrm{n} / \mathrm{N}=72 / 6$ in CTRL vs $\mathrm{n} / \mathrm{N}=57 / 6$ in ISO, $\mathrm{p}=0.518$ ) but accelerated $\mathrm{Ca}^{2+}$ release in RAP (TTP [ms]: $111 \pm 9$ in CTRL $89 \pm 5$ in ISO, $\mathrm{n} / \mathrm{N}=33 / 5$ in CTRL vs $\mathrm{n} / \mathrm{N}=43 / 5$ in ISO, $\mathrm{p}=0.052$ ).

\section{Adrenergic response of $\mathrm{I}_{\mathrm{CaL}}$ and $\mathrm{SR} \mathrm{Ca}^{2+}$ content}

$\mathrm{I}_{\mathrm{CaL}}$ reduction is a prominent feature of AF-induced atrial remodelling, contributing to $\mathrm{CaT}$ amplitude reduction and slowing of whole cell $\mathrm{Ca}^{2+}$ release. To study peak $\mathrm{I}_{\mathrm{CaL}}$, AMs from SHAM and RAP were interrogated in a whole-cell voltage clamp configuration (Fig 2A). CTRL on ISO data were recorded in the same AMs. 
In line with our previous data, ${ }^{3}$ RAP myocytes exhibited smaller $\mathrm{I}_{\mathrm{CaL}}$ compared to SHAM myocytes $\left(\mathrm{I}_{\mathrm{CaL}}[\mathrm{pA} / \mathrm{pF}]:-10.13 \pm 0.81\right.$ in SHAM vs. $-5.18 \pm 0.90$ in RAP, $\mathrm{n} / \mathrm{N}=7 / 4$ for SHAM and $\mathrm{n} / \mathrm{N}=7 / 4$ for RAP, $* \mathrm{p}<0.05)$. In SHAM and RAP cells the response to ISO was preserved, showing higher peak currents after exposure. The differences between groups remained significant after ISO treatment $\left(\mathrm{I}_{\mathrm{CaL}}[\mathrm{pA} / \mathrm{pF}]:-12.97 \pm 1.41\right.$ in SHAM vs. $-8.47 \pm 1.50$ in RAP, $\mathrm{n} / \mathrm{N}=7 / 4$ for SHAM and $\mathrm{n} / \mathrm{N}=$ $7 / 4$ for RAP, $* \mathrm{p}<0.05)$.

Another major factor regulating $\mathrm{CaT}$ amplitude and kinetics is the $\mathrm{SR} \mathrm{Ca}^{2+}$ content (Fig 2B). To assess SR $\mathrm{Ca}^{2+}$ content, we integrated $\mathrm{I}_{\mathrm{NCX}}$ depended inward current evoked by $8 \mathrm{~s}$ exposure to $10 \mathrm{mM}$ caffeine and found that $\mathrm{Ca}^{2+}$ content was not different between SHAM and RAP AMs in CTRL (pC/pF: $1.1 \pm 0.16$ in SHAM vs. $1.01 \pm 0.10$ in RAP, $\mathrm{n} / \mathrm{N}=7 / 4$ for SHAM and RAP, $p=0.89$ ). The difference between RAP and SHAM remained insignificant after

A

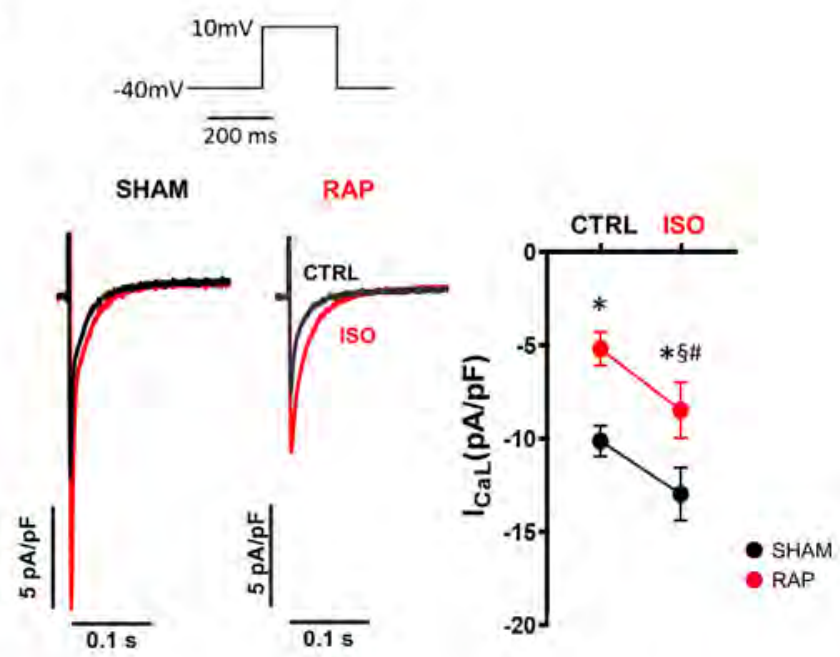

B
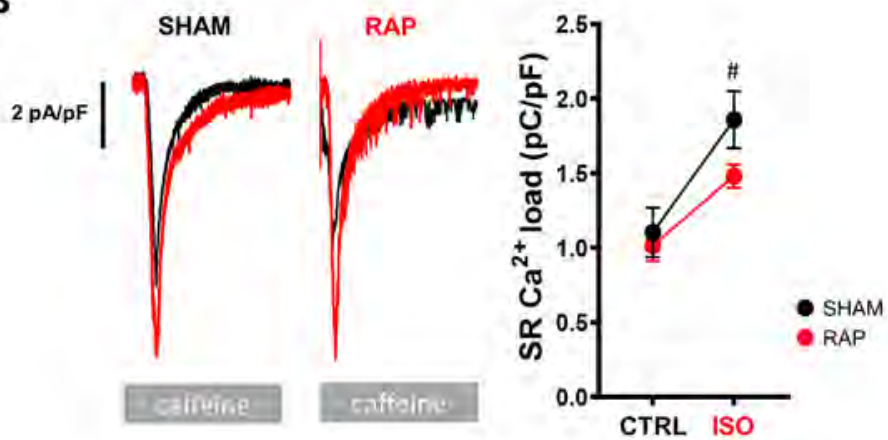

Figure 2 Adrenergic Response of $\mathrm{I}_{\mathrm{CaL}}$ and SR Ca ${ }^{2+}$ content. A, Left Representative examples of $\mathrm{I}_{\mathrm{CaL}}$ recorded in SHAM and RAP AMs in the absence (black) and presence (red) of ISO evoked by a $200 \mathrm{~ms}$ voltage step from $-40 \mathrm{mV}$ to $10 \mathrm{mV}$. Right Paired data of mean $\mathrm{I}_{\mathrm{CaL}}$ density in SHAM and RAP AMs. B, Left Examples of normalised inward currents recorded in voltage clamped AMs in response to $10 \mathrm{mM}$ Caffeine in the absence and presents of ISO. Right, Mean data of SR $\mathrm{Ca}^{2+}$ content in SHAM and RAP AMs in the presents and absence of ISO. Data from $\mathrm{n} / \mathrm{N}=7 / 4$ for SHAM and $\mathrm{n} / \mathrm{N}=7 / 4$ for RAP. A repeated 2-way ANOVA with a Bonferroni post hoc test for multiple comparisons 
ISO treatment. (pC/pF: $1.86 \pm 0.19$ in SHAM vs. $1.48 \pm 0.08$ in RAP, $\mathrm{n} / \mathrm{N}=7 / 4$ for SHAM and RAP, $p=0.137$ ). In RAP, SR $\mathrm{Ca}^{2+}$ content did not change significantly in response to ISO ( $p$ $=0.084)$ unlike in SHAM AMs $(\# \mathrm{p}=0.006)$.

\section{Early remodelling of the TAT network after tachypacing}

Because of the implications for synchronous $\mathrm{Ca}^{2+}$ release, we investigated the TAT system in freshly isolated SHAM and RAP AMs. The TAT network in AMs is sparse compared to ventricular cells and its density is further reduced after five days of tachypacing (Fig 3B, $\mu \mathrm{m} /$ $\mu \mathrm{m}^{2}: 0.041 \pm 0.032$ vs $0.024 \pm 0.019 \mathrm{n} / \mathrm{N}=85 / 7$ in SHAM and $\mathrm{n} / \mathrm{N}=49 / 9$ in RAP, $\left.{ }^{* *} \mathrm{p}<0.005\right)$. Furthermore, we analysed the TAT network based on the orientation relative to the long axis of the myocyte. Plotted as frequency histogram, SHAM AMs show two peaks of comparable height (Fig 3C, Left). The first at $0^{\circ}$ represents axial tubules, the second peak at $90^{\circ}$ depicts transverse tubules oriented perpendicular to the first population. In RAP myocyte the second peak was diminished (Fig 3C, Centre) indicating a predominant loss of transverse tubules in response to pacing, quantified as TAT component change in Fig 3C, Right. As a consequence of persevered ATs, the maximal distance between membrane structures (sarcolemma or ATs) was comparable between SHAM and RAP myocytes (in $\mu \mathrm{m}: 3.42 \pm 0.12$ in SHAM and $3.67 \pm 0.16$ in RAP, $\mathrm{n} / \mathrm{N}=137 / 6$ in SHAM and $\mathrm{n} / \mathrm{N}=89 / 5$ in RAP, $\mathrm{p}=0.204$ ).

A

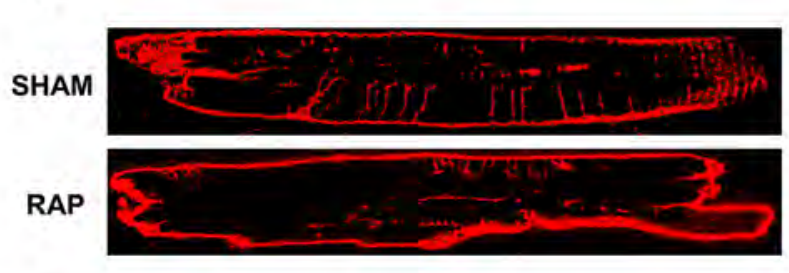

C

SHAM

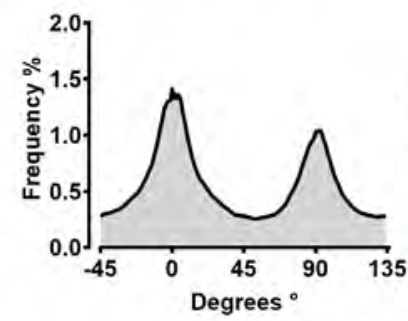

B

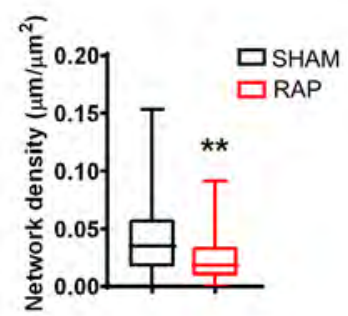

TAT component change

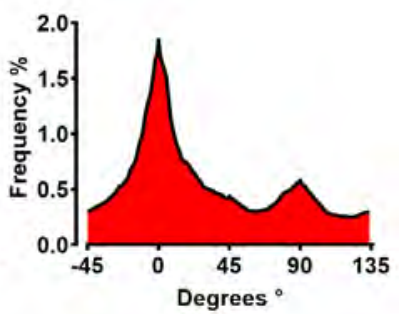

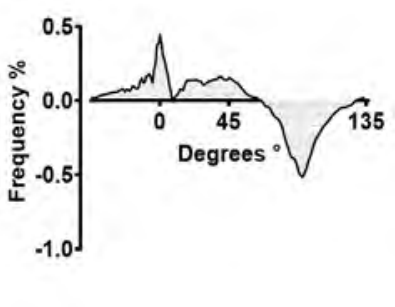

Figure 3 TAT Network density and orientation in SHAM and RAP animals. A, Examples of freshly isolated intact AMs from SHAM and RAP. B, Average TAT network length normalised to cell area. C, Frequency distribution of TAT network orientation. $0^{\circ}$ denotes tubules that are aligned with the long axis of the myocytes (AT), $90^{\circ}$ indicates transversally orientated tubules (TT). From Left to Right, frequency histogram of TAT orientation in SHAM, RAP and change in TAT component orientation by subtracting diminished compared to the first peak (C, Centre). Subtracting SHAM and RAP histograms demonstrate the relative gain of AT components and the loss of TT after tachypacing (C, Right). 


\section{Atrial Myocytes from RAP exhibit lower baseline RYR phosphorylation}

To investigate RYR phosphorylation, we employed in situ co-immunolabeling. Myocytes were electrically stimulated at $1 \mathrm{~Hz}$ and superfused with $37^{\circ} \mathrm{C}$ NT solution (SHAM) or NT solution supplemented with $300 \mu \mathrm{M}$ ISO (RAP) for 5 minutes before fixation with 4\%PFA. Coimmunostaining of SHAM AMs showed apparent RYR phosphorylation in CTRL, indicated by the first peak (Black curve in Fig 4B, Left) and a rightward shift after ISO treatment reflecting increased RYR phosphorylation (Red curve in Fig4.B, Left; $\mathrm{n} / \mathrm{N}=33 / 10$ in CTRL and $\mathrm{n} / \mathrm{N}=21 / 10$ in ISO, $\left.{ }^{* * *} \mathrm{p}<0.001\right)$. In RAP AMs we failed to detect a phosphorylation peak in CTRL, (Black curve in Fig4.B, Right) indicative of low or absent baseline phosphorylation. After ISO treatment a pronounced peak became apparent (Red curve in Fig4.B, Right, $\mathrm{n} / \mathrm{N}=30 / 8$ in CTRL and $\mathrm{n} / \mathrm{N}=37 / 8$ in ISO, $* * * \mathrm{p}<0.001$ )

A

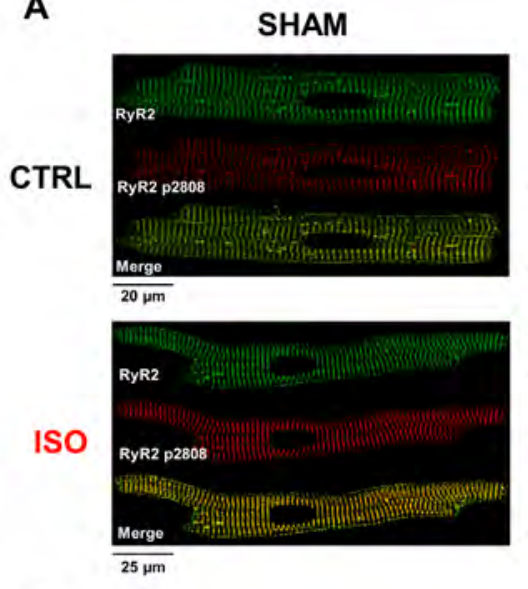

B

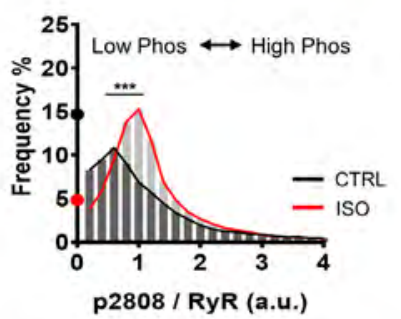

RAP
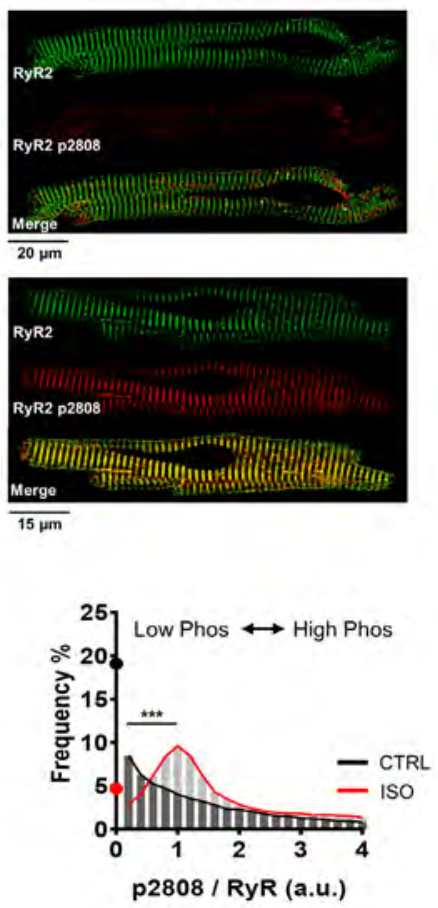

Figure 4 Phosphorylation state of PKA-phosphorylated RYR in SHAM and RAP AMs. A, Upper Panel Example coimmunostaining for RYR and PKA phosphorylated RYR2-p2808 and merged images in SHAM and RAP. Lower Panel: Representative examples for SHAM and RAP myocytes after the exposure to ISO. B, Left frequency histogram of RYR-p2808/RYR cluster distribution in SHAM AMs without (black) and with ISO treatment (red). Clusters from $\mathrm{n} / \mathrm{N}=33 / 10$ in CTRL and $\mathrm{n} / \mathrm{N}=21 / 10$ in RAP, $* * * \mathrm{p}<0.001$. Right Frequency histogram of RYR-p2808/RYR cluster distribution in RAP AMs. Without (black) and with ISO treatment (red). Clusters from $\mathrm{n} / \mathrm{N}=30 / 8$ in $\mathrm{CTRL}$ and $\mathrm{n} / \mathrm{N}=37 / 8$ in RAP, $* * * \mathrm{p}<0.001$. 
Phosphorylation of RYR2 clusters depends on its subcellular location

AMs were stained with WGA, a dye for labelling TAT structures and the sarcolemma, before immunolabeling with RYR and RYR-p2808 ABs (Fig 5A). Based on co-localisation with the WGA RYR-p2808/RYR clusters were assigned to three compartments denoted: SS RYRs below the sarcolemma, TAT - around TAT structures, and lastly UC - RYR that could not be linked to WGA positive structures. Similar to Fig 4B, for each compartment relative RYR cluster phosphorylation was plotted in the form of a frequency histogram. In CTRL the

A

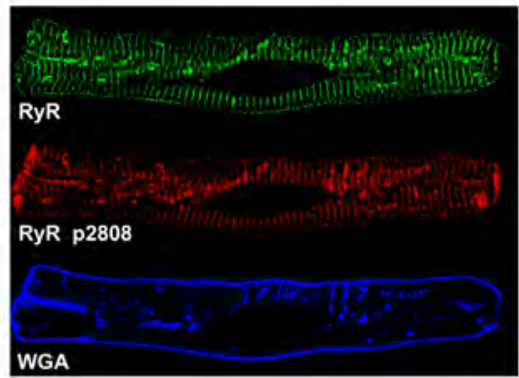

C

SHAM

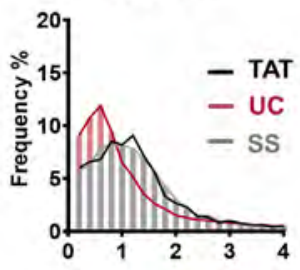

RAP

B
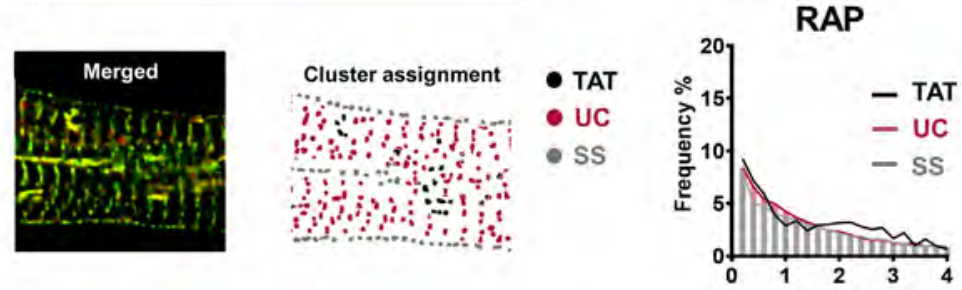

Figure 5 Localisation dependent Phosphorylation in AMs A, Example image a rabbit AM coimmunostained with RYR, RYR-p2808 and WGA to visualise membrane structures. B, Merged and zoomed region from example on the Left. On the Right assigned clusters based on location (Subsarcolemmal - SS, transverse axial tubule network - TAT and uncoupled - UC). C, Frequency histogram of RYR-p2808/RYR in CTRL AMs from SHAM and RAP animals base on their subcellular location.

frequency histogram revealed varying degrees of phosphorylation in SHAM AMs (Fig5C, Upper panel) depending on the location of RYR clusters. In SHAM AMs, clusters associated with SS (Grey curve) or TAT (Black curve) showed more highly phosphorylated clusters compared to UC clusters (Red curve; UC vs TAT $\mathrm{p}<0.001$, UC vs SS $\mathrm{p}<0.001$, TAT vs SS $\mathrm{p}=0.9, \mathrm{n} / \mathrm{N}=33 / 10$ ). In CTRL conditions, RAP AMs (Fig5C, Lower panel) did not show the differential phosphorylation between SS (Grey curve) and UC RYRs (Red curve). However the phosphorylation of TAT clusters was significantly higher (Black curve; UC vs SS p $=0.9$, UC vs TAT $\mathrm{p}<0.001$, SS vs TAT $\mathrm{p}<0.001, \mathrm{n} / \mathrm{N}=30 / 8)$.

\section{Membrane structures correlate with altered CaT kinetics}

Intact AMs dual-stained with di-4-ANEPPS - to visualise the sarcolemma and TAT network - and a $\mathrm{Ca}^{2+}$ indicator allowed us to correlate $\mathrm{CaT}$ with membrane structures. Signals were recorded from both dyes simultaneously (Fig 6B). Based on signal positive pixels of the di-4-ANEPPS image CaTs were again assigned to subsarcolemmal region (SS), TAT network 
A

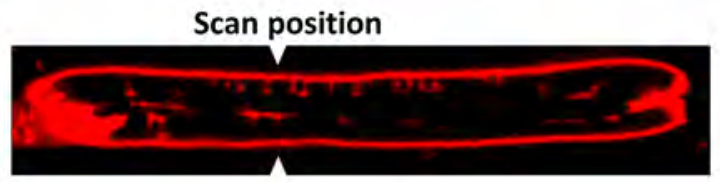

B

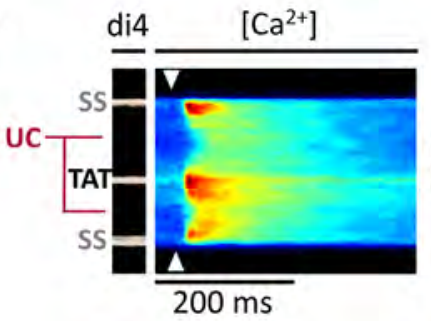

C
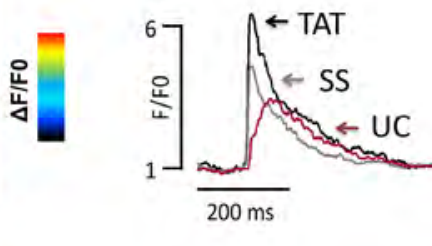

Figure $6 \mathrm{Ca}^{2+}$ release is faster in regions coupled to membrane structures. A, Confocal image of aa AM stained with di-4-ANNEPS to visualise TAT structures and loaded with Fluo4-AM for $\mathrm{Ca}^{2+}$. The white arrow heads denote the position of the confocal scan line in B. Images were taken in the centre of the myocyte along the short axis of the cell. B, Transversal line-scan recording of AMs electrically stimulated at $1 \mathrm{~Hz}$ superfused with NT at $37^{\circ} \mathrm{C}$. A thresholded di-4-ANEPPS image was used to segment the CaT into SS (Scan lines overlaying the outermost di-4-ANEPPS positive signal), AT (Lines superimposing di-4-ANEPPS positive region in the centre of the cell between SS) and UC (Scan lines furthest away from di-4-ANEPPS positive structures). F/F0, Normalised fluorescence intensity ratio indicated by look-up-table. (C) $\mathrm{CaT}$ at $\mathrm{AT}, \mathrm{SS}$ and UC. The slower $\mathrm{Ca}^{2+}$ release and lower $\mathrm{CaT}$ amplitude in uncoupled regions compared to AT and SS demonstrate differences in subcellular CaT kinetics.

(TAT), and uncoupled regions (UC). Robust $\mathrm{Ca}^{2+}$ release could be detected at TAT sites, confirming intact CICR of these structures. CaTs at UC sites appeared to be slower $\mathrm{Ca}^{2+}$ release and the CaT was smaller compared to TAT or SS regions.

In RAP ISO dependent phosphorylation of RYRs in all subcellular compartments is preserved

We analysed RYR phosphorylation in CTRL and ISO treated AMs from SHAM and RAP animals based on their subcellular compartment (Fig7.A). In SHAM AMs treated with ISO, average phosphorylation of RYR clusters shifted to the right as an expression of higher RYR cluster phosphorylation after ISO. In TAT and SS clusters the effect was less pronounced (Effect size: $g=1.67$ for TAT and $g=4.29$ for SS) than in UC regions (Effect size: $g=$ 11.25). Also, RAP AMs treated with ISO exhibited significantly higher RYR phosphorylation across all locations compared to CTRL AMs, with an effect size largest at TAT $(g=8.84)$ and again less pronounced in TAT $(g=1.16)$ and SS $(g=4.17)$.

Local CaT amplitudes showed similar responses to ISO when compared to the global CaT amplitudes (Fig 7C). We recorded higher CaT amplitudes in UC (F/F0: $3.42 \pm 0.13$ in SHAM vs $2.45 \pm 0.22$ in RAP, ${ }^{*} \mathrm{p}<0.05, \mathrm{n} / \mathrm{N}=77 / 6$ in SHAM and $34 / 5$ in RAP) and TAT (F/F0: $3.35 \pm 0.13$ in SHAM vs $2.43 \pm 0.19$ in RAP, $* \mathrm{p}<0.05, \mathrm{n} / \mathrm{N}=55 / 6$ in SHAM and 20/5 in RAP) regions of SHAM compared to RAP CTRL. In SS regions the CaT amplitude in CTRL conditions was not different between groups (F/F0: $3.89 \pm 0.16$ in SHAM vs $3.06 \pm 0.15$ in RAP, $\mathrm{p}=0.05, \mathrm{n} / \mathrm{N}=77 / 6$ in SHAM and $34 / 5$ in RAP). ISO treatments increased CaT amplitude (for all CTRL vs ISO: \# $<<0.05$ in SHAM and $\S p<0.05$ in RAP) and abolished 
differences between SHAM and RAP AMs in UC (F/F0: 4.49 \pm 0.17 in SHAM vs 4.00 \pm 0.21 in RAP, $\mathrm{p}=0.05, \mathrm{n} / \mathrm{N}=60 / 6$ in SHAM and $45 / 5$ in RAP) and TAT (F/F0: 4.39 \pm 0.22 in SHAM vs $3.81 \pm 0.22$ in RAP, $n / N=45 / 6$ in SHAM and 20/5 in RAP).

A
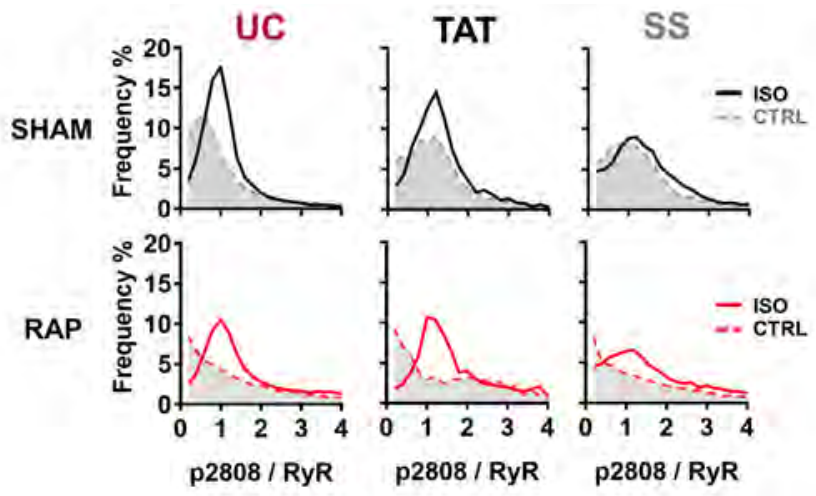

B
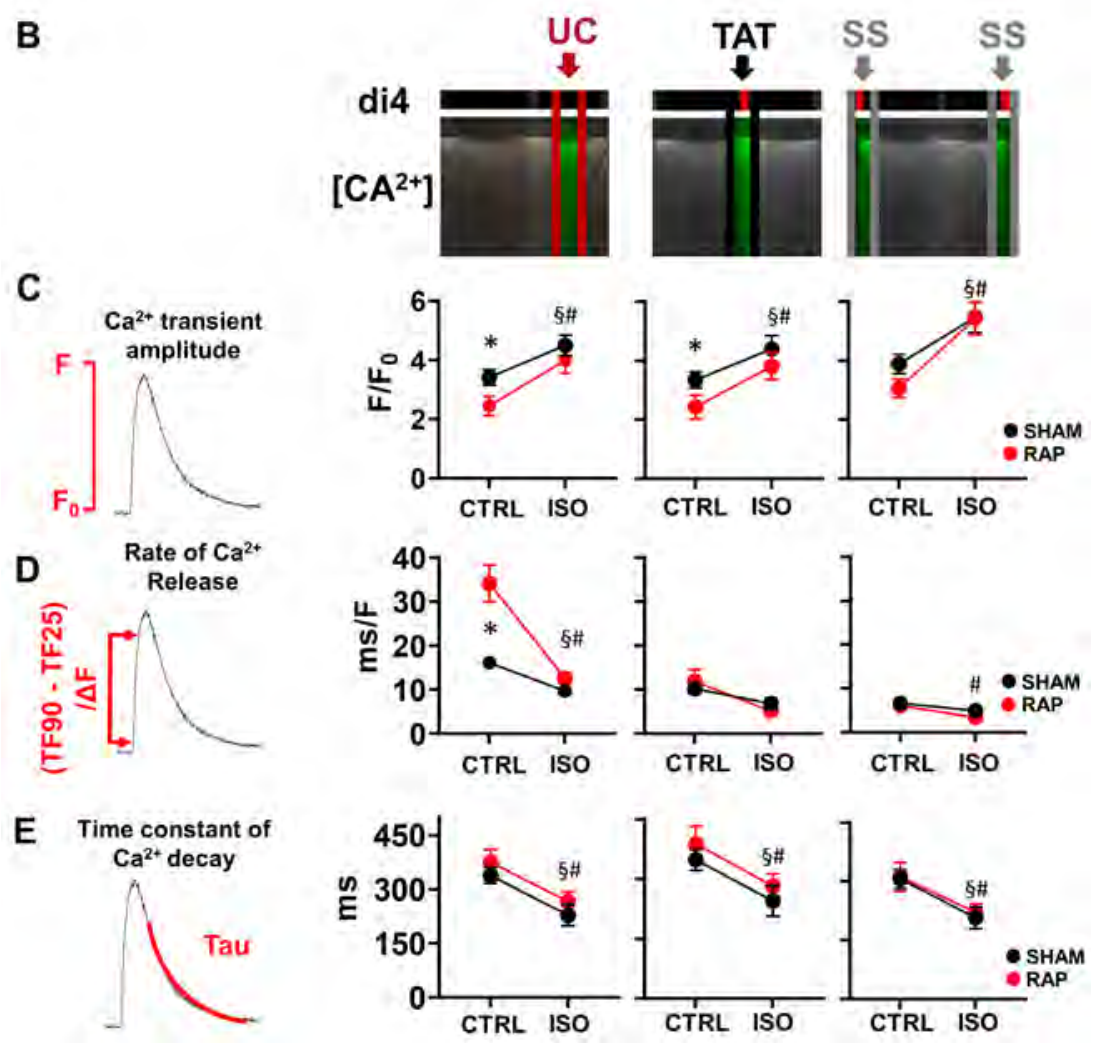

Figure 7 Site specific structure-function relationship in SHAM and RAP. A, Site specific frequency histograms of RYR-p2808/RYR phosphorylation in CTRL (dotted line) and ISO treated AMs (solid line). The upper panels show the histograms for SHAM AMs the lower panel the histograms for RAP AMs and are grouped by subcellular compartment from Left to Right: UC, TAT, SS. B, For illustration, an example line scan of a AMs stained with di-4-ANEPPS to determine the subcellular local of CaTs. $\mathbf{C}, \mathrm{CaT}$ amplitude, $\mathbf{D}, \mathrm{Ca}^{2+}$ release and $\mathbf{E}, \mathrm{Ca}^{2+}$ reuptake in SHAM (Black) and RAP (Red) AMs. From Left to Right at UC, AT and SS sides, in CTRL and after ISO treatment. 
Rate of $\mathrm{Ca}^{2+}$ release was not different between RAP and SHAM at SS and TAT sites in CTRL and there was no appreciable change in the rate of $\mathrm{Ca}^{2+}$ release at these sites after ISO (Fig 7C, Centre and Right). However, in UC regions (Fig 7C, Left). $\mathrm{Ca}^{2+}$ release in RAP AMs was on average two times slower than UC regions in SHAM myocytes (ms/F: 16.2 \pm 1.3 in SHAM vs $34.2 \pm 4.1$ in RAP, $\mathrm{p}<0.05, \mathrm{n} / \mathrm{N}=77 / 6$ in SHAM and $34 / 5$ in RAP, $\mathrm{p}<0.001$ ). ISO treatment abolished the striking difference in the rate of $\mathrm{Ca}^{2+}$ release between SHAM and RAP (ms/F: $9.8 \pm 0.7$ in SHAM vs 12.7.2 \pm 1.25 in RAP, $\mathrm{n} / \mathrm{N}=60 / 6$ in SHAM and 45/5 in RAP, $\mathrm{p}=$ $0.65)$. Lastly, we assessed $\mathrm{Ca}^{2+}$ reuptake by fitting a mono-exponential decay function to local CaTs (Fig 7D). As expected ISO significantly hastened $\mathrm{Ca}^{2+}$ reuptake, but we could not detect differences between RAP and SHAM myocytes neither in CTRL nor in ISO treated cells.

A

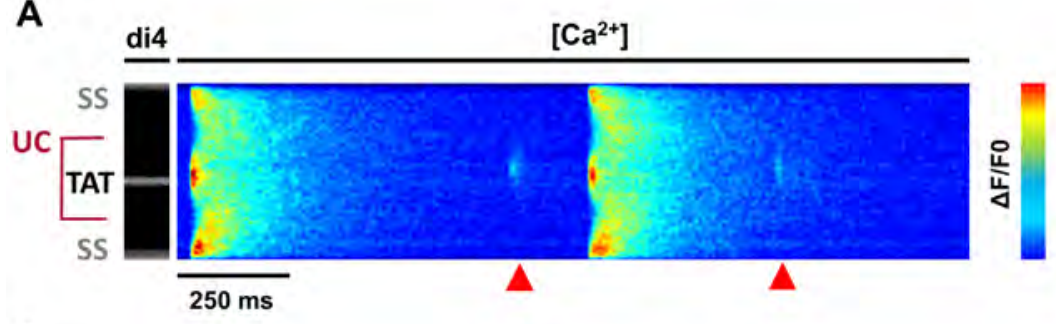

B

\section{C}
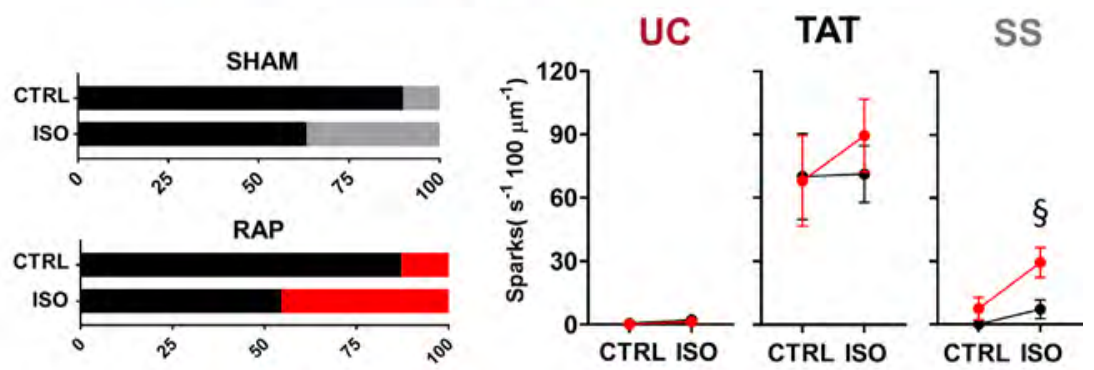

Figure $8 \mathrm{Ca}^{2+}$ sparks predominantly occur at AT. A, Transversal line-scan of a AMs loaded with Fluo4-AM, Ca ${ }^{2+}$ sparks (red arrowheads) occur between electrically evoked CaT. The co-staining with di-4-ANNEPS to identify membrane structures reveals a tight coupling of $\mathrm{Ca}^{2+}$ Sparks to the TAT network. F/F0, Normalised fluorescence intensity ratio indicated by look-up-table. $\mathrm{B}, \mathrm{Ca}^{2+}$ spark rate based on the subcellular location of spark occurrence in SHAM and RAP AMs normalised to the width of location. C, In CTRL and ISO an equal fraction of SHAM and RAP AMs exhibited $\mathrm{Ca}^{2+}$ sparks. 
In both, SHAM and RAP AMs, spontaneous $\mathrm{Ca}^{2+}$ release events, in the form of $\mathrm{Ca}^{2+}$ sparks, could be detected between electrically evoked CaTs in a subset of cells (Fig 8A red arrowheads). In CTRL, $10 \%$ of SHAM and $12 \%$ of RAP AMs exhibited $\mathrm{Ca}^{2+}$ sparks. After ISO treatment, the fraction of AMs that developed $\mathrm{Ca}^{2+}$ sparks during the observation period increased to $36 \%$ in SHAM and $45 \%$ in RAP (Fig 8B).

$\mathrm{Ca}^{2+}$ sparks in UC regions were a rare event ([Sparks/100 $\left.\mu \mathrm{m} / \mathrm{s}\right]$ CTRL: $0.16 \pm 0.51$ in SHAM vs $0.15 \pm 0.15$ in RAP; ISO: $2.28 \pm 0.45$ in SHAM vs $1.37 \pm 0.39$ in RAP), but more frequent next to the sarcolemma ([Sparks $/ 100 \mu \mathrm{m} / \mathrm{s}]$ CTRL: Sparks $/ 100 \mu \mathrm{m} / \mathrm{s}: 0.0 \pm 0.0$ in SHAM vs $7.40 \pm 5.34$ in RAP; ISO: 7.15 \pm 4.90 in SHAM vs 29.41 \pm 7.16 in RAP). The predominant location for $\mathrm{Ca}^{2+}$ spark was close to TAT structures ([Sparks/100 $\left.\mu \mathrm{m} / \mathrm{s}\right]$ CTRL: Sparks $/ 100 \mu \mathrm{m} / \mathrm{s}$ : $70.14 \pm 20.30$ in SHAM vs $68.14 \pm 21.42$ in RAP, $n=8$ in SHAM and $n=11$ in RAP; ISO: Sparks $/ 100 \mu \mathrm{m} / \mathrm{s}: 71.27 \pm 13.4$ in SHAM vs $80.54 \pm 17.26$ in RAP) regardless of group or exposure to ISO. Although ISO increases the fraction of AMs we could detect sparks in, ISO did not change $\mathrm{Ca}^{2+}$ spark frequency except in SS regions of RAP AMs $(\S: \mathrm{p}=0.03)$

\section{DISCUSSION}

In the present study, we characterised the effect of beta-adrenergic stimulation on spatiotemporal $\mathrm{Ca}^{2+}$ dynamics in atrial myocytes after a period of a sustained high atrial activation rate. We found that an intact beta-adrenergic response after short term tachypacing normalises $\mathrm{CaT}$ amplitude by synchronising $\mathrm{Ca}^{2+}$ release. Furthermore, we observed an intact TAT network in rabbit atrial myocytes with a sizeable fraction of longitudinally orientated tubules which, unlike transverse tubule, persist after rapid pacing and support synchronised $\mathrm{Ca}^{2+}$ release.

\section{ISO normalises global CaT amplitude RAP AMs but not I ${ }_{\text {CaL }}$}

Consistent with previous findings, $\mathrm{CaT}$ amplitude after rapid pacing was significantly reduced compared to SHAM treated AMs. ${ }^{3}$ The application of ISO led to an increased CaT amplitude in both SHAM and RAP AMs. The effect was more substantial in RAP AMs, which resulted in comparable CaT amplitudes between groups.

$\mathrm{Ca}^{2+}$ release in myocytes is proportional to the available $\mathrm{I}_{\mathrm{CaL}}{ }^{14}$ Stimulating $\mathrm{I}_{\mathrm{CaL}}$ via beta-adrenergic agonists could contribute to the normalisation of the $\mathrm{CaT}$ after pacing. $\mathrm{I}_{\mathrm{CaL}}$ reduction is a prominent feature of $\mathrm{AF}$ induced atrial remodelling and has been attributed to a functional alteration in the absence ${ }^{15}$ and presence ${ }^{16-19}$ of reduced LTCC expression. Previous work of our group found a reduced $\mathrm{I}_{\mathrm{CaL}}$ after five days of RAP without significant changes in subsarcolemmal (SS) CaT amplitude. ${ }^{3}$ Similarly, we observed a significant reduction in $\mathrm{I}_{\mathrm{CaL}}$ after pacing without evident changes in SS CaT amplitude. These findings are in line with published data that show preservation of SS CaTs in ovine ${ }^{20}$ and canine ${ }^{19}$ models of AF.

An explanation for the preserved SS CaT in RAP could be the isolated loss of LTCCs due to a diminished TAT network, ${ }^{21}$ to the effect of unchanged or, owed to LTCC redistribution, higher $\mathrm{I}_{\mathrm{CaL}}$ density in the sarcolemma in RAP. After rapid pacing, the overall TAT network density was indeed reduced - by approximately 50\% - compared to SHAM AMs. Under the 
assumption that the majority of LTCCs resides within the TAT network ${ }^{8}$ the degree of $\mathrm{I}_{\mathrm{CaL}}$ reduction we observed in RAP, again a little under $50 \%$, is in line with preserved $\mathrm{I}_{\mathrm{CaL}}$ in the sarcolemma.

In accordance with published work by Christ et. al, ISO exerted a more pronounced effect on $\mathrm{I}_{\mathrm{CaL}}$ in diseased animals. ${ }^{22}$ In our model $\mathrm{I}_{\mathrm{CaL}}$ increased by $70 \%$ after ISO in RAP compared to a 30\% higher $\mathrm{I}_{\mathrm{CaL}}$ in SHAM myocytes. However, ISO was not able to fully restore $\mathrm{I}_{\mathrm{CaL}}$ in RAP AMs to level recorded in SHAM. The more extensive response to ISO of RAP AMs reflects the lower phosphorylation state in CTRL conditions. Furthermore, the failure to normalise $\mathrm{I}_{\mathrm{CaL}}$ to SHAM levels after ISO supports the hypothesis of reduced LTCC expression as a response to sustained rapid atrial activation.

\section{TAT network alterations after pacing}

Ventricular myocytes have a dense and regular TAT network that allows for a tight coupling between transsarcolemmal $\mathrm{Ca}^{2+}$ influx and $\mathrm{Ca}^{2+}$ induced $\mathrm{Ca}^{2+}$ (CICR) release from adjacent RYRs. ${ }^{23}$ These couplons synchronise $\mathrm{Ca}^{2+}$ release across the myocyte ensuring coordinated contraction. For decades the TAT network of atrial cells was thought to be sparse or even absent, ${ }^{3,5}$ and it was assumed that CICR release relies on slow centripetal propagation from subsarcolemmal regions to the centre of the cell..$^{5}$ This observation is at odds with the faster contractile kinetics of atria. ${ }^{24}$

However In recent years, owed to the advances in targeted atrial myocyte isolation, several reports of TAT networks in atrial myocytes from large mammals and rodents have been published. ${ }^{8,25}$ The most striking feature of the TAT network in the atria is that although it is sparse compared to ventricular TAT networks, there is a significant fraction of axial tubules (AT). ${ }^{25}$ The AT component of the network features high fidelity coupling between LTCC and surrounding clusters of RYRs owed to their ultrastructure. ATs are located in the centre of myocytes to release $\mathrm{Ca}^{2+}$ close to the contractile apparatus that surrounds them. In this way, AT support the fast contractile kinetics of atrial myocytes. ${ }^{6}$ In our study we confirmed that rabbit atrial myocytes have an intact TAT network with a large fraction of AT which release $\mathrm{Ca}^{2+}$ synchronously with RYRs below the surface sarcolemma, indicating intact electrical coupling between the surface and the AT. Unlike in pressure overload conditions where the TAT network proliferates, ${ }^{6}$ after rapid pacing the TAT network density was decreased. The loss of TATs after pacing was mainly carried by a loss of transverse tubule (TT) resulting in a relative gain of AT. Previous work in a sheep AF model shows a comparable loss of TAT density and although the TAT network orientation has not been analysed systematically, the provided examples suggest a predominant loss of the TT network. ${ }^{20}$ Functionally, $\mathrm{Ca}^{2+}$ release kinetics from AT sites were, like SS $\mathrm{Ca}^{2+}$ release kinetics not different between SHAM and RAP myocytes.

\section{ISO rescues slower $\mathrm{Ca}^{2+}$ release from uncoupled RyR}

Although $\mathrm{Ca}^{2+}$ release kinetics were not different between RAP and SHAM myocytes in coupled regions, RYRs clusters furthest away from membrane structures released $\mathrm{Ca}^{2+}$ two times slower in RAP than the corresponding clusters in SHAM myocytes. Because of the preserved AT the maximal distance from the nearest membrane structure to uncoupled clusters of RYRs 
was comparable between groups despite reduced TAT density, ruling out that the slower $\mathrm{Ca}^{2+}$ release in between RAP and SHAM is purely dependent on the distance the $\mathrm{Ca}^{2+}$ wave had to travel.

Differences in local RYR phosphorylation have been suggested to influence $\mathrm{Ca}^{2+}$ release on a subcellular level. In SHAM animals RYRs along the TAT system and below the membrane are hyperphosphorylated at Ser-2808 (the selective PKA phosphorylation target) compared to uncoupled RYRs. Previous work in mice, rat and rabbit show similar results with RYR phosphorylation at the PKA site being higher at TAT compared to uncoupled RYR ${ }^{25}$ In AF models reports of RYR phosphorylation at the PKA site has been somewhat inconsistent with some groups suggesting no change in phosphorylation ${ }^{26}$ and others a higher fraction of phosphorylated RYR in AF. ${ }^{3,27}$ Interestingly, we found a decrease RYR phosphorylation at Ser-2808 in isolated atrial myocytes, after 5 days of tachypacing. This finding is in contrast to data published earlier by our group, which demonstrated higher relative RYR phosphorylation. ${ }^{3}$ An explanation for the inconsistency between the two studies could be the timing of RYR interrogation and the method applied. We used indirect ICC on isolated atrial myocytes treated similarly to the myocytes used for $\mathrm{Ca}^{2+}$ imaging, while the previous study has been conducted on homogenate frozen tissue samples. In-vivo myocytes are subjected to a baseline level of adrenergic stimulation, the lack of such background activation in combination with altered phosphatase activity ${ }^{28}$ could contribute to lower RYR phosphorylation in-vitro

RYR phosphorylation was higher in UC, AT and SS of RAP myocytes after ISO treatment, whereas the changes in SHAM myocytes appeared to be less pronounced. While SHAM animals had a population of RYR that was highly phosphorylated under baseline conditions, such a population was virtually absent in RAP myocytes, where no clear phosphorylation pattern in control conditions could be distinguished.

PKA acts downstream of beta-adrenoreceptors on $\mathrm{Ca}^{2+}$ handling proteins like the LTCC, SERCA and RYR, as well as on the contractile apparatus. ${ }^{29}$ It has been suggested that the effects on $\mathrm{Ca}^{2+}$ release and contractility depend, at least partially, on the phosphorylation of RYR at 2808 by PKA. ${ }^{30}$ PKA dependent RYR phosphorylation has also been linked to cardiac remodelling. ${ }^{31}$ However, evidence for the role of PKA driven RYR phosphorylation in disease is inconclusive, with some published work showing that mice with phosphorylation incompetent RYRs show the same response to ISO when compared to controls and that the animals do not show, as previously believed, ameliorated remodelling after myocardial infarction..$^{32}$ Regardless of the role in cardiac remodelling, others demonstrated an apparent effect of ISO on local $\mathrm{Ca}^{2+}$ release. In experiments conducted in guinea pig myocytes local $\mathrm{Ca}^{2+}$ release is higher after ISO treatment even when SR Ca ${ }^{2+}$ is reduced. ${ }^{33}$ Furthermore, the authors showed that an increase in $\mathrm{SR} \mathrm{Ca}^{2+}$ has only a small effect on CICR after ISO treatment. Another approach to explain the rescued central $\mathrm{Ca}^{2+}$ release in uncoupled RYRs has been published by Maxwell et al. ${ }^{34}$ In an elegant set of experiment the authors show that during the time lag of $\mathrm{Ca}^{2+}$ release between the periphery and central regions, SERCA pumps $\mathrm{Ca}^{2+}$ into the SR. The $\mathrm{Ca}^{2+}$ that is taken up from the edge of the approaching wave during the time lag increases $\mathrm{SR} \mathrm{Ca}^{2+}$ content locally in central regions. This increase in $\mathrm{SR} \mathrm{Ca}^{2+}$ content lowers the level of luminal $\mathrm{Ca}^{2+}$ required for effective CICR. PKA dependent SERCA activation could increase the amount of $\mathrm{Ca}^{2+}$ taken up on the leading edge of the $\mathrm{Ca}^{2+}$ wave, enough to ensure successful centripetal wave propagation. 
The unchanged SR $\mathrm{Ca}^{2+}$ content at baseline and the non-significant increase after ISO support the hypothesis that RYR phosphorylation in uncoupled regions is involved in restoring central CaTs, rather than a local alteration in $\mathrm{SR} \mathrm{Ca}^{2+}$ content. However, the lack of selectivity of PKA with regards to the phosphorylation target and the tightly interconnected mechanisms of CICR complicates the interpretation of our results.

\section{Spark rate is not altered after ISO}

Increased diastolic $\mathrm{Ca}^{2+}$ leak has been suggested to underlie $\mathrm{Ca}^{2+}$ instability in AF. On a myocyte level elementary $\mathrm{Ca}^{2+}$ release events, or sparks, can be used to quantify the SR $\mathrm{Ca}^{2+}$ leak and inform about RYR properties. Several studies show a trend towards increased $\mathrm{Ca}^{2+}$ spark rate in AF caused by a higher RYR phosphorylation. ${ }^{27,35,36}$ In addition to the PKA phosphorylation site at Ser-2808, CaMKII dependent phosphorylation takes place at Ser-2814. In AF atrial myocytes the increase in $\mathrm{Ca}^{2+}$ spark rate appears to arise from the CaMKII phosphorylation site whereas reports for PKA dependent phosphorylation are inconclusive, although the apparent proarrhythmic effect of ISO in patients is well documented. ${ }^{9}$ Current and previous results in our RAP model show that short term tachypacing alone does not lead to increased $\mathrm{Ca}^{2+}$ spark rates. ${ }^{3}$ Furthermore, our data confirm that PKA dependent phosphorylation does not increase $\mathrm{Ca}^{2+}$ spark rates above levels seen in SHAM AMs, with the exception of the SS compartment.

Sparks arising from coupled RYRs are regulated by CaMKII and ROS, whereas sparks from uncoupled RYR are not. ${ }^{37}$ Sparks from coupled RYR are also more frequent. ${ }^{6,38,39}$ In line with previously published literature, we found that in rabbit atrial myocytes, $\mathrm{Ca}^{2+}$ sparks predominantly arise from coupled RyRs. The lack of $\mathrm{Ca}^{2+}$ spark rate increase in uncoupled RYR after ISO stimulation supports the notion that PKA phosphorylation alone is not sufficient for $\mathrm{Ca}^{2+}$ spark generation.

\section{Limitations}

The match between functional $\mathrm{Ca}^{2+}$ release and the furthest distance to a membrane structure, albeit recorded at the same time, might not reflect the exact distance to the nearest structure in all myocytes. Due to the confocality of the image data, membrane structures above and below UC regions might speed up CICR, which would lead to an underestimation of the uncoupling effect. Another limitation is the lack of RYR phosphorylation data at the CaMKII site Ser2814. Due to the limited availability of phosphor specific antibodies, cross-reactivity with the sample did not allow for accurate RYR phosphorylation estimates. Lastly, the duration of the imaging period had to be limited to avoid phototoxic effects of the Di-4-ANEPPS and Blebbistatin. Due to the short imaging periods interpretation of spark data has to be made cautiously. 


\section{Conclusion}

In atrial myocytes after five days of sustained high activation rates, we could demonstrate that beta-adrenergic stimulation restores centripetal $\mathrm{Ca}^{2+}$ propagation and normalises $\mathrm{CaT}$ amplitude mainly by increasing central CaT amplitude and hastening release kinetics. While phosphorylation of RYRs at 2808 might support the CICR in UC RYR clusters, it did not induce more frequent proarrhythmic $\mathrm{Ca}^{2+}$ release events in these clusters.

\section{FUNDING}

This work was supported by a EU Innovative Training Network (RADical reduction of OXidative stress in cardiovascular disease, No. 316738), and by a grant from the Austrian Science Fund to G.A. (I2013-B27).

\section{ACKNOWLEDGEMENTS}

We thank Qinghai Tian PhD, from the Dep. Of Cell Biology, Saarland University, for supporting the implementation of the pixelwise fitting algorithm. 


\section{REFERENCES}

1. Greiser M, Schotten U. Dynamic remodeling of intracellular $\mathrm{Ca}(2)(+)$ signaling during atrial fibrillation. J Mol Cell Cardiol 2013;58:134-142.

2. Sun H, Chartier D, Leblanc N, Nattel S. Intracellular calcium changes and tachycardia-induced contractile dysfunction in canine atrial myocytes. Cardiovasc Res 2001;49:751-761.

3. Greiser M, Kerfant BG, Williams GS, Voigt N, Harks E, Dibb KM, Giese A, Meszaros J, Verheule S, Ravens U, Allessie MA, Gammie JS, van der Velden J, Lederer WJ, Dobrev D, Schotten U. Tachycardia-induced silencing of subcellular Ca2+ signaling in atrial myocytes. J Clin Invest 2014;124:4759-4772.

4. Voigt N, Li N, Wang Q, Wang W, Trafford AW, Abu-Taha I, Sun Q, Wieland T, Ravens U, Nattel S, Wehrens XH, Dobrev D. Enhanced sarcoplasmic reticulum Ca2+ leak and increased $\mathrm{Na}+\mathrm{Ca} 2+$ exchanger function underlie delayed afterdepolarisations in patients with chronic atrial fibrillation. Circulation 2012;125:2059-2070.

5. Huser J, Lipsius SL, Blatter LA. Calcium gradients during excitation-contraction coupling in cat atrial myocytes. J Physiol 1996;494 ( Pt 3):641-651.

6. Brandenburg S, Kohl T, Williams GS, Gusev K, Wagner E, Rog-Zielinska EA, Hebisch E, Dura M, Didie M, Gotthardt M, Nikolaev VO, Hasenfuss G, Kohl P, Ward CW, Lederer WJ, Lehnart SE. Axial tubule junctions control rapid calcium signaling in atria. J Clin Invest 2016;126:3999-4015.

7. Dibb KM, Clarke JD, Horn MA, Richards MA, Graham HK, Eisner DA, Trafford AW. Characterisation of an extensive transverse tubular network in sheep atrial myocytes and its depletion in heart failure. Circ Heart Fail 2009;2:482-489.

8. Frisk M, Koivumaki JT, Norseng PA, Maleckar MM, Sejersted OM, Louch WE. Variable t-tubule organisation and Ca2+ homeostasis across the atria. Am J Physiol Heart Circ Physiol 2014;307:H609-620.

9. Oral H, Crawford T, Frederick M, Gadeela N, Wimmer A, Dey S, Sarrazin JF, Kuhne M, Chalfoun N, Wells D, Good E, Jongnarangsin K, Chugh A, Bogun F, Pelosi F, Jr., Morady F. Inducibility of paroxysmal atrial fibrillation by isoproterenol and its relation to the mode of onset of atrial fibrillation. $J$ Cardiovasc Electrophysiol 2008;19:466-470.

10. Lampert R, Burg MM, Jamner LD, Dziura J, Brandt C, Li F, Donovan T, Soufer R. Effect of beta-blockers on triggering of symptomatic atrial fibrillation by anger or stress. Heart Rhythm 2019;16:1167-1173.

11. Redpath CJ, Rankin AC, Kane KA, Workman AJ. Anti-adrenergic effects of endothelin on human atrial action potentials are potentially antiarrhythmic. J Mol Cell Cardiol 2006;40:717-724.

12. Christ T, Rozmaritsa N, Engel A, Berk E, Knaut M, Metzner K, Canteras M, Ravens U, Kaumann A. Arrhythmias, elicited by catecholamines and serotonin, vanish in human chronic atrial fibrillation. Proc Natl Acad Sci U S A 2014;111:11193-11198.

13. Tian Q, Kaestner L, Lipp P. Noise-free visualisation of microscopic calcium signaling by pixel-wise fitting. Circ Res 2012;111:17-27.

14. Cannell MB, Berlin JR, Lederer WJ. Effect of membrane potential changes on the calcium transient in single rat cardiac muscle cells. Science 1987;238:1419-1423.

15. Schotten U, Haase H, Frechen D, Greiser M, Stellbrink C, Vazquez-Jimenez JF, Morano I, Allessie MA, Hanrath P. The L-type Ca2+-channel subunits alpha1C and beta2 are not downregulated in atrial myocardium of patients with chronic atrial fibrillation. J Mol Cell Cardiol 2003;35:437-443.

16. Brundel BJ, Henning RH, van Gilst WH, van Gelder IC, Crijns HJ. Molecular adaptations in human atrial fibrillation: mechanisms of protein remodelling. Neth Heart J 2001;9:235-239.

17. Yagi T, Pu J, Chandra P, Hara M, Danilo P, Jr., Rosen MR, Boyden PA. Density and function of inward currents in right atrial cells from chronically fibrillating canine atria. Cardiovasc Res 2002;54:405-415.

18. Lugenbiel P, Wenz F, Govorov K, Schweizer PA, Katus HA, Thomas D. Atrial fibrillation complicated by heart failure induces distinct remodeling of calcium cycling proteins. PLoS One 2015;10:e0116395.

19. Wakili R, Yeh YH, Yan Qi X, Greiser M, Chartier D, Nishida K, Maguy A, Villeneuve LR, Boknik P, Voigt N, Krysiak J, Kaab S, Ravens U, Linke WA, Stienen GJ, Shi Y, Tardif JC, Schotten U, Dobrev D, Nattel S. Multiple potential molecular contributors to atrial hypocontractility caused by atrial tachycardia remodeling in dogs. Circ Arrhythm Electrophysiol 2010;3:530-541.

20. Lenaerts I, Bito V, Heinzel FR, Driesen RB, Holemans P, D’Hooge J, Heidbuchel H, Sipido KR, Willems $\mathrm{R}$. Ultrastructural and functional remodeling of the coupling between $\mathrm{Ca} 2+$ influx and sarcoplasmic reticulum $\mathrm{Ca} 2+$ release in right atrial myocytes from experimental persistent atrial fibrillation. Circ Res 2009;105:876-885.

21. Louch WE, Bito V, Heinzel FR, Macianskiene R, Vanhaecke J, Flameng W, Mubagwa K, Sipido KR. Reduced synchrony of $\mathrm{Ca} 2+$ release with loss of T-tubules-a comparison to $\mathrm{Ca} 2+$ release in human failing cardiomyocytes. Cardiovasc Res 2004;62:63-73.

22. Christ T, Boknik P, Wohrl S, Wettwer E, Graf EM, Bosch RF, Knaut M, Schmitz W, Ravens U, Dobrev D. L-type Ca2+ current downregulation in chronic human atrial fibrillation is associated with increased activity of protein phosphatases. Circulation 2004;110:2651-2657. 
23. Wang SQ, Song LS, Lakatta EG, Cheng H. Ca2+ signalling between single L-type Ca2+ channels and ryanodine receptors in heart cells. Nature 2001;410:592-596.

24. Liu R, Feng HZ, Jin JP. Physiological contractility of cardiomyocytes in the wall of mouse and rat azygos vein. Am J Physiol Cell Physiol 2014;306:C697-704.

25. Brandenburg S, Pawlowitz J, Fakuade FE, Kownatzki-Danger D, Kohl T, Mitronova GY, Scardigli M, Neef J, Schmidt C, Wiedmann F, Pavone FS, Sacconi L, Kutschka I, Sossalla S, Moser T, Voigt N, Lehnart SE. Axial Tubule Junctions Activate Atrial $\mathrm{Ca}(2+)$ Release Across Species. Front Physiol 2018;9:1227.

26. Neef S, Dybkova N, Sossalla S, Ort KR, Fluschnik N, Neumann K, Seipelt R, Schondube FA, Hasenfuss G, Maier LS. CaMKII-dependent diastolic SR Ca2+ leak and elevated diastolic Ca2+ levels in right atrial myocardium of patients with atrial fibrillation. Circ Res 2010;106:1134-1144.

27. Vest JA, Wehrens XH, Reiken SR, Lehnart SE, Dobrev D, Chandra P, Danilo P, Ravens U, Rosen MR, Marks AR. Defective cardiac ryanodine receptor regulation during atrial fibrillation. Circulation 2005;111:2025-2032.

28. Laszlo R, Winkler C, Wohrl S, Laszlo S, Eick C, Schreieck J, Bosch RF. Influence of verapamil on tachycardia-induced alterations of PP1 and PP2A in rabbit atrium. Exp Clin Cardiol 2007;12:175-178.

29. Johnson DM, Antoons G. Arrhythmogenic Mechanisms in Heart Failure: Linking beta-Adrenergic Stimulation, Stretch, and Calcium. Front Physiol 2018;9:1453.

30. Marx SO, Reiken S, Hisamatsu Y, Jayaraman T, Burkhoff D, Rosemblit N, Marks AR. PKA phosphorylation dissociates FKBP12.6 from the calcium release channel (ryanodine receptor): defective regulation in failing hearts. Cell 2000;101:365-376.

31. Wehrens XH, Lehnart SE, Reiken S, Vest JA, Wronska A, Marks AR. Ryanodine receptor/calcium release channel PKA phosphorylation: a critical mediator of heart failure progression. Proc Natl Acad Sci U S A 2006;103:511-518.

32. Zhang H, Makarewich CA, Kubo H, Wang W, Duran JM, Li Y, Berretta RM, Koch WJ, Chen X, Gao E, Valdivia HH, Houser SR. Hyperphosphorylation of the cardiac ryanodine receptor at serine 2808 is not involved in cardiac dysfunction after myocardial infarction. Circ Res 2012;110:831-840.

33. Lindegger N, Niggli E. Paradoxical SR Ca2+ release in guinea-pig cardiac myocytes after beta-adrenergic stimulation revealed by two-photon photolysis of caged Ca2+. J Physiol 2005;565:801-813.

34. Maxwell JT, Blatter LA. A novel mechanism of tandem activation of ryanodine receptors by cytosolic and SR luminal $\mathrm{Ca}(2+)$ during excitation-contraction coupling in atrial myocytes. J Physiol 2017;595:38353845 .

35. Voigt N, Heijman J, Wang Q, Chiang DY, Li N, Karck M, Wehrens XHT, Nattel S, Dobrev D. Cellular and molecular mechanisms of atrial arrhythmogenesis in patients with paroxysmal atrial fibrillation. Circulation 2014;129:145-156.

36. Beavers DL, Wang W, Ather S, Voigt N, Garbino A, Dixit SS, Landstrom AP, Li N, Wang Q, Olivotto I, Dobrev D, Ackerman MJ, Wehrens XHT. Mutation E169K in junctophilin-2 causes atrial fibrillation due to impaired RyR2 stabilisation. J Am Coll Cardiol 2013;62:2010-2019.

37. Dries E, Bito V, Lenaerts I, Antoons G, Sipido KR, Macquaide N. Selective modulation of coupled ryanodine receptors during microdomain activation of calcium/calmodulin-dependent kinase II in the dyadic cleft. Circ Res 2013;113:1242-1252.

38. Sheehan KA, Zima AV, Blatter LA. Regional differences in spontaneous Ca2+ spark activity and regulation in cat atrial myocytes. J Physiol 2006;572:799-809.

39. Woo SH, Cleemann L, Morad M. Spatiotemporal characteristics of junctional and nonjunctional focal $\mathrm{Ca} 2+$ release in rat atrial myocytes. Circ Res 2003;92:e1-11. 
Adrenergic control of RyR $\mathrm{Ca}^{2+}$-release microdomains in atrial fibrillation | 


\section{Chapter V}

\section{Quantification of local strain heterogeneities in isolated cardiomyocytes}

Vedrana Balicevica' ${ }^{1}$, Patrick Schönleitner ${ }^{2}$, Maria J. Palazzi ${ }^{3}$, Gudrun Antoons ${ }^{2}$, Sven Loncarica' ${ }^{1}$, Bart Bijnens ${ }^{4}$, Patricia Garcia-Canadilla ${ }^{5}$

${ }^{1}$ University of Zagreb Faculty of Electrical Engineering and Computing, Zagreb, Croatia ${ }^{2}$ Department of Physiology, Maastricht University, Maastricht, The Netherlands ${ }^{3}$ Internet Interdisciplinary Institute (IN3), Universitat Oberta de Catalunya, Barcelona, Catalonia, Spain ${ }^{4}$ ICREA, Barcelona, Spain

${ }^{5}$ Institut d'Investigacions Biomèdiques August Pi i Sunyer, Barcelona, Spain 
$A$ 


\section{ABSTRACT}

Aim: Heart muscle contraction is governed by the propagation of action potentials along myocytes. Though myocardial deformation is mostly studied in the whole heart, recent reports have identified subcellular alterations that can be associated with some pathological conditions. In this paper, we provide an image processing framework for quantifying local contraction mechanics by means of strain and strain rate from line scan images of isolated cardiomyocytes.

Methods and Results: Contractions in time and space were captured with confocal microscopy. We reached sub-pixel precision in local displacement quantification using a 1D spline interpolation of raw cross-correlation results, followed by Laplace-based restoration of a velocity function and a priori based restrictions of cell motion. Strain rate was computed as a spatial derivative of velocities and strain as a temporal integration of the strain rate. We tested our algorithm on a synthetic dataset

that realistically captures cellular contraction, and sets of imaged line scans from rat and rabbit myocytes. First, we evaluated the performance of the method with respect to a synthetic and manually annotated ground truth. Thereafter, we employed the method to analyse differences in subcellular heterogeneities in strain and strain rate in myocytes subjected to interventions known to alter contractile kinetics.

Conclusion: The described algorithm can semi-automatically analyse image-based heterogeneous strain and strain rate along contracting cardiomyocytes from confocal line scan images. We demonstrate that the method can detect differences in subcellular strain and strain rate and could be used to investigate subcellular myocardial mechanics in health and disease on readily available images. 


\section{INTRODUCTION}

Myocardial contraction is a response of cardiac muscle tissue to the electrical activity that occurs with each heartbeat. It is commonly quantified through regional deformation (strain) and deformation rate (strain rate). Non-invasive assessment of strain and strain rate at the whole heart level is common in clinical practice using tissue Doppler imaging or speckle tracking echocardiography. ${ }^{1,2}$ To distinguish between myocytes or sarcomeres, the basic contractile units, resolving powers of these modalities are not sufficient.

Structural differences, spatial distributions of cellular organelles and sarcomere lengths, were found in several disease models. ${ }^{3-5}$ Association between local sarcomere re-lengthening and dyssynchrony in $\mathrm{Ca}^{2+}$ release was experimentally established by Hohendanner et al. ${ }^{6}$, suggesting a novel mechanism of contractile dysfunction. These studies emphasise the need for quantifying cardiomyocyte deformation at a subcellular level.

Since manual annotation of subcellular motion in images is labour-intensive and time-consuming, several automated approaches have been proposed. Fourier transformation was applied to measure mean sarcomere and mitochondria deformation along orthogonal short-axes from confocal images of dyed cells. ${ }^{7}$ Another approach quantified subcellular strains using a correlation-based algorithm in low-resolution time-lapse sequences recorded with phase contrast and differential interface contrast video-microscopy. ${ }^{8}$ In a similar set of images, authors registered the observed motion to a template of cell motion. ${ }^{9}$ Most recently, a new multimodal imaging system was proposed, featuring a built-in algorithm for acquiring strain at a sarcomere level. ${ }^{10}$

In this study, we propose an algorithm that can analyse subcellular strain and strain rate in confocal line-scan images of contracting cardiomyocytes at high temporal and spatial resolution. We begin the analysis by quantifying mean cellular deformation per each scan line and advance towards a detailed assessment of intracellular strain and strain rates. To validate the algorithm, we synthesize a set of images using known deformation kernels that capture realistic properties of contracting cardiac myocytes. To demonstrate the method's capacity to detect changes in subcellular deformation we analyse confocal line scan images recorded from ventricular and atrial myocyte subjected to changes in temperature, beta-adrenergic stimulation and varying degrees of mechanical load, to alter contractile kinetics.

\section{MATERIALS AND METHODS}

\section{Image acquisition}

All animal experiments were approved by the local animal welfare body (DEC2014-112) and performed in accordance with the Directive 2010/63/EU of the European Parliament on the protection of animals used for scientific purposes. Freshly isolated ventricular cardiomyocytes were obtained from adult male Wistar rats (250g, Envigo, UK), following a standard enzymatic isolation procedure. ${ }^{11}$ Atrial myocytes were isolated from New Zealand White Rabbits (2-3 kg, Envigo, UK) of either sex based on a previously published method. ${ }^{12}$ Rat ventricular cells were superfused with Tyrode solution (NT) containing (in $\mathrm{mmol} / \mathrm{L}$ ): 
$\mathrm{NaCl} 136, \mathrm{KCl} 5.4, \mathrm{CaCl}_{2} 1.8, \mathrm{MgCl}_{2} 1$, HEPES 10, glucose 10; and $\mathrm{pH}$ adjusted to 7.40 with $\mathrm{NaOH}$ at $37^{\circ} \mathrm{C}$. In a subset of cells, the sarcolemma (cell membrane) and its T-tubules (transverse extensions that protrude into the cell) were stained with 5 M FM4-64 for 10 min (Life Technologies/Invitrogen). A pressurized perfusion system delivered experimental solutions locally. A multi-channel inline heater with a single outlet (Cell MicroControls, Norfolk, USA) was used to control/change temperature and switch between experimental solutions. To mimic sympathetic stimulation rat, ventricular cells were treated $300 \mu \mathrm{M}$ isoprenaline (ISO) To reach a steady-state effect myocytes were recorded after 5 min of incubating with the compound.

For experiments with rabbit atrial myocytes, cells were glued to glass needles coated with Myotak (IonOptix LCC, US) by pressing down on either end of the cell before lifting them off the bottom of the experimental chamber. The system was controlled with a pair of 3 axis micromanipulators. One glass needle was mounted on a direct drive piezo actuator (MCL, Wisconsin USA) to control cell length. The piezo was driven by the analogue output of a Digidata 1440 AD converter (Molecular Devices, Berkshire, UK). Cells were stretched by $20 \%$ (calculated from the distance between the attachment point of either glass needle).

Myocytes were imaged while being stimulated in an electric field after a $60 \mathrm{~s}$ of stimulation to reach a steady state. Images were recorded, either with an inverted Zeiss AxioObserver Z1 microscope with a 40x/1.3 oil immersion objective and equipped with Zeiss LSM 700 confocal laser scanning unit, or a TE-2000-U inverted microscope (Nikon, Amsterdam, Netherlands) equipped with a C1 confocal line scan unit (Nikon, Amsterdam, Netherlands). The transmitted laser light was collected to record the light image. Pixel size for rat ventricular cells was set at $0,1 \mu \mathrm{m}$ with a scan speed of $1.7 \mathrm{~ms}$ per scan line, for rabbit atrial myocytes pixel size was set to $0.2 \mu \mathrm{m}$, the scan speed remained at $1.7 \mathrm{~ms}$ per scan line. For FM4-64 images, the dye was excited with a $488 \mathrm{~nm}$ laser and emission detected above $650 \mathrm{~nm}$. The scan line was set parallel to the longitudinal axis, covering the full myocyte length in the

A

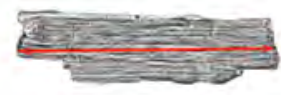

B

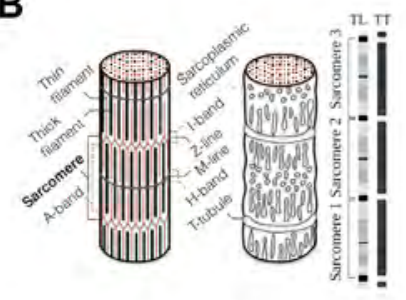

C

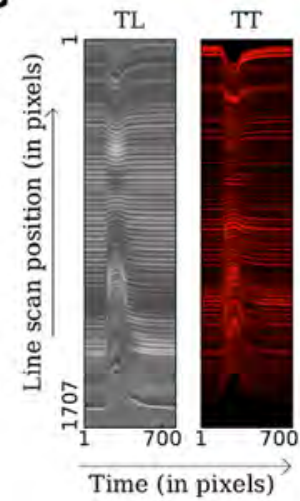

Figure 1: A Example of an isolated cardiomyocyte with a denoted scan line. B Simplified schematic of structures along cardiomyocytes and patterns as captured by confocal line-scan imaging in an ideal (noiseless) case, for transmitted light (TL) and confocal T-tubules (TT) imaging. Patterns are representative of the internal cellular structure. In TL scans, sarcomeres appear as alternating dark Z-disks and light I/A-bands, as compared to alternating light T-tubules and dark I/A-bands in TT scans. T-tubules anchor to Z-disks, thus performing similar local motion to sarcomeres during contraction. C Examples from TL and TT line scan sequence of a rat myocyte. 
focal plane (Fig 1 A). Scanned profiles were stacked in time to form 2D line-scan images. Fig $1 \mathrm{~B}$ illustrates the internal structure of a myocyte and introduces the acquired images cropped to a single contraction period shown in Fig $1 \mathrm{C}$.

\section{Construction of synthetic data sets}

Synthesising line-scan images of isolated contracting cardiomyocytes assumes that the spatio-temporal distributions of strain and the line scan cell patterns are known aforehand.

\section{Definition of strain kernels}

In order to illustrate the deformation effects along the two imaging directions, we defined separable 2D strain kernels via two orthogonal 1D kernels: spatial and temporal, respectively.

- Spatial (vertical) 1D deformation kernel Sinusoidal - with amplitude defining the maximum strain value and period reflecting the level of spatial heterogeneity (number of strain peaks along a scan line).

$$
c(x)=A\left(\cos \frac{2 \pi}{N} x+1\right)
$$

- Temporal (horizontal) 1D deformation kernels Sinusoidal - defined in the first half-period of a sine function to mimic a contraction-relaxation symmetry.

$$
s(t)=\left\{\begin{array}{cc}
-\sin \frac{2 \pi}{T} t, & \text { if } t \in\left\lfloor(2 k+1) \frac{T}{2}, k T\right\rfloor \\
0, & \text { otherwise }
\end{array}\right.
$$

- Gaussian - a summation of two Gaussian functions, where the latter one has a smaller amplitude to introduce the asymmetry by prolonging the relaxation period.

$$
g(t)=A_{1} \exp \left(\frac{t-\mu_{1}}{\sqrt{2} \sigma_{1}}\right)^{2}+A_{2} \exp \left(\frac{t-\mu_{2}}{\sqrt{2} \sigma_{2}}\right)^{2}
$$

- 2D deformation kernels The desired 2D strain kernels are obtained by multiplying the spatial kernel with the temporal kernels: $\sigma_{1}(t, x)=s(t) c(x)$ and $\sigma_{2}(t, x)=g(t) c(x)$. They are designed to deform a $1 \mathrm{D}$ line scan pattern $I\left(t_{0}, x\right)$ by displacing its pixels via $I\left(t, x+\int, \sigma(t, x) d t\right)=I\left(t_{0}, x\right)$.

\section{Generating ideal synthetic images}

Striated patterns of intracellular structures are formed and deformed with respect to simulated modality:

Transmitted light line-scans (TL) - Two grey values were assigned to each sarcomere, alternating bright I/A bands and dark Z-discs, with their lengths being randomly varied along the scan-line. The strain kernel deforms this pattern into an image in $x$ - $t$ (spatio-temporal) space. In reality, cell thickening or thinning along the remaining orthogonal directions $(y$ and $z$ ) also affects the amount of light captured by pixel intensities. We thus modulate the intensity, in the same manner we modulated the strain in $x$ direction - by multiplying it with a product of two cosine functions, one for each remaining direction. 
- $\quad$ Confocal T-tubules line-scans (TT) - The striation pattern was obtained by alternating thin bright T-tubules and thick dark I/A bands, thus simultaneously restricting the intensities and the thickness values. Strain kernels transform this pattern into 2D images. Intensity fluctuation induced by cell contracting in 3D space is absent in fluorescence (TT) imaging.

The described series of operations corresponds to $I(t, x)=T_{i}\left[\sigma\left[I\left(t_{0}, x\right)\right]\right]$, where $I\left(t_{0}, x\right)$ denotes the initial pattern, $\sigma$ describes the pattern deformation and $T_{i}$ is the pixel intensity modulation (applied only for TL images).

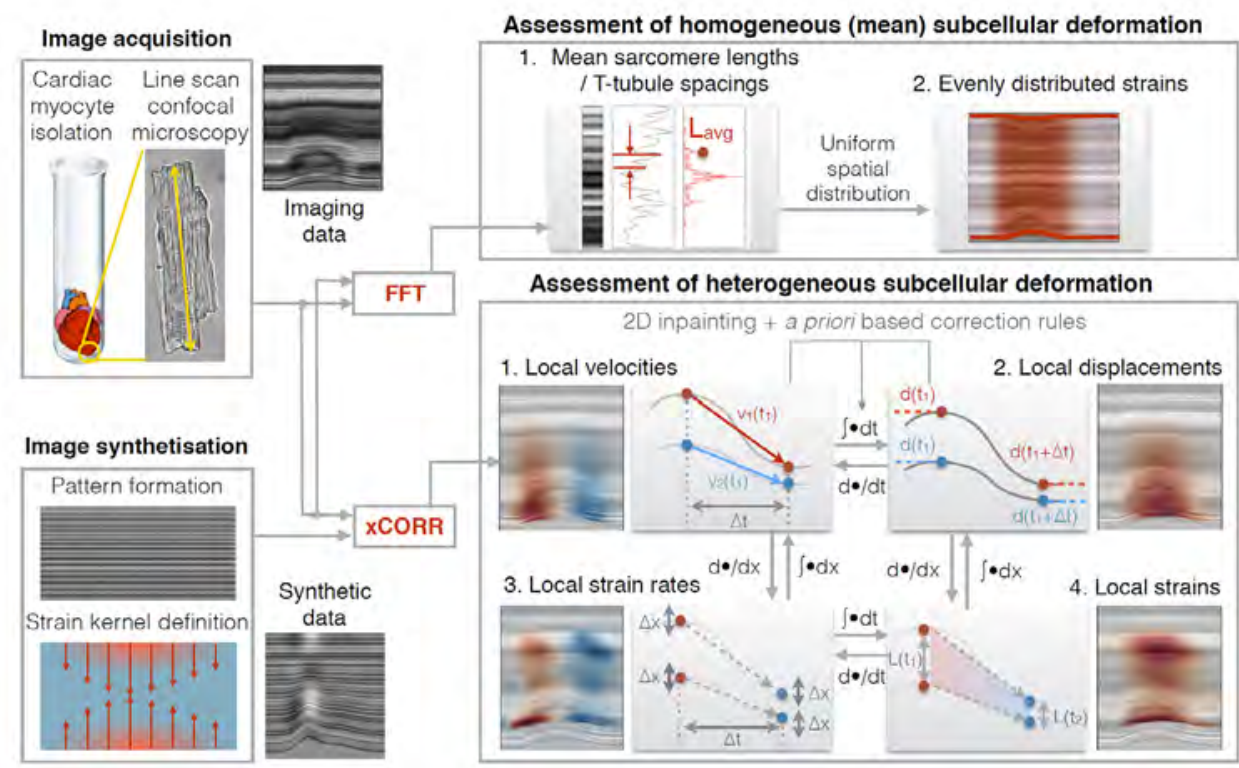

Figure 2: Flowchart of approaches for assessing average and heterogeneous subcellular strain. Two sets of confocal line scan images of contracting cells are introduced - real and synthetic ones. The first approach uses a Fourier transform (FFT) to reach average lengths of observed contractile units $\left(\mathrm{L}_{\mathrm{avg}}\right)$ and thus mean cell strains. The proposed method uses local cross-correlations (xCORR) to translate an image into local velocity measurements. Local displacements, strain rates, and strains follow as illustrated, with inpainting and correction rules that regularise the velocity and displacement calculation. A preview of each result is complemented with its descriptive illustration.

\section{Image degradation}

Noise in microscopy imaging is the combination of thermal (Gaussian) noise in mechanical components and photon (Poisson) noise correlated with the amount of captured photons. The apparent difference in brightness between TL and TT imaging causes the Poisson noise to either diminish or overpower, allowing us to model their degradation separately. To synthesize a noisy TL line scan, we add a zero-mean white Gaussian noise $N_{G}$ to a noiseless image: $I_{N}(t, x)=I(t, x)+N_{G} \quad$. Since this noise is independent of the image content, its power can be increased by increasing the noise variance. For creating a noisy TT image, we have to consider that photon noise $N_{P}$ is related to pixel brightness, so it, in fact, applies as modulation of pixel intensities: $I_{N}(t, x)=N_{P}(I(t, x))$. Specifically, increasing the power of Poisson noise corresponds to decreasing the number of the counted signal photons, which can virtually be obtained by adding the background signal. 
The virtual resolution of all simulated images is $0.1 \mu \mathrm{m}$ and $1,9 \mathrm{~ms}$ per scan line with $1 \mathrm{~Hz}$ for a contraction cycle and $1024 \times 512$ image size. Patterns' parameters were adjusted to match the scale of captured cell structures with the simulated resolution, while deformation kernels' parameters correspond to acquired contraction durations and magnitudes of strain. Noise parameters were tuned to simulate a wide range of signal-to-noise (SNR) ratios. Fig 3 shows examples of synthetic images.
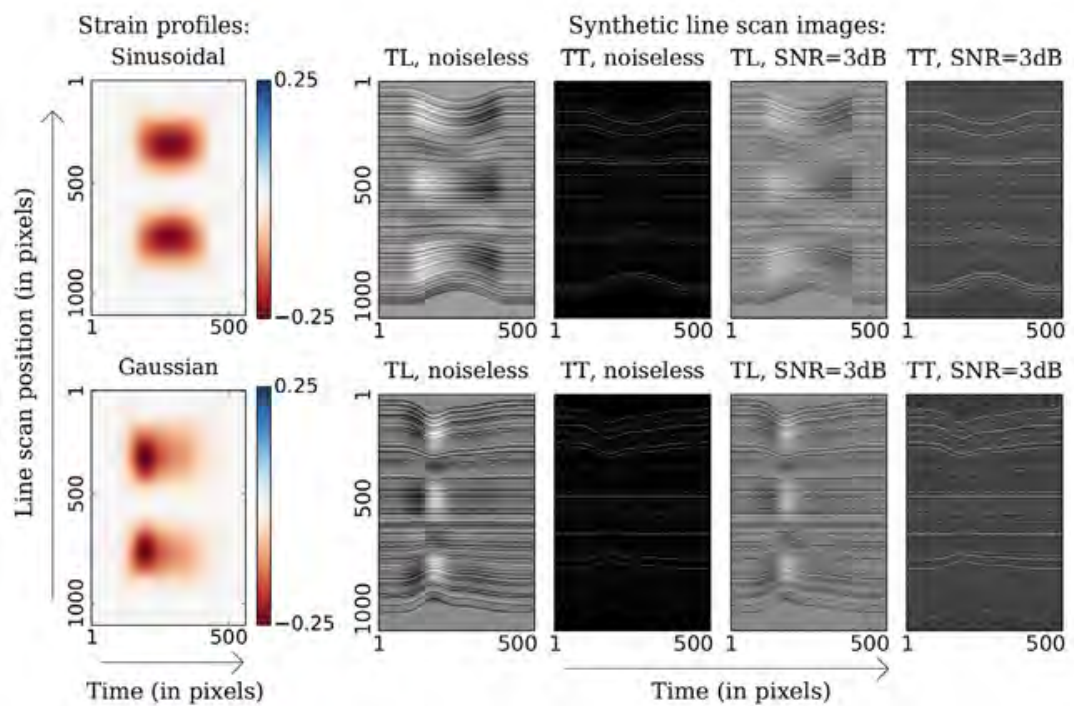

Figure 3: Top row shows a 2D sinusoidal strain kernel, followed by corresponding synthetic transmitted light (TL) and T-tubules (TT) images in a noiseless setting and with modality-dependant noise at $\mathrm{SNR}=3 \mathrm{~dB}$. The bottom row shows equivalent images for a Gaussian strain profile.

\section{Quantification of mean cell deformation}

For quantifying cell deformation, we first assess measures that can be observed at a wholecell level. This refers to the average length and strain per contractile unit, which corresponds to the mean cell strain.

We calculated the mean length of repetitive contractile units in each time point by calculating a Fourier transform (FFT) for each scan line along the contraction period T. Since the Fourier domain assumes the periodicity of an input signal, we suppressed the boundary effects with an FFT-correcting window $w(x)$. To gain subpixel precision, we performed a 1D spline interpolation of each FFT spectrum. The peak in each interpolated spectrum corresponds to the most expressed frequency $\omega_{\max }(t)$ in line scan at time instance $t$ :

$$
\omega_{\max }(t)=\arg \max _{\omega}\left|F F T_{x}(w(x) \cdot I(t, x))\right|, \forall t \in[0, T]
$$

This relates to the most frequent length $L_{a v g}(t)$ via $L_{a v g}(t)=2 \pi / \omega_{\max }(t)$, which is the average sarcomere length for TL line scans and average T-tubule spacing for TT line scans.

By definition, global cell deformation is the instantaneous cell length $\left(L_{\text {Cell }}(t)\right)$ divided with the resting cell length measured at $t_{0}$ : 


$$
\sigma_{G T}(t)=\frac{L_{\text {Cell }}(t)}{L_{\text {Cell }}\left(t_{0}\right)}
$$

For this procedure, we assume the homogeneity in subcellular deformation, which is a special case where the difference between global and local deformations vanishes. Given that a cell consists of $N$ equally long contractile units which contract identically, $L_{\text {Cell }}(t)=N \cdot L_{\text {avg }}(t)$, plugging this into Eq. 5 simulates an even distribution of a mean strain along the cell:

$$
\sigma_{F F T}(t, x)=\frac{L_{\text {avg }}(t)}{L_{\text {avg }}\left(t_{0}\right)}, \forall x \operatorname{in}[1, N]
$$

We further refer to average strain as the "FFT-based strain estimate".

A

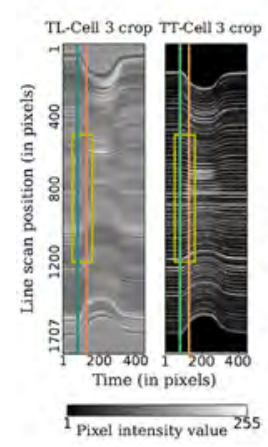

B

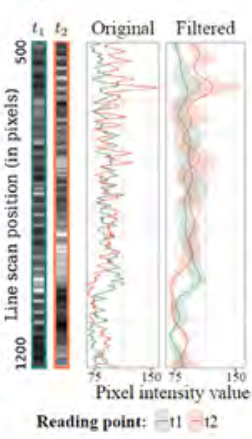

C

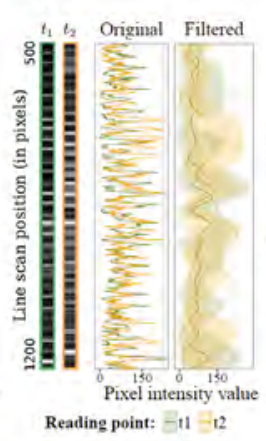

D

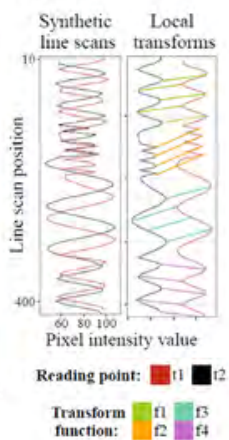

Figure 4: Review of imaged line scan patterns: A TL and TT image crops in grayscale. Vertical lines correspond to line scans at time points $\mathrm{t} 1$ and $\mathrm{t} 2=\mathrm{t} 1+\Delta \mathrm{t}$. Plots alongside show magnified line scan segments from within the square. B TL line scans as 1D images, ie signals. High-frequency components correspond to the alternating sarcomeres (left), and low-frequency components represent local illumination changes (right). Envelope around the low frequency shows the local dynamic range of pixel intensities. C TT line scans, equivalent to B. D A synthetic example that illustrates the assumed transform between two line scans.

\section{Quantification of local cell deformation}

Reducing the FFT window size to capture local strains of small pixel neighbourhoods is ineffective as it reduces the FFT precision substantially. Therefore, we formulate an approach based on a cross-correlation algorithm that maintains the accuracy in strain assessment at the subcellular level.

\section{Local displacement and velocity estimation}

Assessment of local displacements in contracting myocytes assumes that a local brightness pattern along a cell can be identified in each time instance, despite changes in sarcomeres lengths. We propose to trace local patterns in time using cross-correlation coefficient as a similarity measure, adapted to the content of line scan images. Fig 4 clarifies the concept of this solution.

We select a template, an image patch $T\left(t, x_{c}\right)$ at time instance $t$ as a column vector of pixel intensities at locations $\boldsymbol{x}_{c}=x_{c} \pm i, \forall i \in[-n / 2, n / 2]$, where $n$ is the total number of pixels around a central location $\boldsymbol{x}_{c}$ that are being tracked simultaneously. If all points within the template 
make the same small vertical movement $\Delta x$ in given time $\Delta t$, we can compare this template to the same size image patches at time instance $t+\Delta t$ (see Fig $4 \mathrm{D}$ ). This allows us to limit the options for comparison to a reasonably small vertical window of size $w$, thus regularising the maximal possible movement. Test patches that slide along this window are denoted as $F\left(t+\Delta t, \mathbf{x}_{w}\right)$, where $\boldsymbol{x}_{w}=x_{c} \pm i, \forall i \in[-w / 2, w / 2]$. Cross-correlation between a template $T$ and the applicable test patches $F$ is then:

$$
R_{T T F}(\Delta x)=\frac{\sum\left[(t, x)-\overline{T_{t, x}}\right][F(t+\Delta t, x+\Delta x)-\bar{F}]}{\sqrt{\sum\left[T(t, x)-\bar{T}_{t, x}\right]^{2} \sum[F(t+\Delta t, x+\Delta x)-\bar{F}]^{2}}}
$$

Here, $\bar{T}$ and $\bar{F}$ represent mean values within each patch. $\Delta x$ is the shift within $[-w / 2, w / 2]$ around the central pixel $x_{c}$ and is quantised to an integer multiple of the pixel size. Normalisation eliminates the sensitivity to possible illumination changes. To improve the localisation with sub-pixel precision, we interpolated the cross-correlation coefficient vector for each pixel with a 1D cubic spline function (a piecewise cubic curve with continuous second derivative). Instantaneous displacements then correspond to $\Delta x$ values which maximise the interpolated cross-correlation coefficient:

$$
\Delta d(t, x)=\arg \max _{\Delta x} R_{T \mid F}(t, x, \Delta x)
$$

From instantaneous displacements, local velocities follow as $v(t, x)=\Delta d(t, x) / \Delta t$, and local displacements as $d(t, x)=\int d(t x) d t$. Thresholding of the correlation coefficient allows us to dismiss unreliable velocity values but introduces discontinuities in the $2 \mathrm{D}$ velocity function.

\section{Restoration of missing velocity values (Laplace interpolation inpainting)}

Discontinuities in a velocity function are irregularly shaped and scattered throughout the image. Their restoration requires a more sophisticated interpolation method, as in. We choose to pursue a smooth solution within each non-defined region with a Laplace equation $\nabla^{2} v=0$ in 2D:

$$
\frac{\partial^{2} v}{\partial^{2} t}+\frac{\partial^{2} v}{\partial^{2} x}=0
$$

For each pixel with coordinates $\left(t_{i}, x_{i}\right)$ from within a non-defined area, discretisation in a 4-neighbourhood via:

$$
\left.\frac{\partial^{2} v}{\partial^{2} t}\right|_{t_{i}} \approx \frac{v\left(t_{i}+\Delta t, x_{i}\right)-2 v\left(t_{i}, x_{i}\right)+v\left(t_{i}-\Delta t, x_{i}\right)}{(\Delta t)^{2}}
$$

reduces a second-order partial differential equation to a linear one, where $u, d, l$ and $r$ are its four neighbouring pixels (up, down, left and right) with $(\Delta t, \Delta x)$ distances equal to $(1,1)$ :

$$
v_{i}=\frac{1}{4}\left(v_{i, u}+v_{i, d}+v_{i, l}+v_{i, r}\right)
$$

Equations for unknown pixels are complemented with equivalent ones for known pixels on the region boundary. The solution to this set of equations is a continuous velocity function. 

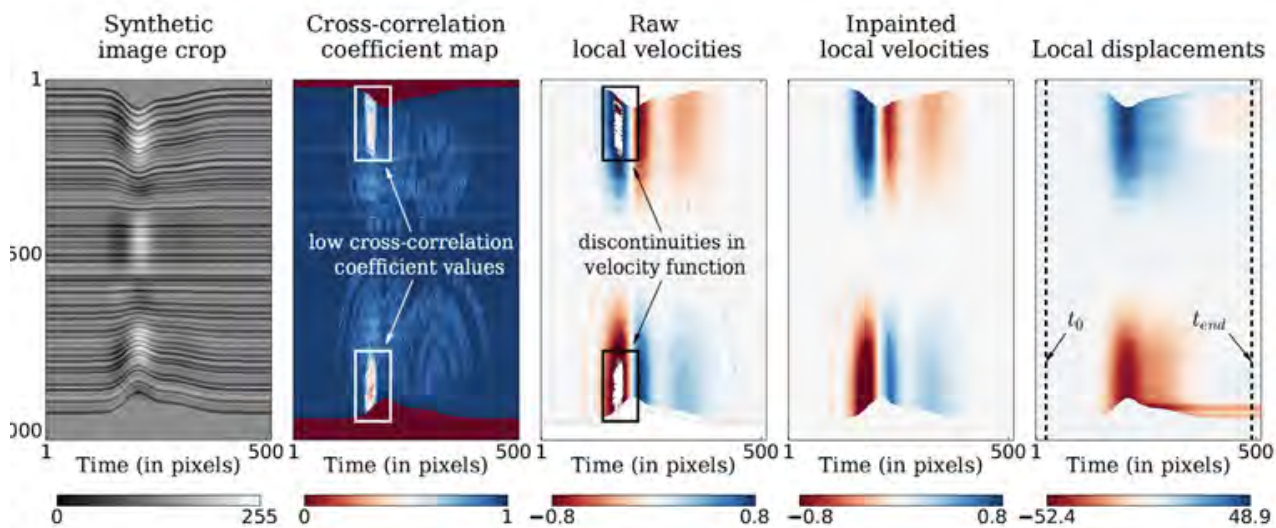

Figure 5: From left to right: A synthetic TL line scan image, cross-correlation coefficient map, velocity map obtained by thresholding the cross-correlation coefficient values, inpainted velocity map, and local displacements map with denoted initial time point $\mathrm{t}_{0}$ and end time point $\mathrm{t}_{\text {end }}$.

\section{Velocity and displacement correction scheme}

Local positions of sarcomeres follow as $l(t, x)=x+d(t, x)$. Reaching a steady state at the end of a contraction means that all sarcomeres return to their initial positions: $l\left(t_{0}, x\right)=l\left(t_{\text {end }}, x\right)$, implying zero displacements: $d\left(t_{\text {end }}\right)=d\left(t_{0}\right)=0$. Elimination of any occurrence of non-zero displacement values at $t_{\text {end }}$ is preferred (Fig 5), as it ensures the viability of repetitive contractions. To do this line scan images, we introduce a set of a priori imposed corrections:

I) Zero-displacement steady state: A positive displacement drift is primarily caused by underestimating negative velocity values and vice-versa. We introduce a velocity correction term to counteract the displacement drift $d$ in the opposite direction:

$$
v_{\text {corr }}(t, x)=\left\{\begin{array}{l}
v^{(-)}(t, x)-\frac{d\left(t_{\text {end }}, x\right)}{T^{(-)}}, \text {for } d\left(t_{\text {end }}, x\right)>0 \\
v^{(+)}(t, x)-\frac{d\left(t_{\text {end }}, x\right)}{T^{(+)}}, \text {for } d\left(t_{\text {end }}, x\right)<0
\end{array}\right.
$$

Here, $T^{(+)}$and $T^{(-)}$denote time periods where the velocity values along the local line scan position are positive $v^{(+)}$or negative $v^{(-)}$, respectively.

II) Fixed cell boundaries: All sarcomeres are enclosed within the cell boundaries. The motion of sarcomeres closest to the edge is consistent with the global deformation of the cell:

$$
l_{\text {corr }}(t, x)=(1-\lambda(x)) l(t, x)+\lambda(x) l\left(t, x_{\text {end }}\right)
$$

Here, $l$ and $l_{\text {corr }}$ are sarcomere locations before and after correction, respectively, and $\lambda$ is the extent of the cell border influence. It is modelled with a monotonically decreasing part of a Gaussian function dependent on a sarcomere distance from the border, with $x_{\text {end }}$ denoting the border coordinate. 
III) Smooth contraction: Local interconnections of subcellular elements within the contracting myocyte resist to an extensive deformation heterogeneity. Since spatial and temporal imaging resolutions are not correlated, we perform local regression smoothing in time and space separately. The idea is to approximate localised subsets of data with a local polynomial of 1 st or 2 nd degree, whichever minimises the regression error in the local neighbourhood.

\section{Strain and strain rate estimation}

We calculate the strain rate $(\sigma)$ as the spatial derivative of the estimated velocity (Eq.14). The natural or Eulerian strain $\left(\sigma_{E}\right)$ is then a temporal integration of the strain rate (Eq.15):

$$
\begin{gathered}
\sigma_{E}^{\grave{\mathrm{U}}}(t, x)=\frac{d}{d x} v(t, x) \\
\sigma_{E}(t, x)=\int_{t}{ }_{t}^{\stackrel{\mathrm{U}}{\sigma_{E}}}(t, x) d t
\end{gathered}
$$

The Eulerian strain expresses strain as a function of a Cartesian spatial coordinate $x$ and time. The lagrangian strain is assessed via $\sigma_{L}\left(t, x^{\prime}\right)=\exp \left(\sigma_{E}(t, x)\right)-1$ and expresses the strain as a function of a sub-cellular point $x^{\prime}$ and time, thus acknowledging the cell structure.

\section{Manual annotation of acquired images}

To calculate a ground truth for local cell strain in the acquired images, sarcomere edges in TL images and T-tubules in TT images were manually annotated along two scan lines: one positioned in a region before the initiation of contraction and the other at the moment of maximal re-lengthening. Local lengths of annotated patterns were determined by subtracting $x$ coordinates of vertically consecutive annotations. Local strains were then calculated by definition, by dividing the change in length of each annotated pattern with its original length.

\section{Evaluation scheme}

Experiments were performed so that follows the advance in I) complexity of image content - starting from a simplified abstract dataset to a set of more complex acquired images, and II) the level of analysis of cell contraction mechanics, from mean to exact subcellular deformation quantification. All images were analysed in grayscale.

The resolution of synthetic images was validated via mean sarcomere lengths and T-tubules spacings. To unfold the concentrated mean strain value along the cell length, the strain was assumed to be homogeneously distributed, allowing us to assess deviations of the mean strain from the local ground truth. The selected error metrics are the root mean square (RMS) error (Eq.17) and the deviation in strain estimation at the time instance where ground truth strain reaches its maximum value (Eq.17). 


$$
\begin{array}{r}
e_{r m s}=\frac{1}{\max \left(\left|\sigma_{G T}\right|\right)} \sqrt{\frac{1}{N} \Sigma\left(\sigma_{G T}-\sigma \Phi^{2}\right.} \\
e_{\max }=\left.\frac{1}{\max \left(\left|\sigma_{G T}\right|\right)}\left(\max \left(\left|\sigma_{G T}\right|\right)-\max (\mid \sigma \Phi) \mid\right)\right|_{\max }
\end{array}
$$

Here, $\sigma \notin$ denotes the estimated strain, $\sigma_{G T}$ is the ground truth strain, $t_{\max }$ is the temporal coordinate of $\sigma_{G T}$ maximum and $N$ is the number of pixels in an image. Both errors were calculated for ground truth strain kernels and normalised with the maximum ground truth strain value.

Cross-correlation based registration of subcellular patterns translates an image into a set of measurements of subcellular mechanics. Accordingly, its parameters determine the accuracy of a local strain estimation. To understand their individual influence on the result, we performed a parameter sensitivity study with synthetic line-scan images. Evaluated parameters were: (1) $\Delta T$ - temporal shift between a template and a comparable pattern, (2) $n$ - template size, (3) $w_{\max }$ - maximum allowed displacement and (4) $\theta$ - cross-correlation coefficient threshold. We examined the algorithm in 4D parameter space defined with a plausible range of parameter values. The causal relationship between the algorithm parameters (predictor variables) and the RMS error (predicted value) was evaluated with multivariate linear regression, i.e. its $\beta$ coefficients:

$$
e_{r m s}=\beta_{0}+\beta_{\Delta T} \Delta T+\beta_{w_{\max }} w_{\max }+\beta_{n} n+\beta_{\theta} \theta
$$

The optimal set of parameter values was identified as the one that minimises the RMS error.

To determine the limitations of the method in noisy conditions, the algorithm with optimal parameter settings was further tested on images degraded with modality-specific noise. The level of noise was quantified by means of signal-to-noise ratio, $S N R=10 \log \left(I^{2} / N^{2}\right)$.

In the set of imaged line scans, the optimal parameters were adjusted considering the respective imaging resolutions. The evaluation was performed using the same error metrics as in the evaluation of the synthetic dataset.

The proposed method was also evaluated on TL scans of myocytes subjected to interventions known to modify contractility on a whole-cell level in different environments: I) In rat ventricular myocytes at body temperature $\left(37^{\circ} \mathrm{C}\right)$ and at room temperature $\left(21^{\circ} \mathrm{C}\right)$. II) In response to adrenergic stimulation. III) Atrial rabbit myocytes subjected to varying degrees of preload.

In these three experiments, heterogeneity in subcellular strain was evaluated by means of standard deviation (SD) along three scan lines that capture contraction at its three key moments: at time of half-maximal contraction $\left(t \sigma_{\text {con }}\right)$, peak contraction $\left(t \sigma_{\max }\right)$, and half-maximal relaxation $\left(t \sigma_{\text {rel }}\right)$.: 


$$
\begin{aligned}
& \left.\mathrm{t}\right|_{\sigma_{\text {con }}} \text {, where } \sigma_{\text {con }}=\frac{\sigma_{\max }}{2} \text { and } \frac{\mathrm{d} \sigma}{\mathrm{dt}}<0 ; \\
& \left.\mathrm{t}\right|_{\sigma_{\max }}, \text { where } \sigma_{\max }=\max \sigma ; \\
& \left.\mathrm{t}\right|_{\sigma_{\text {red }}} \text {, where } \sigma_{\text {re }}=\frac{\sigma_{\max }}{2} \text { and } \frac{\mathrm{d} \sigma}{\mathrm{dt}}>0 ;
\end{aligned}
$$

\section{Statistics}

Data are shown as mean \pm SEM. Statistical comparisons were made using paired student t-test, 2-way ANOVA, or 1-way ANOVA where applicable. A p-value $<0.05$ was considered statistically significant.

A

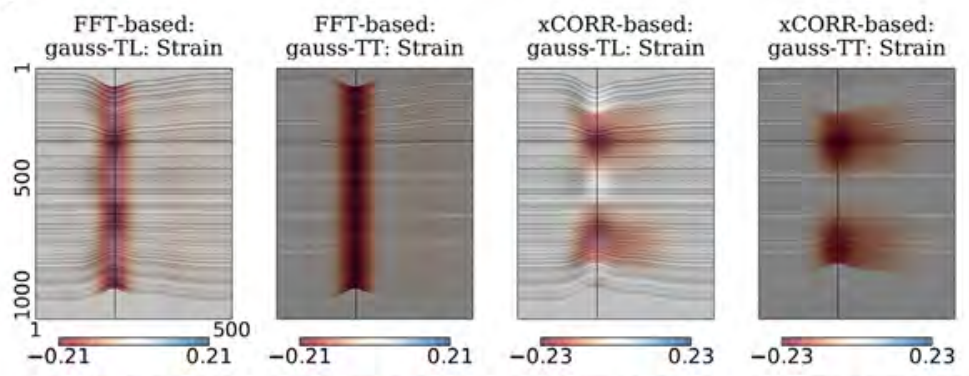

gauss-TL: Strain rate gauss-TT: Strain rate gauss-TL: Strain rate gauss-TT: Strain rate

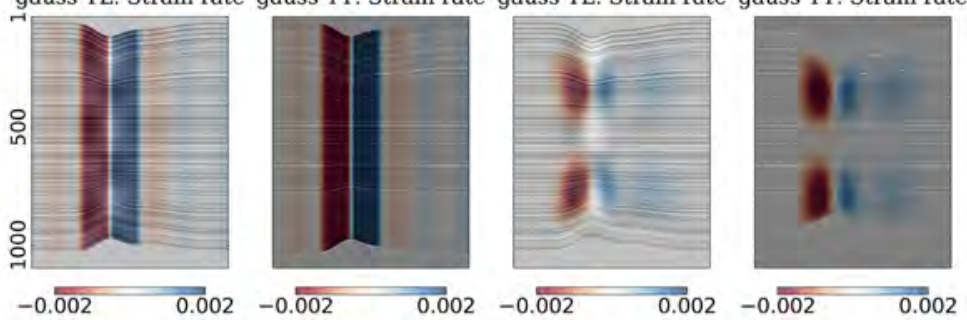

B
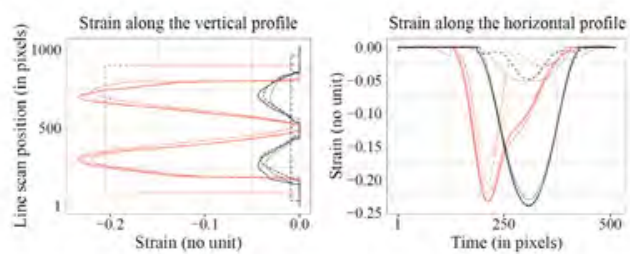

C
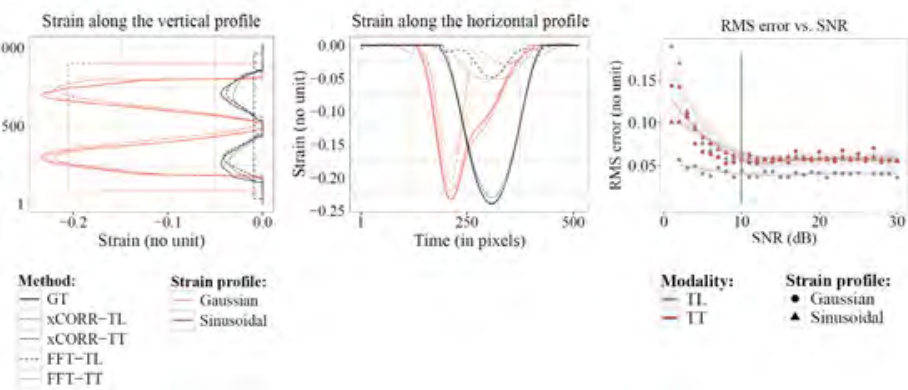

Modality: Strain profile: $\begin{array}{ll}- \text { II. } & \bullet \text { Gaussian } \\ - \text { II } & \wedge \text { Sinusoidal }\end{array}$

Figure 6: A Strain and strain rate maps obtained using the proposed method with optimal settings and FFT-based method for scenarios (2) and (4) in Table 3. Obtained maps are superimposed onto synthetic images. B Comparison of local strain along orthogonal profiles that capture maximum cell deformation, as marked in A. Profiles are given for all four scenarios from Table 3. TL and TT images for the same strain profile share a mutual ground truth (GT). C Strain estimation error obtained by analysing synthetic line-scan images of cardiomyocytes simulated with different levels of signal-to-noise degradation. 


\begin{tabular}{ll|llll}
\hline \multicolumn{2}{c|}{ Image content } & \multicolumn{4}{c}{ Regression coefficient } \\
\hline Mode & Profile & $\beta_{\Delta T}$ & $\beta_{w_{\max }}$ & $\beta_{n}$ & $\beta_{\theta}$ \\
\hline \hline \multirow{2}{*}{ TL } & sin & $-0.3148^{*}$ & $-0.2571^{*}$ & 0.0264 & -0.0027 \\
& gauss & $-0.2564^{*}$ & -0.0674 & $-0.1559^{*}$ & $-0.0578^{*}$ \\
\multirow{2}{*}{ TT } & sin & $-0.3070^{*}$ & $0.1054^{*}$ & $-0.3257^{*}$ & 0.0114 \\
& gauss & $-0.1639^{*}$ & $0.0959^{*}$ & $-0.2814^{*}$ & $0.1165^{*}$ \\
\hline
\end{tabular}

For regression, parameter and error vaues were standardized to mean and standard deviation of $(\mu, \sigma)=(0,1)$. Legend : TL - transmitted light, TT - T-tubules, sin - sinusoidal, gauss Gaussian, ${ }^{*}$ - p-value $<0.01$.

Table 1 Coefficients of multivariate linear regression for strain estimation in noiseless synthetic data

\begin{tabular}{|c|c|c|c|c|c|c|c|c|c|c|c|}
\hline & \multirow{2}{*}{\multicolumn{2}{|c|}{$\frac{\text { Scenario }}{\text { Image content }}$}} & \multicolumn{3}{|c|}{ FFT-based method } & \multicolumn{6}{|c|}{ XCORR-based method } \\
\hline & & & \multirow{2}{*}{$\begin{array}{c}\text { Sarc. length } \\
L_{a v g}\end{array}$} & \multicolumn{2}{|c|}{ Error } & \multicolumn{4}{|c|}{ Parameter } & \multicolumn{2}{|c|}{ Error } \\
\hline & Mode & Profile & & $e_{r m s}$ & $e_{\max }$ & $n$ & $\Delta T$ & $w_{\max }$ & $\theta$ & $e_{r m s}$ & $e_{\max }$ \\
\hline$\overline{(1)}$ & \multirow{2}{*}{ TL } & $\sin$ & $1.75 \mu \mathrm{m}$ & 0.3306 & 0.802 & 35 & 9 & $\overline{12}$ & 0.8 & 0.0378 & 0.037 \\
\hline (2) & & $\exp$ & $1.72 \mu \mathrm{m}$ & 0.2479 & 0.126 & 45 & 9 & 16 & 0.6 & 0.0253 & 0.032 \\
\hline (3) & \multirow{2}{*}{ TT } & $\sin$ & $1.88 \mu \mathrm{m}$ & 0.2939 & 0.795 & 45 & 9 & 12 & 0.6 & 0.0436 & 0.025 \\
\hline (4) & & $\exp$ & $1.78 \mu \mathrm{m}$ & 0.2117 & 0.284 & 55 & 7 & 16 & 0.6 & 0.0413 & 0.005 \\
\hline & & & $a v g=$ & 0.2710 & 0.502 & & & & & 0.0370 & 0.025 \\
\hline
\end{tabular}

Table 2 Evaluation of local strains obtained with the FFT-based approach via mean lengths of contractile units and the cross-correlation based method with an optimal set of parameters, for the noiseless artificial dataset.

\section{RESULTS}

Strain estimation in synthetic line scans images.

In the set of idealised simulations of cell line scans, we estimated mean cellular strains using the FFT approach and subcellular strains using the proposed cross-correlation based algorithm with a variety of parameter settings. Each setting corresponded to one permutation of plausible parameter values, defined as follows: $\Delta T \in[1,10], \mathrm{n} \in[25,75], w_{\max } \in[8,30]$ and $\theta$ $\in[0.6,0.9] . \Delta T, n$ and $w_{\text {max }}$ are measured in the number of pixels and $\theta$ in normalised pixel intensity value. The error in strain estimation was quantified for a synthesised strain kernel. With a representative amount of resulting parameter-error pairs, we performed a multivariate linear regression. Table 1 shows the regression results per each imaging modality and deformation profile in synthetic line scan images.

From a series of tests conducted with the cross-correlation based approach, the highest accuracy in strain estimation was obtained with parameter values enlisted in Table 2. Alongside this, we enlist mean sarcomere lengths and T-tubule spacings obtained with FFT and the evaluation of the corresponding evenly distributed strains. Local strain and strain rate maps for scenarios (2) and (4) from Table 2 are displayed in Fig 6 A. Fig 6 B shows strain profiles along the denoted vertical and horizontal sections for all scenarios, against the ground truth profiles extracted from strain kernels.

The robustness of the algorithm with optimal sets of parameters to noise inherent to imaging modality was evaluated at SNR values in the range $(1,30)$. Fig 6 C shows pixel intensity distributions in acquired and synthetic images for several SNR values and the effect of SNR on the strain estimation error. 


\begin{tabular}{|c|c|c|c|c|c|c|c|c|}
\hline \multirow{2}{*}{\multicolumn{2}{|c|}{$\begin{array}{c}\text { Scenario } \\
\text { Image content }\end{array}$}} & \multicolumn{4}{|c|}{ FFT-based method } & \multicolumn{3}{|c|}{ XCORR-based method } \\
\hline & & \multirow{2}{*}{$\frac{\text { Sarc. length }}{L_{\text {avg }}}$} & \multicolumn{3}{|c|}{ Error } & \multicolumn{3}{|c|}{ Error } \\
\hline Cell sample & Mode & & $\bar{e}_{r m s, G T}$ & $e_{r m s, G T}$ & $e_{\max , G T}$ & $e_{r m s, G T}$ & $e_{r m s, G T}$ & $e_{\max , G T}$ \\
\hline \multirow{2}{*}{ Cell 1} & $\overline{\mathrm{TL}}$ & $1.7441 \mu \mathrm{m}$ & 0,3011 & 0.2916 & 0.4913 & 0.0948 & 0.0889 & 0.0096 \\
\hline & $\mathrm{TT}$ & $1.7035 \mu \mathrm{m}$ & 0.3086 & 0.2843 & 0.5384 & 0.1246 & 0.1331 & 0.0184 \\
\hline \multirow{2}{*}{ Cell 2} & TL & $1.6838 \mu \mathrm{m}$ & 0.1744 & 0.1649 & 0.2875 & 0.1371 & 0.1098 & 0.1156 \\
\hline & TT & $1.6608 \mu \mathrm{m}$ & 0.2515 & 0.2257 & 0.3337 & 0.1280 & 0.1493 & 0.0261 \\
\hline \multirow{2}{*}{ Cell 3} & $\mathrm{TL}$ & $1.7290 \mu \mathrm{m}$ & 0.1793 & 0.1771 & 0.3956 & 0.1055 & 0.0972 & 0.0023 \\
\hline & TT & $1.7072 \mu \mathrm{m}$ & 0.2061 & 0.1773 & 0.5299 & 0.1067 & 0.1152 & 0.0074 \\
\hline \multicolumn{3}{|r|}{$a v g=$} & 0.2368 & 0.2202 & 0.4294 & 0.1161 & 0.1156 & 0.0155 \\
\hline
\end{tabular}

Note: GT in subscript denotes an error calculated with respect to annotated ground truth points, and GT denotes an error calculated with respect to spline-interpolated ground truth.

Table 3 Evaluation of local strains obtained with the FFT-based approach via mean lengths of contractile units and the cross-correlation based method, for the imaged dataset.

\section{Strain estimation in acquired line scan images}

First, we analysed line scans of three cardiomyocytes in transmitted light T-tubules confocal modalities along a cropped contraction period, respectively. The analysis covered FFT-based estimation of average cell strains and cross-correlation based quantification of local strains using the optimal set of parameters. Fig 7 displays one of the original lines scans with manual annotations used for calculating the strain ground truth, followed by the strain maps estimated using the FFT approach and our proposed algorithm. Vertical strain profiles are plotted against manual measurements in annotated points and their spline interpolation. The evaluation was performed per annotated scan line for each cell accordingly. Results are given in Table 3 in terms of RMS error and deviation from the ground truth maximum.
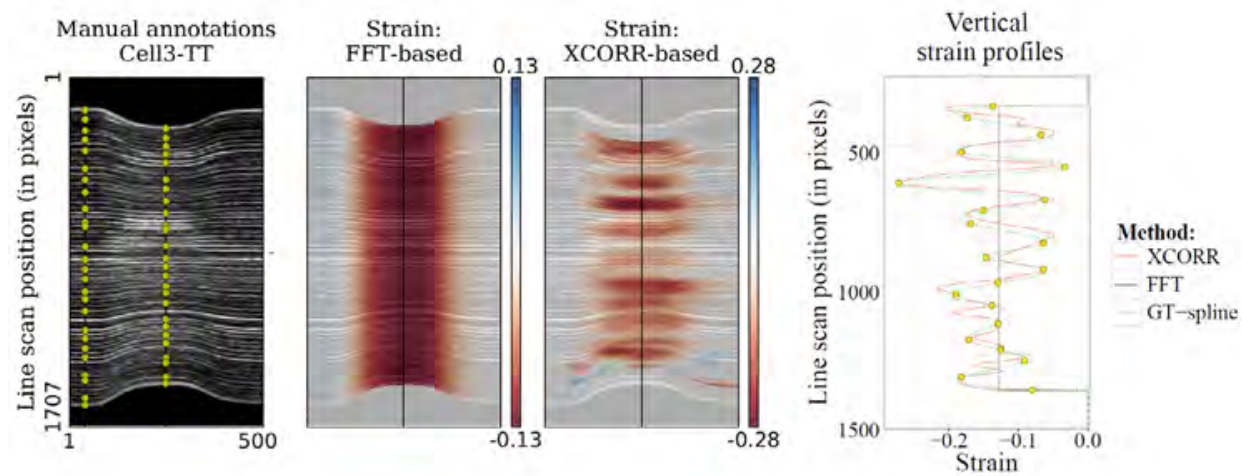

Figure 7: Comparison of results of a T-tubules image. From left to right: Original cell scan with landmarks representing manual annotations of sarcomeres. (Each point annotating a sarcomere at rest has its pair at a moment of maximal contraction needed for calculating the ground truth in a later point.) Local strain maps obtained with FFT and cross-correlation (XCORR) are overlaid on the original image. Comparison of vertical profile. 
A
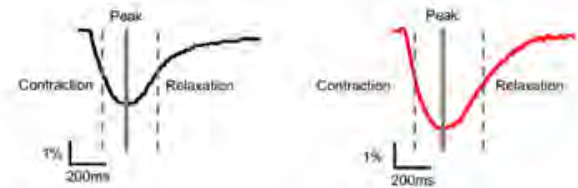

B

Strain at Peak contraction
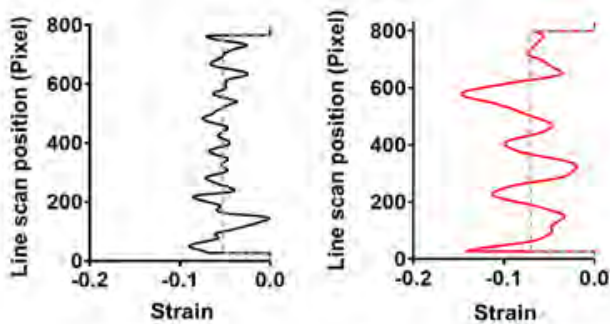

C

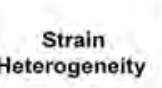

Relaxation
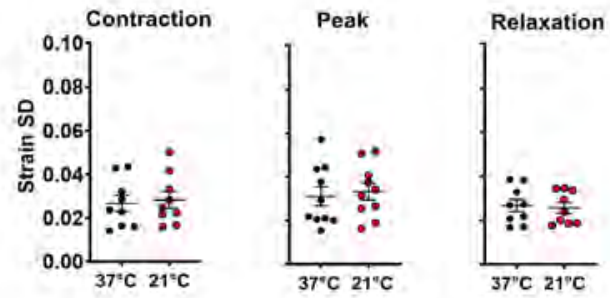

D
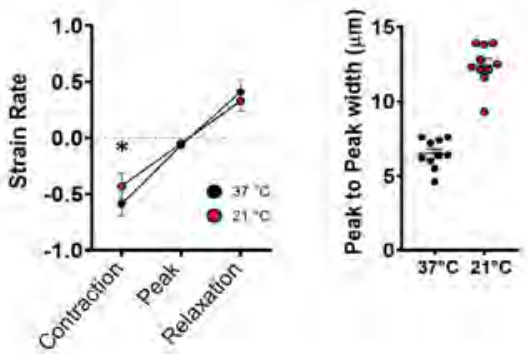

Figure 8: Strain and Strain rate heterogeneity of electrically stimulated rat cardiac myocytes in response to temperature changes A Examples of cell shorting at body temperature (black) and room temperature (red). B Strain values along a scan line at the peak of the contraction (solid line) and mean strain from the same line (dashed line) at body temperature (Left) and room temperature (Right). C Standard deviation of strain at half-maximal contraction (n $=9$ ), peak contraction $(p=10)$ and half-maximal relaxation $(\mathrm{p}$ =9). $\mathbf{D}$ Left Strain rate during contraction $(\mathrm{n}=9)$, peak $(\mathrm{p}=$ 10) and relaxation $(p=9)$. Right Peak to Peak distances between high strain regions at peak shortening.

\section{Temperature effects on local strain}

In the first set of experiments, we recorded TL images from rat ventricular myocytes electrically stimulated at $1 \mathrm{~Hz}$ at body temperature $\left(37^{\circ} \mathrm{C}\right)$ and room temperature $\left(21^{\circ} \mathrm{C}\right)$. Fig $8 \mathrm{~A}$ illustrates cell shortening calculated from the confocal line scan images. In Fig 8B, Local strain values along the scan line that represents peak contraction are plotted. The mean strain value of the same scan line is plotted in grey.

Strain heterogeneity at all observed time points (Fig 8C) was comparable between myocytes superfused with $\mathrm{NT}$ at $37^{\circ} \mathrm{C}$ and $21^{\circ} \mathrm{C}$, (Contraction: $0.027 \pm 0.004$ at $37^{\circ} \mathrm{C}$ vs $0.028 \pm 0.004$ at $21^{\circ} \mathrm{C}, \mathrm{n}=9, \mathrm{p}=\mathrm{ns}$; Peak: $0.031 \pm 0.004$ at $37^{\circ} \mathrm{C}$ vs $0.033 \pm 0.004$ at $21^{\circ} \mathrm{C}, \mathrm{n}=10, \mathrm{p}=$ ns , Relaxation: $0.027 \pm 0.003$ at $37^{\circ} \mathrm{C}$ vs $0.026 \pm 0.002$ at $21^{\circ} \mathrm{C}, \mathrm{n}=9, \mathrm{p}=\mathrm{ns}$ ). The strain rate during contraction was smaller at $21^{\circ} \mathrm{C}$ (Contraction: $-0.588 \pm 0.107$ at $37^{\circ} \mathrm{C}$ vs -0.429 \pm 0.116 at $21^{\circ} \mathrm{C}, \mathrm{n}=8, \mathrm{p}<0.05$ ) and at peak contraction, close to zero. At half maximal relaxation strain rates at $21^{\circ} \mathrm{C}$ did not differ from strain rates observed at body temperature; 
A

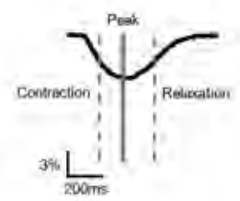

B

Strain at Peak contraction

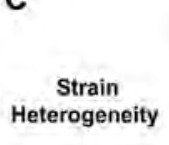

D

Strain Rate Heterogeneity

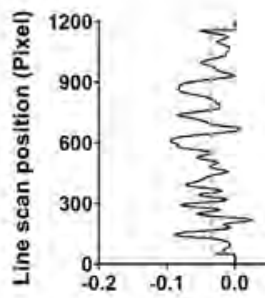

Contraction
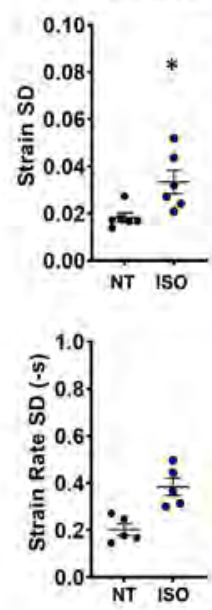
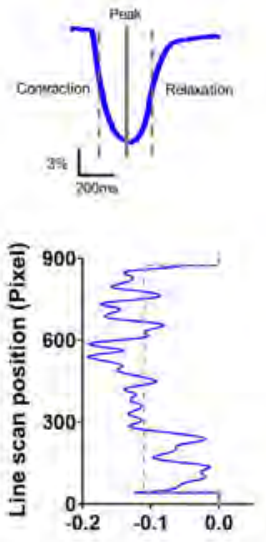

Relaxation

Peak
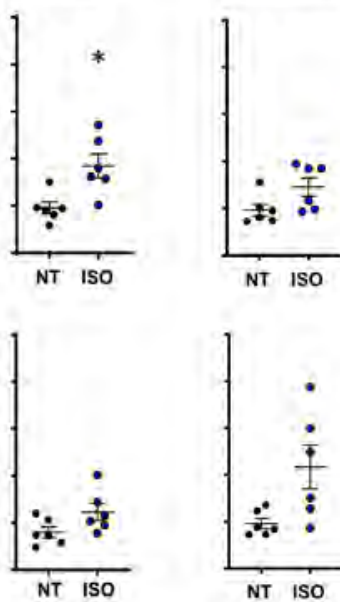

Figure 9: Strain and Strain rate heterogeneity of rat cardiac myocytes in response to adrenergic stimulation. A Examples of cell shorting before and after exposure to ISO B Strain values along a scan line at the peak of the contraction (solid line) and mean strain (dashed line) before and after ISO C The standard deviation of strain at half-maximal contraction and peak contraction and relaxation. D Heterogeneities in strain rates during contraction, peak contraction, and relaxation. For all graphs $n=6$.

(Relaxation: $0.410 \pm 0.111$ at $37^{\circ} \mathrm{C}$ vs $0.329 \pm 0.088$ at $21^{\circ} \mathrm{C}, \mathrm{n}=8, \mathrm{p}=0.67$ );. (Fig $8 \mathrm{D}$, Left) . Although strain heterogeneity as measured by the strain SD did not change at $21^{\circ} \mathrm{C}$, the examples in Fig 8B show a distinct pattern of alternating regions with higher and lower strain. This alternans between these regions was significantly slower at $21^{\circ} \mathrm{C}(\mathrm{Fig} 8 \mathrm{D}, \mathrm{Right})$ compared to $37^{\circ} \mathrm{C}$, as measure by the peak to peak distance ( $\mu \mathrm{m}: 6.5 \pm 0.3$ at $37^{\circ} \mathrm{C}$ vs $12.4 \pm 0.4$ at $\left.21^{\circ} \mathrm{C}, \mathrm{n}=10, \mathrm{p}<0.005\right)$.

\section{Adrenergic stimulation increases subcellular strain heterogeneity}

Adrenergic signalling has profound effects on contractility and $\mathrm{Ca}^{2+}$ handling. Mean strain at peak contraction was higher $(-0.044 \pm 0.002$ in NT vs $-0.077 \pm 0.014$ in ISO, $n=6, p<0.05)$. After ventricular myocytes were exposed to ISO heterogeneity in local strain increased (Fig 9C). The effect was significant at half maximal contraction $(0.018 \pm 0.002$ for NT vs $0.033 \pm 0.005$ for ISO, $\mathrm{n}=6, \mathrm{p}<0.05$ ) and peak cell shortening (Peak: $0.019 \pm 0.004$ for NT 
A

B

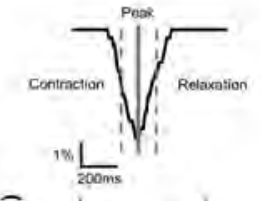

Strain at Peak contraction

C

Strain Heterogeneity
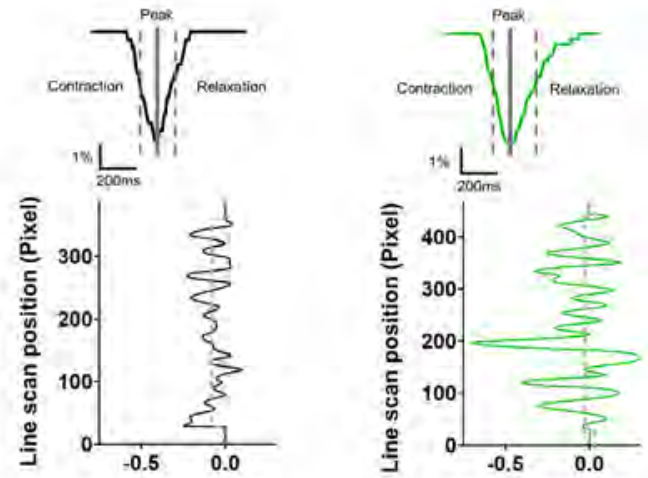

Contraction

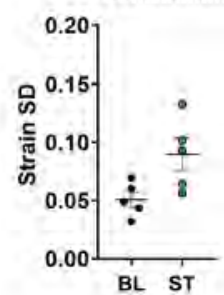

D

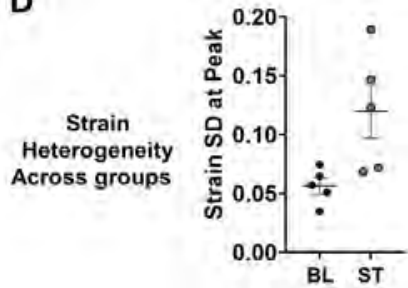

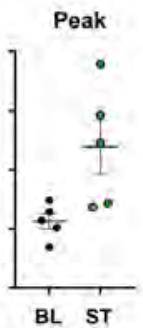
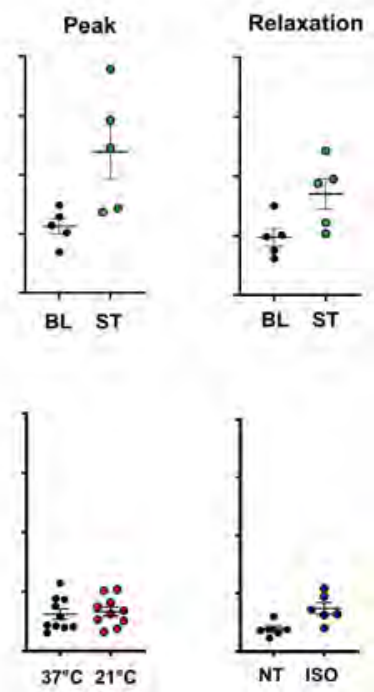

Figure 10: Strain heterogeneities in response to mechanical load. A Examples of auxotonic cell shortening of atrial myocytes before and after application of $20 \%$ stretch B Example of local Strain along a scan line at peak contraction recorded at baseline and severe stretch. C Local strain heterogeneity in stretched atrial myocytes during contraction, peak, and relaxation. $\mathrm{n}=5$ for all time points. D Comparison between Strain rate heterogeneity at peak contraction between, stretched rabbit atrial myocytes (Left, $\mathrm{n}=$ 5), and rat ventricular myocytes subjected to temperature changes (Center, $\mathrm{n}=10)$, or treated with ISO (Right, $n=6$ ).

vs $0.037 \pm 0.005$ for ISO, $\mathrm{n}=6, \mathrm{p}<0.05)$ but not during relaxation $(0.019 \pm 0.003$ for NT vs $0.029 \pm 0.004$ for ISO, $\mathrm{n}=6, \mathrm{p}=0.072$. Dispersion in strain rate (Fig 9D) was significant during contraction (Contraction: $0.202 \pm 0.024$ for NT vs $0.384 \pm 0.038$ for ISO, $\mathrm{n}=6, \mathrm{p}$ $<0.05$ ) and at peak shortening Peak: $0.160 \pm 0.022$ for NT vs $0.246 \pm 0.036$ for ISO, $\mathrm{n}=$ $6, \mathrm{p}<0.05)$. At half maximal relaxation strain rate heterogeneity did not reach statistical significance $(0.193 \pm 0.022$ for NT vs $0.434 \pm 0.094$ for ISO, $n=6, p=0.085)$.

\section{Atrial myocytes contraction auxotonically exhibited positive strain during contraction}

In vivo, cardiac myocytes are subjected to cyclic stretch during diastolic filling to which they react with an immediate increase in force development. To investigate the potential effects of a more physiological mechanical environment in vitro, atrial rabbit myocytes were electrically stimulated while subjected to low or high preload. At high preloads ( $20 \%$ Stretch - ST) strain heterogeneity during contraction $(0.051 \pm 0.007$ at BL vs $0.090 \pm 0.013$ at ST, $n$ 
$=5, \mathrm{p}<0.01)$, relaxation $(0.049 \pm 0.008$ at $\mathrm{BL}$ vs $0.085 \pm 0.013$ at $\mathrm{ST}, \mathrm{n}=5, \mathrm{p}<0.05)$ and at peak cell shortening (Peak: $0.056 \pm 0.007$ at BL vs $0.120 \pm 0.023$ at $\mathrm{ST}, \mathrm{n}=5, \mathrm{p}<0.05$ ) was higher compared to unstretched cells (Baseline - BL, Fig 10C). In isotonically contracting myocytes strain rates were predominantly negative (Fig 8B and Fig 9B), indicating that even within regions of local strain minima the cell was still contracting. However, atrial myocytes contracting auxotonically showed regions of positive strain as an expression of local elongation/stretch during active contraction (Fig 10B). Overall strain heterogeneities were higher in atrial myocytes at high preload, when compared to rat ventricular myocytes that contract isotonically (Fig 10D).

\section{DISCUSSION}

In this paper, we present and validate an automated method for quantifying regional contraction from line scan images of isolated cardiomyocytes. A series of experimental results confirmed the effectiveness of the proposed algorithm to detect differences in strain and strain rate in contracting myocytes.

In both the synthetic and imaged line scans of contracting myocytes, we first quantified mean cell strains and considered a homogeneous strain distribution feasible with FFT. Mean sarcomere lengths and T-tubules spacings assessed with FFT were in the expected range ${ }^{6}$, showing that the virtual spatial resolution of synthetic images was representative of the real imaging setup and provided realistic strain measurements. Even though the average contraction did reflect the global cell contraction, averaging prevented the determination of local maxima and minima of the strain value, this is reflected by the error, especially in terms of the deviation of the strain maximum (see Table 1 and Table 2).

The proposed algorithm's performance in idealised (noiseless) scenarios was the key indicator of its performance and was examined with respect to its parameters via multivariate regression. The obtained coefficients quantify an increase in RMS error for a unit change in a parameter value, thus measuring the influence of each parameter individually. The combinatorial impact of variables was excluded from the analysis.

The choice of the cross-correlation time step $\Delta T$ showed the largest impact on the strain estimation accuracy for transmitted light images, and slightly smaller for T-tubules line scans. This confirms that only within a limited period, local deformation is small enough to allow for its successful identification. The ratio of the maximum displacement $w_{\max }$ and the time step $\Delta T$, in fact, represents the maximum local velocity. Due to a trade-off between the deformation heterogeneity and its local smoothness, the maximum in the measurement of global cell contraction velocity is a good indicator for limiting the corresponding local measurements.

The length of the tracked pattern $n$ was the most sensitive parameter when processing T-tubules images. As compared to transmitted light line scans, a larger patch was required to capture a sufficiently distinguishable local pattern. Considering the sarcomere lengths and tubular spacings assigned when synthesising the images, at least three to four neighbouring contractile units moved similarly and captured enough pattern variability to be tracked simultaneously. 


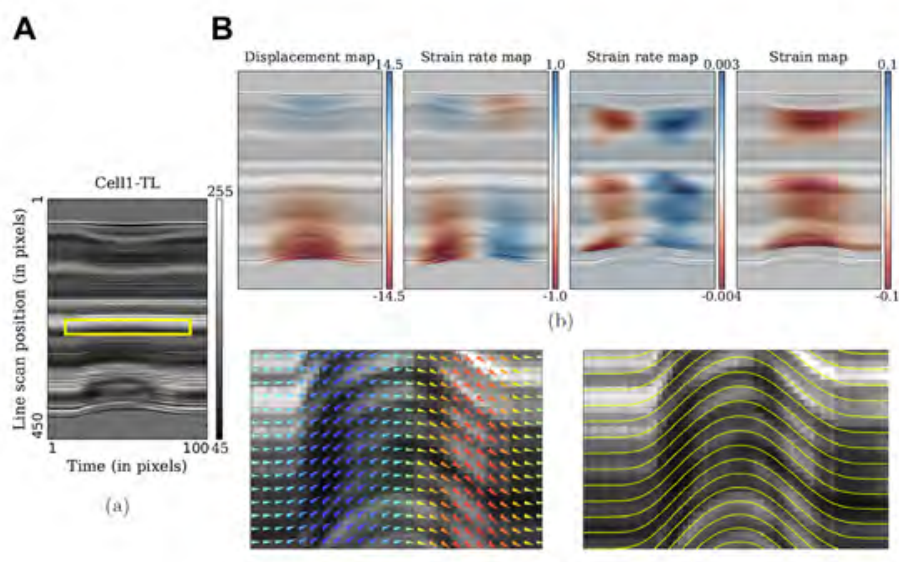

(e)

Figure 11: Visualisation of results for a TL image. A Crop from an acquired sequence. B - Upper panels Local displacements, velocities, strains, and strain rates mapped over the original image. B - Lower panel Velocity vector field (left) and pixel traces obtained by tracking equidistant points on the scan line (right) for the square segment marked in $\mathbf{A}$.

The cross-correlation coefficient threshold $\theta$ regulates the pattern (mis)matching. The velocity inpainting procedure successfully reconstructed the dismissed values assuming that the values on the border of the non-defined area were correct and that the range of existing values was preserved. Mismatching was less likely in a noiseless setting, resulting in low sensitivity of the parameter $\theta$ and reaching the optimum at low $\theta$ values.

The optimal parameter setting of the proposed algorithm resulted in high accuracy of local strain estimation overall idealised scenarios. In comparison with evenly distributed mean deformation obtained with FFT, both error measures were reduced for an order of magnitude.

With the same setup, we examined the influence of the imaging modality-specific noise on the algorithm performance. In terms of normalised pixel intensity distributions, signal-to-noise ratios close to $10 \mathrm{~dB}$ correspond to the most realistic portrayal of the imaged cell contraction. RMS error values were expectedly higher for low SNRs as compared to ideal imaging conditions. However, the algorithm maintained the high accuracy despite extensive image degradation that interfered with the estimation process, reaching the plateau in estimation error at 10dB SNR as well.

Evaluation of subcellular strain assessment in imaged data was performed for strain calculated from manually annotated sarcomere locations. Manual measurements revealed that calculating strain at microscopic resolution was highly sensitive to the precision of manual annotations. Additionally, since one annotated point was at the same time a bottom of one sarcomere and a top of another, a miss-annotation in a single pixel on a scan line influenced two strain values. Due to the sensitivity of this procedure, we selected a single line scan of interest, capturing each cell at its shortest length.

Along the line scan of interest, we observed a good match between strain profiles assessed with the proposed algorithm and profiles obtained with spline interpolation of ground truth values. However, due to small dislocations between the two curves, their similarity is not entirely captured by RMS error. Considering the obtained RMS values, the performance of 
the algorithm for imaged data was commensurate to performance for synthetic images with lower signal-to-noise ratios. On the other hand, the deviation of strain maximum reflected on the successful strain estimation in points of extreme deformation.

To further evaluate the performance of the proposed method, we analysed transmitted light images from myocytes subjected to interventions known to change contractile kinetics on the whole-cell level. In the first set of experiments using rat ventricular myocytes, we let the temperature of the experimental solution drop from $37^{\circ} \mathrm{C}$ to $21^{\circ} \mathrm{C}$. At lower temperatures, contractile kinetics were slower, at the same time twitch force increased as the myocytes approach the steady-state Force- $\mathrm{Ca}^{2+}$ relationship. ${ }^{13}$ While at low temperatures the major determinant for relaxation resides within the myofilament at physiological temperatures and slow beating frequencies, as they would occur in larger mammals, the rate-limiting step is determined by $\mathrm{Ca}^{2+}$ removal. ${ }^{13}$ Indeed, $\mathrm{Ca}^{2+}$ reuptake has been linked to regional differences in sarcomere re-lengthening. ${ }^{6}$ Therefore. it is conceivable that temperature-induced changes in the rate-limiting step of relaxation could lead to differences in strain heterogeneity between relaxation and contraction (where the rate-limiting step is always myofilament based ${ }^{14}$ ). Assessing strain heterogeneity based on the SD of local strain failed to identify such differences within and between groups. Interestingly, the frequency between regions of high and low strain along the longitudinal axis at peak shortening was significantly lower at room temperature. Subcellular heterogeneity in strain might be facilitated by regional differences in local elasticity. ${ }^{15}$ At room temperature, slower force development could have a "smoothing effect" that leads to a more gradual change between high and low strain regions.

In the second series of experiments we exposed rat ventricular cells to the beta-adrenoreceptor agonist Isoprenaline. Adrenergic signalling exerts its effect on both $\mathrm{Ca}^{2+}$ handling proteins and myofilaments. On a whole-cell level this resulted in a higher contractile amplitude and faster relaxation. On the whole heart level, adrenergic stimulation can increase regional strain differences. ${ }^{16}$ On a single myocyte level, we observed higher levels of strain dispersion at a half-maximal contraction and at peak shortening after the treatment with ISO. At half-maximal relaxation, however, the heterogeneity in strain was no longer significant between groups. A modelling study based on data from rat ventricular myocytes collected at comparable conditions suggests that heterogeneities in strain during relaxation depend indeed on $\mathrm{Ca}^{2+}$ reuptake ${ }^{15}$, which adrenergic signalling can synchronise. ${ }^{6}$ On the other hand, the subcellular strain during the contraction appears to be influenced by the regional elastic properties of the myocyte. ${ }^{15}$

The last set of experiments demonstrates that our algorithm can detect changes in local strain in mechanically loaded myocytes. When cardiac myocytes are stretched force development increases instantaneously, this phenomenon is known as the Frank-Starling mechanism. The observed mean strain at peak contraction was in agreement with other functional data showing higher force development in stretched atrial myocytes (unpublished data). Furthermore, we observed higher levels of strain heterogeneity in stretched atrial myocytes compared to baseline conditions. Interestingly, we found regions with positive strain values during active cell shortening. In non-uniform multicellular muscle preparations, positive strain has been reported in the past. In these preparations more strongly contracting segments shorten while the weaker segments of the muscle are stretched. The active stretch of weaker regions induces length-depended activation to the point that the weaker segments can support the forceful contraction of the stronger segments. ${ }^{17}$ Atrial myocytes differ in structure and function: they are longer and thinner than ventricular myocytes, their $\mathrm{Ca}^{2+}$ release is less synchronous and 
their composition of myosin and titin is distinct. On a subcellular level, these differences could worsen strain heterogeneity, especially under load. Thus, the same mechanisms that maximises tension development against the backdrop of local non-uniformity in multicellular preparations might be operating on a myocytes level in the atria.

\section{Conclusion}

Clarifying the heart contraction mechanisms at a myocyte level is of great interest for cardiac research. In this paper, we presented a method for automating the quantification of contraction-induced subcellular deformation from transmitted light and T-tubules confocal microscopy line scan images of contracting isolated cardiomyocytes.

In our approach to myocyte analysis, we first examined average deformation at the wholecell level using a Fourier transform. For advancing to a higher level of detail, we propose a novel tool that improves the common cross-correlation approach using spline interpolation for reaching sub-pixel precision and with a set of empirically observed restrictions for regularising subcellular motion. In line scan images, cross-correlation assumes that the temporal transform function of a local cell structure is piecewise linear. By enforcing the mathematically described motion restrictions, we ensured that the obtained subcellular deformations follow the noticeable natural progression of the overall cell contraction while preserving the local heterogeneity. We evaluated the method on the synthetic and the imaged line-scans acquired with transmitted light and confocal microscopy. Despite the differences in captured patterns and noise inherent to the two modalities, we obtained high accuracy for both modalities in both the simulated and the acquired images of contracting cells.

Experiments performed in ventricular and atrial myocytes showed that our method could detect changes in strain on a subcellular level in response to interventions that affect global contractility.

The subcellular motion has been described before but at slower speeds or using special imaging techniques and labelling. The proposed method can identify heterogeneities in contraction and relaxation, employing a readily available imaging modality without the need for fluorescence labelling at high spatial and temporal resolution.

To further investigate the manifestation and role of cellular micro-mechanics in cardiac performance, the now accessible local deformation measurements are yet to be linked to measurements of local functional $\left(\mathrm{Ca}^{2+}\right.$ release) and structural cell properties (organelle distributions). 


\section{REFERENCES}

1. Shah AM, Solomon SD. Myocardial deformation imaging: current status and future directions. Circulation 2012;125:e244-248.

2. Voigt JU, Pedrizzetti G, Lysyansky P, Marwick TH, Houle H, Baumann R, Pedri S, Ito Y, Abe Y, Metz S, Song JH, Hamilton J, Sengupta PP, Kolias TJ, d'Hooge J, Aurigemma GP, Thomas JD, Badano LP. Definitions for a common standard for 2D speckle tracking echocardiography: consensus document of the EACVI/ASE/Industry Task Force to standardise deformation imaging. Eur Heart J Cardiovasc Imaging 2015;16:1-11.

3. Maier HJ, Schips TG, Wietelmann A, Kruger M, Brunner C, Sauter M, Klingel K, Bottger T, Braun T, Wirth T. Cardiomyocyte-specific IkappaB kinase (IKK)/NF-kappaB activation induces reversible inflammatory cardiomyopathy and heart failure. Proc Natl Acad Sci U S A 2012;109:11794-11799.

4. Roman-Campos D, Sales-Junior P, Duarte HL, Gomes ER, Guatimosim S, Ropert C, Gazzinelli RT, Cruz JS. Cardiomyocyte dysfunction during the chronic phase of Chagas disease. Mem Inst Oswaldo Cruz 2013;108:243-245.

5. Carrier L, Mearini G, Stathopoulou K, Cuello F. Cardiac myosin-binding protein C (MYBPC3) in cardiac pathophysiology. Gene 2015;573:188-197.

6. Hohendanner F, Ljubojevic S, MacQuaide N, Sacherer M, Sedej S, Biesmans L, Wakula P, Platzer D, Sokolow S, Herchuelz A, Antoons G, Sipido K, Pieske B, Heinzel FR. Intracellular dyssynchrony of diastolic cytosolic $[\mathrm{Ca}(2)(+)]$ decay in ventricular cardiomyocytes in cardiac remodeling and human heart failure. Circ Res 2013;113:527-538.

7. Yaniv Y, Juhaszova M, Wang S, Fishbein KW, Zorov DB, Sollott SJ. Analysis of mitochondrial 3D-deformation in cardiomyocytes during active contraction reveals passive structural anisotropy of orthogonal short axes. PLoS One 2011;6:e21985.

8. Kamgoue A, Ohayon J, Usson Y, Riou L, Tracqui P. Quantification of cardiomyocyte contraction based on image correlation analysis. Cytometry A 2009;75:298-308.

9. Lichter J, Li H, Sachse FB. Measurement of Strain in Cardiac Myocytes at Micrometer Scale Based on Rapid Scanning Confocal Microscopy and Non-Rigid Image Registration. Ann Biomed Eng 2016;44:3020-3031.

10. Awasthi S, Izu LT, Mao Z, Jian Z, Landas T, Lerner A, Shimkunas R, Woldeyesus R, Bossuyt J, Wood BM, Chen YJ, Matthews DL, Lieu DK, Chiamvimonvat N, Lam KS, Chen-Izu Y, Chan JW. Multimodal SHG-2PF Imaging of Microdomain Ca2+-Contraction Coupling in Live Cardiac Myocytes. Circ Res 2016;118:e19-28.

11. Liu Y, Steinbusch LKM, Nabben M, Kapsokalyvas D, van Zandvoort M, Schonleitner P, Antoons G, Simons PJ, Coumans WA, Geomini A, Chanda D, Glatz JFC, Neumann D, Luiken J. Palmitate-Induced Vacuolar-Type $\mathrm{H}(+)$-ATPase Inhibition Feeds Forward Into Insulin Resistance and Contractile Dysfunction. Diabetes 2017;66:1521-1534.

12. Verkerk AO, Geuzebroek GS, Veldkamp MW, Wilders R. Effects of acetylcholine and noradrenalin on action potentials of isolated rabbit sinoatrial and atrial myocytes. Front Physiol 2012;3:174.

13. Janssen PM, Stull LB, Marban E. Myofilament properties comprise the rate-limiting step for cardiac relaxation at body temperature in the rat. Am J Physiol Heart Circ Physiol 2002;282:H499-507.

14. Davis JP, Tikunova SB. Ca(2+) exchange with troponin $\mathrm{C}$ and cardiac muscle dynamics. Cardiovasc Res 2008;77:619-626.

15. Garcia-Canadilla P, Rodriguez JF, Palazzi MJ, Gonzalez-Tendero A, Schonleitner P, Balicevic V, Loncaric S, Luiken J, Ceresa M, Camara O, Antoons G, Crispi F, Gratacos E, Bijnens B. A two dimensional electromechanical model of a cardiomyocyte to assess intra-cellular regional mechanical heterogeneities. PLoS One 2017;12:e0182915.

16. Wierzbowska-Drabik K, Plewka M, Kasprzak JD. Variability of longitudinal strain in left ventricular segments supplied by non-stenosed coronary artery: insights from speckle tracking analysis of dobutamine stress echocardiograms in patients with high coronary risk profile. Arch Med Sci 2017;13:82-92.

17. ter Keurs HE. The interaction of $\mathrm{Ca} 2+$ with sarcomeric proteins: role in function and dysfunction of the heart. Am J Physiol Heart Circ Physiol 2012;302:H38-50. 


\section{Chapter VI}

General Discussion

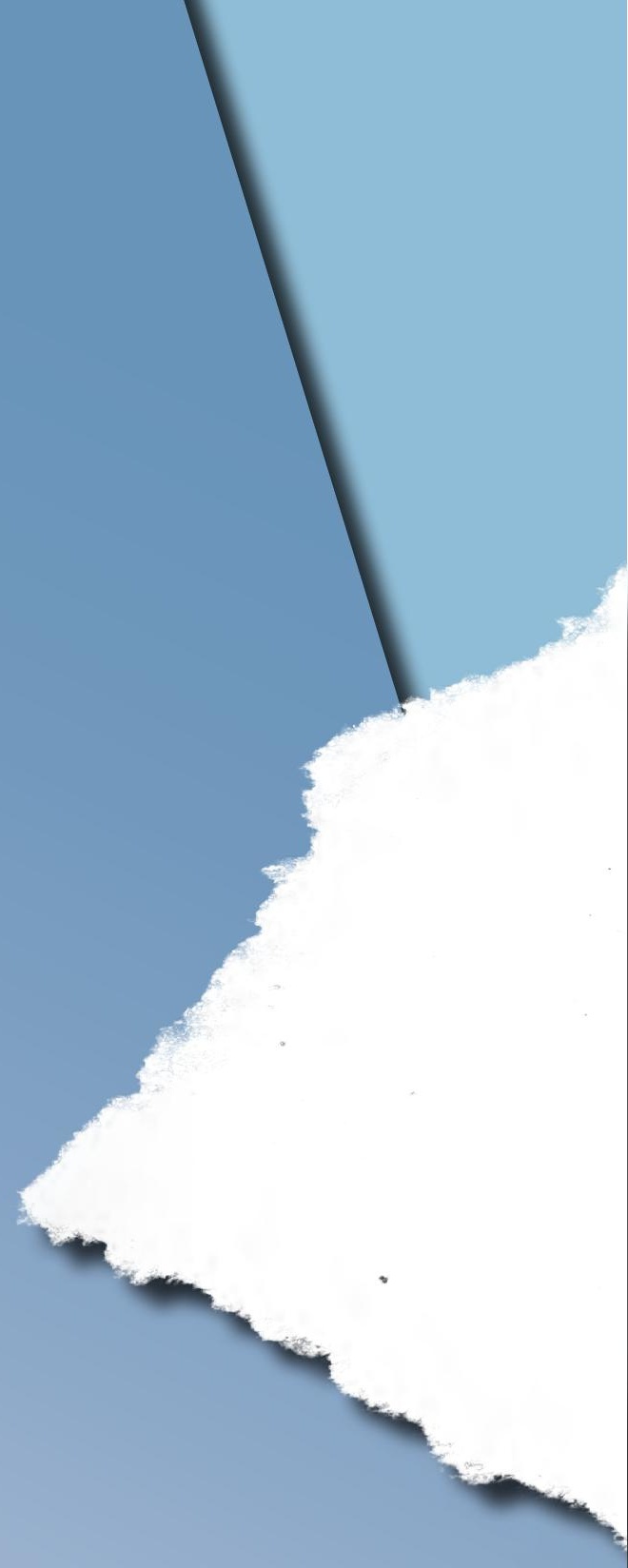



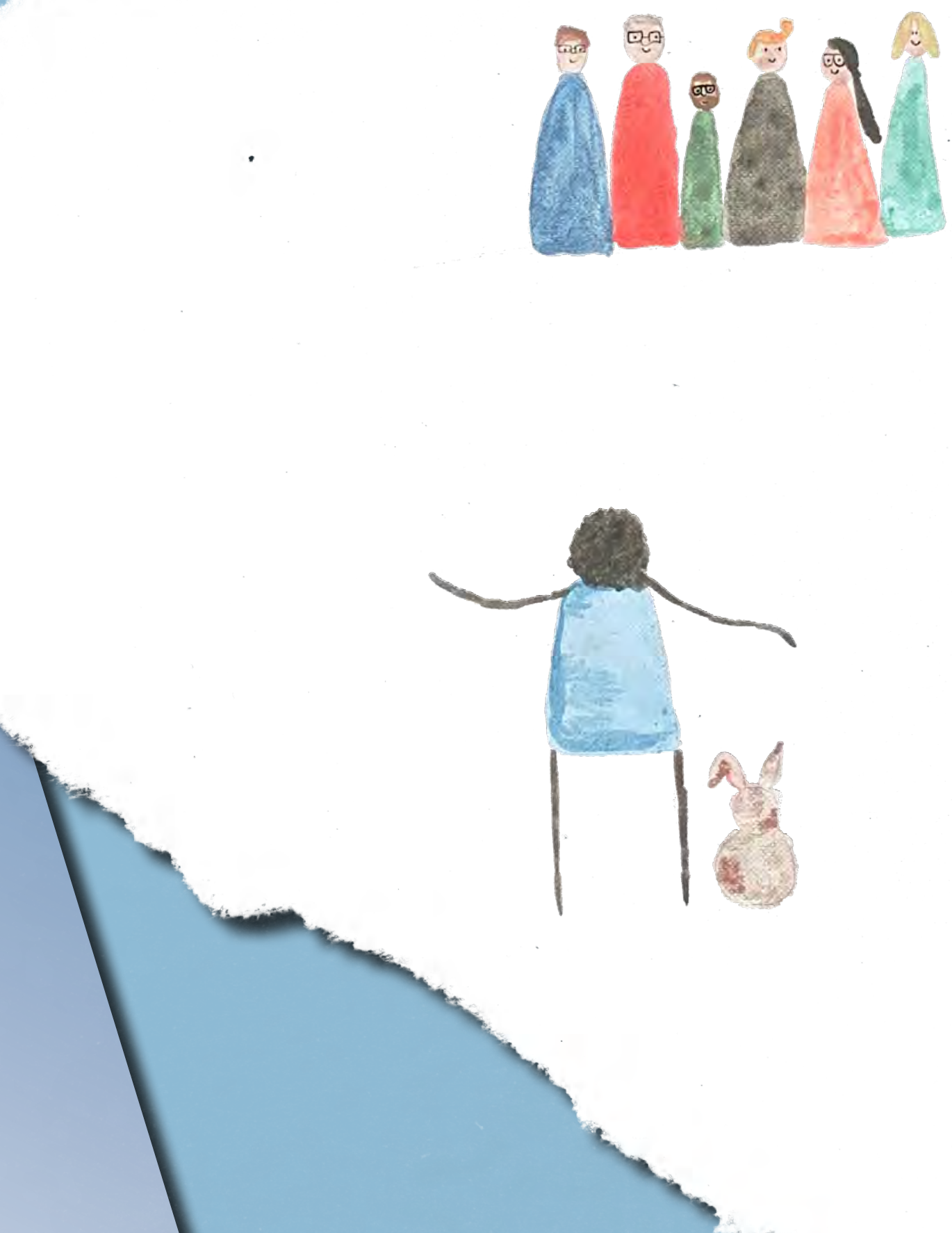


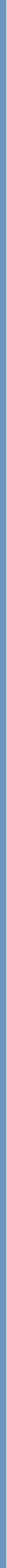




\section{GENERAL DISCUSSION}

The focus of this thesis is to investigate the effects of stretch and adrenergic stimulation on subcellular $\mathrm{Ca}^{2+}$ handling in the atria. Atrial stretch and sympathetic activation have been linked to atrial arrhythmias, but the underlying mechanisms are incompletely understood. The work performed in this thesis tries to improve our pathophysiological understanding of atrial arrhythmias. With an ageing population, the prevalence of atrial fibrillation (AF) will further increase in the decades to come. To treat AF more effectively, beyond controlling ventricular rate and management of stroke risk, more detailed knowledge about proarrhythmic mechanisms operative in subgroups of patients or under specific circumstances is urgently required.

Chapter 2 discusses the effects mechanical stimuli can exert on microdomain $\mathrm{Ca}^{2+}$ handling in cardiac myocytes. Experiments that interrogate mechanosensitive pathways in isolated single cells remain challenging and the type of stress the myocytes is subjected to varies markedly between methods, with each stressor triggering the activation of distinct pathways. Furthermore, structural and functional differences between ventricular and atrial myocytes may exist and result in activation of distinct mechano-sensitive pathways implying that separate mechanisms are responsible for stretch sensitive arrhythmias in ventricles and atria.

In Chapter 3, we investigated the effect of uniaxial stretch on atrial $\mathrm{Ca}^{2+}$ handling and showed that the mechanism triggering spontaneous $\mathrm{Ca}^{2+}$ release events in atrial myocytes is different from the pathway documented in the ventricle. Although we could show that GsMTx-4 abolishes the stretched induced increase in $\mathrm{Ca}^{2+}$ spark rate, it did not significantly lower the number of coordinated, "escape beat" like, $\mathrm{Ca}^{2+}$ release events that we observed in close temporal relationship with the stretch stimulus.

In Chapter 4, we investigated the effect of beta-adrenergic stimulation, another known modulator of atrial arrhythmias, on the spatiotemporal $\mathrm{Ca}^{2+}$ release in atrial myocytes after five days of rapid atrial activation. We elaborated on ultrastructural changes of the TAT network organization and tried to link RYR phosphorylation and TAT network organization to $\mathrm{Ca}^{2+}$ release on a subcellular level.

Finally, in the last experimental chapter (Chapter 5), we presented a novel method that allows to semiautomatically quantify subcellular strain and strain rate. We used confocal line scans, a widely used imaging modality for asseing subcellular $\mathrm{Ca}^{2+}$ signals, and showed that our method can detect local strain heterogeneities of atrial and ventricular myocytes in response to stretch and adrenergic stimulation.

\section{Mechanosensitive pathways and subcellular $\mathrm{Ca}^{2+}$ handling}

Mechanical stimulation can influence the electrical properties of the heart and even cause rhythm disturbances. In literature, this mechanism is referred to as mechano-electric coupling. ${ }^{1}$ A group of ion channels, so-called stretch-activated channels (SAC) represent the molecular entity that translates mechanical stress into electrical signals. ${ }^{2}$ Besides mechano-electrical coupling, the activation of rapid signalling pathways by mechanical stimuli has gained attention over the last years. ${ }^{3}$ In Chapter 2 we discussed recent findings of mechanosensitive pathways, specifically regulating $\mathrm{Ca}^{2+}$ release within confined $\mathrm{Ca}^{2+}$ microdomains. 
In the whole heart the myocardium is subjected to various mechanical stimuli. During a cardiac cycle, myocytes experience rapid changes in length and load and because of the laminar organization of the heart also shear forces.

To delineate the effects of each mechanical stimulus, several experimental techniques have been developed to isolate them, such as; embedding myocytes in viscoelastic gels to simulate changes in afterload, uniaxial stretch to mimic preload, and pressurized fluid jets to simulate shear forces. Although separating the components from each other remains challenging, the evidence available suggests that each mechanical stimulus is associated with the activation of distinct signalling pathways. ${ }^{4}$

Most studies of mechano-sensitive atrial $\mathrm{Ca}^{2+}$ handling focused on the effects of shear stress. ${ }^{5}$,

${ }^{6}$ But, despite atrial dilatation being a prominent feature of vulnerable atria, relatively little attention has been paid to effects that occur in response changes in preload and afterload. Hence, most of the current knowledge of stretch sensitive mechanisms on $\mathrm{Ca}^{2+}$ handling stems from ventricular myocytes.

Atrial myocytes differ profoundly from ventricular myocytes. One such striking difference is the transverse-axial tubule (TAT) network organization (Chapter 4 and ${ }^{7}$ ). In the ventricle the TAT network is dense and regular, allowing for an effective coupling between L-type $\mathrm{Ca}^{2+}$ channel (LTCC) residing in the TAT and adjacent - or junctional - ryanodine receptors (RYRs) by forming $\mathrm{Ca}^{2+}$ microdomains. These microdomains ensure the synchronous $\mathrm{Ca}^{2+}$ release observed in the ventricle. ${ }^{8}$ In the atria the TAT network is sparse and heterogeneous and as a consequence the fraction of non-junctional RYRs is higher. An often discussed result of this ultrastructural difference is that $\mathrm{Ca}^{2+}$ release in the atria is dyssynchronous compared to $\mathrm{Ca}^{2+}$ release in ventricular myocytes. ${ }^{7,9}$ As mentioned, $\mathrm{Ca}^{2+}$ microdomains are involved in translating mechanical stimuli into $\mathrm{Ca}^{2+}$ signals and the distinct organization of these $\mathrm{Ca}^{2+}$ microdomains in the atria could have implications for effects mechanical stimuli exert.

\section{Uniaxial stretch in the atrium}

In Chapter 3 we presented data that support the speculations elaborated on in Chapter 2 regarding differences in atrial mechano-sensing.

In ventricular myocytes axial stretch leads to a burst in reactive oxygen production (ROS) by NOX-2, a membrane bound NADPH-oxidase. ${ }^{10}$ The sudden increase in local ROS is believed to elevate RYR open probability, either directly via oxidation of the channel or indirectly via CaMKII activation.

The higher RYR open probability can be visualized by an increase in $\mathrm{Ca}^{2+}$ spark rate. ${ }^{11}$ We found that uni-axial stretch in rabbit atrial myocytes was followed by elevated $\mathrm{Ca}^{2+}$ spark frequency, too. However, scavenging ROS with NAC or blocking the membrane bound NOX-2 with a peptide inhibitor, interventions that both abolished the increase in $\mathrm{Ca}^{2+}$ spark rate in the ventricle ${ }^{10,12}$, exhibited no effect in the atria.

On the other hand, preventing trans-sarcolemmal $\mathrm{Ca}^{2+}$ entry from the extracellular solution, or treating the cell with GsMTx-4 abolished the stretch effect on $\mathrm{Ca}^{2+}$ spark rate in atrial rabbit myocytes while none of these interventions was effective in ventricular cells. ${ }^{12}$ GsMTx-4 has 
shown various beneficial effects in the context of muscular dystrophy, Infarction/Reperfusion injury and stretch-induced arrhythmias. ${ }^{13-15}$ In the intact atria GsMTx-4 shortened episodes of AF that were evoked by burst pacing and prolonged by stretch. ${ }^{16}$ As noted, we found that GsMTX-4, abolished the stretch induced increase in $\mathrm{Ca}^{2+}$ spark rate. This observation is in line with the antiarrhythmic effects reported in the intact atria. Interestingly, we also observed a higher baseline $\mathrm{Ca}^{2+}$ spark rate compared to control myocytes.

GsMTx-4 is believed to stabilize the tension of the outer monolayer of the cell membrane, thereby inhibiting the influx of Cations via $\mathrm{SAC}_{\mathrm{ns}} \cdot{ }^{17}$ However, it has been suggested that the tension of the outer membrane could be transferred to the cytosolic monolayer, where it can more easily potentiate mechano-sensitive $\mathrm{K}^{+}$channels. ${ }^{13,18}$ Activation of these rectifying

$\mathrm{K}^{+}$channels could counteract $\mathrm{Ca}^{2+}$ leak induced inward $\mathrm{I}_{\mathrm{NCX}}$ and stabilize the membrane potential, making the cell less prone to arrhythmogenic afterdepolarizations. Thus, myocytes that would otherwise reach the threshold for spontaneous activity caused by high $\mathrm{Ca}^{2+}$ leak, do not in the presence of GsMTx-4. Myocytes that exhibited spontaneous activity were excluded from our $\mathrm{Ca}^{2+}$ Spark analysis. Hence, increasing the threshold for $\mathrm{Ca}^{2+}$ dependent afterdepolarizations could lead to the inclusion of myocytes without treatment would have been spontaneous.

\section{Tissue heterogeneity and cardiac stretch}

It has been shown repeatedly that acute atrial stretch is proarrhythmic. Although changes in the ERP in response to volume challenges are inconsistent, several authors reported higher vulnerability for arrhythmias in dilated atria. ${ }^{19-21}$

In the light of our findings in Chapter 3, that GsMTx-4 could not prevent the occurrence of coordinated $\mathrm{Ca}^{2+}$ release events, and published results showing GsMTx-4 not to inhibit the shortening of ERP in the stretched atria $^{16}$, it is tempting to speculate that several mechanosensitive mechanisms are superimposed and aggravated by heterogeneities in the amount of local stretch.

However, there might be alternative explanations. The complex 3D structure of the atria that leads to heterogeneity in conduction ${ }^{22}$, reflects the variable muscle thickness of the tissue itself. This heterogeneity in muscle thickness can also give rise to inhomogeneities in stretch that are exaggerated by higher hemodynamic loads..$^{23,24}$ Although speculative, atrial dilatation could modify ERP, graded by the amount of strain, through mechanical modulation of otherwise voltage-gated ion channels ${ }^{2}$ such as Nav 1.5 and LTCC. Additionally, heterogeneous strain responses to volume load could activate stretch sensitive pathways, especially in areas where the muscle is weaker. The inhomogeneous increase in $\mathrm{Ca}^{2+}$ spark rate (Chapter 3), or the activation of SAC could influence action potential duration and resting membrane potential, thereby modifying the underlying substrate or directly trigger stretched induced excitations.

Seo et al. found that a sudden volume challenge of the ventricle was associated with stretch-induced depolarizations. They attributed this to inhomogeneities in the ventricular wall. The stretch evoked electrical activity was sensitive to $\mathrm{Gd}^{3+}$, an unspecific inhibitor of SAC, but not the stabilization of $\mathrm{Ca}^{2+}$ release by ryanodine. ${ }^{25}$ This observation contrasts with 
data obtained in single ventricular myocytes demonstrating that stretch effects $\mathrm{Ca}^{2+}$ leak ${ }^{3,12}$, and atrial myocytes (Chapter 3) were stretch dependent "escape beats" were not sensitive to SAC inhibition. Hence, further efforts are needed to explain these discrepancies between whole hearts and isolated myocytes.

\section{Non-uniformity in muscle as source of arrhythmias}

As discussed in the previous section, strain heterogeneities can potentially be deleterious. The effects of strain heterogeneities on a subcellular level, however, are not well documented. Spatio-temporal $\mathrm{Ca}^{2+}$ release and reuptake heterogeneities have been observed in response to pathological stimuli ${ }^{26}$ and prolongation in local $\mathrm{Ca}^{2+}$ reuptake could be linked to slower local sarcomere relaxation. ${ }^{27}$

In order to investigate strain heterogeneities specialized imaging techniques, labelling strategies or even manual annotations were employed in the past. In Chapter $\mathbf{5}$ we presented a semi-automated analysis method that relies on more readily available confocal lines scans and no specific labelling schemes.

In stretched myocytes, the analysis of local strain revealed that under high preload positive strain values during active contraction could occur. While parts of the cell shortened and therefore assumed negative strain values, others were stretched out during active contraction. The amount of positive strain was higher with larger preloads. In literature, local stretch during muscle shortening has been suggested to preserve overall contractile forces. ${ }^{28}$ However, under certain circumstances, this phenomenon can become arrhythmogenic. ${ }^{29}$

Another set of experiments revealed that treatment with a beta-adrenoreceptor agonist increased local heterogeneities during contraction and at peak shortening, but these heterogeneities were not present during relaxation (Chapter 5). As shown in Chapter 4, ISO can synchronize $\mathrm{Ca}^{2+}$ release in atrial myocytes. Therefore, increased homogeneity in contraction after ISO treatment could be expected, if the rate-limiting step depends on $\mathrm{Ca}^{2+}$ release. However, a computer model analysing the effect of the subcellular mechanical properties and local $\mathrm{Ca}^{2+}$ release has shown that during contraction subcellular inhomogeneities in the cells elastic properties are responsible for strain heterogeneities, while during relaxation $\mathrm{Ca}^{2+}$ reuptake is the primary determinant. ${ }^{30}$ Preliminary analysis of local $\mathrm{Ca}^{2+}$ release after ISO showed more homogeneous and hastened $\mathrm{Ca}^{2+}$ reuptake in line with more homogenous subcellular strain. Taken together our findings support the validity of our proposed method for local strain analysis in line-scan images. (Data not shown)

\section{Adrenergic signalling after short term pacing}

That the activation of the autonomic nervous system is a crucial factor in atrial arrhythmias is well-known. ${ }^{31,32}$ High levels of sympathetic activation can increase circulating catecholamines and are associated with hypertension and heart failure. Comorbidities such as obesity, metabolic syndrome and sleep apnea can further aggravate sympathetic drive.

On a cellular level, sympathetic stimulation exerts positive inotropic and lusitropic effects that depend on the PKA-mediated phosphorylation of $\mathrm{I}_{\mathrm{CaL}}$, disinhibition of SERCA by PLB phosphorylation, and reduced $\mathrm{Ca}^{2+}$ affinity due to phosphorylation of $\mathrm{TnC} .{ }^{33}$ Another target 
of PKA are RYRs. ${ }^{34}$ RYR phosphorylation has been linked to a more significant $\mathrm{Ca}^{2+}$ leak, and more frequent $\mathrm{Ca}^{2+}$ sparks. ${ }^{35} \mathrm{Ca}^{2+}$ leaking form the SR might become arrhythmogenic by inducing inward $\mathrm{I}_{\mathrm{NCX}}$ current and trigger EADs and DADs. Short term high atrial activation rates, similarly to paroxysmal $\mathrm{AF}$, initiate antiarrhythmic adaptation, most notably a reduction in $\mathrm{I}_{\mathrm{CaL}}$, an increase in $\mathrm{I}_{\mathrm{NCX}}$, and a loss of centripetal $\mathrm{Ca}^{2+}$ propagation. ${ }^{36}$ However, a high activation rate alone does not increase the number of $\mathrm{Ca}^{2+}$ sparks seen in other AF studies. ${ }^{35,37}$

In Chapter 4, we investigated the effect of beta-adrenoreceptor stimulation after five days of rapid electrical activation. ISO could rescue the loss of centripetal $\mathrm{Ca}^{2+}$ propagation, $\mathrm{Ca}^{2+}$ release and $\mathrm{CaT}$ amplitude most likely by a combination of increased $\mathrm{SR} \mathrm{Ca}^{2+}$ content and RYR phosphorylation.

Furthermore, we found an intact TAT network in rabbit atrial cells confirming the existence of a distinct TAT network previously believed to be absent from the rabbit atria. ${ }^{36,38}$ We also confirmed the TAT network as the primary origin of $\mathrm{Ca}^{2+}$ sparks, as suggested by Brandenburg et al. ${ }^{9}$

However, phosphorylation of RYR by PKA did lead to an increase in $\mathrm{Ca}^{2+}$ sparks in rapidly paced myocytes, supporting the growing evidence that the PKA dependent phosphorylation is not crucial for RYR Ca ${ }^{2+}$ leak. ${ }^{39}$

\section{The interplay between adrenergic signalling and stretch}

Evidence of a direct interplay of uniaxial-stretch and beta-adrenergic signalling is lacking. In the ventricle, the preload dependent mechanism that produces ROS upon stretch does not appear to share an common pathway with beta-adrenergic signalling. ${ }^{40}$

In the atria, our understanding of basic stretch depended mechanisms is even less developed. However, experiments simulating a stretch-activated inward current show that, in the presence of ISO atrial myocytes exhibit spontaneous activity more readily. ${ }^{41}$

Indirectly, sympathetic activation can increase the stretch the atria are exposed to by increasing hemodynamic load, and speed up heart rate leading to higher strain rates experienced by the myocardium. Indeed, experiments performed in frog hearts suggest that high strain rates lower the level of stretch necessary to induce aberrant triggered activity. ${ }^{42}$ Thus, sympathetic activation could indirectly interact with stretch sensitive pathways.

\section{Summary}

In the past decades, understanding triggers of AF the structural changes that occur in the fibrillating atria has attracted much attention. In this thesis, we investigated cellular proarrhythmic mechanisms in the atria in more detail.

While the effect of stretch and adrenergic signalling on spatiotemporal $\mathrm{Ca}^{2+}$ release in myocytes is more commonly studied in the context of cardiomyopathies and myocardial infarction, Chapter 3 and Chapter 4 illustrate implications for the atria. 
Our results show that atrial stretch can lead to potentially proarrhythmic changes in $\mathrm{Ca}^{2+}$ handling, via a mechanism distinct from pathways reported in the ventricle. Therefore it could offer and atrial-selective treatment target.

Furthermore, Chapter 4 demonstrates that adrenergic signalling after periods of rapid atrial activation can restore $\mathrm{Ca}^{2+}$ handling without noticeable proarrhythmic changes.

However, Chapter 3 and Chapter 5 reveal the effects of mechanical load on $\mathrm{Ca}^{2+}$ handling and contraction. Treatment with ISO could worsen their proarrhythmic effects and play an important role in the pathophysiology of AF.

Taken together, this thesis shines a light on modifying factors of atrial fibrillation and emphasizes the need for a holistic view of the pathophysiology behind it, to enable the development of mechanism-tailored therapeutic concepts in AF. 


\section{REFERENCES}

1. Quinn TA, Kohl P, Ravens U. Cardiac mechano-electric coupling research: fifty years of progress and scientific innovation. Prog Biophys Mol Biol 2014;115:71-75.

2. Peyronnet R, Nerbonne JM, Kohl P. Cardiac Mechano-Gated Ion Channels and Arrhythmias. Circ Res 2016;118:311-329.

3. Prosser BL, Khairallah RJ, Ziman AP, Ward CW, Lederer WJ. X-ROS signaling in the heart and skeletal muscle: stretch-dependent local ROS regulates $[\mathrm{Ca}(2)(+)]$ i. J Mol Cell Cardiol 2013;58:172-181.

4. Schonleitner P, Schotten U, Antoons G. Mechanosensitivity of microdomain calcium signalling in the heart. Prog Biophys Mol Biol 2017;130:288-301.

5. Woo SH, Risius T, Morad M. Modulation of local Ca2+ release sites by rapid fluid puffing in rat atrial myocytes. Cell Calcium 2007;41:397-403.

6. Son MJ, Kim JC, Kim SW, Chidipi B, Muniyandi J, Singh TD, So I, Subedi KP, Woo SH. Shear stress activates monovalent cation channel transient receptor potential melastatin subfamily 4 in rat atrial myocytes via type 2 inositol 1,4,5-trisphosphate receptors and $\mathrm{Ca}(2+)$ release. J Physiol 2016;594:29853004.

7. Frisk M, Koivumaki JT, Norseng PA, Maleckar MM, Sejersted OM, Louch WE. Variable t-tubule organization and Ca2+ homeostasis across the atria. Am J Physiol Heart Circ Physiol 2014;307:H609-620.

8. Louch WE, Bito V, Heinzel FR, Macianskiene R, Vanhaecke J, Flameng W, Mubagwa K, Sipido KR. Reduced synchrony of $\mathrm{Ca} 2+$ release with loss of T-tubules-a comparison to $\mathrm{Ca} 2+$ release in human failing cardiomyocytes. Cardiovasc Res 2004;62:63-73.

9. Brandenburg S, Kohl T, Williams GS, Gusev K, Wagner E, Rog-Zielinska EA, Hebisch E, Dura M, Didie M, Gotthardt M, Nikolaev VO, Hasenfuss G, Kohl P, Ward CW, Lederer WJ, Lehnart SE. Axial tubule junctions control rapid calcium signaling in atria. J Clin Invest 2016;126:3999-4015.

10. Prosser BL, Ward CW, Lederer WJ. X-ROS signaling: rapid mechano-chemo transduction in heart. Science 2011;333:1440-1445.

11. Jian Z, Han H, Zhang T, Puglisi J, Izu LT, Shaw JA, Onofiok E, Erickson JR, Chen YJ, Horvath B, Shimkunas R, Xiao W, Li Y, Pan T, Chan J, Banyasz T, Tardiff JC, Chiamvimonvat N, Bers DM, Lam $\mathrm{KS}$, Chen-Izu Y. Mechanochemotransduction during cardiomyocyte contraction is mediated by localized nitric oxide signaling. Sci Signal 2014;7:ra27.

12. Iribe G, Ward CW, Camelliti P, Bollensdorff C, Mason F, Burton RA, Garny A, Morphew MK, Hoenger A, Lederer WJ, Kohl P. Axial stretch of rat single ventricular cardiomyocytes causes an acute and transient increase in Ca2+ spark rate. Circ Res 2009;104:787-795.

13. Wang J, Ma Y, Sachs F, Li J, Suchyna TM. GsMTx4-D is a cardioprotectant against myocardial infarction during ischemia and reperfusion. J Mol Cell Cardiol 2016;98:83-94.

14. Ward CW, Sachs F, Bush ED, Suchyna TM. GsMTx4-D provides protection to the D2.mdx mouse. Neuromuscul Disord 2018;28:868-877.

15. Yeung EW, Whitehead NP, Suchyna TM, Gottlieb PA, Sachs F, Allen DG. Effects of stretch-activated channel blockers on [Ca2+]i and muscle damage in the mdx mouse. J Physiol 2005;562:367-380.

16. Bode F, Sachs F, Franz MR. Tarantula peptide inhibits atrial fibrillation. Nature 2001;409:35-36.

17. Nishizawa K, Nishizawa M, Gnanasambandam R, Sachs F, Sukharev SI, Suchyna TM. Effects of Lys to Glu mutations in GsMTx4 on membrane binding, peptide orientation, and self-association propensity, as analyzed by molecular dynamics simulations. Biochim Biophys Acta 2015;1848:2767-2778.

18. Gnanasambandam R, Ghatak C, Yasmann A, Nishizawa K, Sachs F, Ladokhin AS, Sukharev SI, Suchyna TM. GsMTx4: Mechanism of Inhibiting Mechanosensitive Ion Channels. Biophys J 2017;112:31-45.

19. Antoniou A, Milonas D, Kanakakis J, Rokas S, Sideris DA. Contraction-excitation feedback in human atrial fibrillation. Clin Cardiol 1997;20:473-476.

20. Chen YJ, Tai CT, Chiou CW, Wen ZC, Chan P, Lee SH, Chen SA. Inducibility of atrial fibrillation during atrioventricular pacing with varying intervals: role of atrial electrophysiology and the autonomic nervous system. J Cardiovasc Electrophysiol 1999;10:1578-1585.

21. Tse HF, Pelosi F, Oral H, Knight BP, Strickberger SA, Morady F. Effects of simultaneous atrioventricular pacing on atrial refractoriness and atrial fibrillation inducibility: role of atrial mechanoelectrical feedback. J Cardiovasc Electrophysiol 2001;12:43-50.

22. Eijsbouts SC, Majidi M, van Zandvoort M, Allessie MA. Effects of acute atrial dilation on heterogeneity in conduction in the isolated rabbit heart. J Cardiovasc Electrophysiol 2003;14:269-278.

23. Yamazaki M, Mironov S, Taravant C, Brec J, Vaquero LM, Bandaru K, Avula UM, Honjo H, Kodama I, Berenfeld O, Kalifa J. Heterogeneous atrial wall thickness and stretch promote scroll waves anchoring during atrial fibrillation. Cardiovasc Res 2012;94:48-57.

24. Satoh T, Zipes DP. Unequal atrial stretch in dogs increases dispersion of refractoriness conducive to developing atrial fibrillation. J Cardiovasc Electrophysiol 1996;7:833-842.

25. Seo K, Inagaki M, Nishimura S, Hidaka I, Sugimachi M, Hisada T, Sugiura S. Structural heterogeneity 
in the ventricular wall plays a significant role in the initiation of stretch-induced arrhythmias in perfused rabbit right ventricular tissues and whole heart preparations. Circ Res 2010;106:176-184.

26. Heinzel FR, Bito V, Biesmans L, Wu M, Detre E, von Wegner F, Claus P, Dymarkowski S, Maes F, Bogaert J, Rademakers F, D’Hooge J, Sipido K. Remodeling of T-tubules and reduced synchrony of Ca2+ release in myocytes from chronically ischemic myocardium. Circ Res 2008;102:338-346.

27. Hohendanner F, Ljubojevic S, MacQuaide N, Sacherer M, Sedej S, Biesmans L, Wakula P, Platzer D, Sokolow S, Herchuelz A, Antoons G, Sipido K, Pieske B, Heinzel FR. Intracellular dyssynchrony of diastolic cytosolic $[\mathrm{Ca}(2)(+)]$ decay in ventricular cardiomyocytes in cardiac remodeling and human heart failure. Circ Res 2013;113:527-538.

28. ter Keurs HE. The interaction of $\mathrm{Ca} 2+$ with sarcomeric proteins: role in function and dysfunction of the heart. Am J Physiol Heart Circ Physiol 2012;302:H38-50.

29. Wakayama Y, Miura M, Stuyvers BD, Boyden PA, ter Keurs HE. Spatial nonuniformity of excitation-contraction coupling causes arrhythmogenic Ca2+ waves in rat cardiac muscle. Circ Res 2005;96:12661273.

30. Garcia-Canadilla P, Rodriguez JF, Palazzi MJ, Gonzalez-Tendero A, Schonleitner P, Balicevic V, Loncaric S, Luiken J, Ceresa M, Camara O, Antoons G, Crispi F, Gratacos E, Bijnens B. A two dimensional electromechanical model of a cardiomyocyte to assess intra-cellular regional mechanical heterogeneities. PLoS One 2017;12:e0182915.

31. Sharifov OF, Fedorov VV, Beloshapko GG, Glukhov AV, Yushmanova AV, Rosenshtraukh LV. Roles of adrenergic and cholinergic stimulation in spontaneous atrial fibrillation in dogs. $J$ Am Coll Cardiol 2004;43:483-490.

32. Shen MJ, Zipes DP. Role of the autonomic nervous system in modulating cardiac arrhythmias. Circ Res 2014;114:1004-1021.

33. Bers DM. Cardiac excitation-contraction coupling. Nature 2002;415:198-205.

34. Huke S, Bers DM. Ryanodine receptor phosphorylation at Serine 2030, 2808 and 2814 in rat cardiomyocytes. Biochem Biophys Res Commun 2008;376:80-85.

35. Voigt N, Li N, Wang Q, Wang W, Trafford AW, Abu-Taha I, Sun Q, Wieland T, Ravens U, Nattel S, Wehrens XH, Dobrev D. Enhanced sarcoplasmic reticulum Ca2+ leak and increased Na+-Ca2+ exchanger function underlie delayed afterdepolarizations in patients with chronic atrial fibrillation. Circulation 2012;125:2059-2070.

36. Greiser M, Kerfant BG, Williams GS, Voigt N, Harks E, Dibb KM, Giese A, Meszaros J, Verheule S, Ravens U, Allessie MA, Gammie JS, van der Velden J, Lederer WJ, Dobrev D, Schotten U. Tachycardia-induced silencing of subcellular Ca2+ signaling in atrial myocytes. J Clin Invest 2014;124:4759-4772.

37. Hove-Madsen L, Llach A, Bayes-Genis A, Roura S, Rodriguez Font E, Aris A, Cinca J. Atrial fibrillation is associated with increased spontaneous calcium release from the sarcoplasmic reticulum in human atrial myocytes. Circulation 2004;110:1358-1363.

38. Brandenburg S, Pawlowitz J, Fakuade FE, Kownatzki-Danger D, Kohl T, Mitronova GY, Scardigli M, Neef J, Schmidt C, Wiedmann F, Pavone FS, Sacconi L, Kutschka I, Sossalla S, Moser T, Voigt N, Lehnart SE. Axial Tubule Junctions Activate Atrial Ca(2+) Release Across Species. Front Physiol 2018;9:1227.

39. Valdivia HH. Ryanodine receptor phosphorylation and heart failure: phasing out S2808 and "criminalizing" S2814. Circ Res 2012;110:1398-1402.

40. Johnson DM, Antoons G. Arrhythmogenic Mechanisms in Heart Failure: Linking beta-Adrenergic Stimulation, Stretch, and Calcium. Front Physiol 2018;9:1453.

41. Wagner MB, Kumar R, Joyner RW, Wang Y. Induced automaticity in isolated rat atrial cells by incorporation of a stretch-activated conductance. Pflugers Arch 2004;447:819-829.

42. Fasciano RW, 2nd, Tung L. Factors governing mechanical stimulation in frog hearts. Am J Physiol 1999;277:H2311-2320. 
General Discussion | 123 
Appendix

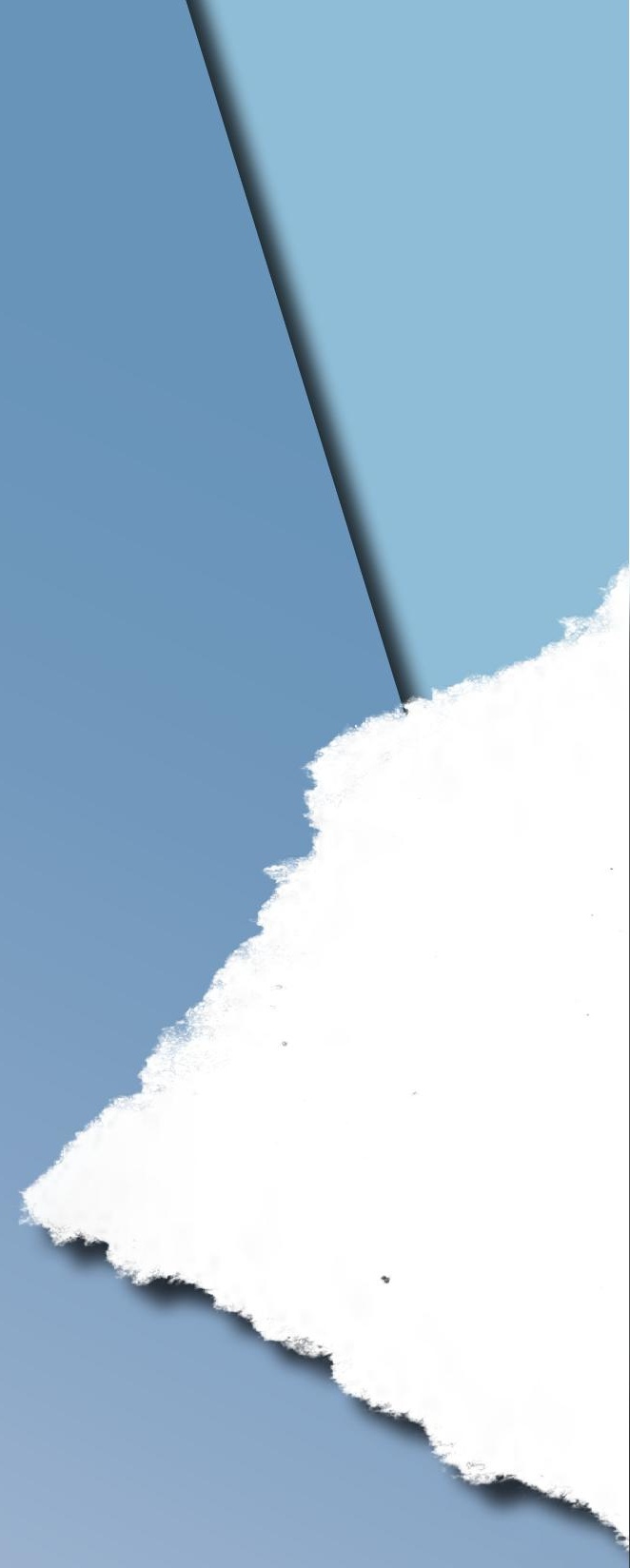





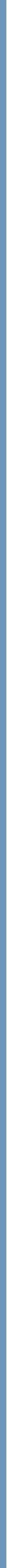




\section{SUMMARY}

Atrial fibrillation is one of the most common rhythm disorders in clinical practice. It is characterized by the rapid and chaotic electrical activation of the atria and irregular activation of the ventricle. As a consequence of the irregular atrial activation, the blood flow in the atria is disturbed. This promotes the formation of blood clots. The blood clots can dislodge from the heart and travel to the brain where they can block blood flow, causing strokes. A sizeable percentage of the population suffers from atrial fibrillation and the severity of the consequences makes it of paramount importance to diagnose atrial fibrillation early and treat it efficiently.

Atrial fibrillation is a progressive disease, initially short-lived episodes become longer and longer over time. Structural and functional changes take place, such as fibrosis hypertrophy, changes in $\mathrm{Ca}^{2+}$ handling, and energy metabolism. All these changes ultimately culminate in sustained atrial fibrillation.

Understanding the factors that can modify the time course of AF or its (re)initiation, such as mechanical stimulation, adrenergic signaling or contractile heterogeneity might be crucial to treat atrial fibrillation more effectively in the future.

The main focus of this thesis was to investigate these modifying factors and the effects they exert on $\mathrm{Ca}^{2+}$ handling on a subcellular level. Chapter $\mathbf{2}$ and $\mathbf{3}$ discuss the effect of mechanical stimulation. Chapter 2 serves as a detailed summary of the known effects of different forms of mechanical cues that myocytes in the heart might be subjected to. A major effect of such mechanical stimulation is called mechano-electrical coupling, where a sudden stretch of cardiac muscle leads to an immediate change in the myocytes membrane potential. In the last decade another mechanism has come to light, termed mechano-chemo transduction. This mechanism is characterized by the translation of stretch into fast acting chemical signals within the myocytes. Although well established in the ventricle, the evidence in atrial preparations in sparse. In Chapter 3 of this thesis we investigated the possibility of such rapid mechano-chemo transduction in the rabbit atrium. We subjected single atrial myocytes to uni-axial stretch and monitored the effects on spontaneous subcellular $\mathrm{Ca}^{2+}$ release events. Like in the ventricle, we found that axial stretch leads to an increase in spontaneous $\mathrm{Ca}^{2+}$ release events in the atria. However, in the atrium is appears to be triggered by the influx of cations over the cell membrane and not, like in the ventricle, by rapid mechano-chemo transduction. Furthermore we found coordinated $\mathrm{Ca}^{2+}$ release events, reminiscence of electrically evoked $\mathrm{Ca}^{2+}$ transients, right after the application of stretch. This observation is in line with the concept of mechano-electrical coupling in atrial myocytes.

Another modifying factor for atrial fibrillation is adrenergic signaling. In Chapter 4 we investigated the effect of Isoprenaline, a sympathomimetic, on rabbit atrial myocytes after a period of high atrial activation rates. Such high activation rate alone leads to the loss of centripetal $\mathrm{CaT}$ propagation, known as $\mathrm{Ca}^{2+}$ signaling silencing. We show that adrenergic stimulation can normalize CaT amplitude mainly by re-establishing $\mathrm{Ca}^{2+}$ release in center of atrial myocytes. While the phosphorylation of RYRs by Isoprenaline may support $\mathrm{Ca}^{2+}$ release, it did not cause the generation of more frequent proarrhythmic $\mathrm{Ca}^{2+}$ sparks. Thus supporting the idea that phosphorylation of RYRs by Isoprenaline is not sufficient for $\mathrm{Ca}^{2+}$ instabilities in the atria. 
In Chapter 5 we took a closer look at heterogeneities in subcellular movements (strain) withing a single myocyte. In order to investigate strain heterogeneities specialized imaging techniques, labeling strategies or even manual annotations were employed in the past. We propose a semi-automated analysis methods that relies on transmitted light images acquired with a more readily available confocal microscope, that can detect changes in subcellular movement in response various interventions. We found that in stretched atrial myocytes under conditions of high preload, local strain can become positive e.i. parts of the myocyte stretch during the contraction phase. In a second set of experiments we subjected the cells to adrenergic stimulation and found an increase in local heterogeneities during contraction and at peak shortening, but this heterogeneities were lost in relaxation. This is in line with preliminary results that link Isoprenaline to more homogeneous $\mathrm{Ca}^{2+}$ reuptake and computer models that predict subcellular properties as major factor for heterogeneities during contraction.

This thesis tries to shine some new light on potentially proarrhythmic factors in the atria. Most of these mechanisms are well documented in heart failure or cardiomyopathies, but their effects on atrial physiology is not well understood. We found that myocardial stretch of the atrium can lead to more frequent $\mathrm{Ca}^{2+}$ release events and proarrhythmic activity that relies on a mechanism distinct from the one reported in the ventricle. Furthermore, we could demonstrate that adrenergic stimulation on a single cell level can normalize $\mathrm{Ca}^{2+}$ transients without apparent proarrhythmic $\mathrm{Ca}^{2+}$ instabilities after sustained rapid electrical activation. Lastly, we proposed a new method to investigate localized heterogeneities in myocyte contractions and found changes in subcellular strain in response to stretch and adrenergic stimulation. Taken together, this thesis emphasise the need to understand modifying factors of AF in greater detail in an attempt to develop targeted therapies in the future. 


\section{ZUSAMMENFASSUNG}

Vorhofflimmern ist eine der häufigsten Rhythmusstörungen in der klinischen Praxis. Vorhofflimmern ist gekennzeichnet durch die schnelle und chaotische elektrische Aktivierung der Vorhöfe und die unregelmäßige Aktivierung der Ventrikel. Infolge der unregelmäßigen atrialen Aktivierung wird der Blutfluss in den Vorhöfen gestört, dies fördert die Bildung von Blutgerinnsel. Die Embolie können sich vom Herzen lösen und zum Gehirn gelangen, wo sie den Blutfluss blockieren und einen Schlaganfall verursachen können. Ein beträchtlicher Prozentsatz der Bevölkerung leidet an Vorhofflimmern, und die Schwere der Folgen macht es von größter Bedeutung, Vorhofflimmern frühzeitig zu diagnostizieren und effizient $\mathrm{zu}$ behandeln.Vorhofflimmern ist eine fortschreitende Krankheit, anfangs kurzlebige Episoden werden mit der Zeit immer länger. Strukturelle und funktionelle Veränderungen wie Fibrose, Hypertrophie, Veränderungen im $\mathrm{Ca}^{2+}$-Handling und Energiestoffwechsel finden statt. All diese Veränderungen gipfeln letztendlich in anhaltendem Vorhofflimmern. Das Verständnis der Faktoren, die den zeitlichen Verlauf von Vorhofflimmers oder dessen (Wieder-) Auslösung verändern können, wie mechanische Stimulation, adrenerge Signalübertragung oder kontraktile Heterogenität, könnte entscheidend sein, um Vorhofflimmern in Zukunft wirksamer behandeln zu können.

Das Hauptaugenmerk dieser Thesis lag auf der Untersuchung dieser modifizierenden Faktoren und ihrer Auswirkungen auf die $\mathrm{Ca}^{2+}$ - Homöostase auf subzellulärer Ebene. In den Kapiteln 2 und 3 wird die Wirkung der mechanischen Stimulation auf den Herzmuskel erörtert. Kapitel 2 dient als detaillierte Zusammenfassung der bekannten Auswirkungen verschiedener Formen mechanischer Signale, denen Myozyten im Herzen ausgesetzt sein könnten. Ein Effekt einer solchen mechanischen Stimulation wird als mechano-elektrische Kopplung bezeichnet, bei der eine plötzliche Dehnung des Herzmuskels zu einer sofortigen Änderung des Membranpotentials der Myozyten führt. In den letzten zehn Jahren ist ein anderer Mechanismus ans Licht gekommen, der als mechano-chemo Transduktion bezeichnet wird. Dieser Mechanismus ist durch die Umwandlung von Dehnungssignale in rasch wirkende chemische Signale innerhalb der Myozyten gekennzeichnet. Obwohl im Ventrikel gut etabliert, sind die Hinweise in atrialen Präparaten spärlich. In Kapitel 2 dieser Arbeit untersuchten wir die mögliche Existenz einer solchen schnellen mechanisch-chemischen Signaltransduktion im Vorhof. Wir haben einzelne atriale Myozyten einer gedehnt und die Auswirkungen auf spontane subzelluläre $\mathrm{Ca}^{2+}$-Freisetzungsereignisse überwacht. Wie im Ventrikel beschrieben, fanden wir eine Zunahme der spontanen $\mathrm{Ca}^{2+}$-Freisetzung in den Vorhöfen. Im Atrium scheint es jedoch durch das Einströmen von Kationen über die Zellmembran ausgelöst zu werden und nicht wie im Ventrikel durch eine schnelle mechanisch-chemische Transduktion. Darüber hinaus fanden wir koordinierte $\mathrm{Ca}^{2+}$-Freisetzungsereignisse, die an elektrisch hervorgerufene $\mathrm{Ca}^{2+}$-Transienten erinnern, welche unmittelbar nach einem Dehnungsereignisses auftreten. Diese Beobachtung steht im Einklang mit dem Konzept der mechano-elektrischen Kopplung in atrialen Myozyten.

Ein weiterer modifizierender Faktor für Vorhofflimmern ist die adrenerge Signalübertragung. In Kapitel 4 untersuchten wir die Wirkung von Isoprenalin, einem Sympathomimetikum, auf atriale Myozyten von Kaninchen nach einer Periode hoher atrialer Aktivierungsraten. Solche hohen Aktivierungsraten allein führen zu einem Verlust der zentripetalen CaTAusbreitung, die als „Ca ${ }^{2+}$-Signaling Silencing” bekannt ist. Wir zeigen, dass eine adrenerge Stimulation die CaT-Amplitude, hauptsächlich durch Wiederherstellung der 
$\mathrm{Ca}^{2+}$-Freisetzung im Zentrum der atrialen Myozyten, normalisieren kann. Während die Phosphorylierung von RYRs, den $\mathrm{Ca}^{2+}$-Freisetzungskanälen der internen $\mathrm{Ca}^{2+}$-Speicher, durch Isoprenalin die $\mathrm{Ca}^{2+}$-Freisetzung unterstützen kann, führte Sie nicht häufigerer zu proarrhythmischer $\mathrm{Ca}^{2+}$-Freisetzungen. Dies unterstützt die Idee, dass die Phosphorylierung von RYRs durch Isoprenalin für $\mathrm{Ca}^{2+}$-Instabilitäten in den Vorhöfen nicht ausreicht. In Kapitel 5 haben wir uns die Heterogenitäten in subzellulären Bewegungen einzelner Myozyten genauer angesehen. Um kontraktile Heterogenität zu untersuchen, wurden in der Vergangenheit spezielle Bildgebungstechniken, Markierungsstrategien oder sogar manuelle Annotationen eingesetzt. Wir schlagen eine halbautomatische Analysemethode vor, die auf Durchlichtbildern beruht, die mit einem gängigen konfokalen Mikroskop aufgenommen wurden und Änderungen der subzellulären Bewegung als Reaktion auf verschiedene Eingriffe erkennen können. Wir fanden heraus, dass in gedehnten atrialen Myozyten unter Bedingungen hoher Vorlast lokaler Strain positiv werden kann, d.h. Teile der Myozyten dehnen sich während der Kontraktionsphase. In einer zweiten Reihe von Experimenten haben wir die Zellen einer adrenergen Stimulation unterzogen und einen Anstieg der lokalen Heterogenität während der Kontraktion festgestellt, diese Heterogenität konnte in der Relaxationsphase nicht nachgewiesen werden. Dies steht im Einklang mit vorläufigen Ergebnissen, einer homogeneren $\mathrm{Ca}^{2+}$-Wiederaufnahme nach Isoprenalin Behandlung und Computermodellen, die subzelluläre Eigenschaften als Hauptfaktor für Heterogenität während der Kontraktion vorhersagen.

Diese Arbeit versucht, potenziell proarrhythmische Faktoren in den Vorhöfen genauer zu beläuchten. Die meisten dieser Mechanismen sind bei Herzinsuffizienz oder Kardiomyopathien gut dokumentiert, aber ihre Auswirkungen auf die atriale Physiologie sind nicht in Detail erforscht. Wir fanden heraus, dass die Myokarddehnung des Atriums zu häufigeren $\mathrm{Ca}^{2+}$ -Freisetzungsereignissen und proarrhythmischen Aktivitäten führen kann, die auf einem Mechanismus beruhen, der sich von dem im Ventrikel dokumentierten Mechanismus unterscheidet. Darüber hinaus konnten wir zeigen, dass eine adrenerge Stimulation in isolierten Myozyten $\mathrm{Ca}^{2+}$-Transienten ohne offensichtliche proarrhythmische $\mathrm{Ca}^{2+}$-Instabilitäten nach anhaltender schneller elektrischer Aktivierung normalisieren kann. Letztlich schlagen wir eine neue Methode zur Untersuchung lokalisierter Heterogenität der Myozytenkontraktionen vor und fanden Veränderungen des subzellulären Verformung als Reaktion auf Dehnung und adrenerge Stimulation. Zusammengenommen unterstreicht diese Arbeit die Notwendigkeit, modifizierende Faktoren von Vorhofflimmern genauer zu untersuchen, um in Zukunft gezielte Therapien entwickeln zu können. 


\section{VALORIZATION}

The social and economical relevance of atrial fibrillation

Atrial fibrillation (AF) is the rapid and irregular rhythm of the upper chambers of the heart and it is the most common sustained cardiac rhythm disorder. ${ }^{1}$ By itself AF is rarely life threatening, but the impact can be life altering. Patients suffering from AF complain about palpitations, chest-pain and heart failure-like symptoms. They are more likely to be admitted to the hospital for treatment of complications associated with their disease and can suffer side effects from the treatment that is supposed to help them. Blood clots that originate in the fibrillating atrium travel to the brain, which can lead to progressive cognitive decline, or, more fulminate, to lethal strokes. ${ }^{2}$

Not only does AF impact the life of each individual patient, it is also presents a challenge for our healthcare system. The chronic nature of AF makes constant supervision and treatment over years necessary.

Currently, $2 \%$ of the adult population suffer from AF. In Europe alone 10 million people are currently affected. ${ }^{3}$ With about one in four people expected to develop atrial arrhythmias during their life time, the expected changes in demographic will lead to a doubling of AF cases by the middle of the century. ${ }^{4}$ The consequences for the healthcare system are substantial. In the Netherlands, the costs of AF amount to more than 583 million Euro annually. The direct costs amount to more than $2 \%$ of annual national healthcare costs, numbers that are comparable to diabetes or multiple sclerosis. ${ }^{5}$

\section{The novelty of this research}

This thesis is of a fundamental nature, and thus possible clinical applications or new treatment strategies based on the work presented here are speculative. However, the findings can support other researchers in their quest to understand the pathophysiology of atrial fibrillation better and develop new treatment strategies.

In the late 1960s and early 1970s the work of Philippe Coumel, a pioneer in the field of electrophysiology, resulted in the concept of Coumel's triangle of arrhythmogenesis. This concept postulates that for a clinical arrhythmia to arise three main ingredients need to be present. A trigger that initiates the arrythmia, the underlying substrate to maintain it and factors that modify the trigger and the substrate. ${ }^{6}$

Studying triggers and substrates of AF has led to the development of complex theories and equally complex treatment strategies, with varying success. On a cellular level modifying factors have not gotten as much attention. This thesis aims to help to fill the gaps in our understanding regarding some known modifying factors.

The first main topic of this thesis is the effect that mechanical stimulation can have on the heart in general and on the atrium in particular. The heart is in its essence a pump, that supplies the body with the necessary oxygen to function. Every heart beat starts with an electrical signal in the atria that is propagated throughout the heart and translated into muscle contraction. To adapt to the constantly changing demands of the body the cardiac muscle developed ways to sense mechanical cues and react to them. 
On a more general level, this thesis elaborates on the importance of considering mechanosensitive pathways when designing and conducting experiments and sensitizing researchers to potential pitfalls in translating findings in unloaded myocytes in-vitro to whole model organisms or even to humans.

Most of the work regarding mechanosensitive mechanisms has been performed in ventricular preparations. The novelty of our research is that we were the first to describe stretch dependent effects on subcellular $\mathrm{Ca}^{2+}$ release in the atria, which appears to differ from previously described pathways in the ventricle. Although, the molecular candidate for atrial mechano-sensing is still elusive, it might offer an atrial selective treatment target in the future.

We also found that on occasions sudden stretch of atrial myocytes led to spontaneous and coordinated $\mathrm{Ca}^{2+}$ release events, similar to electrically evoked $\mathrm{Ca}^{2+}$ transients. Those transients could not be suppressed by our interventions, suggesting yet a different pathway that remains to be studied in detail. This phenomenon also illustrates that modifying factors can alter the substrate of AF and at the same time exert effects on the triggers of the arrhythmia.

The second major part of this thesis revolves around the effects of adrenergic stimulation on subcellular $\mathrm{Ca}^{2+}$ release after short term high activation rates. After short episodes of AF cardiac myocytes within the atria adapt to the fast rhythm by altering their $\mathrm{Ca}^{2+}$ handling in order to protect themselves from the deleterious and pro-arrhythmic effects off fast activation rates and $\mathrm{Ca}^{2+}$ overload.

When stressed, the body release catecholamines, in what is commonly referred to as the "fight or flight" response. Adrenaline, the mediator of this response, leads to a more forceful heart beat but at the same time has been shown to be proarrhythmogenic, especially after episodes of AF. The anti-arrhythmic adaptations observed after sustained high activation rates are at odds with the increased susceptibility for the reinitiation of the arrhythmia in response to adrenaline.

In Chapter four we investigated this inconsistency and found that the effect of catecholamines on atrial myocytes after pacing is more pronounced, effectively resulting in $\mathrm{Ca}^{2+}$ handling kinetics comparable to healthy myocytes. We could confirm the effects of adrenaline on $\mathrm{Ca}^{2+}$ proteins reported by other groups but could not substantiate an increased susceptibility for $\mathrm{Ca}^{2+}$ instabilities that could help explain the higher rates of AF reinitiation after catecholamine treatment in clinical practice.

The last novel aspects of this thesis proposes a new way to analyse the contractile movements of cardiac myocytes on a subcellular level. In the past analysing such subcellular contractions was done manually or with highly specialized equipment. We propose a method that employees readily available tools in a semi-automated manner. Our method allowed us to analyse subcellular contraction in response to adrenergic stimulation or axial stretch. Linking local $\mathrm{Ca}^{2+}$ release to $\mathrm{Ca}^{2+}$ reuptake, or correlating $\mathrm{Ca}^{2+}$ dynamics to underlying contraction can now be routinely performed. Other staining protocols can potentially be used to link contractile heterogeneity to the cytoskeleton or other cell organelles, to unravel links between the structure of the cell and it's function. 
In conclusion, this thesis tried to elucidate the effects of two noteworthy modifying factors of atrial fibrillation on a subcellular level. We could demonstrate mechanosensitive pathways that differ from pathways present in the ventricle, studied the effects of adrenergic signalling in a model of atrial fibrillation and lastly proposed a new method to analyse subcellular contraction in single myocytes.

We believe that the results presented here are stepping stones for further efforts aimed at understanding the pathophysiology of atrial fibrillation in more detail and devise effective treatment strategies in the future. 


\section{REFERENCES}

1. Benjamin EJ, Wolf PA, D’Agostino RB, Silbershatz H, Kannel WB, Levy D. Impact of atrial fibrillation on the risk of death: the Framingham Heart Study. Circulation 1998;98:946-952.

2. Marini C, De Santis F, Sacco S, Russo T, Olivieri L, Totaro R, Carolei A. Contribution of atrial fibrillation to incidence and outcome of ischemic stroke: results from a population-based study. Stroke 2005;36:1115-1119.

3. Zoni-Berisso M, Lercari F, Carazza T, Domenicucci S. Epidemiology of atrial fibrillation: European perspective. Clin Epidemiol 2014;6:213-220.

4. Krijthe BP, Kunst A, Benjamin EJ, Lip GY, Franco OH, Hofman A, Witteman JC, Stricker BH, Heeringa J. Projections on the number of individuals with atrial fibrillation in the European Union, from 2000 to 2060. Eur Heart J 2013;34:2746-2751.

5. Heemstra HE, Nieuwlaat R, Meijboom M, Crijns HJ. The burden of atrial fibrillation in the Netherlands. Neth Heart J 2011;19:373-378.

6. Farre J, Wellens HJ. Philippe Coumel: a founding father of modern arrhythmology. Europace 2004;6:464465 . 


\section{ACKNOWLEDGMENTS}

The realization of this thesis has been possible thanks to the cooperation of many colleagues, whom had a substantial impact on this journey, and that made this learning experience so unique.

I will, therefore, try to summarize my acknowledgments in the following section.

First and foremost, I would like to thank my thesis promotor Prof. Uli Schotten. Dear Uli, I would like to thank you for giving me the opportunity to join your research group and for giving me all the support and the means to carry my research on over the past years. It was a honour to be your PhD student and I would like to express my gratitude for the great scientific discussions and feedback you provided on our work.

Dear Dr. Antoons, dear Gudrun, our journey started a long ago, and I will never forget all the support and guidance you have gifted me with during my $\mathrm{PhD}$ trajectory. Uncountable are the learning opportunities and the scientific discussion sessions we had in the lab, all the good advices and the true commitment to make sure I could successfully complete this thesis. I truly appreciate the time you took to review my work, discuss about it, and make sure I would develop as a critical thinker and as a scientist.

Dear Dr. Crijns, thank you for supporting during my $\mathrm{PhD}$ trajectory and for helping me in polishing the final manuscript.

Sincere thanks to my thesis committee member: Prof. Paul Volders, Prof. Fritz Prinzen, Prof. William Louch and Dr. Toen de Boer.

Dear Marion, thank you for all the hours of hard work and thank you for supporting me in the planning and execution of the experiments necessary for this thesis. Thank you for your dedication, even if this meant sacrificing your private time and stretching hours. I always have appreciated your willingness to help and the attention to keep a neat and positive environment. Without you my $\mathrm{PhD}$ wouldn't have been possible.

Dear Dragan, my friend and companion for this adventure, it has been great meeting you, and I am glad I had you as a support in the hardest time. It has been a pleasure to be in the same office with you and share discussions about science but also enjoy the coffee breaks and the more fundamental discussions about life.

Dear Elisa, Billy, Vladimír, Martijn, Arne, Stef, and Sander, it was a pleasure to working with you and I truly enjoyed the time together. You are all fantastic colleagues and good professionals. I am proud of having been part of such a research team, and I wish you all to have success for your present and future endeavours.

Dear Bianca, Vivian and Jolanda, thanks for being always so friendly and supportive when I had a question. And thanks for all the efforts and dedication to find always the best solutions. I am very glad I had the opportunity to be your colleague.

Dear Remi, I can not thank you enough for the countless hours you poured into reviewing and tweaking the "stretch paper", for mediating between parties and picking up the story where I left off. 


\section{6}

Appendix

Dear Michael, I would like to truly thank you for the support you gave me since I started at IonOptix. Thanks to your patients, advice and support during the last two years I managed to finish this thesis.

Dear members of the animal facility and of IvD, dear Huub, Petra and Saskia, thank you for taking such a great care of the animals and thank you for the uncountable hours you spent to support my research and make the workflow easier to manage. Thanks for helping me finding the best solutions, taking into account animal welfare as a fist and foremost priority. I am glad to have had the opportunity to work together.

I would also like to express my special thankfulness to my mother, the rest of my family and my friends for offering me their time and support no matter what. Without your love and care I would have never been able to carry on. I am proud of having you and I feel very lucky to be surrounded by the amazing people you are. Thank you very much.

Dear Giulia, I cannot begin to express my unfailing gratitude to you. Without your support this thesis would not have been possible. Without you the past months and years would not have been filled with joy and laughter. Without you I would not have made it. You make everyday special, every minute valuable. I love you. 


\section{CURRICULUM VITAE}

Patrick Schönleitner was born on $14^{\text {th }}$ of January 1989 in Linz, Austria. He graduated in 2008 from BRG Fadingerstraße with a focus on natural sciences. In the same year he moved to Styria and started his studies at the Medical University in Graz, where he graduated in 2013 with the thesis: "Expression and function of $\mathrm{Na}^{+}$handling proteins in young $\beta 1$-adrenergic receptor transgenic mice at an early stage of cardiac remodeling" During his studies, he was engaged in basic research activities at the department of Internal Medicine - Division of Cardiology under the supervision of Dr. Frank Heinzl and Dr. Gudrun Antoons.

After his graduation, he accepted a position as early stage researcher at the Medical University Graz, investigating stretch in induced changes in the $\mathrm{Ca}^{2+}$ homeostasis in rats.

In December 2014, he moved to Maastricht as a Marie Sklowdowska Curie Fellow within RADOX ITN (RADical reduction of Oxidative stress in cardiovascular disease - international Training Network) to work on novel pathways of atrial fibrillation in response to mechanical stimulation and adrenergic activation under the supervision of Prof. Schotten and Dr. Antoons. He presented his work at national and international conferences, being awarded the runner-up at 16th Dutch-German Joint Meeting of the Molecular Cardiology Working Groups for his work presented in this thesis.

In February 2019, he started as a research scientist at IonOptix BV Amsterdam, the Netherlands. 
